\title{
PERFIS DE AÇO FORMADOS A FRIO SUBMETIDOS À FLEXÃO: ANÁLISE TEÓRICO-EXPERIMENTAL
}

\author{
Carlos Eduardo Javaroni
}

Tese apresentada à Escola de Engenharia de São Carlos, da Universidade de São Paulo, como parte dos requisitos para obtenção do título de Doutor em Engenharia de Estruturas

ORIENTADOR: Prof. Dr. Roberto Martins Gonçalves

São Carlos 


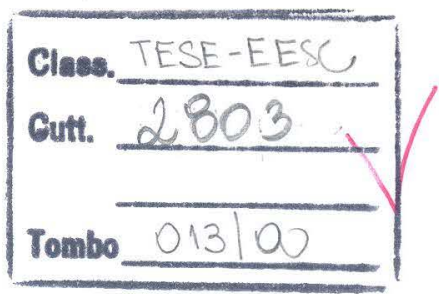

Sys 1071607

Ficha catalográfica preparada pela Seção de Tratamento da Informação do Serviço de Biblioteca - EESC/USP

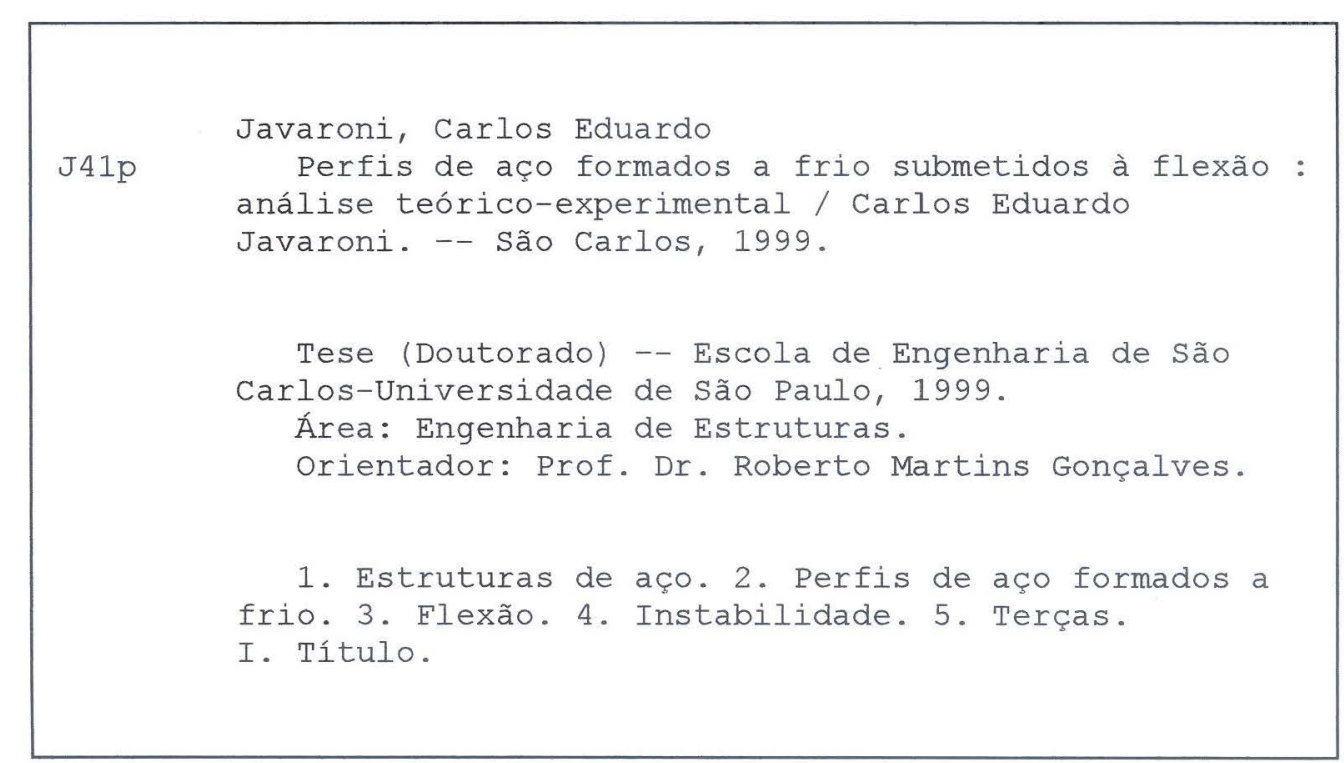




\section{FOLHA DE APROVAC̄̃̃O}

Candidato: Engenheiro CARLOS EDUARDO JAVARONI

Tese defendida e aprovada em 10-12-1999

pela Comissão Julgadora:

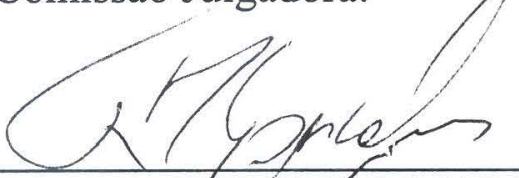

Prof. Doutor ROBERTO MARTINS GONÇALVES (Orientador)

(Escola de Engenharia de Sãe Carlos - Universidade de São Paulo)

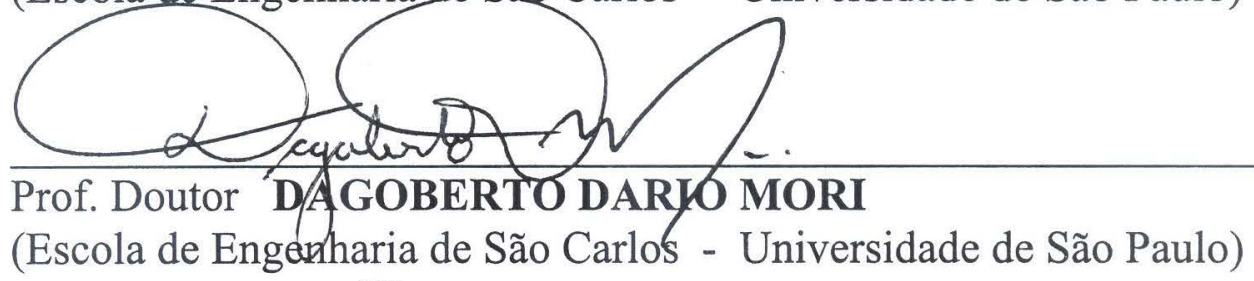

Proth/lingia

\section{Prof. Titular JÕ̃O BENTO DE HANAI}

(Escola de Engenharia de São Carlos - Universidade de São Paulo)

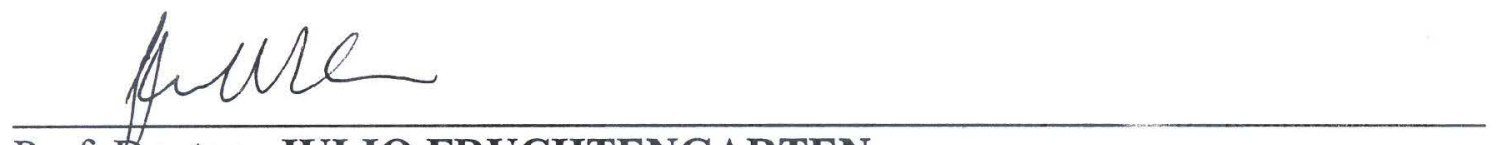

Prof. Doutor JULIO FRUCHTENGARTEN

(Escola Politécnica - Universidade de São Paulo)

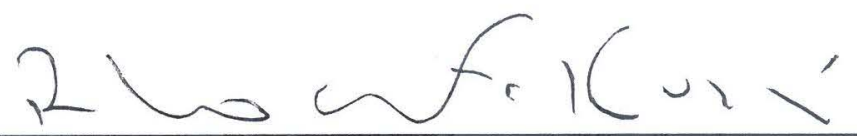

Prof. Doutor RICARDO HALLAL FAKURY

(Universidade Federal de Minas Gerais - UFMG)

$$
\text { hin inde Oung }
$$

Profa. Doutora ANA LÚCIA HOMCE DE CRESCE EL DEBS

Coordenadora da Área de Engenharia de Estruturas

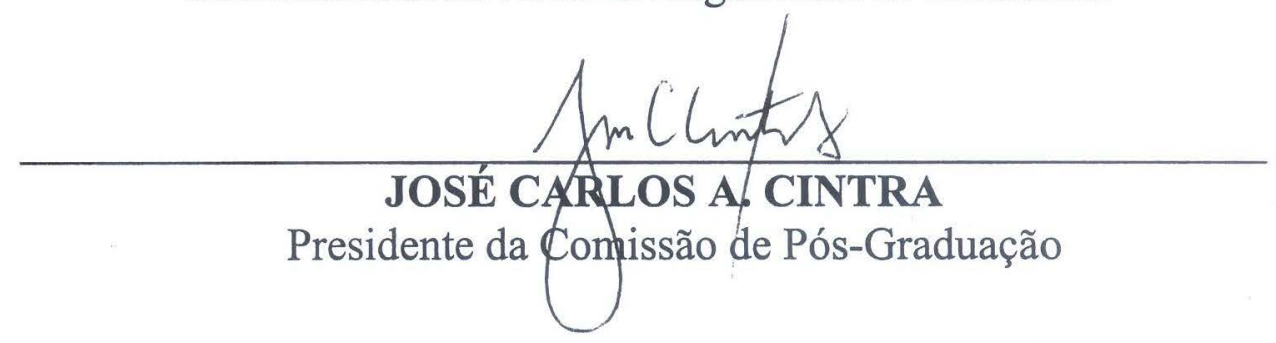


À minha esposa, Sueli. Aos meus filhos, Rafael, Alexandre e Júlia. 


\section{AGRADECIMENTOS}

Ao Professor Roberto Martins Gonçalves pela orientação, apoio e compreensão dispensada na elaboração deste trabalho.

Aos Professores da Área de Estruturas Metálicas, Roberto, Jairo e Maximiliano, pela amizade e colaboração no desenvolvimento do trabalho.

Aos funcionários do Laboratório de Engenharia de Estruturas, Amauri, Jorge, Mário, Mauri, Luís e Valdir, pelo auxílio prestado na execução dos ensaios.

Ao Professor Toshiaki Takeya, pela colaboração no desenvolvimento dos ensaios.

Aos funcionários e professores da Faculdade de Engenharia da Unesp, campus de Bauru, pelo apoio, incentivo e a amizade.

Ao CNPq pela bolsa de estudos e à FAPESP pelo auxílio financeiro ao projeto de pesquisa. 


\section{SUMÁRIO}

LISTA DE FIGURAS vii

LISTA DE TABELAS xii

LISTA DE SÍMBOLOS xiv

RESUMO Xix

$\begin{array}{ll}\text { ABSTRACT } & x x\end{array}$

\section{INTRODUÇÃO}

1.1. ASPECTOS GERAIS SOBRE O USO DOS PERFIS DE CHAPA DOBRADA 1

1.2. PESQUISAS E NORMAS TÉCNICAS 4

1.3. OBJETIVOS E ESCOPO DO TRABALHO 6

\section{PERFIS DE CHAPA DOBRADA}

2.1. INTRODUÇÃO

2.2. INSTABILIDADE LOCAL - FLAMBAGEM DE CHAPA 12

2.2.1. Introdução 12

2.2.2. Resistência pós-flambagem e o conceito de largura efetiva 17

2.2.3. Elementos enrijecidos à compressão 19

2.2.4. Elemento não enrijecido à compressão 21

2.2.5. Elemento sob tensões não uniformes 22

2.2.6. Enrijecedores de borda e enrijecedores intermediários 24

2.2.6.1. Introdução 24

2.2.6.2. Enrijecedores de borda $\quad 25$

2.2.6.3. Enrijecedores intermediários $\quad 27$

2.2.6.4. Largura efetiva para elemento com enrijecedor de borda 29 
2.2.6.5.Largura efetiva para elemento com enrijecedor intermediário 31 2.3. INSTABILIDADE GLOBAL 32

2.3.1. Introdução 32

2.3.2. Tensões 33

2.3.3. Energia de deformação 34

2.3.4. Energia potencial 35

2.3.4.1. Energia potencial da tensão normal provocada pelos momentos fletores durante a rotação $\phi \quad 35$

2.3.4.2. Energia potencial devida ao momento torçor 37

2.3.4.3. Energia potencial da força normal 38

2.3.4.4. Energia potencial do bimomento 39

2.3.4.5. Energia potencial das ações transversais $\quad 41$

2.3.4.6. Expressão da energia total 42

2.3.5. Equações gerais da instabilidade por flexão e torção 43

2.4. INSTABILIDADE POR DISTORÇÃO 44

2.4.1. Introdução 44

2.4.2. O modelo de Hancock 46

2.4.2.1. Formulação analítica 46

2.4.3. O modelo de Peköz, Soroushian 53

2.4.3.1. Introdução 53

2.4.3.2. Formulação Analítica 54

2.5. CONSIDERAÇÕES FINAIS 58

3. APLICAÇÃO AOS PERFIS FLETIDOS

3.1. INTRODUÇÃO 60

3.2. FLAMBAGEM LOCAL DA MESA (FLM) 61

3.3. FLAMBAGEM LOCAL DA ALMA (FLA) 62

3.3.1. Tensões normais 62

3.3.2. Tensões de cisalhamento 63

3.3.3. Tensões normais e de cisalhamento combinadas 66 
3.4. Flambagem lateral COM torção (FLT) 68

3.4.1. Perfis com dupla simetria 69

3.4.1.1. Coeficiente de equivalência de momento na flexão 71

3.4.2. Perfis monossimétricos 78

3.4.2.1. Perfis tipo $U$ com trecho sob momento fletor constante $\quad 80$

3.4.2.2. Perfis tipo $U$ com trecho sob momento gradiente. 82

3.4.2.3. Perfis tipo $U$ com força concentrada entre travamentos laterais 84

3.4.3. Perfis tipo $Z$

3.5. FLAMBAGEM POR DISTORÇÃO 86

3.6. CÁLCULO DAS FORÇAS CRÍTICAS PARA OS ENSAIOS DOS PERFIS ISOLADOS 90

3.7. SOBRE O DIMENSIONAMENTO DOS PERFIS CONECTADOS ÀS TELHAS 94

3.7.1. Procedimento do AISI (1996) 96

3.7.2. Procedimento do Eurocode (1993) 97

3.8. COMENTÁRIOS 102

\section{ENSAIOS EM PERFIS FLETIDOS}

4.1. INTRODUÇÃO 105

4.2. SEÇÕES TRANSVERSAIS E PROCESSO DE FABRICAÇÃO DOS PERFIS 106

4.3. METODOLOGIA EMPREGADA 107

4.4. CARACTERIZAÇÃO DO AÇO 111

4.5. IMPERFEIÇÕES GEOMÉTRICAS INICIAIS

4.6. MOdELOS ENSAIADOS

4.7. ApResentação dos Resultados 122

4.7.1. Esquema de carregamento $1 \quad 126$

4.7.2. Esquema de carregamento $2 \quad 135$

4.7.3. Esquema de carregamento $3 \quad 138$

4.8. ANÁLISE DOS RESULTADOS 140 


\section{ENSAIOS EM PERFIS CONECTADOS ÀS TELHAS DE AÇO}

5.1. INTRODUÇÃO 148

5.2. SEÇÕES TRANSVERSAIS E PROCESSO DE FABRICAÇÃO DOS PERFIS $\quad 150$

5.3. METOdOLOGIA EMPREGADA 151

5.4. MODELOS ENSAIADOS 161

5.5. ApresentaÇão dos Resultados 163

5.6. ANÁLISE DOS RESULTADOS 179

5.6.1. O fator de redução $F_{R} \quad 179$

5.6.2. O método de Peköz, Soroushian 184

5.6.3. O procedimento do Eurocode (1993) 187

5.6.4. Flambagem por distorção 188

5.6.5. Determinação das tensões através dos ensaios 190

5.6.6. Perfis com linhas de corrente 192

6. CONCLUSÕES

6.1. AsPeCtOS GERAIS SOBRE O DESENVOLVIMENTO DO TRABALHO 193

6.2. Perfis de ChaPA dobRada Fletidos 195

6.3. Perfis CONECTAdos Às TelHAS de AÇO 196

6.4. SUGESTÕES PARA TRABALHOS FUTUROS 199

REFERÊNCIAS BIBLIOGRÁFICAS 200

ANEXO I - GRÁFICOS 205 


\section{LISTA DE FIGURAS}

Figura 2.1 : Flambagem local para a mesa comprimida do perfil fletido

Figura 2.2 : Flambagem por distorção para a mesa comprimida do perfil fletido

Figura 2.3 : Flambagem lateral com torção de vigas

Figura 2.4 : Distribuição de tensões para elementos comprimidos enrijecidos

Figura 2.5 : Largura efetiva de um elemento enrijecido à compressão

Figura 2.6 : Elementos submetidos a tensões não uniformes 22

Figura 2.7 : Enrijecedores de borda e intermediário 24

Figura 2.8 : Elemento efetivo de um enrijecedor 31

Figura 2.9 : Trabalho da tensão $\sigma$ durante a rotação $\phi \quad 36$

Figura 2.10 : Deslocamento de um ponto genérico da seção 39

Figura 2.11 : Força $\mathrm{P}_{\mathrm{i}}$ aplicada no ponto A 41

Figura $2.12:$ Instabilidade por distorção 44

Figura 2.13 : Modelo de cálculo para instabilidade por distorção 47

Figura 2.14 : Distorção da alma de perfis: a) comprimido; b) fletido 52

Figura 2.15 : Idealização do comportamento dos perfis sob efeito de sucção 53

Figura 2.16 : Dimensões da seção transversal da barra 55

Figura 2.17 : Idealização de uma barra flexo-comprimida 56

Figura 3.1 : Distribuição de tensões em regime elástico para vigas contidas lateralmente 
Figura 3.2 : Relações de interação entre f e $\tau$

Figura 3.3 : Coeficiente de equivalência de momento 71

Figura 3.4 : Valores de $\mathrm{C}_{\mathrm{b}}$ segundo alguns autores 73

Figura 3.5 : Diagrama de momento com variação linear 74

Figura 3.6 : Esquema de carregamento para um perfil tipo $U \quad 80$

Figura 3.7 : Perfil tipo U sob força concentrada no meio do vão 82

Figura 3.8 : Perfil tipo $U$ : força concentrada entre travamentos laterais 84

Figura 3.9 : Detalhe do traspasse dos perfis. a) Perfis tipo $U$. b) Perfis tipo $Z$

Figura 4.1 : Seções transversais e nomenclatura 106

Figura 4.2 : Esquemas de carregamentos para os ensaios à flexão 108

Figura 4.3 : Detalhe do travamento lateral entre perfis 109

Figura 4.4 : Posição dos extensômetros nas seções transversais dos perfis tipo $U$ e $U$ enrijecido.

Figura 4.5 : Aplicação de forças e dispositivos de ensaios para os carregamentos utilizados

Figura 4.6 : Vista geral de um ensaio em andamento

Figura 4.7 : Dimensões nominais do corpo de prova para ensaio à tração

Figura 4.8 : Dispositivo para leitura das imperfeições geométrica longitudinais

Figura 4.9 : Detalhe da realização de medida da deslocada inicial do perfil

Figura 4.10 : Posições para medidas das deslocadas longitudinais 116

Figura 4.11 : Imperfeições geométricas para o perfil tipo U 116

Figura 4.12 : Imperfeições geométricas para o perfil tipo Z 117

Figura 4.13 : Vista do apoio. a) Vista lateral. b)Vista frontal, interna 120

Figura 4.14 : Transdutores de deslocamento. a) Verticais.

b) Horizontais no meio do vão 121

Figura 4.15 : Flambagem local da mesa (FLM) para o perfil U2B 125 
Figura 4.16 : Flambagem lateral com torção: a) conjunto U3. b) conjunto U13

Figura 4.17 : Gráficos força aplicada $x$ deformação: Conjunto U2.

a) Perfil U2A. b) Perfil U2B

Figura 4.18 Gráfico força aplicada x giro: Perfil U2A 128

Figura 4.19 : Falha para o conjunto U2: a) FLM. b) Vista frontal 129

Figura 4.20 : Gráficos força aplicada x deformação: Conjunto U21.

a) Perfil U21A. b) Perfil U21B 130

Figura 4.21 Gráfico força $x$ deslocamento: Conjunto U21 131

Figura 4.22 : Gráfico força $\times$ giro: Conjunto U21 132

Figura 4.23 :: Gráficos força $x$ deformação: Conjunto U5. a) Perfil U5A. b) Perfil U5B 133

Figura 4.24 : Gráfico força aplicada x giro: Conjunto U5 134

Figura 4.25 : Gráfico força aplicada x deslocamento: Conjunto U5 134

Figura 4.26 : Gráfico força aplicada x giro: Conjunto Z1 135

Figura 4.27 : Gráficos força aplicada $x$ deformação:Conjunto U22.

a) Perfil U22A. b) Perfil U22B. 137

Figura 4.28 : Gráfico força aplicada x deslocamento: Conjunto U22 138

Figura 4.29 : Flambagem local da mesa: conjunto U26. a) Vista geral do Perfil A. b) Detalhe da falha 139

Figura 4.30 : Gráfico força aplicada x giro - conjunto U26: Flambagem local da mesa.

Figura 4.31 : Gráfico força aplicada x giro - conjunto U28: Flambagem lateral com torção $\quad 140$

Figura 4.32 : Tensões normais na mesa comprimida - perfil U2A 143

Figura 5.1 : Seções transversais e nomenclatura dos perfis conectados às telhas de aço

Figura 5.2 : Caixa de sucção: Dimensões gerais 152

Figura 5.3 : Caixa de sucção em fase de montagem 153

Figura 5.4 : Caixa de sucção preparada para o início de um ensaio 153

Figura 5.5 : Caixa de sucção - dimensões gerais 154 
Figura 5.6 : Posicionamento dos transdutores de deslocamentos 155

Figura 5.7 : Disposição dos transdutores de deslocamento linear 156

Figura 5.8 : Posição dos extensômetros nas seções transversais ensaiadas 156

Figura 5.9 : Posição dos extensômetros na alma 157

Figura 5.10 : Seção transversal com extensômetros posicionados 157

Figura 5.11 : Seção transversal da telha de aço na posição de montagem 158

Figura 5.12 : Fixação telha-terça e falha para um teste piloto 159

Figura 5.13 : Caixa de sucção para teste em uma telha 160

Figura 5.14 : Caixa de sucção em fase de testes 160

Figura 5.15 : Falha do conjunto para o teste preliminar 161

Figura 5.16 : Linhas de correntes para as terças (cantoneiras e barras redondas)

Figura 5.17 : Deslocamentos horizontais para as mesas do perfil (Ensaio 1). 164

Figura 5.18 : Deslocamentos verticais no centro do vão (Ensaio 1) 164

Figura 5.19 : Giro para a seção central (Ensaio 3) 167

Figura 5.20 : Deslocamentos horizontais e verticais observados (Ensaio 3) 167

Figura 5.21 : Flambagem local da mesa para uma terça em perfil tipo U127×50x2,25 (Ensaio 8) 168

Figura 5.22 : Flechas obtidas para os perfis tipo U127x50×3,00 170

Figura 5.23 : Deslocamentos horizontais das mesas comprimidas dos perfis tipo U127 $\times 50 \times 3,00$

Figura 5.24 : Posição deslocada após a FLM - Ensaio 11

Figura 5.25 : Resultado dos deslocamentos horizontais das mesas superiores para os perfis sem linha de corrente 173

Figura 5.26 : Gráfico pressão $\times$ deformação - Ensaio 6

Figura 5.27 : Gráfico pressão $x$ deformações nas mesas - Ensaio $7 \quad 175$

Figura 5.28 : Gráfico pressão $x$ deformações na alma - Ensaio $7 \quad 175$

Figura 5.29 : Gráficos pressão x deformação. a)Ensaio 2. b)Ensaio 3176 
Figura 5.30 : Deslocamentos horizontais no meio do vão para as mesas comprimidas dos perfis ensaiados com linhas de correntes

Figura 5.31 : Gráfico pressão x deformação - Ensaio 10

Figura 5.32 : Determinação do coeficiente de apoio elástico Ensaio 7

Figura 5.33 : Superposição das tensões normais

Figura 5.34 : Modelo admitido para cálculo da tensão crítica de flambagem por distorção

Figura 5.35: Tensões normais nas mesas obtidas nos ensaios $\left(\mathrm{kN} / \mathrm{cm}^{2}\right)$ 


\section{LISTA DE TABELAS}

Tabela 2.1 : Valores de k para chapas longas

Tabela 3.1 : Coeficientes A e B para forças transversais 76

Tabela 3.2 : Valores comparativos de $\mathrm{C}_{\mathrm{b}} \quad 85$

Tabela 3.3 : Valores previstos para as forças críticas correspondentes 92

Tabela 4.1 : Propriedades geométricas das seções transversais estudadas

Tabela 4.2 : Características mecânicas obtidas no ensaio à tração 113

Tabela 4.3 : Variações dimensionais para os perfis 118

Tabela 4.4 : Perfis ensaiados à flexão 119

Tabela 4.5 : Resultados obtidos nos ensaios à flexão 123

Tabela 4.6 : Modos de falha previstos e observados 126

Tabela 4.7 : Modos de falha previstos e observados (carregamento 2) 136

Tabela 4.8 : Valores comparativos da força P 142

Tabela 4.9 : Valores comparativos da força P (carregamento 2) 145

Tabela 4.10 : Valores comparativos da força P (carregamento 3) 146

Tabela 4.11 : Comparações entre os resultados obtidos $\left(K_{t}=0,5\right.$ e $\left.K_{y}=1\right) \quad 146$

Tabela 5.1 : Perfis ensaiados 162

Tabela 5.2 : Pressão de referência para as terças 166

Tabela 5.3 : Modos de falha para os perfis conectados às telhas 169

Tabela 5.4 : Momentos fletores último e de escoamento 180

Tabela 5.5 : Valores do coeficiente de redução para o perfil tipo Z 182

Tabela 5.6 : Valores do coeficiente de redução para o perfil tipo U 183

Tabela 5.7 : Tensões normais nos perfis segundo Peköz, Soroushian 186 
Tabela 5.8 : Tensões normais nos perfis segundo o Eurocode

Tabela 5.9 : Tensão crítica de flambagem por distorção para barras comprimidas

Tabela 5.10 : Tensão crítica de flambagem por distorção para barras fletidas

Tabela 5.11 : Resultados das tensões normais máximas $\left(\mathrm{kN} / \mathrm{cm}^{2}\right)$ 


\section{LISTA DE SÍMBOLOS}

\section{Letras romanas maiúsculas}

A : : área da seção transversal bruta da barra

A ef : área efetiva da seção transversal da barra, calculada com tensão $\sigma=\sigma_{\mathrm{cr}}$

$A_{\text {ef }}^{\prime} \quad$ : área efetiva reduzida da seção transversala para enrijecimento parcial

$A_{s} \quad$ : área reduzida do enrijecedor intermediário ou de extremidade área do enrijecedor transversal bruta do parafuso

$\mathrm{A}_{\mathrm{s}} \mathrm{S} \quad$ : área efetiva do enrijecedor intermediário ou de borda

$A_{s t} \quad$ : área mínima do enrijecedor transversal de alma ou área do enrijecedor

B : largura nominal de parede, é a largura total de parede incluindo as regiões de dobra

Bimomento

$\mathrm{C}_{\mathrm{b}} \quad$ : coeficiente da equivalência de momento na flexão

$\mathrm{C}_{\omega} \quad$ : constante de empenamento da seção transversal bruta da barra

D : parâmetro empregado no cálculo da área mínima Ast dos enrijecedores transversais

Rigidez à flexão da placa

E : módulo de elasticidade (205.000 MPa)

$\mathrm{E}_{\mathrm{t}} \quad$ : módulo de elasticidade tangente

$\mathrm{F}_{\mathrm{R}} \quad$ : Coeficiente de redução

G : módulo de elasticidade transversal do aço $(0,385 \mathrm{E}=78.925 \mathrm{MPa})$

H : parâmetro empregado no cálculo da tensão crítica de flambagem elástica por flexo-torção das seções monossimétricas 
$\mathrm{l}_{\mathrm{a}} \quad$ : momento de inércia adequado do enrijecedor intermediário ou de borda

$I_{\min } \quad:$ momento de inércia mínimo do enrijecedor intermediário

$I_{\mathrm{s}} \quad$ : momento de inércia da seção bruta do enrijecedor, em torno do seu próprio eixo barricêntrico paralelo ao elemento a ser enrijecido. Para enrijecedor de borda, a parte curva entre o enrijecedor e o elemento a ser enrijecido não deve ser considerada

$\mathrm{I}_{\mathrm{s}, \mathrm{min}} \quad$ : momento de inércia minímo para o enrijecedor em relação ao plano médio da alma

$\mathrm{I}_{\mathrm{sf}} \quad$ : momento de inércia da seção bruta do elemento com enrijecedores intermediários (incluindo os enrijecedores intermediários) em relação ao seu próprio eixo principal

$I_{x}, I_{y}$ : momentos de inércia da seção bruta em relação aos eixos principais

lyc : momento de inércia da porção comprimida da seção em relação ao eixo baricêntrico paralelo à alma, tomando-se a seção bruta

$\mathrm{I}_{\mathrm{t}} \quad$ : momento de inércia à torção livre ou de St. Venant

$\mathrm{K}$ : parâmetro de flambagem da barra Coeficiente de apoio elástico

$\mathrm{K}_{\mathrm{t}} \quad$ : parâmetro de flambagem por torção

$\mathrm{K}_{\mathrm{x}}$ : parâmetro de flambagem por flexão em relação ao eixo $\mathrm{x}$

$\mathrm{K}_{\mathrm{y}} \quad$ : parâmetro de flambagem por flexão em relação ao eixo y

L $\quad$ : comprimento livre (não contraventado) da barra comprimento do cordão de solda

$\mathrm{L}_{\mathrm{t}} \quad$ : comprimento livre (não contraventado) à torção da barra comprimida

$\mathrm{L}_{x} \quad$ : comprimento livre (não contraventado) à flexão em relação ao eixo $\times$ para barra comprimida

$\mathrm{L}_{y} \quad$ : comprimento livre (não contraventado) à flexão em relação ao eixo y para barra comprimida

M : momento fletor 


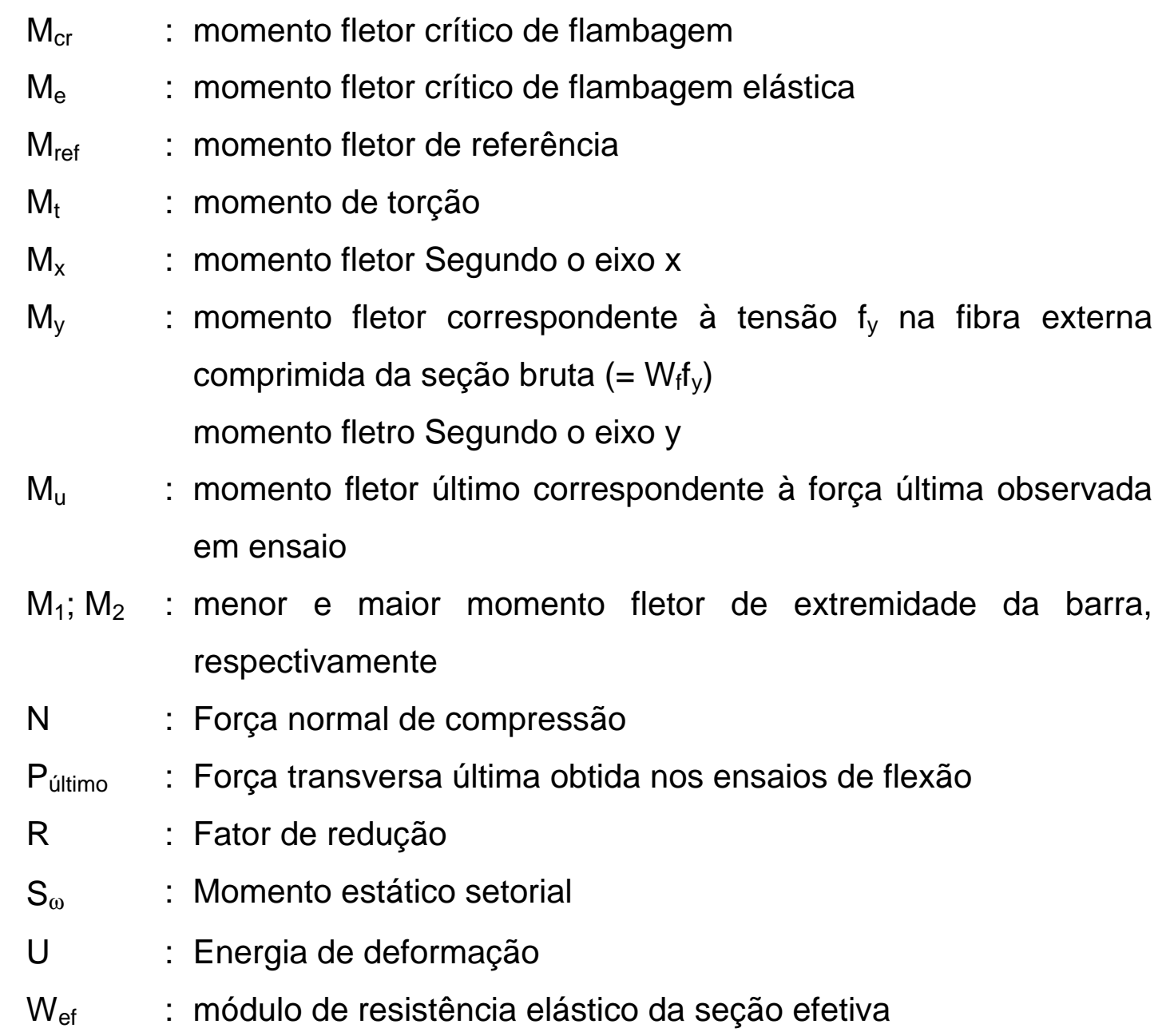

\section{Letras romanas minúsculas}

a : distância entre enrijecedores constante

b : largura da parede, é a dimensão plana do elemento sem incluir dobras

$b_{\text {ef }} \quad$ : largura efetiva

$b_{\text {ef }}^{\prime} \quad$ : largura efetiva modificada do sublemento ou elemento

bo : largura de um elemento com enrijecedor (es) intermediário (s)

d : altura da seção transversal da viga dimensão nominal do enrijecedor de borda

$d_{s} \quad$ : largura efetiva reduzida do enrijecedor de borda

$d_{s} \quad$ : largura efetiva do enrijecedor de borda

$\mathrm{f}_{\mathrm{cr}} \quad$ : tensão crítica de flambagem elástica da chapa 
$f_{u} \quad$ : resistência à ruptura do aço em termos de tensão, obtida em ensaios de tração

$f_{x} \quad$ : Tensão de compressão na chapa, segundo o eixo $x$

$f_{y} \quad$ : resistência ao escoamento do aço em termos de tensão, obtida em ensaios de tração

h $\quad$ : altura da parte plana da alma altura da seção transversal

k : parâmetro de flambagem de chapa constante em geral

I : Comprimento em geral

$k_{v} \quad$ : parâmetro de flambagem de chapa por cisalhamento

$\mathrm{k}_{\mathrm{x}} \quad$ : rigidez à translação da mola na direção $\mathrm{x}$

$\mathrm{k}_{\mathrm{x}} \quad$ : rigidez à rotação da mola

$\mathrm{p}_{\mathrm{u}} \quad$ : pressão última medida no ensaio das terças

q : : força distribuída por unidade de comprimento da viga

$r \quad$ : raio de giração da seção bruta

$\mathrm{r}_{\mathrm{i}} \quad$ : raio interno de dobramento

ro : raio de giração polar da seção bruta em relação ao centro de torção

$r_{x} \quad$ : raio de giração da seção bruta em relação ao eixo principal $x$

$r_{y} \quad$ : raio de giração da seção bruta em relação ao eixo principal y

$\mathrm{s} \quad$ : espaçamento dos furos na direção perpendicular à solicitação

t : espessura da chapa ou da parede do perfil menor espessura da parte conectada

$\mathrm{u}, \mathrm{v}$ : deslocamentos do centro de cisalhamento nas direções $\mathrm{x}$ e $\mathrm{y}$, respectivamente

w : deslocamento na direção z

$\mathrm{x}_{0}, \mathrm{y}_{0}:$ : coordenadas do centro de torção

\section{Letras gregas}

$\alpha, \beta \quad$ : parâmetros para o cálculo da tensão crítica de flambagem por distorção 


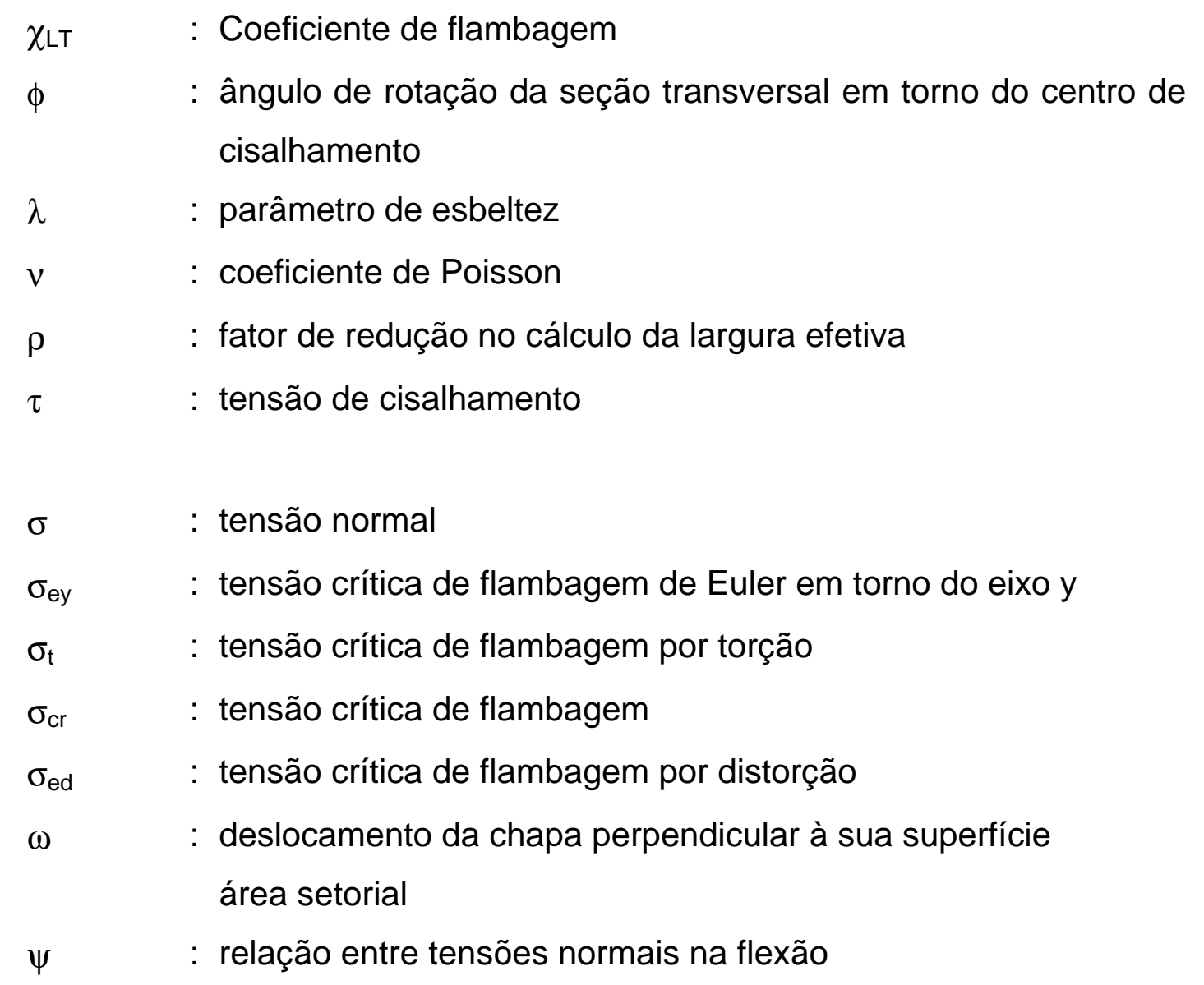




\section{RESUMO}

Javaroni, C. E. (1999). Perfis de aço conformados a frio submetidos à flexão: Análise teórico-experimental. São Carlos, 1999. 255p. Tese (Doutorado) Escola de Engenharia de São Carlos, Universidade de São Paulo.

Atualmente, os perfis de chapa dobrada têm encontrado intensa aplicação como elementos estruturais nas construções em aço e como consequência, estão sujeitos aos mais diversos tipos de carregamentos. Este trabalho apresenta os aspectos gerais do dimensionamento de perfis de chapa dobrada submetidos à flexão enquanto utilizados como vigas propriamente dito e, também, enquanto utilizados como terças. Analisam-se seções tipo $U$, tipo $U$ enrijecido e tipo $Z$ enrijecido. Os ensaios em perfis fletidos foram realizados sobre 3 diferentes condições de carregamento, com dois vãos distintos, em um total de sessenta e quatro perfis ensaiados. Para os perfis conectados às telhas de aço, os ensaios foram realizados em uma "caixa de sucção" desenvolvida especificamente para este projeto. Os perfis foram conectados às telhas pela mesa por meio de parafusos autobrocantes, sendo realizados quinze ensaios. Os resultados dos ensaios são comparados com os resultados teóricos, resultados normatizados e resultados de alguns procedimentos aproximados.

Palavras-chave: estruturas de aço; perfis de aço formados a frio; flexão; instabilidade; terças. 


\section{ABSTRACT}

Javaroni, C. E. (1999). Cold-formed steel members in flexure: theoreticalexperimental analyses. São Carlos, 1999. 255p. Tese (Doutorado) Escola de Engenharia de São Carlos, Universidade de São Paulo.

Nowadays, the cold-formed steel members have intense application as structural elements in constructions and, in consequence, they are subjected to several types of loads. This work presents the general aspects of the study of cold-formed steel members subjected to flexion used as beams and, also, as purlins. Sections of type $U$, type $C$ and type $Z$ are analysed. The tests in beams were carried out under three different conditions of loads, with two distinct spans, in total of sixty four tests. For the purlins connected to roof system, the tests were in a "suction box", developed especially for this project. The purlins were connected to the roof system by the flange by using self-drilling screws, being carried out fifteen tests. The results of those tests are compared with the theoretical results, design specification provisions and results of some approximated procedures.

Keywords: steel structures; cold-formed steel; beam; buckling; purlins. 


\section{INTRODUÇÃO}

\subsection{Aspectos gerais sobre o uso dos perfis de chapa dobrada}

Os processos construtivos que se utilizam de estruturas metálicas encontram aplicações em larga escala, com perspectivas de grande crescimento, advindas das diversas vantagens que trazem. Pode-se citar:

- Qualidade uniforme, desde o projeto até o acabamento final;

- Facilidade e rapidez de fabricação e de montagem, como consequência, retorno do investimento financeiro em menor tempo;

- Otimização do canteiro de obras e diminuição do desperdício;

- Menor peso próprio da estrutura quando comparado com outros materiais, possibilitando uma fundação mais econômica;

- Possibilidade de reutilização de perfis.

Para as obras de grande porte, a estrutura principal é constituída de perfis laminados e perfis soldados. Os perfis de aço formados a frio, quando utilizados, são elementos secundários tais como terças, longarinas, apoios de forros e contraventamentos. 
Os perfis laminados padrão americano possuem grande relação massa/resistência, portanto, nem sempre apresentam soluções econômicas para o projeto.

Os perfis laminados com abas paralelas representam uma solução melhor aos anteriores, entretanto, não são ainda produzidos pelas nossas siderúrgicas e a disponibilidade desses no mercado nacional depende da sua importação.

Os perfis soldados permitem sua fabricação com as dimensões necessárias ao projeto. Porém, necessitam de prazo maior para entrega e apresentam custo maior devido ao corte de chapas, soldagem e desempenamento.

Os perfis de aço formados a frio, dada a grande variedade das formas de seções transversais que podem ser obtidas e da boa relação massa/resistência, alcançaram lugar de destaque entre as estruturas metálicas, principalmente em obras de menor porte, as quais possuem, em geral, pequenos vãos e carregamentos de pequena intensidade.

Como estrutura principal, o uso dos perfis de aço formados a frio dá-se em edifícios de pequena altura, residências e galpões em geral. Fôrmas para concretagem, andaimes e escoramentos, terças, longarinas e armações para forros são outros exemplos que ilustram a versatilidade desses perfis na construção civil.

Apesar da grande aceitação dos perfis de aço formados a frio no mercado, a inexistência de uma norma nacional atualizada, hoje em fase de aprovação, e a falta de uma disciplina específica nos cursos de graduação dificultam a correta aplicação desses perfis, fazendo com que muitos projetista de estruturas utilizem a mesma filosofia de projeto aplicada aos perfis laminados e soldados.

Os perfis de aço formados a frio apresentam uma série de características que os diferenciam dos perfis laminados e soldados.

A conformação a frio das chapas finas altera as características mecânicas do aço virgem, ocorrendo acréscimo na tensão limite de escoamento e na tensão limite de resistência à tração, como consequências 
tem-se a redução na ductilidade do material e o aparecimento de novas tensões residuais, as quais superpõe-se às já existentes antes da conformação a frio. Esses efeitos são mais pronunciados na região dos cantos dobrados.

A pequena espessura das chapas utilizadas resulta em elevada relação largura/espessura dos elementos planos que compõe a seção transversal. Os perfis assim obtidos estão sujeitos à flambagem local dos seus elementos, o que não representa, em geral, o esgotamento da capacidade resistente da barra. A teoria da instabilidade de chapas permite prever a carga crítica e a análise do comportamento pós-crítico pode ser feita através do conceito da largura efetiva.

A instabilidade global de uma barra formada por chapas esbeltas pode ocorrer ou por flexão, ou por torção, ou por uma combinação de flexão e torção.

A flambagem lateral em vigas tem sido muito pesquisada. A teoria de Vlassov (1962) considera a não validade da hipótese de Bernoulli (as seções planas permanecem planas e ortogonais ao eixo após a flexão), surgindo tensões normais oriundas do empenamento das seções transversais das vigas.

Os estudos sobre o comportamento dos perfis de aço formados a frio como elementos estruturais tiveram início nos trabalhos pioneiros do professor George Winter, desenvolvidos a partir de 1939, na Universidade Cornell. ${ }^{1}$

A determinação da resistência de vigas em perfis de aço formados a frio, resultante dos trabalhos de Winter (1943, 1944 e 1959), é ainda adotada nas mais recentes versões das especificações do American Iron and Steel Institute (AISI), edição de 1996, e do Canadian Standarts Association (CSA), edição de 1995, normas específicas sobre o dimensionamento dos perfis conformados a frio.

A solução teórica de Timoshenko, Gere (1961), para uma viga tipo I sob momento de flexão uniforme, simplesmente apoiada, tem sido usada

${ }^{1}$ YU, W. W. (1985) Cold formed steel design. New York: Wiley-Interscience. 545p. 
como uma solução de referência. Para outras situações, o fator de modificação de momentos $\left(C_{b}\right)$, conforme Salvadori $(1955,1956)$, é utilizado para avaliar a resistência à flambagem lateral com torção de vigas sob momento gradiente.

Um outro modo de instabilidade diferente dos anteriores pode ocorrer. Este modo é chamado de flambagem distorcional e nele ocorre, como o próprio nome sugere, a distorção da seção transversal em seu próprio plano. É mais comum para seções com enrijecedores de borda e envolve a rotação da mesa e enrijecedor de borda em torno da junção alma e mesa.

Este modo de falha tem sido extensivamente pesquisado atualmente e, em geral, ignorado pelos projetistas, apesar de previsto em várias recomendações normativas empregadas no projeto de estruturas com chapa dobrada.

\subsection{Pesquisas e normas técnicas}

O uso de perfis de chapa dobrada na construção começou por volta de 1850 nos Estados Unidos e Inglaterra. Entretanto, não encontrou ampla utilização até 1940.

Frente à necessidade de normas específicas e a ausência de experiências e informações de pesquisas, o Committee on Building Research and Technology, então chamado Committee on Building Codes, do AISI (American Iron and Steel Institute) desenvolveu um projeto de pesquisa na Universidade Cornell em 1939 com o propósito de estudar o comportamento de perfis estruturais de chapa fina de aço dobrada a frio e obter informações reais para a formulação de uma norma específica.

As pesquisas desenvolvidas pelo professor George Winter e seus colaboradores resultaram no desenvolvimento de métodos de cálculo concernentes ao projeto de perfis de aço formados a frio.

Em 1946, a primeira edição do 'Specification for the design of light gage steel structural member' foi organizada e publicada pelo AISI. Esta 
norma baseava-se nos resultados das pesquisas realizadas na Universidade Cornell e na experiência prática acumulada nesta área. Foram realizadas revisões em 1956, 1960, 1962, 1968, 1980, 1986, 1991 e 1996, refletindo as técnicas desenvolvidas e os resultados de contínuas pesquisas.

A norma do AISI obteve reconhecimento em todo o mundo desde a sua primeira edição, sendo utilizada como referência para o desenvolvimento de pesquisas e em projetos de estruturas em chapa dobrada.

$\mathrm{Na} 14^{\text {th }}$ International Specialty Conference on Cold-Formed Steel Structures, realizada em outubro de 1998, em St. Louis, foram publicados 41 artigos com resultados de pesquisas recentemente desenvolvidas em vários países do mundo, incluindo Austrália, Brasil, Canadá, Coréia do Sul, Estados Unidos, França e Inglaterra. ${ }^{2}$

No Brasil, as pesquisas em estruturas de aço tem se intensificado nos últimos anos. Ainda que desenvolvidas em alguns centros de pesquisa, verifica-se a sua disseminação em todo o país e uma maior aproximação entre universidades, fábricas de estruturas metálicas e siderúrgicas. Isto tem possibilitado avanços na construção metálica brasileira tornando o aço uma solução cada vez mais competitiva, técnica e economicamente.

Sobre os aspectos normativos, o dimensionamento dos perfis de chapa dobrada tem suas recomendações dadas pela NB-143 'Cálculo de estruturas de aço constituídas por perfis leves', de 1967. Em vista da falta de atualização dessa norma, a maioria dos projetistas de estruturas metálicas segue as prescrições do AISI, o qual possui edições mais recentes e abrangentes.

Atualmente, a NB-143 encontra-se em processo de revisão e atualização, sendo o trabalho coordenado pelos professores da área de estruturas metálicas do Departamento de Engenharia de Estruturas da EESC/USP, sob o patrocínio da ABCEM. Este trabalho tem como referência a norma do AISI/96, bem como o Eurocode $3 / 93$ e a norma australiana

${ }^{2}$ Yu, W. W; LaBoube, R.A. (1998) International specialty conference: Cold-formed steel - design and construction, 14., St. Louis, 1998. Proceedings. 
AS/NZS 4600/96, seguindo o método dos estados limites, em acordo com a NBR-8800.

\subsection{Objetivos e escopo do trabalho}

Este trabalho tem como objetivo a análise dos diversos modos de falha aos quais estão sujeitos os perfis de aço formados a frio quando submetidos à flexão. São utilizados perfis tipo $U, U$ e $Z$ enrijecidos, desenvolvendo-se um programa experimental, obtendo-se um conjunto de resultados a serem confrontados com os valores teóricos e normatizados.

O estudo foi realizado em duas situações distintas. A primeira referese à utilização dos perfis tipo $U$ e tipo $U$ enrijecido como perfis fletidos, isoladamente, com travamentos laterais em pontos discretos. Os perfis foram submetidos à ação de forças concentradas, variando-se a distância entre os pontos travados lateralmente e os pontos de aplicação das forças. São discutidos os diversos modos de falha encontrados, a carga última de ensaio, os deslocamentos medidos e os valores teóricos correspondentes.

A segunda situação refere-se ao uso dos perfis tipo $U, U$ enrijecido e Z enrijecido como terças, conectados por parafusos auto-brocantes às telhas de aço, sujeitos a ações de sucção devidas ao efeito do vento em coberturas. Os ensaios foram realizados em uma "caixa de sucção" especialmente desenvolvida para estes ensaios. A simulação do carregamento foi realizada através da retirada do ar contido no interior dessa caixa por meio de um aspirador. Nesta parte da pesquisa busca-se avaliar a influência da restrição lateral imposta pela telha e o uso das linhas de correntes no modo de falha da terça.

O trabalho está organizado de tal forma que o capítulo 2 apresenta os aspectos teóricos sobre a instabilidade dos perfis de seção aberta de parede delgada, discutindo-se os modos de flambagem local e flambagem global, os quais constituem a fundamentação teórica para o projeto e dimensionamento dos perfis de chapa dobrada. 
O estudo da instabilidade aplicado aos casos ensaiados está apresentado no capítulo 3, onde foram obtidos os resultados teóricos para posterior comparação com os resultados experimentais.

Os capítulos 4 e 5 apresentam o desenvolvimento da análise experimental dos perfis isolados e perfis conectados às telhas, respectivamente. Apresentam-se a metodologia utilizada, os modelos ensaiados e os resultados representativos das observações realizadas.

As conclusões sobre o desenvolvimento do trabalho e os resultados encontrados, bem como algumas sugestões para o desenvolvimento de trabalhos futuros estão apresentadas no capítulo 6 .

Os principais trabalhos consultados para o desenvolvimento desta tese encontram-se listados nas referências bibliográficas.

No Anexo I encontram-se os resultados apresentados em forma de gráficos, correspondentes aos dados obtidos diretamente do ensaio através do sistema de aquisição de dados. 


\section{PERFIS DE CHAPA DOBRADA - INSTABILIDADE}

\subsection{Introdução}

Os perfis de chapa dobrada estão sujeitos ao modo de falha por instabilidade sob carregamentos frequentemente menores que aqueles que correspondem à plastificação total ou parcial da sua seção transversal.

A instabilidade do perfil pode ser classificada como sendo do tipo local ou global, podendo ocorrerem simultaneamente. A ocorrência de um ou de outro tipo de instabilidade está condicionada às características geométricas dos perfis e às condições de vínculos e de carregamentos.

$\mathrm{Na}$ figura 2.1 ilustra-se o fenômeno da instabilidade local, flambagem local da mesa de um perfil tipo $U$ com enrijecedores de borda sujeito à flexão. Neste caso, o elemento de chapa componente do perfil, a mesa comprimida, sofre deslocamentos na direção normal ao seu plano.

A determinação do carregamento crítico para o elemento pode ser feita através da aplicação da teoria clássica da flambagem de chapas.

Ressalta-se que a ocorrência da flambagem local não ocasiona, em geral, o fim da capacidade resistente do perfil. Excedida a carga crítica da chapa ocorre uma redistribuição das tensões atuantes, produzindo efeito estabilizante na chapa. Este comportamento pós-crítico, analisado à luz da teoria das placas com grandes deslocamentos, pode ser levado em 
consideração através do conceito da largura efetiva, largura fictícia sujeita a uma distribuição uniforme de tensão.

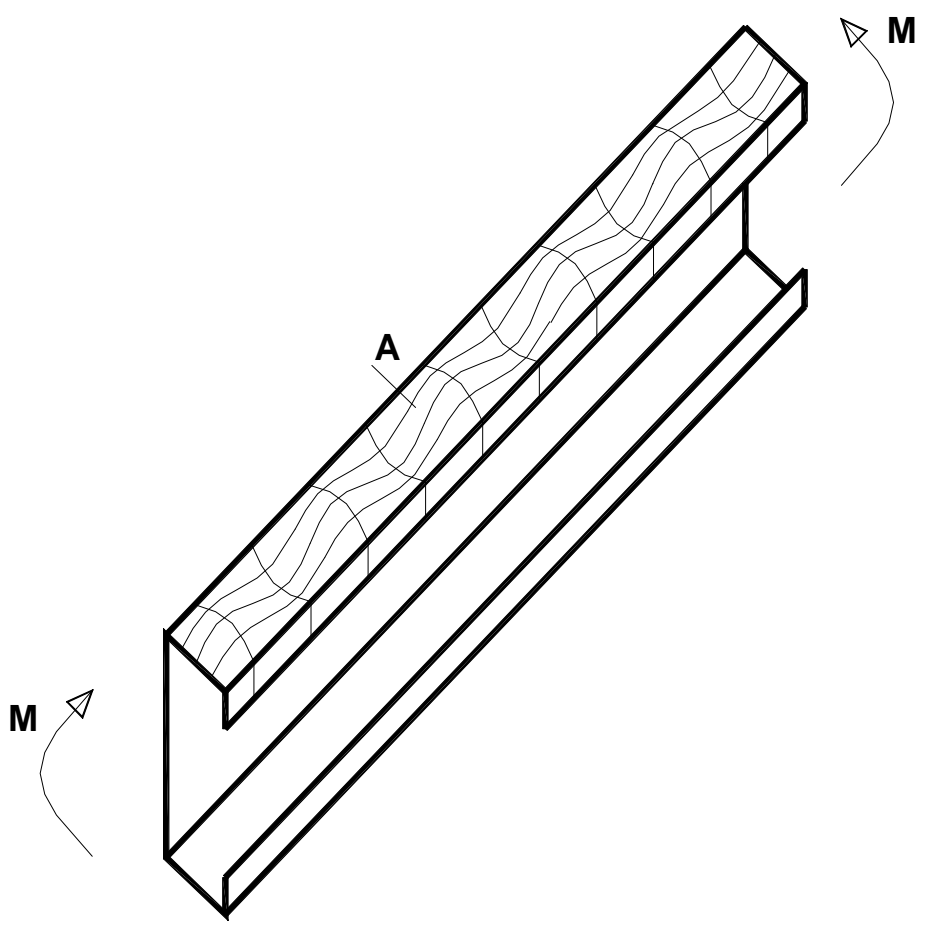

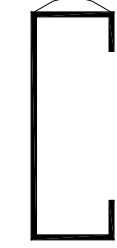

Corte A

Figura 2.1: Flambagem local para a mesa comprimida do perfil fletido.

Um outro modo de instabilidade local que pode caracterizar a falha do perfil é aquele onde ocorre a distorção da seção transversal em seu próprio plano, envolvendo deslocamentos laterais e rotações das partes componentes do perfil. Este tipo de instabilidade, instabilidade por distorção, pode ocorrer em perfis cujas partes comprimidas da seção transversal não possuem contenção lateral. Este fenômeno pode ocorrer em situações tais como:

- terças de coberturas conectadas às telhas de aço, quando submetidas aos efeitos de sução devido ao vento;

- perfis tipo $U$ e tipo $Z$ submetidos à flexão; 
- perfis tipo $U$ e tipo $Z$ utilizados como vigas contínuas de piso onde as mesas inferiores não apresentam contenção lateral nas regiões de momento fletor negativo.

$\mathrm{Na}$ figura 2.2 ilustra-se a ocorrência da instabilidade por distorção para um perfil tipo $U$ enrijecido podendo-se observar os deslocamentos laterais e a rotação na junção da alma com a mesa.

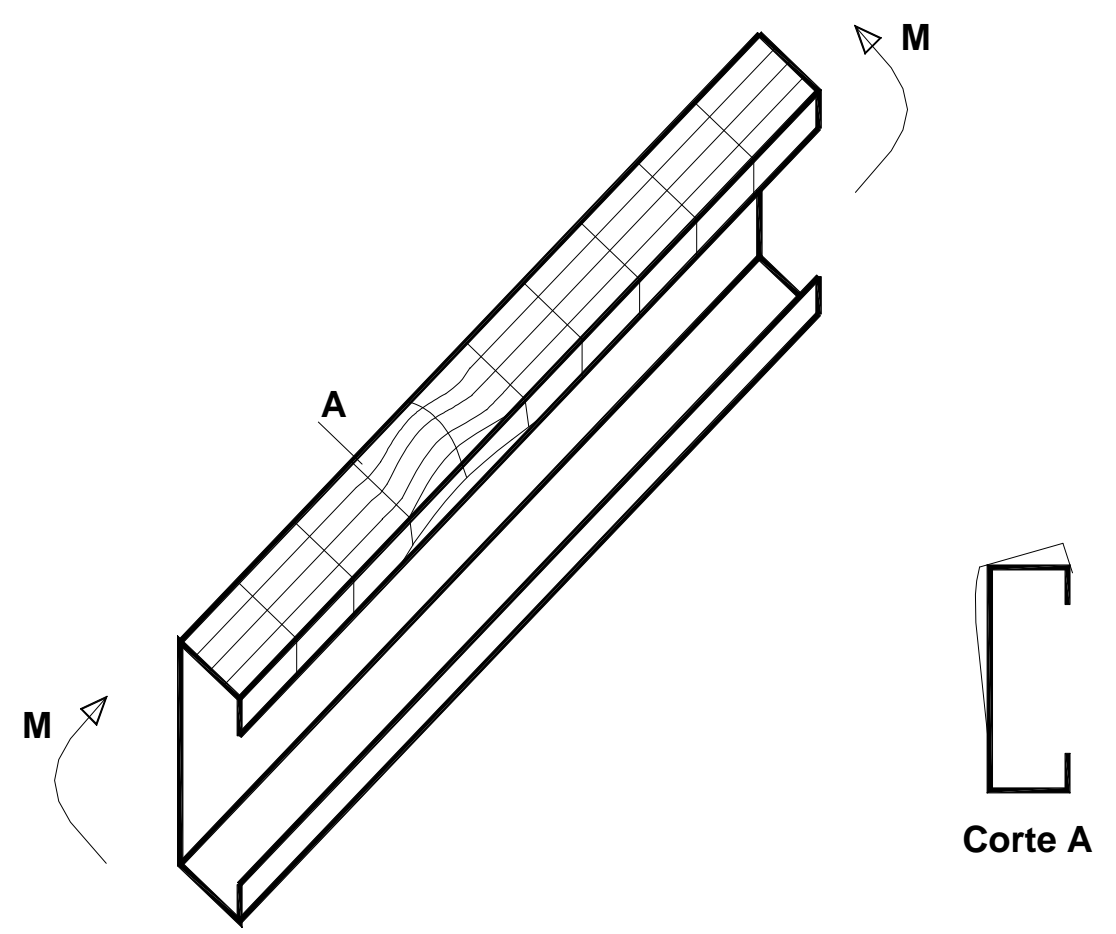

Figura 2.2: Flambagem por distorção para a mesa comprimida do perfil fletido.

A instabilidade global de um perfil de chapa dobrada pode ocorrer basicamente de três formas.

A primeira, bastante comum em pilares esbeltos, ocorre em torno do eixo de menor inércia, a flambagem por flexão.

A segunda forma dá-se pela rotação da seção transversal em torno de um eixo longitudinal, a flambagem por torção.

Finalmente, a terceira forma, de maior complexidade, envolve uma combinação de flexão e flexo-torção, sendo caracterizada em vigas sem 
contenção lateral e, neste caso, denominada de flambagem lateral com torção, conforme ilustra-se na figura 2.3.

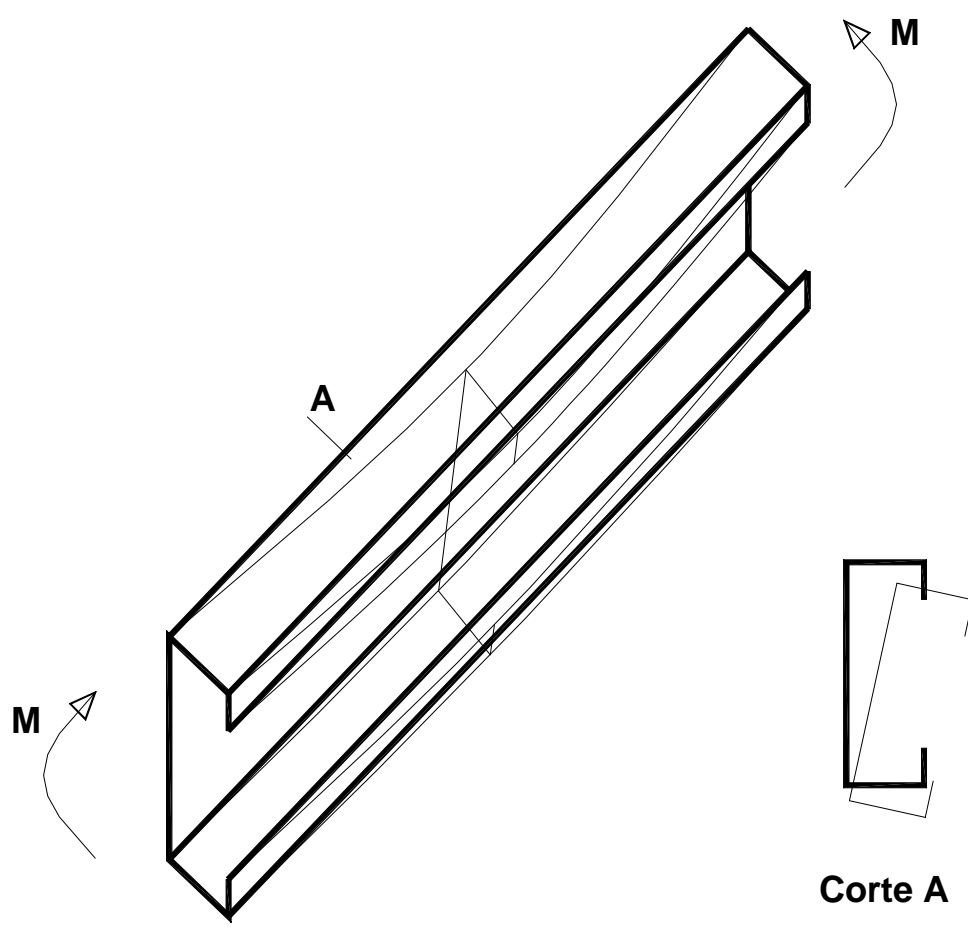

Figura 2.3: Flambagem lateral com torção de vigas.

Também para a flambagem lateral de viga, a reserva de resistência pós-crítica é pequena e corresponde a deslocamento exagerados para o uso corrente da estrutura.

Deve-se observar que a ocorrência dos modos de instabilidade local e global podem interagir, ocorrendo simultaneamente em uma mesma barra. Essa interação é tratada através do método da largura efetiva, modificandose a seção transversal da barra.

No desenvolvimento deste capítulo apresentam-se os aspectos teóricos que envolvem as formas de instabilidade dos perfis de aço e a sua aplicação ao projeto de estruturas constituídas por elementos estruturais de aço formados a frio, os perfis de chapa dobrada. 


\subsection{Instabilidade Local - Flambagem de Chapa}

\subsubsection{Introdução}

Nos perfis de aço, os elementos planos que constituem a seção transversal estão sujeitos à flambagem isoladamente, flambagem de chapa, sob tensão inferior àquela que provoca o escoamento inicial da seção ou mesmo daquela que provoca a flambagem global do perfil.

Este fenômeno pode ocorrer em elementos solicitados à compressão axial, à compressão por flexão, cisalhamento, etc. Entretanto, isto não significa, necessariamente, o fim da capacidade resistente do perfil. Observa-se que os elementos de chapa possuem considerável resistência pós-flambagem, podendo apresentar resistência maior que aquela determinada pela tensão crítica de flambagem local.

$\mathrm{Na}$ verificação da flambagem deve-se distinguir entre os diversos tipos de elementos planos que compõe a seção transversal do perfil, identificando-se os vários tipos de vinculações idealizadas para os elementos e o tipo de solicitação a que estão submetidos.

Define-se como elemento comprimido enrijecido um elemento plano, comprimido, no qual as duas bordas paralelas à direção da tensão são suportadas por enrijecedores (apoios) adequados. Como exemplo pode-se citar almas de perfis tipo I e de perfis tipo $U$.

Um elemento comprimido não enrijecido é aquele no qual uma borda, paralela à direção da tensão, é livre, tal como as mesas de um perfil tipo $U$.

$\mathrm{Na}$ verificação da esbeltez dos elementos que compõem a seção transversal do perfil de chapa dobrada, a sua largura é medida sobre a parte reta do elemento, não se incluindo a parte curva.

Considerando-se uma chapa quadrada, simplesmente apoiada e sujeita à tensão de compressão uniforme em uma direção, a flambagem ocorrerá com curvatura simples nas duas direções. 
Para chapas longas, $(l / b \geq 3,0)$, a configuração deslocada da chapa após a flambagem apresenta uma série de ondas cuja largura é aproximadamente igual a largura $b$ da chapa.

A tensão crítica de flambagem da chapa pode ser determinada resolvendo-se a equação diferencial 2.1, Timoshenko, Gere (1961):

$$
\frac{\partial^{4} w}{\partial x^{4}}+2 \frac{\partial^{4} w}{\partial x^{2} \partial y^{2}}+\frac{\partial^{4} w}{\partial y^{4}}+\frac{f_{x} t}{D} \frac{\partial^{2} w}{\partial x^{2}}=0
$$

onde:

$$
\begin{aligned}
& D=\frac{E t^{3}}{12\left(1-v^{2}\right)} \\
& E=\text { módulo de elasticidade } \text {. } \\
& v=\text { coeficiente de Poisson. } \\
& t=\text { espessura da chapa. } \\
& w=\text { deslocamento da chapa na direção do eixo } \mathrm{z} \text {, perpendicular à } \\
& f_{x}=\text { tensão de compressão na direção do eixo x. }
\end{aligned}
$$

Se $m$ e $n$ são os números de meia onda senoidal nas direções $x$ e $y$, respectivamente, o deslocamento $\omega$ da chapa pode ser representado pela série dupla:

$$
w=\sum_{m=1}^{\infty} \sum_{n=1}^{\infty} A_{m n} \operatorname{sen} \frac{m \pi x}{l} \operatorname{sen} \frac{n \pi y}{b}
$$

a qual satisfaz as condições de contorno para uma chapa simplesmente apoiada em todas as bordas.

Resolvendo-se a equação (2.1) usando-se a equação (2.2), encontrase a tensão crítica de flambagem elástica para a chapa em consideração: 


$$
f_{c r}=\frac{D \pi^{2}}{t b^{2}}\left[m\left(\frac{b}{l}\right)+\frac{n^{2}}{m}\left(\frac{l}{b}\right)\right]^{2}
$$

O menor valor para a tensão crítica será para $n=1$, isto é, somente uma meia onda senoidal na direção $y$. Portanto:

$$
f_{c r}=\frac{k D \pi^{2}}{t b^{2}}
$$

onde:

$$
k=\left[m\left(\frac{b}{l}\right)+\frac{n^{2}}{m}\left(\frac{l}{b}\right)\right]^{2}
$$

é o chamado coeficiente de flambagem de chapa.

Substituindo-se o valor de D na equação (2.4):

$$
f_{c r}=k \frac{\pi^{2} E}{12\left(1-v^{2}\right)(b / t)^{2}}
$$

O valor do coeficiente de flambagem de chapa, $k$, varia para diferentes relações de $l / b$, para diferentes condições de contorno e para diferentes tipos de solicitação.

Observa-se que o valor de $k$ é igual a 4 para valores inteiros da relação $l / b$. Este valor também é válido para valores relativamente grandes da relação $l / b(l / b \geq 4)$.

No estudo de elementos das estruturas em aço predominam as chapas longas $(l / b>4)$, o que representa o caso individual dos elementos das seções transversais geralmente utilizadas nas estruturas. 
Assim, para uma chapa longa simplesmente apoiada em suas quatro bordas com tensão de compressão uniforme em uma direção:

$$
f_{c r}=\frac{\pi^{2} E}{3\left(1-v^{2}\right)(b / t)^{2}}
$$

Valores de $k$ para chapas longas, sob diferentes distribuições de tensão e condições de contorno são apresentados na tabela 2.1.

Para tensões de compressão na chapa acima do limite de proporcionalidade do material, a chapa torna-se anisotrópica, apresentando propriedades diferentes em direções diferentes. A equação (2.6) não mais se aplica ao problema.

Bleich (1952), propôs a seguinte equação diferencial para a flambagem inelástica de chapas:

$$
R \frac{\partial^{4} w}{\partial x^{4}}+2 \sqrt{R} \frac{\partial^{4} w}{\partial x^{2} \partial y^{2}}+\frac{\partial^{4} w}{\partial y^{4}}+\frac{f_{x} t}{D} \frac{\partial^{2} w}{\partial x^{2}}=0
$$

onde:

$R=E_{t} / E$, sendo $E_{t}$ o módulo de elasticidade tangente do material.

A tensão crítica de flambagem inelástica para a chapa é dada por:

$$
f_{c r}=k \frac{\pi^{2} E \sqrt{R}}{12\left(1-v^{2}\right)(b / t)^{2}}
$$

O termo $\sqrt{R}$

redução plástica de uma chapa comprimida. Este fator varia com o tipo de solicitação e com as condições de contorno da chapa. 
TABELA 2.1 - Valores de $k$ para chapas longas.

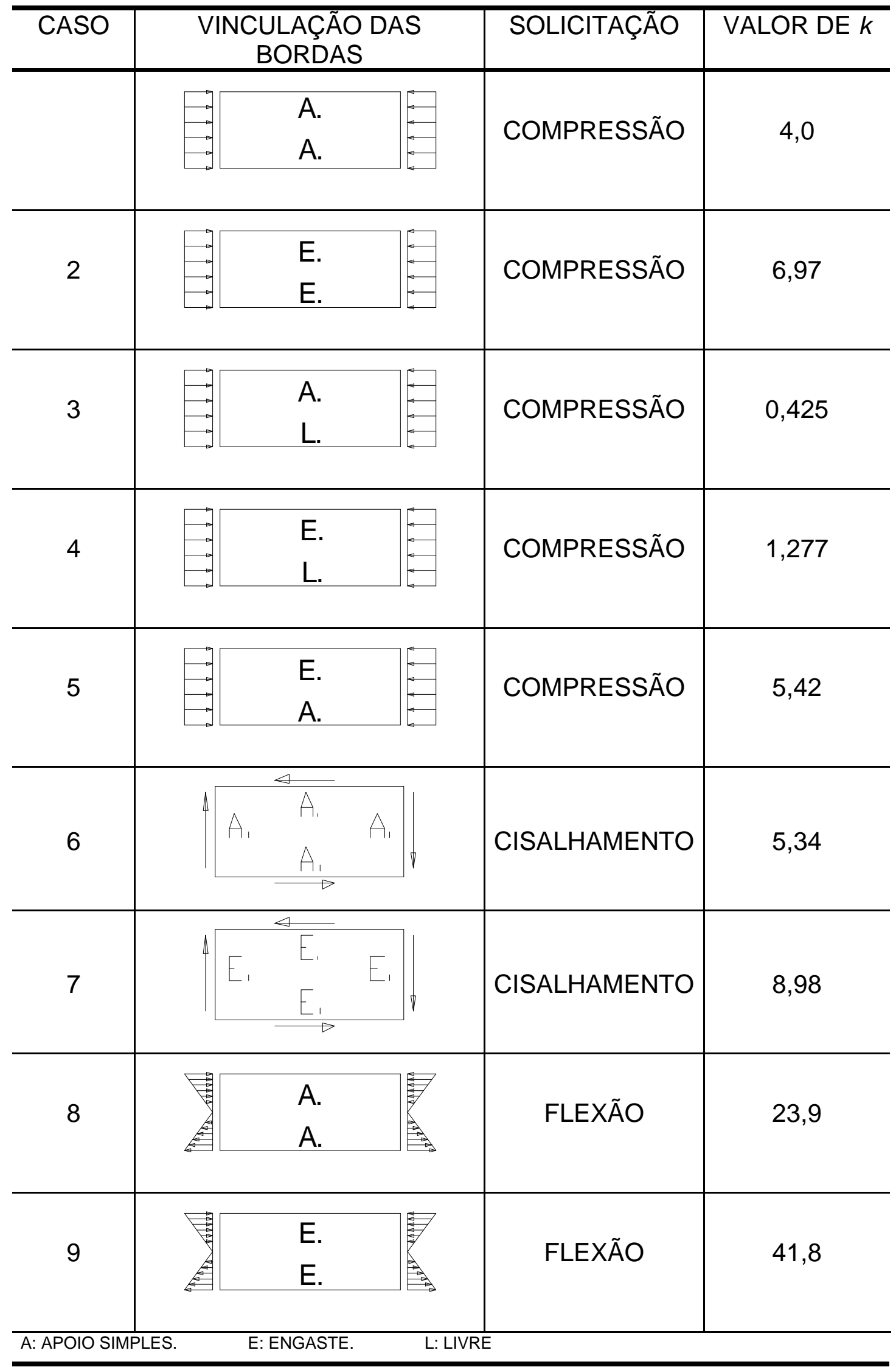




\subsubsection{Resistência pós-flambagem e o conceito de largura efetiva}

As chapas, ao contrário de elementos unidimensionais, não atingem o colapso quando a tensão de flambagem é alcançada. Acréscimos de tensão podem ser suportados devido à redistribuição de tensões para as partes enrijecidas desta chapa. Este fenômeno é denominado como resistência pós-flambagem.

A distribuição de tensões na chapa é uniforme até a iminência da flambagem. Ocorrida a flambagem, há uma redistribuição de tensões para as regiões que apresentam deslocamentos menores, regiões mais rígidas, como as regiões vizinhas aos apoios, resultando em uma distribuição de tensões não uniforme. O processo continua a ocorrer até que a tensão máxima iguala-se à tensão de escoamento do aço atingindo, então, o colapso convencional da chapa. A distribuição de tensões na seção transversal da chapa para o histórico de tensões é ilustrada na figura 2.4 .
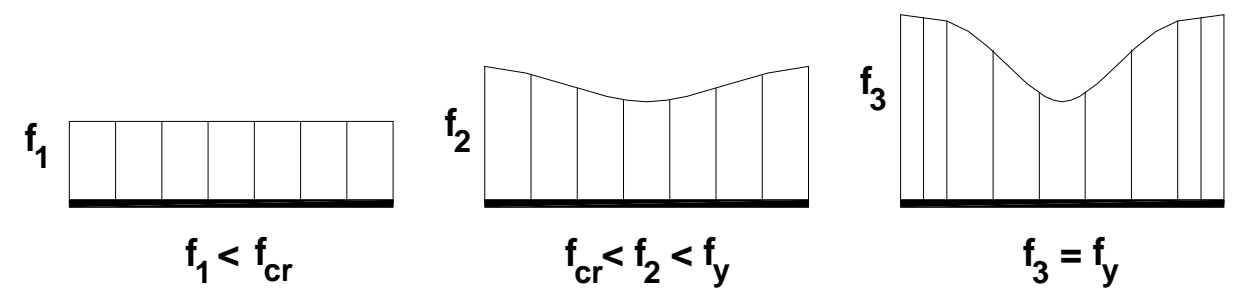

Figura 2.4: Distribuição de tensões para elementos comprimidos enrijecidos.

O comportamento pós-flambagem pode ser analisado levando-se em consideração os grandes deslocamentos envolvidos.

A equação diferencial (2.10) foi obtida por VON KARMAN em 1910:

$$
\frac{\partial^{4} w}{\partial x^{4}}+2 \frac{\partial^{4} w}{\partial x^{2} \partial y^{2}}+\frac{\partial^{4} w}{\partial y^{4}}=\frac{t}{D}\left(\frac{\partial^{2} F}{\partial y^{2}} \frac{\partial^{2} w}{\partial x^{2}}-2 \frac{\partial^{2} F}{\partial x \partial y} \frac{\partial^{2} w}{\partial x \partial y}+\frac{\partial^{2} F}{\partial x^{2}} \frac{\partial^{2} w}{\partial y^{2}}\right)=0
$$

sendo $F$ a função de tensão para a fibra média da chapa, e: 


$$
f_{x}=\frac{\partial^{2} F}{\partial y^{2}} \quad f_{y}=\frac{\partial^{2} F}{\partial x^{2}} \quad \tau_{x y}=-\frac{\partial^{2} F}{\partial x \partial y}
$$

A solução da equação diferencial (2.10), devido sua complexidade, tem pequena aplicação prática. Por esta razão, o conceito de largura efetiva foi introduzido por VON KARMAN em 1932.

Nesta aproximação, a distribuição não uniforme de tensões é substituída por uma distribuição uniforme de tensões, iguais às tensões das bordas, sobre uma largura efetiva ' $b_{e f}$ ', fictícia, como se ilustra na figura 2.5.

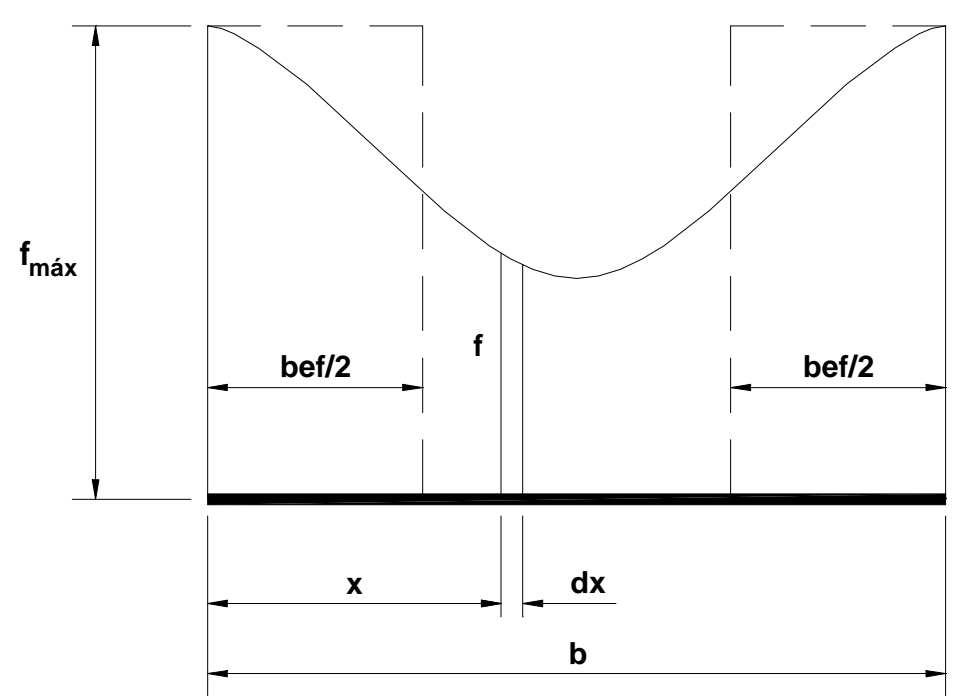

Figura 2.5: Largura efetiva de um elemento enrijecido à compressão.

A largura efetiva ' $b_{e f}$ ' é obtida de modo que as resultantes das duas distribuições de tensões sejam iguais, isto é:

$$
\int_{0}^{b} f d x=b_{e f} f_{\max }
$$

Para o caso de uma largura particular da chapa, onde a flambagem ocorre quando a tensão de compressão atinge o limite de escoamento do 
aço, o valor teórico de b, para uma chapa longa, pode ser determinado igualando-se $f_{c r}$ a $f_{y}$ :

$$
f_{c r}=f_{y}=\frac{\pi^{2} E}{3\left(1-v^{2}\right)(b / t)^{2}}
$$

ou

$$
b=c t \sqrt{E / f_{y}}=1,9 t \sqrt{E / f_{y}}
$$

onde:

$$
\begin{aligned}
& f_{y}=\text { tensão limite de escoamento do aço. } \\
& v=0,3 \\
& c=\frac{\pi}{\sqrt{3\left(1-v^{2}\right)}}=1,9
\end{aligned}
$$

A equação (2.14) é a equação clássica de von Karman para o cálculo da largura efetiva de elementos enrijecidos, apresentada em 1932.

\subsubsection{Elementos enrijecidos à compressão}

Com base em intensas pesquisas com seções de aço formadas a frio, Winter mostrou que a equação (2.14) aplica-se igualmente para elementos no qual a tensão máxima é inferior à tensão limite de escoamento. Adicionalmente, os resultados experimentais indicaram que o termo ' $c$ ' da equação (2.14) depende principalmente do parâmetro adimensional $\left(\sqrt{E / f_{\max }}(t / b)\right)$, apresentando a seguinte equação: 


$$
c=1,9\left(1-0,475\left(\frac{t}{b}\right) \sqrt{\frac{E}{f_{\text {má }}}}\right)
$$

Como conclusão dessas pesquisas, WINTER apresentou, em 1946, a expressão modificada para o cálculo da largura efetiva ' $b_{e}$ ' de um elemento comprimido enrijecido:

$$
b_{\text {ef }}=1,9 t \sqrt{\frac{E}{f_{\text {máx }}}}\left(1-0,475\left(\frac{t}{b}\right) \sqrt{\frac{E}{f_{\text {máx }}}}\right)
$$

Em 1968, a equação (2.17) foi substituída pela equação (2.18), a qual apresenta resultados mais próximos dos observados em ensaios.

$$
b_{e f}=1,9 t \sqrt{\frac{E}{f_{\text {máx }}}}\left(1-0,415\left(\frac{t}{b}\right) \sqrt{\frac{E}{f_{\text {máx }}}}\right)
$$

Esta equação pode ser generalizada para a determinação da largura efetiva de elementos enrijecidos à compressão sob diferentes condições de contorno:

$$
b_{\text {ef }}=0,95 t \sqrt{\frac{k E}{f_{\text {máx }}}}\left(1-0,208\left(\frac{t}{w}\right) \sqrt{\frac{k E}{f_{\text {máx }}}}\right)
$$

onde $k$ é o coeficiente de flambagem de chapa.

Fazendo-se $b_{e f}=b$, a partir da equação (2.19), pode-se obter:

$$
\begin{aligned}
& \rho=(1-0,22 / \lambda) / \lambda \\
& \lambda=\frac{1,052}{\sqrt{k}}\left(\frac{b}{t}\right) \sqrt{\frac{f_{\text {máx }}}{k E}}
\end{aligned}
$$


Através da equação (2.20) pode-se determinar o valor de $\lambda$ para 0 qual o elemento enrijecido à compressão é totalmente efetivo, ou seja, $b_{e f}=b$ quando $\lambda \leq 0,673$.

Para situações em serviço, na determinação de deslocamentos por exemplo, o mesmo procedimento pode ser utilizado, porém substituindo-se $f_{\text {máx }}$ pela tensão de serviço ' $f$ ', resultante das ações nominais devidamente combinadas.

\subsubsection{Elemento não enrijecido à compressão}

Um elemento não enrijecido à compressão pode escoar se a relação $(b / t)$ do elemento é menor que um determinado valor. Se ocorrer a flambagem local do elemento, então a relação $(b / t)$ excede aquele valor.

A tensão crítica de flambagem elástica para uma chapa sujeita a tensões uniformes de compressão com uma borda livre pode ser também determinada pela equação (2.6).

Quando a relação $(b / t)$ do elemento excede aproximadamente 25 , 0 elemento perde estabilidade de forma gradual, com uma tensão aproximadamente igual a tensão de flambagem local e retorna à forma original após o descarregamento. Isto porque a tensão de flambagem é inferior à tensão de proporcionalidade do aço.

Kalyanaraman et. al. (1977) demonstraram que a equação da largura efetiva de WINTER, equação (2.19), constitui-se em um indicador adequado da capacidade resistente do elemento se o coeficiente correto de flambagem de chapa ' $k$ ' é empregado.

Para uma chapa retangular longa, simplesmente apoiada ao longo de três borda, tendo a última livre, o coeficiente de flambagem de chapa é $k=0,425$. 


\subsubsection{Elemento sob tensões não uniformes}

Em barras estruturais onde o elemento comprimido é perpendicular à linha neutra, a distribuição de tensões neste elemento não é uniforme, variando proporcionalmente à distância à linha neutra.

A figura 2.6 ilustra duas situações possíveis de distribuição de tensões não uniformes nos elementos enrijecidos e não enrijecidos. A área hachurada representa a largura efetiva do elemento sob tensões de compressão não uniformes.

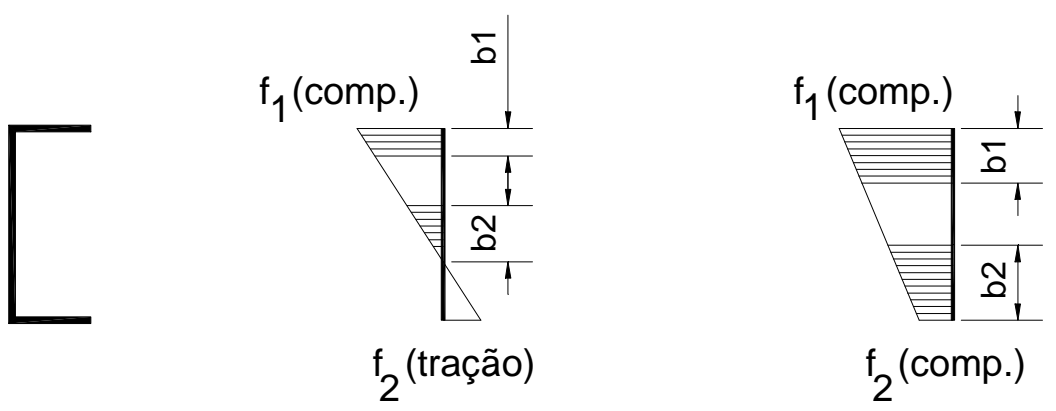

a)

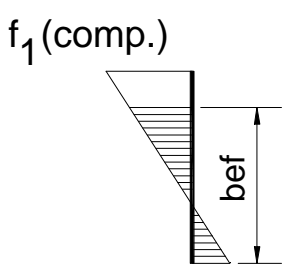

$\mathrm{f}_{2}$ (tração)

b)

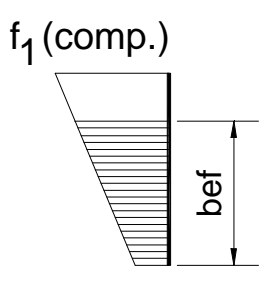

$\mathrm{f}_{2}$ (comp.)

Figura 2.6: Elementos submetidos a tensões não uniformes.

A equação (2.19) pode ser utilizada para o cálculo sua largura efetiva de um elemento não enrijecido admitindo-se uma distribuição uniforme de tensões com valor ' $f_{1}$ ', figura 2.6, e o coeficiente de flambagem de chapa ' $k$ ' igual a 0,43. Embora estas considerações não representem um aumento na resistência pós-flambagem do elemento não enrijecido deve-se ressaltar a 
existência de outras expressões para a determinação de ' $k$ ', como aquelas apresentadas pelo Eurocode (1993).

Para elementos enrijecidos, a largura efetiva do elemento é tomada como $\left(b_{1}+b_{2}\right)$, conforme mostra-se na figura 2.6a. As larguras $b_{1}$ e $b_{2}$ devem ser determinadas da seguinte maneira:

$$
\begin{aligned}
& b_{1}=\frac{b_{e f}}{3-\psi} \\
& b_{2}=\frac{b_{e f}}{2} \text { para } \psi \leq-0,236 \\
& b_{2}=b_{e f}-b_{1} \text { para } \psi>-0,236 \\
& k=4+2(1-\psi)^{3}+2(1-\psi) \\
& \psi=\frac{f_{1}}{f_{2}}
\end{aligned}
$$

O valor de $b_{e f}$ é obtido através das equações (2.20) e (2.21), utilizando-se $k$ dado pela expressão (2.25). $f_{1}$ e $f_{2}$ são as tensões, conforme figura 2.6. $f_{1}$ é a tensão de compressão, convencionada positiva, e $f_{2}$ é a tensão de tração, convencionada negativa, ou de compressão. Se ambas forem de compressão, $f_{1}>f_{2}$.

A largura efetiva do elemento, $\left(b_{1}+b_{2}\right)$, não deve exceder a parte comprimida do elemento. 


\subsubsection{Enrijecedores de borda e enrijecedores intermediários}

\subsubsection{Introdução}

As seções típicas de chapa dobrada são compostas de elementos enrijecidos e não enrijecidos. Devido a presença de uma borda livre ou quando a relação $(b / t)$ de um elemento comprimido enrijecido é relativamente grande, um aumento em sua resistência pode ser obtido adicionando-se enrijecedores de extremidade ou intermediários, adequadamente.

Esses enrijecedores, figura 2.7, devem fornecer um 'apoio' longitudinal aos elementos comprimidos. Ressalta-se que 0 termo longitudinal implica no fato de o enrijecedor ser paralelo à direção da tensão de compressão.
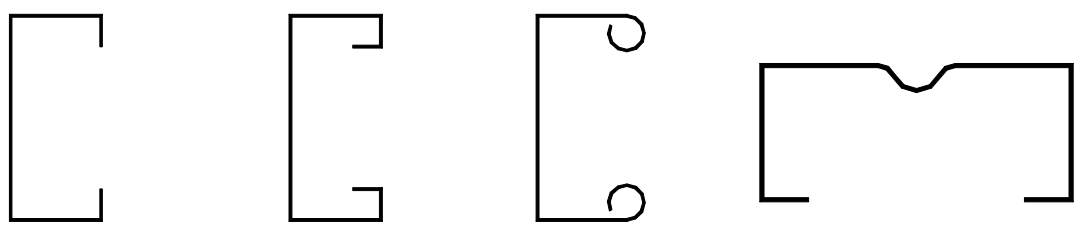

Figura 2.7: Enrijecedores de borda e intermediário.

Dois modos de flambagem, fundamentalmente diferentes, caracterizam o comportamento dos elementos planos enrijecidos através do uso de enrijecedores.

O primeiro é o modo de flambagem do enrijecedor, onde a instabilidade inicia-se pela flambagem do enrijecedor na direção perpendicular ao plano do elemento ao qual deveria constituir um apoio contínuo. Neste caso, o enrijecedor induz, simultaneamente, à flambagem local do elemento comprimido.

O segundo modo é a flambagem local do elemento plano, onde a instabilidade inicia-se pela flambagem do mesmo. Neste caso, o enrijecedor 
possui características de rigidez suficientes para ser idealizado como um apoio contínuo ao elemento comprimido.

\subsubsection{Enrijecedores de borda}

Estudos desenvolvidos por Desmond et al (1981) para os modos de flambagem possíveis para o elemento de chapa enrijecido, a influência do enrijecedor na flambagem do elemento plano pode ser colocada como se segue:

- Para relações $d / b$ ( $d$ é a altura do enrijecedor e b a largura da mesa) menores que aproximadamente 0,12 , a rigidez do enrijecedor não é suficiente para caracterizar um apoio ao elemento plano. Consequentemente, a flambagem do conjunto inicia-se pela flambagem do enrijecedor de borda.

- Para $0,12<d / b<0,4$, a flambagem inicia-se simultaneamente no elemento plano e no enrijecedor. O coeficiente de flambagem de chapa ' $k$ ' aproxima-se, assintoticamente, de 4,0.

- Para $d / b>0,4$, a flambagem inicia-se pela flambagem do elemento plano enrijecido.

Neste último caso, $d / b>0,4$, a instabilidade local do enrijecedor de borda interage com a do elemento enrijecido e inicia-se uma flambagem prematura desse elemento. Deve-se notar que formas de enrijecedores de borda, diferentes daquelas formadas por simples viradas de bordas de $90^{\circ}$ não estão, em geral, propensas à interação e para tais enrijecedores, dimensões excessivamente maiores não afetam a tensão crítica de flambagem do conjunto.

Desmond et. al. (1981) obtiveram o momento de inércia adequado do enrijecedor de borda, determinado para três casos distintos. $O$ momento de 
inércia é referido em relação ao eixo central do enrijecedor, paralelo ao elemento a ser enrijecido.

\section{Caso I}

$$
\frac{b}{t} \leq \frac{1,28}{3} \sqrt{\frac{E}{f}}
$$

onde:

$b=$ largura plana do elemento.

$t=$ espessura do elemento.

$E=$ módulo de elasticidade do aço.

$f=$ tensão de compressão no elemento.

Neste caso, a largura efetiva do elemento comprimido não enrijecido é igual a sua largura plana, isto é, não se necessita de enrijecedor de borda.

\section{Caso II}

$$
\frac{1,28}{3} \sqrt{\frac{E}{f}}<\frac{b}{t} \leq 1,28 \sqrt{\frac{E}{f}}
$$

O momento de inércia adequado ao enrijecedor, $I_{a}$, de modo que o elemento comporte-se como um elemento comprimido enrijecido será:

$$
I_{a}=399\left\{\left[\left(\frac{b}{t}\right) / 1,28 \sqrt{E / f}\right]-0,33\right\}^{3} t^{4}
$$

\section{Caso III}

$$
\frac{b}{t}>1,28 \sqrt{\frac{E}{f}}
$$




$$
I_{a}=\left\{\left[115\left(\frac{b}{t}\right) / 1,28 \sqrt{E / f}\right]+5\right\}^{3} t^{4}
$$

Para enrijecedores formados a partir de virada simples de borda tendo ângulo reto com o elemento a ser enrijecido, a altura total da aba ' $d$ ' deve ser no mínimo:

$$
d=\left(24 \frac{b}{t}-156\right)^{1 / 3} t \geq 4,8 t
$$

Esse tipo de enrijecedor não deve ser utilizado para elementos cuja relação 'b/t' exceda 60 .

\subsubsection{Enrijecedores intermediários}

Desmond et. al. (1981), através de uma análise apurada sobre a utilização de um único enrijecedor intermediário em um elemento esbelto comprimido, concluíram que o momento de inércia que o enrijecedor intermediário deve possuir para ser considerado como tal, é determinado de acordo com três casos distintos:

\section{Caso I}

$$
\frac{b_{0}}{t} \leq 1,28 \sqrt{\frac{E}{f}}
$$

Neste caso, a largura efetiva do elemento comprimido enrijecido é igual a sua largura plana e não há necessidade de enrijecedor intermediário. $b_{0}$ é a largura plana total do elemento de chapa. 


\section{Caso II}

$$
\begin{aligned}
& 1,28 \sqrt{\frac{E}{f}}<\frac{b_{0}}{t}<3,84 \sqrt{\frac{E}{f}} \\
& I_{a}=\left\{\left[50\left(\frac{b_{0}}{t}\right) / 1,28 \sqrt{E / t}\right]-50\right\} t^{4}
\end{aligned}
$$

\section{Caso III}

$$
\begin{aligned}
& \frac{b_{0}}{t} \geq 3,84 \sqrt{\frac{E}{f}} \\
& I_{a}=\left\{\left[128\left(\frac{b_{0}}{t}\right) / 1,28 \sqrt{E / t}\right]-285\right\} t^{4}
\end{aligned}
$$

No caso de elementos comprimidos com enrijecimentos múltiplos, cada enrijecedor deverá apresentar um momento de inércia mínimo, $I_{\text {mín }}$, dado por Yu (1986):

$$
I_{\text {min }}=3,66\left[\left(\frac{b}{t}\right)^{2}-0,136 \frac{E}{f}\right]^{1 / 2} t^{4} \geq 18,4 t^{4}
$$

onde $(b / t)$ é a razão largura plana para espessura do maior subelemento a ser enrijecido.

$\mathrm{Na}$ utilização de dois ou mais enrijecedores intermediários, deve-se observar:

- somente enrijecedores intermediários adjacentes a elemento de alma devem ser efetivamente considerados; 
- se os enrijecedores intermediários estiverem dispostos próximos $\left(b_{e f}=b\right)$, o conjunto comporta-se como um elemento simples à compressão, cuja rigidez é dada pelo momento de inércia do elemento multi-enrijecido, incluindo os enrijecedores.

No cálculo da razão largura para espessura do elemento, deve-se considerar um elemento equivalente de largura ' $b_{0}$ ' igual a distância total entre almas ou entre alma e enrijecedor de borda, e uma espessura equivalente 'to' determinada por:

$$
t_{0}=\sqrt[3]{12 l / b_{0}}
$$

onde I é o momento de inércia total do elemento com enrijecimento múltiplo, incluindo os enrijecedores.

\subsubsection{Largura efetiva para elemento com enrijecedor de borda}

O cálculo da largura efetiva de um elemento comprimido enrijecido por meio de enrijecedor de borda é feito através das equações (2.20) e (2.21).

O coeficiente de flambagem de chapa ' $k$ ' é determinado de forma a considerar a interação entre o elemento enrijecido e o enrijecedor e as expressões de $b_{\text {ef }}$ e $A_{e f}^{\prime}$ permitem avaliar também um elemento parcialmente enrijecido $\left(I_{s t}<I_{a}\right)$ :

$$
\begin{aligned}
0,25<(d / b) \leq 0,80: \\
k=\left[4,82-5\left(\frac{d}{b}\right)\right]\left(\frac{l_{s t}}{l_{a}}\right)^{n}+0,43 \leq 5,25-5\left(\frac{d}{b}\right)
\end{aligned}
$$




$$
\begin{aligned}
& (d / b) \leq 0,25: \\
& k=3,57\left(\frac{I_{s t}}{I_{a}}\right)^{n}+0,43 \leq 4,0 \\
& b_{e f}^{\prime}=b_{e f}\left(\frac{I_{s t}}{I_{a}}\right) \leq b_{e f} \\
& A_{e f}^{\prime}=A_{e f}\left(\frac{l_{s t}}{l_{a}}\right) \leq A_{e f}
\end{aligned}
$$

onde:

$d$ = dimensão definida na figura 2.8.

$b=$ largura plana do elemento comprimido.

$I_{s t}=$ momento de inércia do enrijecedor .

$n=1 / 2$ para $\frac{1,28}{3} \sqrt{\frac{E}{f}}<\frac{b}{t} \leq 1,28 \sqrt{\frac{E}{f}}$

$n=1 / 3$ para $\frac{b}{t}>1,28 \sqrt{\frac{E}{f}}$

$b_{\text {ef }}=$ largura efetiva do elemento enrijecido.

$b^{\prime}{ }_{\text {ef }}=$ largura efetiva no caso de se ter enrijecimento parcial $\left(I_{s t}<I_{a}\right)$.

$A_{e f}=$ área efetiva do elemento enrijecido.

$A^{\prime}{ }_{\text {ef }}=$ área efetiva reduzida no caso de se ter enrijecimento parcial. 


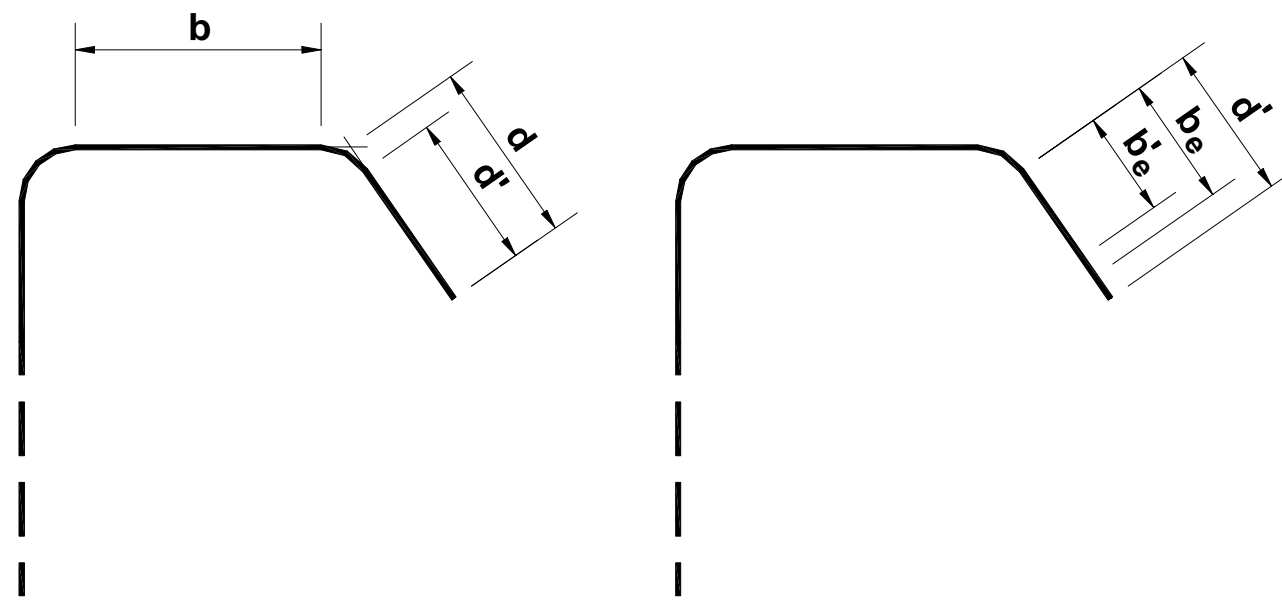

Figura 2.8: Elemento efetivo de um enrijecedor.

Observa-se que um enrijecedor de borda é um elemento não enrijecido à compressão e deverá ter suas propriedades geométricas efetivas determinadas como tal.

\subsubsection{Largura efetiva para elemento com enrijecedor intermediário}

Para subelementos de um elemento com enrijecimento múltiplo à compressão, a largura efetiva é geralmente menor que a de um elemento enrijecido.

Para um elemento com enrijecimento múltiplo, dado por apenas um enrijecedor intermediário, a largura efetiva do subelemento é obtida através das equações (2.20) e (2.21) com o coeficiente de flambagem de chapa ' $k$ ' dado por:

$$
k=3\left(\frac{I_{s t}}{I_{a}}\right)^{n}+1 \leq 4,0
$$


onde:

$I_{s t}=$ momento de inércia do enrijecedor.

$I_{a}=$ momento de inércia adequado para o enrijecedor.

$$
\begin{aligned}
n & =1 / 2 \text { para } 1,28 \sqrt{\frac{E}{f}}<\frac{b}{t}<3,84 \sqrt{\frac{E}{f}} \\
& =1 / 3 \text { para } \frac{b}{t} \geq 3,84 \sqrt{\frac{E}{f}}
\end{aligned}
$$

No caso de ter-se $\left(I_{s t}<I_{a}\right)$, o cálculo da área efetiva do enrijecedor intermediário deve ser realizado de acordo com a equação (2.43) se a razão largura plana para espessura é menor que 60 .

\subsection{Instabilidade Global}

\subsubsection{Introdução}

A barra, de comprimento " $l$ ", será referida a um sistema de eixos xyz, sendo x e y os eixos principais de inércia da seção transversal da barra e z o eixo longitudinal que contém os centros de gravidade das seções transversais.

As hipóteses assumidas são:

- a espessura 't' é muito menor que as dimensões características da seção e estas muito menores que o comprimento da barra;

- a projeção da seção é considerada indeformável no seu plano e suas dimensões não variam com $z$.

- A distorção na linha do esqueleto é nula, ou seja, $\gamma_{s z}=0$. 
A instabilidade de barras prismática de seção aberta qualquer foi sistematicamente estudada por Vlasov (1962) obtendo as equações gerais de equilíbrio para uma situação genérica do problema.

A dedução das equações gerais de instabilidade será apresentada de forma sucinta, através da expressão da energia.

\subsubsection{Tensões}

A tensão normal para um carregamento qualquer de forças longitudinais e de forças transversais cuja linha de ação passa pelo centro de torção da seção será dada por:

$$
\sigma=\frac{N}{A}+\frac{M_{x}}{I_{x}} y+\frac{M_{y}}{I_{y}} x+\frac{B}{C_{\omega}} \omega
$$

onde:

$N$ = força normal, positiva se de tração.

$M=$ momento fletor, positivo se traciona o lado positivo do eixo coordenado.

$B$ = bimomento, positivo se traciona a parte positiva da área setorial.

$A$ = área da seção.

$I=$ momento principal de inércia.

$C_{\omega}=$ Constante de empenamento.

$\omega=$ área setorial.

As tensões de cisalhamento, além daquela provocada pela força cortante, são provenientes da torção livre $\left(\tau_{l}\right)$ e da flexo-torção $\left(\tau_{f t}\right)$, equação (2.46). 


$$
\tau=\tau_{f}+\tau_{l}+\tau_{f t}=\frac{V M_{s}}{b l}+\frac{M_{t}}{l_{t}} t+\frac{M_{f t} S_{\omega}}{t C_{\omega}}
$$

onde:

$V=$ força cortante.

$M_{s}=$ momento estático da seção.

$b=$ largura da seção na fibra onde $\tau$ é calculado.

$I$ = Momento de inércia.

$M_{t}=$ momento de torção.

$M_{f t}=$ momento torçor de flexo-torção.

$I_{t}=$ momento de inércia à torção.

$S_{\omega}=$ momento estático setorial.

Ressalta-se que a parcela da tensão de cisalhamento oriunda da flexo-torção é contraditória à hipótese de deformações nulas na linha do esqueleto visto que, a existência das tensões $\tau_{f t}$ ocasiona distorções na superfície média da barra, contrariando as hipótese inicialmente assumidas. Este fato é desprezado por ser $\tau_{f t}$ pequena quando comparado às tensões $\tau_{l}$, desprezando-se, assim, as distorções por ela produzidas na linha do esqueleto.

\subsubsection{Energia de deformação}

A energia de deformação, utilizando-se as relações da lei de Hooke, é dada por:

$$
U=\frac{1}{2 E} \int_{0}^{l}\left(\int_{A} \sigma^{2} d A\right) d z+\frac{1}{2 G} \int_{0}^{l}\left(\int_{A} \tau^{2} d A\right) d z
$$


onde $\mathrm{E}$ e G são, respectivamente, o módulo de elasticidade e o módulo de elasticidade transversal.

$\mathrm{Na}$ primeira parcela da equação (2.47), a tensão $\sigma$ é dada pela equação (2.45). Na segunda, a tensão $\tau$ é dada pela equação (2.46).

Desprezando-se, como usualmente se faz, a contribuição da força normal, a contribuição da força cortante e a contribuição do momento de flexo-torção, e sendo válidas as relações:

$$
M_{x}=-E I_{x} v^{\prime \prime}, M_{y}=-E I_{y} u^{\prime \prime}, B=E C_{\omega} \phi^{\prime \prime}, M_{t}=G I_{t} \phi^{\prime}
$$

onde a linha representa a derivação em relação a z, a expressão da energia de deformação é dada por:

$$
U=\frac{1}{2} \int_{0}^{l}\left(E I_{x} V^{\prime \prime 2}+E I_{y} u^{\prime \prime 2}+E C_{\omega} \phi^{\prime \prime 2}+G I_{t} \phi^{\prime 2}\right) d z
$$

\subsubsection{Energia potencial}

$\mathrm{Na}$ expressão (2.48) apresenta-se somente a contribuição das tensões trabalhando com as deformações correspondentes, provocadas pelos deslocamentos $u$ e $v$ e pela rotação $\phi$. Como, na iminência da perda de estabilidade, a barra está submetida a tensões que não estão relacionadas aos deslocamentos e rotação correspondentes, outras parcelas de energia devem ser consideradas.

\subsubsection{Energia potencial da tensão normal provocada pelos momentos fletores durante a rotação $\phi$}

A contribuição $T_{1}$ das tensões $\sigma$ para a energia potencial é dada por: 


$$
T_{1}=\int_{0}^{l} \int_{A} \sigma \delta d A
$$

De acordo com o elemento $d A d z$, indicado na Figura 2.9, tem-se:

$$
\delta=d z(1-\cos \alpha)=2 d z \operatorname{sen}^{2} \frac{\alpha}{2}
$$
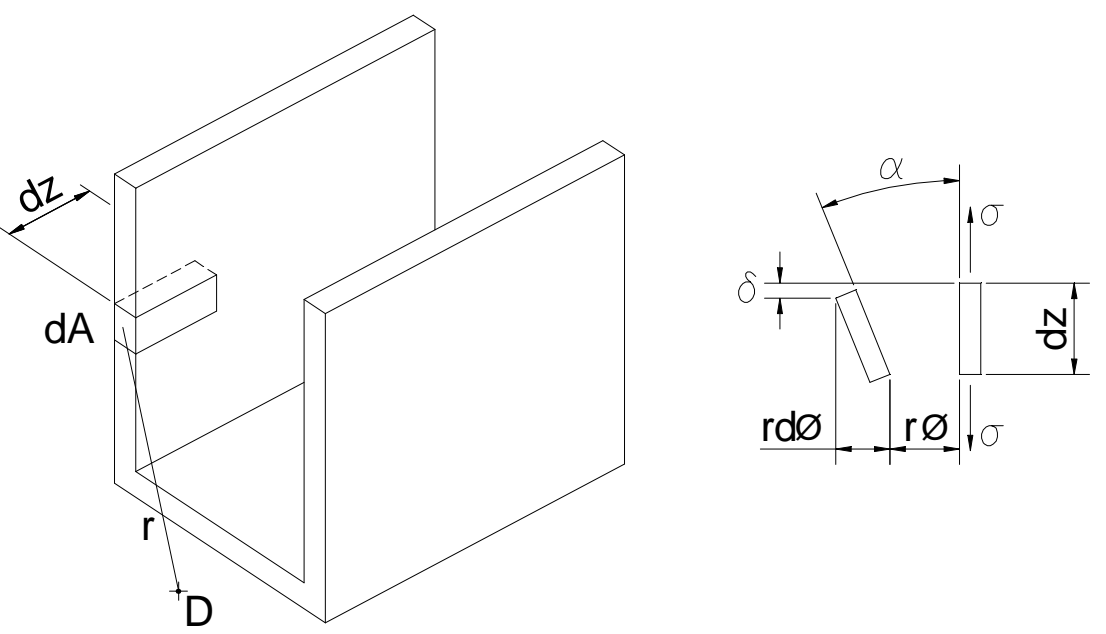

Figura 2.9: Trabalho da tensão $\sigma$ durante a rotação $\phi$.

Sendo $\alpha$ pequeno pode-se escrever:

$\alpha=\frac{r d \phi}{d z}=r \phi^{\prime}$

A distância $r$ pode ser obtida por:

$$
r^{2}=\left(x-x_{0}\right)^{2}+\left(y-y_{0}\right)^{2}
$$

de onde: 


$$
\delta=\frac{\left(x-x_{0}\right)^{2}+\left(y-y_{0}\right)^{2}}{2} \phi^{\prime 2} d z
$$

Assim, substituindo-se a expressão de $\delta$, juntamente com a de $\sigma$ na equação (2.49) e efetuando-se a integral ao longo da área obtém-se a expressão de $T_{1}$ :

$$
T_{1}=\frac{1}{2} \int_{0}^{l} \phi^{\prime 2}\left[2 M_{x}\left(k_{y}-y_{0}\right)+2 M_{y}\left(K_{x}-x_{0}\right)\right] d z
$$

onde estão sendo introduzidas as seguintes características geométricas da seção transversal:

$$
\begin{aligned}
& k_{x}=\frac{1}{2 I_{y}} \int_{A} x\left(x^{2}+y^{2}\right) d A \\
& k_{y}=\frac{1}{2 I_{x}} \int_{A} y\left(x^{2}+y^{2}\right) d A
\end{aligned}
$$

que são as coordenadas do centro do círculo de estabilidade nos eixos x e y, respectivamente.

\subsubsection{Energia potencial devida ao momento torçor}

O aparecimento de momento torçor antes da perda de estabilidade pode ocorrer quando a barra estiver submetida à ação de um bimomento. Para uma barra solicitada por um momento torçor $M_{t}$, a energia correspondente ao elemento de comprimento dz será:

$$
d T_{2}=-M_{t} d \phi
$$

de onde se obtém: 


$$
T_{2}=-\int_{0}^{l} M_{t} \phi^{\prime} d z
$$

\subsubsection{Energia potencial da força normal}

Considerando-se novamente a Figura 2.9, o ângulo $\alpha$ pode ser dado por:

$$
\alpha=\frac{\sqrt{(d u)^{2}+(d v)^{2}}}{d z}
$$

Substituindo esta expressão de $\alpha$ na expressão de $\delta$ encontra-se:

$$
\delta=\frac{1}{2}\left(u^{\prime 2}+v^{\prime 2}\right) d z
$$

Observando-se a Figura 2.10, para uma nova posição de equilíbrio da barra, quando esta estiver submetida a um carregamento capaz de causar sua instabilidade, as expressões dos deslocamentos de um ponto genérico $\mathrm{Q}(\mathrm{x}, \mathrm{y})$ da seção, segundo os eixos principais, são:

$$
\begin{aligned}
& u_{Q}=u-\left(y-y_{0}\right) \phi \\
& v_{Q}=v-\left(x-x_{0}\right) \phi
\end{aligned}
$$

Derivando-se estas expressões e substituindo-as na expressão de $\delta$, juntamente com $\sigma$, obtém-se a expressão de $T_{3}$, correspondente a parcela da energia potencial da força normal:

$$
T_{3}=\frac{1}{2} \int_{0}^{l} N\left[r_{0}^{2} \phi^{\prime 2}+2\left(u^{\prime} y_{0}-v^{\prime} x_{0}\right) \phi^{\prime}+u^{\prime 2}+v^{\prime 2}\right] d z
$$


onde $r_{0}=\sqrt{x_{0}^{2}+y_{0}^{2}+\left(I_{x}+I_{y}\right) / A}$ é o raio de giração polar.

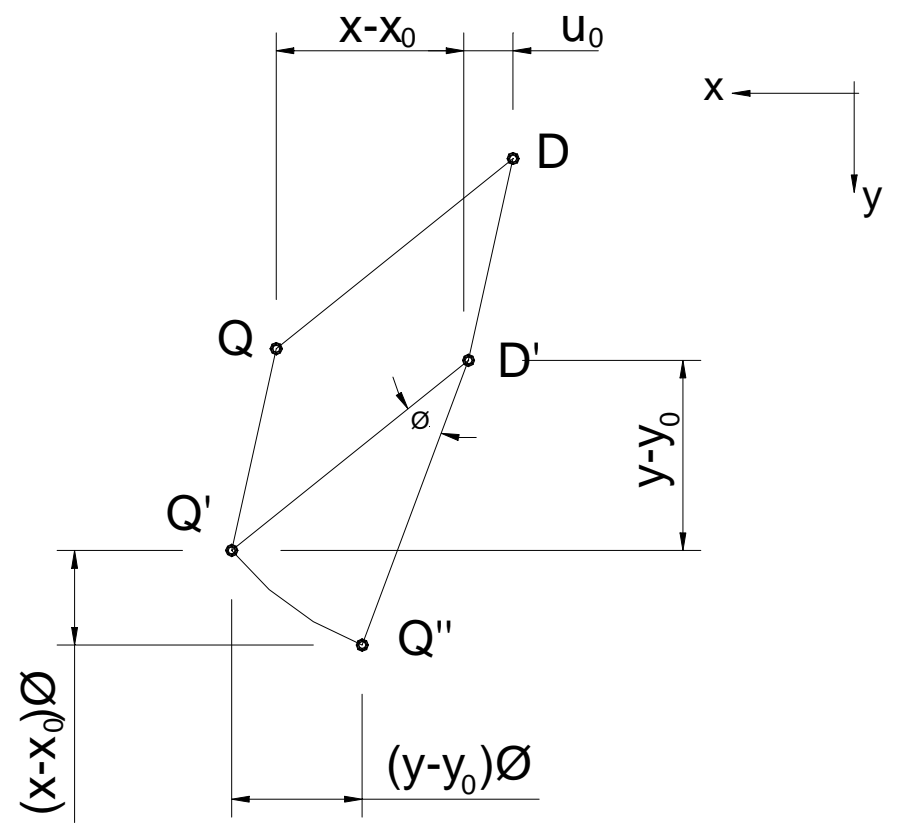

Figura 2.10: Deslocamento de um ponto genérico da seção.

\subsubsection{Energia potencial do bimomento}

Uma parte da contribuição do bimomento é análoga a parcela do item anterior:

$$
T_{4}=\int_{0}^{l} \int_{A} \frac{B}{C_{\omega}} \omega d A \delta
$$

Com as substituições adequadas e realizando-se as operações e integrações indicadas obtém-se a expressão final desta parcela:

$$
T_{4}=\frac{1}{2} \int_{0}^{l} \frac{U_{\omega}}{C_{\omega}} B \phi^{\prime 2} d z
$$


onde $U_{\omega}$ é uma característica geométrica da seção, introduzida por Vlasov (1962):

$$
U_{\omega}=\int_{A} \omega\left(x^{2}+y^{2}\right) d A
$$

Para seções com um eixo de simetria, $U_{\omega}=0$. Quando $U_{\omega}$ é nulo, o bimomento não altera o valor da carga crítica, entretanto, altera a espécie do problema.

A outra parcela da contribuição do bimomento para a energia total é o trabalho dos bimomentos aplicados durante o empenamento por eles produzidos. Nas extremidades o empenamento $w$, com seu sentido positivo coincidindo com o sentido positivo do eixo z, é dado por:

$$
\begin{aligned}
& w_{e}=\omega \phi_{e}{ }^{\prime} \\
& w_{d}=\omega \phi_{d}{ }^{\prime}
\end{aligned}
$$

onde $\phi_{e}^{\prime}$ e $\phi_{d}^{\prime}$ são as derivadas do ângulo de giro nas extremidades esquerda e direita, respectivamente.

Com os bimomentos $B_{e}$ e $B_{d}$ aplicados às extremidades esquerda $\mathrm{e}$ direita, por meio de tensões $\sigma_{e} e \sigma_{d}$, escreve-se para a expressão desta parcela da energia potencial:

$$
T_{5}=B_{e} \phi_{e}{ }^{\prime}-B_{d} \phi_{d}{ }^{\prime}
$$

\subsubsection{Energia potencial das ações transversais}

As ações transversais serão constituídas por forças concentradas $P_{i}$ e força distribuída $q$, cujas linhas de ação passam pelo centro de torção da 
seção transversal da barra. Suas componentes na direções dos eixos x e y serão, respectivamente, $P_{x i}, P_{y i}, q_{x}$ e $q_{y}$.

Para uma força genérica $P_{i}$, aplicada em um ponto qualquer da seção transversal com excentricidade $e_{j}$ em relação ao centro de torção $D$, durante a rotação da seção, a parcela da energia correspondente ao deslocamento 'a' da força $P_{i}$, Figura 2.11, é dada por:

$$
T_{6}^{i}=-P_{i} \frac{e_{i} \phi_{i}^{2}}{2}
$$

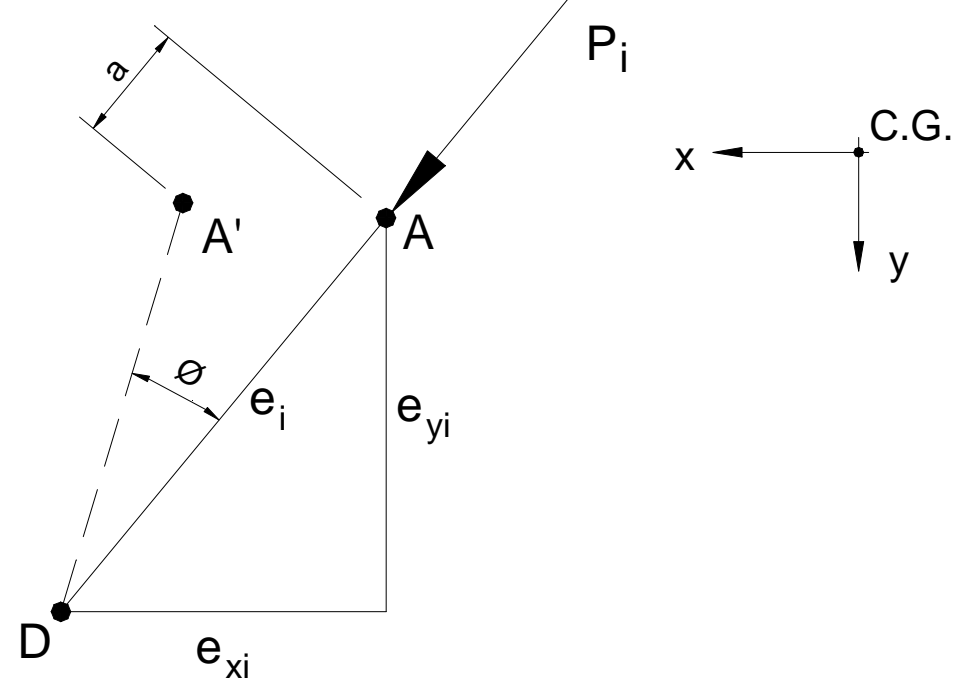

Figura 2.11: Força $P_{i}$ aplicada no ponto $A$.

Considerando-se as componentes de $P_{i}$ nas direções $\mathrm{x}$ e $\mathrm{y}$, a expressão anterior fornece:

$$
T_{6}^{i}=-\frac{\phi_{i}^{2}}{2}\left(P_{x i} e_{x i}+P_{x i} e_{y i}\right)
$$

Falta, ainda, a parcela das componentes de $P_{i}$ nos deslocamentos do centro de torção, $u_{i}$ e $v_{i}$. Com esta contribuição e as parcelas 
correspondentes à força distribuída $q$, cuja elaboração é feita de maneira análoga, obtém-se a expressão da energia potencial das forças transversais:

$$
\begin{array}{r}
T_{6}=-\sum_{i} P_{x i} u_{i}-\sum_{i} P_{y i} v_{i}-\sum_{i} \frac{P_{x i} \phi_{i}^{2} e_{x i}}{2}-\sum_{i} \frac{P_{y i} \phi_{i}^{2} e_{y i}}{2}- \\
\int_{0}^{l} q_{x} u d z-\int_{0}^{l} q_{y} v d z-\frac{1}{2} \int_{0}^{l} q_{x} \phi^{2} e_{x} d z-\frac{1}{2} \int_{0}^{l} q_{y} \phi^{2} e_{y} d z
\end{array}
$$

Utilizando-se o princípio dos trabalhos virtuais aplicado ao conjunto de forças $P_{i}$ e $q$, com esforços internos correspondentes, $M_{x}$ e $M_{y}$, correlacionados aos deslocamentos $u$ e $v$ com curvaturas correspondentes, resulta a expressão final para $T_{6}$ :

$$
\begin{aligned}
T_{6}= & -\frac{1}{2} \sum_{i} P_{x \phi} \phi_{i}^{2} e_{x i}-\frac{1}{2} \sum_{i} P_{y i} \phi_{i}^{2} e_{y i}-\frac{1}{2} \int_{0}^{l} q_{x} \phi^{2} e_{x} d z+ \\
& -\frac{1}{2} \int_{0}^{l} q_{y} \phi^{2} e_{y} d z+\int_{0}^{l}\left(M_{x} v^{\prime \prime}+M_{x} u^{\prime \prime} \phi+M_{y} u^{\prime \prime}-M_{y} v^{\prime \prime} \phi\right) d z
\end{aligned}
$$

\subsubsection{Expressão da energia total}

Somando-se os resultados parciais da energia de deformação e as diversas parcelas da energia potencial, obtém-se a expressão da energia total que pode ser colocada na forma de um funcional:

$$
\begin{aligned}
U= & \int_{0}^{l} F\left(u, u^{\prime}, u^{\prime \prime}, v, v^{\prime}, v^{\prime \prime}, \phi, \phi^{\prime}, \phi^{\prime \prime}\right) d z+ \\
& -\frac{1}{2} \sum_{i} \phi_{i}^{2}\left(P_{x i} e_{x i}+P_{y i} e_{y i}\right)+B_{e} \phi_{e}^{\prime}-B_{d} \phi_{d}^{\prime}
\end{aligned}
$$

onde o funcional $F$ é dado por: 


$$
\begin{aligned}
F=\frac{1}{2} & {\left[\left(N r_{0}^{2}+2 M_{x}\left(k_{y}-y_{0}\right)+2 M_{y}\left(k_{x}-x_{0}\right)+B \frac{U_{\omega}}{C_{\omega}}\right) \phi^{\prime 2}\right]+} \\
& \frac{1}{2}\left[-\left(q_{x} e_{x}+q_{y} e_{y}\right) \phi^{2}+2 M_{x} u^{\prime \prime} \phi\right]+ \\
& \frac{1}{2}\left[E I_{x} v^{\prime \prime 2}+E I_{y} u^{\prime \prime 2}+E C_{\omega} \phi^{\prime \prime 2}+G I_{t} \phi^{\prime 2}\right]+ \\
& \frac{1}{2}\left[2 M_{x} u^{\prime \prime} \phi-2 M_{y} v^{\prime \prime} \phi+2 M_{x} v^{\prime \prime}+2 M_{y} u^{\prime \prime}-2 M_{t} \phi^{\prime}\right]+ \\
& \frac{1}{2}\left[2 N\left(y_{0} w^{\prime}-x_{0} v^{\prime}\right) \phi^{\prime}+N\left(u^{\prime 2}+v^{\prime 2}\right)\right]
\end{aligned}
$$

\subsubsection{Equações gerais da instabilidade por flexão e torção}

A energia total será extrema na posição de equilíbrio.

Para determinar o extremo do funcional $F$, recorre-se às equações de Euler, as quais conduzem às equações gerais da instabilidade por flexão e torção:

$$
\begin{aligned}
& E I_{x} v^{i v}-\left[N\left(v^{\prime}-x_{0} \phi^{\prime}\right)\right]^{\prime}+M_{x}^{\prime \prime}-\left(M_{y} \phi\right)^{\prime \prime}=0 \\
& E I_{y} u^{i v}-\left[N\left(u^{\prime}+y_{0} \phi^{\prime}\right)\right]^{\prime}+\left(M_{x} \phi\right)^{\prime \prime}+M_{y}^{\prime \prime}=0 \\
& E C_{\omega} \phi^{i v}-G I_{t} \phi^{\prime \prime}+ \\
& -\left[\left(N r_{0}^{2}+2 M_{x}\left(k_{y}-y_{0}\right)+2 M_{y}\left(k_{x}-x_{0}\right)+B \frac{U_{\omega}}{C_{\omega}}\right) \phi^{\prime}\right]^{\prime}- \\
& \left(N u^{\prime}\right)^{\prime} y_{0}+\left(N v^{\prime}\right)^{\prime} x_{0}-\left(q_{x} e_{x}+q_{y} e_{y}\right) \phi+ \\
& M_{x} u^{\prime \prime}-M_{y} v^{\prime \prime}-M_{t}^{\prime}=0
\end{aligned}
$$

Dependendo das condições de carregamento e da geometria da barra poderão ocorrer as seguintes situações:

- Flambagem por flexão com elástica $u$ ou $v$, flambagem de Euler;

- Flambagem por torção com elástica $\phi$, flambagem puramente torcional; 
- Flambagem por flexão e torção com elásticas $u$ ou $v$ e $\phi$, flambagem lateral com torção.

\subsection{Instabilidade por Distorção}

\subsubsection{Introdução}

Para os elementos comprimidos a flambagem por distorção caracteriza-se por apresentar rotação de cada aba e enrijecedores em torno da junção alma e aba em direções opostas e translação ortogonal à alma, figura 2.9.a.

Quando submetidos à flexão, ocorre a flambagem da parte comprimida da alma juntamente com a aba, podendo ocorrer translação da seção na direção normal à alma, figura 2.9.b.

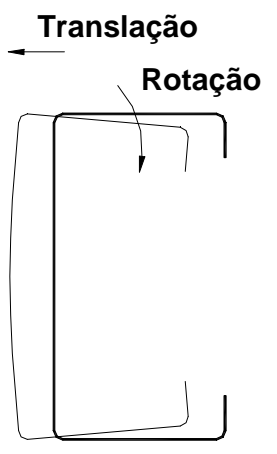

a) Compressão

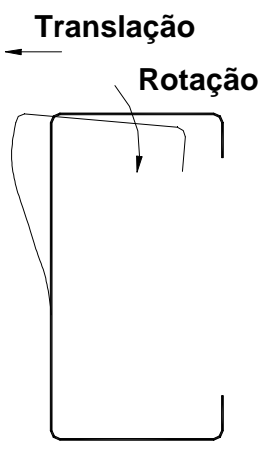

b) Flexão

Figura 2.12: Instabilidade por distorção.

O modo de instabilidade por distorção em elementos com enrijecedores de borda e com enrijecedores intermediários foi analisado por Desmond et al (1981a, 1981b). Nesses trabalhos o modo de instabilidade por distorção foi chamado de instabilidade do enrijecedor, onde a rigidez deste elemento não é suficiente para servir de 'apoio' à mesa do perfil. 
Para considerar esse enrijecimento parcial 0 coeficiente de flambagem de chapa para o elemento enrijecido é inferior a 4, incluindo-se uma redução na largura efetiva do elemento. Esse procedimento encontrase incorporado na norma do AISI, conforme apresentado no item 2.2.6.

Os resultados experimentais foram obtidos a partir de perfis tipo I formados pela união de dois perfis tipo $U$, cujo arranjo impede a flambagem da alma, ocasionando restrições à flambagem distorcional. Entretanto, devese ressaltar que o objetivo específico do trabalho era verificar 0 comportamento dos enrijecedores de borda e enrijecedores intermediário.

Trabalhos de Willi, Wallace (1990) e Ellifritt (1998), demonstram resultados não conservadores para as especificações do AISI.

Outros métodos para a análise da instabilidade por distorção têm proposto o tratamento da mesa e enrijecedor como uma coluna sobre base elástica, onde esta base elástica é representada por uma mola, a qual depende da rigidez à flexão das partes adjacentes do elemento plano e das suas condições de contorno.

Um grande número de modelos para a determinação da carga crítica correspondente à instabilidade por distorção utiliza-se da teoria de Vlasov.

Fruchtengarten (1995) apresenta uma revisão bibliográfica sobre alguns modelos utilizados para o cálculo da carga crítica da instabilidade por distorção para perfis de aço. Através da análise comparativa dos modelos apresentados, utiliza de programa de elementos finitos para o cálculo da carga crítica.

A seguir apresentam-se o modelo de Hancock (1997) para a determinação da carga crítica de instabilidade por distorção para os perfis de chapa dobrada fletidos e o modelo de Peköz, Soroushian (1982) para perfis conectados a painéis através da mesa tracionada. 


\subsubsection{O modelo de Hancock}

O modo de instabilidade por distorção tem sido estudado sistematicamente por Hancock, entre outros pesquisadores sob sua orientação, cujo estudos conduziram a expressões analíticas para o cálculo da carga crítica para barras comprimidas, Hancock (1985); Lau, Hancock (1987); Kwon, Hancock (1992); e para barras fletidas, Hancock (1997); Bambach et al (1998).

O modelo representativo desses estudos idealiza a mesa e enrijecedor comprimido do perfil como uma barra comprimida sujeita à instabilidade por flexo-torção, apoiada elasticamente na alma. Este apoio é representado por uma mola lateral e outra mola rotacional. A seção formada pela parte comprimida é considerada indeformável no seu plano.

A expressão analítica é obtida inicialmente para uma barra comprimida, e posteriormente alterada para barras fletidas. Esta alteração corresponde à uma modificação no coeficiente da mola rotacional.

\subsubsection{Formulação analítica}

Tem-se como base para a obtenção da expressão analítica para 0 cálculo da carga crítica as equações obtidas por Vlasov (1962) e por Timoshenko, Gere (1961) para a instabilidade de uma barra comprimida com apoio elásticos contínuos.

Seja a seção transversal indicada na Figura 2.13.a. Isolando-se a mesa e o enrijecedor da seção, Figura 2.13b, tem-se as coordenadas do centro de torção $D\left(x_{0}, y_{0}\right)$ referidas a um sistema de eixos $(x O y)$, onde 0 eixo x é paralelo à mesa, com origem no centro de gravidade da seção idealizada $\left(h_{x}, h_{y}\right)$.

A força de compressão de flambagem elástica pode ser obtida resolvendo-se o sistema de equações diferenciais (2.63): 


$$
\begin{aligned}
& E I_{x} v^{i v}+E I_{x y} u^{i v}+N\left(v^{\prime \prime}-x_{0} \phi^{\prime \prime}\right)+Q_{y}=0 \\
& E I_{y} u^{i v}+E I_{x y} v^{i v}+N\left(u^{\prime \prime}+y_{0} \phi^{\prime \prime}\right)+k_{x}\left[u+\left(y_{0}-h_{y}\right) \phi\right]=0 \\
& E C_{\omega} \phi^{i v}-\left(G I_{t}-\frac{I_{0}}{A} N\right) \phi^{\prime \prime}-N\left(x_{0} v^{\prime \prime}-y_{0} u^{\prime \prime}\right)+ \\
& +k_{x}\left[u+\left(y_{0}-h_{y}\right) \phi\right]\left(y_{0}-h_{y}\right)-Q_{y}\left(x_{0}-h_{x}\right)+k_{\phi} \phi=0
\end{aligned}
$$

onde:

$$
\begin{array}{ll}
A & =\text { área da seção idealizada; } \\
E & =\text { módulo de elasticidade; } \\
G & =\text { módulo de elasticidade transversal; } \\
I_{x}, I_{y} & =\text { momentos de inércia; } \\
I_{x y} & =\text { produto de inércia; } \\
l_{0} & =\text { momento de inércia polar; } \\
I_{t} & =\text { momento de inércia à torção; } \\
C_{\omega} & =\text { constante de empenamento; } \\
k_{x} & =\text { rigidez à translação da mola na direção } x, \\
k_{\phi} & =\text { rigidez à rotação da mola; } \\
Q_{y} & =\text { reação de apoio na direção y. }
\end{array}
$$

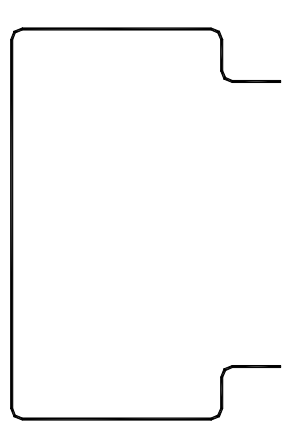

a) Seção transversal

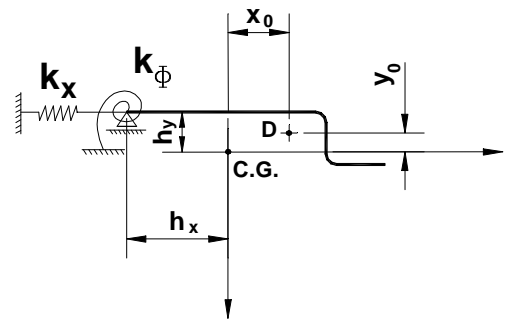

b) Modelo idealizado

Figura 2.13: Modelo de cálculo para instabilidade por distorção. 
Adotando-se como solução das equações anteriores expressões da forma:

$$
\begin{aligned}
& \phi=A_{1} \operatorname{sen} \frac{\pi z}{\lambda} \\
& u=A_{2} \operatorname{sen} \frac{\pi z}{\lambda} \\
& v=\left(x_{0}-h_{x}\right) \phi=\left(x_{0}-h_{x}\right) A_{1} \operatorname{sen} \frac{\pi z}{\lambda}
\end{aligned}
$$

onde:

$$
\begin{aligned}
& A_{1}, A_{2}=\text { constante } \\
& \lambda \quad=\text { meio comprimento de onda de flambagem } .
\end{aligned}
$$

e substituindo-se essas funções no sistema de equações (2.63), encontrase:

$$
\begin{aligned}
& {\left[\frac{\pi^{2}}{\lambda^{2}} E I_{x y}\left(x_{0}-h_{x}\right)+\frac{\lambda^{2}}{\pi^{2}} k_{x}\left(y_{0}-h_{y}\right)-N y_{0}\right]^{2}} \\
& -\left(\frac{\pi^{2}}{\lambda^{2}} E I_{y}+\frac{\lambda^{2}}{\pi^{2}} k_{x}-N\right)\left\{\frac{\pi^{2}}{\lambda^{2}}\left[E C_{\omega}+E I_{x}\left(x_{0}-h_{x}\right)^{2}\right]+G I_{t}\right. \\
& \left.-\left(\frac{I_{0}}{A}-x_{0}^{2}+h_{x}^{2}\right) N_{t}+\frac{\lambda^{2}}{\pi^{2}}\left[k_{x}\left(y_{0}-h_{y}\right)^{2}+k_{\phi}\right]\right\}=0
\end{aligned}
$$

Pode-se, então, determinar um valor mínimo para a força de compressão $N$, correspondente a um determinado valor de $\lambda$.

Deve-se observar que o valor de $\lambda$ é igual ao comprimento $L$ da barra dividido pelo número $n$ de meia onda de flambagem ao longo do comprimento da barra. Ainda, o valor da carga crítica permanece inalterado com o acréscimo de $n$. 
A influência do coeficiente de mola $k_{x}$ é significativa. Embora a carga crítica tenha grande variação para diferentes valores de $k_{x}$, os valores correspondente de $\lambda$ permanecem próximos.

A rigidez rotacional $k_{\phi}$ ao longo da borda longitudinal de uma placa retangular de largura $b$, sujeita à tensão de compressão $\sigma$ e momento fletor distribuído ao longo dessa borda pode ser determinada de acordo com as expressões 2.68, Lau, Hancock, (1987).

$$
\begin{aligned}
& k_{\phi}=\frac{D\left(\alpha^{2}+\beta^{2}\right)}{b}\left(\alpha \tanh \frac{\alpha}{2}+\beta \tan \frac{\beta}{2}\right)^{-1} \\
& \alpha=\pi \sqrt{\left(\frac{b}{\lambda}\right)} \sqrt{\left(\frac{b}{\lambda}+\sqrt{k}\right)} \\
& \beta=\pi \sqrt{\left(\frac{b}{\lambda}\right)} \sqrt{\left(-\frac{b}{\lambda}+\sqrt{k}\right)} \\
& k=\frac{b^{2} t}{\pi^{2} D} \sigma
\end{aligned}
$$

Nessas expressões, b é a largura da placa, t é a sua espessura e $D$ é a rigidez unitária à flexão da placa.

Com o intuito de se promover o cálculo da carga crítica de flambagem por distorção , $N_{c r}$, manualmente, Lau, Hancock (1987), observando que o valor crítico de $\lambda$ para $k_{x}=0$ é próximo do valor crítico quando $k_{x} \rightarrow \infty$, enquanto o valor real permanece entre esses dois, adotaram o valor de $k_{x} \rightarrow \infty$ como uma primeira aproximação para a resolução do sistema de equações diferenciais (2.63).

Dessa forma, o valor do deslocamento $u$ fica dado por:

$$
u=-\left(y_{0}-h_{y}\right) \phi=-\left(y_{0}-h_{y}\right) A_{1} \operatorname{sen} \frac{\pi z}{\lambda}
$$


Substituindo as equações (2.64), (2.66) e (2.69) nas equações (2.63) obtém-se o valor crítico da força de compressão de instabilidade por distorção:

$$
\begin{aligned}
& N_{c r}=\frac{\frac{\pi^{2}}{\lambda^{2}} E I_{\omega c}+G I_{t}+\frac{\lambda^{2}}{\pi^{2}} k_{\phi}}{\frac{I_{x}+I_{y}}{A}+h_{x}^{2}+h_{y}^{2}} \\
& I_{\omega c}=C_{\omega}+I_{x}\left(x_{0}-h_{x}\right)^{2}+I_{y}\left(y_{0}-h_{y}\right)^{2}-2 I_{x y}\left(x_{0}-h_{x}\right)\left(y_{0}-h_{y}\right)
\end{aligned}
$$

Fazendo-se:

$$
k_{\phi}=\frac{2 D}{b_{w}}
$$

onde $b_{w}$ é a altura da alma do perfil e derivando-se e igualando-se a zero a expressão de $N_{c r}$ obtém-se para $\lambda$ :

$$
\lambda_{c r}=\pi\left(\frac{E l_{\omega c} b_{w}}{2 D}\right)^{0,25}
$$

Lau, Hancock (1987), a partir dos estudos dos coeficientes de restrição elástica à rotação devidos a Bleich (1952) e estudos desenvolvidos para seções transversais tipo $U$ enrijecidos aproximaram a expressão de $k_{\phi}$ como sendo:

$$
k_{\phi}=\frac{2 D}{b_{w}+0.06 \lambda}\left(1-\frac{\frac{P^{\prime}}{\sigma_{w}}}{}\right)
$$

Utilizando-se dessas expressões e com $k_{x}=0$ na equação (2.67) a carga crítica para a flambagem por distorção será: 


$$
N_{c r}=\frac{E}{2}\left[\left(\alpha_{1}+\alpha_{2}\right) \pm \sqrt{\left(\alpha_{1}+\alpha_{2}\right)^{2}-4 \alpha_{3}}\right]
$$

onde:

$$
\begin{aligned}
& \alpha_{1}=\frac{\eta}{\beta_{1}}\left(\beta_{2}+0,039 I_{t} \lambda^{2}\right)+\frac{k_{\phi}}{\beta_{l} \eta E} \\
& \alpha_{2}=\eta\left(I_{y}-2 y_{0} \frac{\beta_{3}}{\beta_{l}}\right) \\
& \alpha_{3}=\eta\left(\alpha_{1} I_{y}-\frac{\eta \beta_{3}^{2}}{\beta_{1}}\right) \\
& \beta_{1}=h_{x}^{2}+\frac{I_{x}+I_{y}}{A} \\
& \beta_{2}=C_{\omega}+I_{x}\left(x_{0}-h_{x}\right)^{2} \\
& \beta_{3}=I_{x y}\left(x_{0}-h_{x}\right) \\
& \left.\beta_{4}=\beta_{2}+\left(y_{0}-h_{y}\right) I_{y}\left(y_{0}-h_{y}\right)-2 \beta_{3}\right] \\
& \lambda=4,80\left(\frac{\beta_{4} b_{w}}{t^{3}}\right)^{0,25} \\
& \eta=\left(\frac{\pi}{\lambda}\right)^{2}\left[1-\frac{1,11 P^{\prime}}{E A t^{2}}\left(\frac{b_{w}^{2} \lambda}{b_{w}^{2}+\lambda^{2}}\right)^{2}\right]
\end{aligned}
$$

$P^{\prime}$ é obtido a partir de (2.75.a) fazendo-se $k_{\phi}=0$ em (2.75.b) e $\sigma_{w}$ é a tensão de flambagem local para a alma do perfil, equação (2.76).

$$
\sigma_{w}=\frac{\pi^{2} D}{t b_{w}^{2}}\left(\frac{b_{w}}{\lambda}+\frac{\lambda}{b_{w}}\right)
$$


Para utilização das equações anteriores para o cálculo da carga crítica em perfis fletidos, Hancock (1997) alterou o coeficiente de rigidez à torção da mola.

Para um perfil comprimido, a distorção das mesas ocorre em direções opostas podendo-se idealizar a alma como um elemento restrito nas extremidades, com momentos fletores iguais e contrários ali aplicado, Figura 2.14.a.

Já para um perfil fletido, a distorção dá-se apenas na mesa comprimida, idealizando-se a alma do perfil como um elemento restrito nas extremidades, com momento fletor aplicado à apenas uma extremidade, Figura 2.14.b.

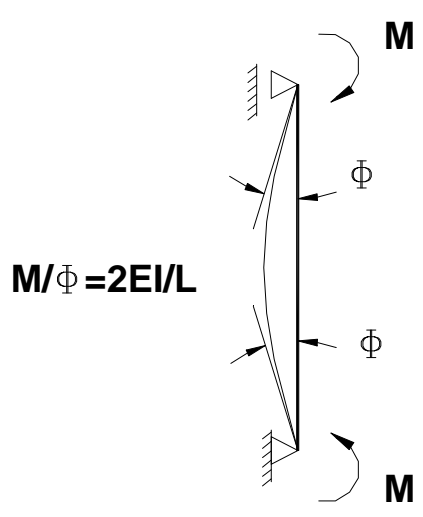

a) Compressão

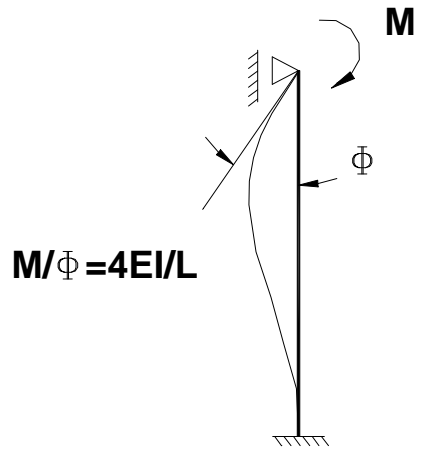

b) Flexão

Figura 2.14: Distorção da alma de perfis: a) comprimido. B) fletido.

Como sugere a própria Figura 2.11, Hancock (1997) adota como coeficiente de rigidez à rotação o dobro daquele dado pela equação (2.75.k).

Dessa forma, para perfis fletidos, o cálculo da carga crítica de flambagem por distorção é feito como acima, substituindo-se a equação (2.75.k) pela equação (2.77).

$$
k_{\phi}=\frac{2 E t^{3}}{5,46\left(b_{w}+0,06 \lambda\right)}\left[1-\frac{1,11 P^{\prime}}{E A t^{2}}\left(\frac{b_{w}^{2} \lambda}{b_{w}^{2}+\lambda^{2}}\right)^{2}\right]
$$




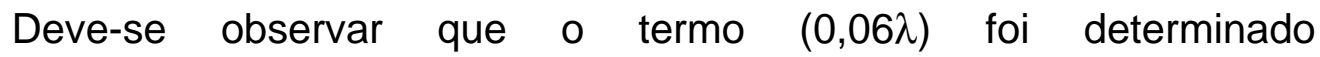
especificamente para perfis com enrijecedores perpendiculares à mesa, necessitando de maiores estudos para outros tipos de enrijecedores.

\subsubsection{O modelo de Peköz, Soroushian}

\subsubsection{Introdução}

O modelo proposto por Peköz, Soroushian (1982) aplica-se às barras fletidas com seções transversais tipo $U$ e tipo $Z$, continuamente conectadas a painéis através da mesa tracionada. Este é o caso típico para as terças de cobertura quando solicitadas por ação de sucção devida ao efeito do vento.

O comportamento do perfil é idealizado através da superposição de dois estágios diferentes: um de deslocamento vertical e o outro de rotação, como ilustrada a Figura 2.15.
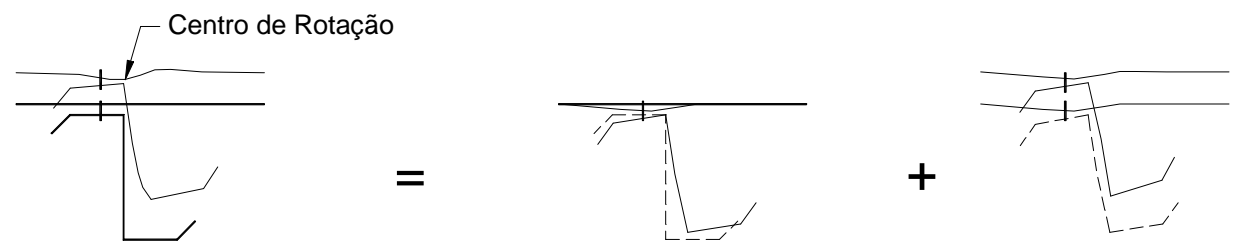

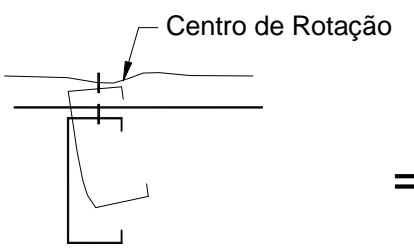

(Estágio Final)

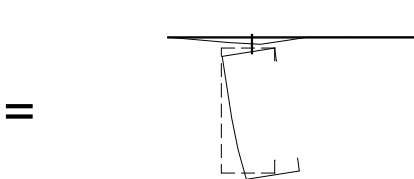

(Rotação)

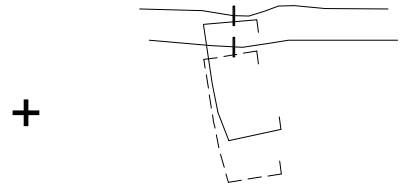

(Deslocamento Vertical)

Figura 2.15: Idealização do comportamento dos perfis sob efeito de sucção. 
O deslocamento vertical é analisado através dos preceitos da Resistência dos Materiais, no caso, flexão simples, com o momento de inércia calculado para a seção rotacionada.

A rotação envolve os deslocamentos laterais e o giro, os quais são analisados através de um modelo analítico aproximado.

\subsubsection{Formulação Analítica}

Para o desenvolvimento das equações os perfis são assumidos com restrição ao giro no plano da mesa.

A tensão normal máxima atuante no perfil será obtida pela superposição das tensões normais oriundas da flexão no plano da alma com as tensões normais oriundas do deslocamento lateral e giro:

$$
\sigma=\frac{M_{x}}{W_{x}}+\frac{M_{y}}{W_{y}}
$$

onde:

$$
\begin{aligned}
M_{x}= & \text { momento fletor devido à flexão simples, em torno do eixo } \mathrm{x} . \\
W_{x}= & \text { módulo de resistência elástico da seção transversal da barra } \\
& \text { em relação ao eixo } \mathrm{x} . \\
W_{y}= & \text { módulo de resistência elástico da seção transversal } \\
& \text { idealizada em relação ao eixo paralelo à alma. } \\
M_{y}= & \text { Momento fletor na seção idealizada, em torno do eixo } \\
& \text { paralelo à alma, passando pelo centro de gravidade da seção. }
\end{aligned}
$$

O momento fletor $M_{y}$ é obtido a partir de uma força lateral idealizada, resultante das tensões de cisalhamento na mesa devidas à ação vertical.

Seja a seção transversal apresentada na Figura 2.16. 


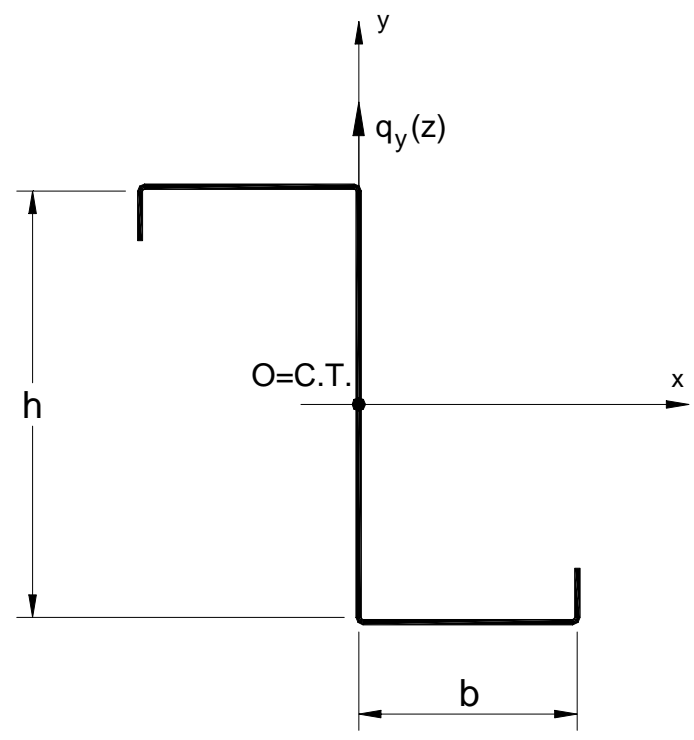

Figura 2.16: Dimensões da seção transversal da barra.

A força horizontal distribuída ao longo do comprimento do perfil na seção idealizada pode ser expressa por:

$$
q_{x}(z)=-\frac{d H_{x}(z)}{d z}=q_{y}(z)\left(\frac{W_{x i} b}{2 l_{x}^{0}}+\alpha\right)
$$

onde:

$q_{y}(z)=$ força distribuída na direção vertical.

$H_{X}(z)=$ resultante das tensões de cisalhamento na mesa.

$W_{x i}=$ momento estático da aba inferior em relação ao eixo $\mathrm{x}$.

$I_{X}^{O}=$ momento de inércia da seção deformada em relação ao eixo horizontal.

$\alpha=$ razão entre a distância do centro de rotação até a junção da alma com a mesa e a altura da alma (0 para seções tipo Z).

Em uma seção qualquer da barra idealizada, a força normal vale: 


$$
N(z)=\frac{M_{x}}{I_{x}} y A_{c}=\frac{M_{x}}{I_{x}} M_{S}
$$

sendo $M_{S}$ o momento estático da seção idealizada em relação ao eixo x.

A força de compressão por unidade de comprimento é obtida como:

$$
p(z)=\frac{d N(z)}{d z}=V_{y} \frac{M_{S}}{I_{x}}
$$

Com as suposições anteriores a análise da viga é feita como sendo uma barra flexo-comprimida, Figura 2.17.

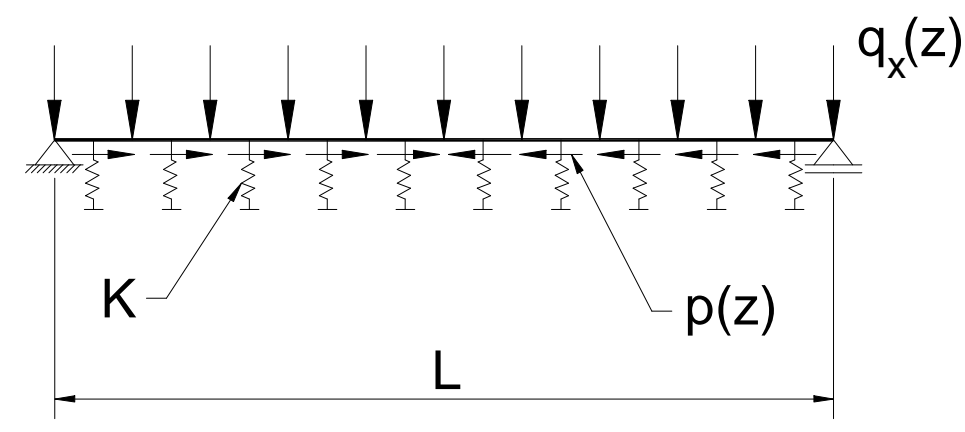

Figura 2.17: Idealização de uma barra flexo-comprimida.

A expressão da energia potencial total pode ser expressa por:

$$
\begin{aligned}
V=2\left[\int_{0}^{L / 2} \frac{E l_{y}^{0}}{2}\left(u^{\prime \prime}-u_{0}^{\prime \prime}\right)^{2} d z+\int_{0}^{L / 2} \frac{K\left(u-u_{0}\right)^{2}}{2} d z\right. \\
\left.\quad-\int_{0}^{L / 2} q_{x}(z)\left(u-u_{0}\right) d z-\int_{0}^{L / 2} \frac{1}{2} p(z)\left(u^{\prime 2}-u_{0}{ }^{\prime 2}\right) d z\right]
\end{aligned}
$$

sendo $u$ a configuração final da mesa e $u_{0}$ a imperfeição inicial cujas funções podem ser expressas por meio da seguintes séries:

$$
u=\sum_{n=1,3,5 \ldots} a_{n} \operatorname{sen} \frac{n \pi x}{L}
$$




$$
u_{0}=\sum_{n=1,3,5 \ldots} a_{0 n} \operatorname{sen} \frac{n \pi x}{L}
$$

$l_{y}^{0}$ é o momento de inércia da seção idealizada em relação ao eixo central paralelo à alma e $K$ é o coeficiente do apoio elástico.

Deve-se observar que $u$ é o deslocamento lateral total da mesa, aí já incluído a imperfeição inicial.

Como resultado do deslocamento lateral e giro, o momento de inércia com respeito ao eixo central perpendicular à posição inicial da alma deve ser reduzido, conforme os autores:

$$
I_{y}^{0}=I_{y}\left(1-\left(\frac{u}{h}\right)^{2}\right)
$$

O valor do coeficiente do apoio elástico pode ser obtido a partir da equação (2.86), onde, desprezando-se a redução no momento fletor:

$$
q_{x}(z)=q_{y}(z)\left(\frac{b^{2} t h}{4 I_{x}}+\alpha\right)
$$

Assumindo-se um valor de $q_{y}(z)$ como sendo o de falha da barra, determina-se o valor correspondente de $q_{x}(z)$. A partir de um gráfico força lateral contra deslocamento lateral o valor de $K$ é determinado para aquele valor de $q_{x}(z)$

O momento fletor na seção idealizada será dado por:

$$
M_{y}=E l_{y}^{0}\left(u^{\prime \prime}-u_{0}{ }^{\prime \prime}\right)=\frac{\pi^{2} E l_{y}^{0}}{L^{2}} \sum_{n=l, 3, \ldots} n^{2}\left(a_{n}-a_{0 n}\right) \operatorname{sen} \frac{n \pi x}{L}
$$


A amplitude dos deslocamentos pode se determinada através do método de Ritz. Entretanto, de acordo com os autores, tomando-se apenas um termo da série o erro em $u$ é inferior a $5 \%$. Pode-se obter:

$$
\begin{aligned}
& a=\frac{c\left(\frac{h b^{2} t}{4 I_{x}}+\alpha\right)+a_{0}}{1-0,9 \frac{h b t}{4 I_{x}} c} \\
& c=\frac{1,27 q_{y}(z)}{\frac{\pi^{4} E b^{3} t}{12 L^{4}}+K}
\end{aligned}
$$

Deve-se observar que, por simplicidade de notação, o termo a corresponde ao termo $a_{1}$ e $a_{0}$ ao termo $a_{01}$ do desenvolvimento das séries (2.83) e (2.84) na equação (2.82).

Dessa forma, a expressão para o cálculo da máxima tensão normal para seção tipo $Z$ ou seção tipo U é dada por:

$$
\sigma_{\text {máx }}=\frac{M_{x}}{I_{x}} \frac{h}{2}+\frac{\pi^{2} E b}{2 L^{2}}\left(a-a_{0}\right)
$$

Como critério de projeto, a tensão normal máxima deve ser limitada à tensão limite de escoamento do material ou à tensão crítica corresponde à flambagem local para os elementos de chapa comprimidos.

\subsection{Considerações finais}

Neste capítulo foram abordados os diversos aspectos sobre os problemas de instabilidade inerentes à análise dos perfis de seção aberta.

Os modos de instabilidade local, mesa e alma, são tratados pela teoria das chapas e precisa-se levar em consideração a reserva de 
resistência pós-flambagem, considerável nesses elementos e necessária na avaliação da sua resistência última. Esta análise pós-crítica é feita através do conceito de largura efetiva, como proposto nos trabalhos pioneiros do professor George Winter.

Para os problemas de instabilidade global, a teoria de Vlasov fornece os valores da carga crítica, em regime elástico linear para algumas situações de carregamento e vínculos. Embora esta carga crítica nem sempre corresponda à carga de ruína da barra, esta é tida como uma carga de referência para se estimar a carga de ruína. Nessa estimativa, várias aproximações são feitas procurando-se reproduzir os valores observados e o comportamento do material nos ensaios desenvolvidos.

No modo de instabilidade por distorção da seção transversal, a teoria de Vlasov é tomada como base para a determinação da carga crítica em vários modelos propostos.

Para o caso específico do modelo de Hancock, a aplicação da teoria de Vlasov é utilizada na determinação da carga crítica de instabilidade por distorção de barras comprimidas, onde trata-se a mesa e enrijecedor como uma coluna sobre restrição elástica. Posteriormente, assume-se o mesmo modelo para os perfis fletidos, corrigindo-se o coeficiente de mola rotacional, admitindo-se um valor igual a 2 vezes ao obtido para barras comprimidas.

No modelo de Peköz, Soroushian, não está explicito um valor de carga crítica, mas sim, a verificação da tensão máxima, de tração ou de compressão, a qual deve ser limitada aos valores característicos do material.

No capítulo seguinte faz-se a aplicação dos aspectos teóricos apresentados para o dimensionamento dos perfis de chapa dobrada submetidos à flexão. 


\section{APLICAÇÃO AOS PERFIS FLETIDOS}

\subsection{Introdução}

Neste capítulo discute-se a aplicação dos modelos e das formulações teóricas apresentadas no capítulo 2 para os perfis sujeitos à flexão.

São abordados os perfis fletidos, enquanto utilizados de forma isolada como vigas, e posteriormente, os perfis conectados às telhas, enquanto utilizados como terças.

Todas as hipóteses sobre condições de carregamento e vínculos adotadas são coerentes com aquelas a serem reproduzidas nos ensaios correspondentes, apresentados nos capítulos seguintes.

O projeto de vigas em estruturas de aço consiste, basicamente, na verificação dos seguintes estados limites últimos: escoamento da seção transversal, instabilidade local dos elementos comprimidos da seção transversal e instabilidade global da viga, isto é, flambagem lateral com torção.

A seguir, são apresentados os critérios utilizados para a determinação da resistência nominal para cada estado limite aplicável. 


\subsection{Flambagem local da mesa (FLM)}

Para seções transversais cuja linha neutra encontra-se próxima à mesa tracionada, figura 3.1a, a máxima tensão normal ocorre na mesa comprimida, $f_{c}=f_{y}>f_{t}$.

A resistência nominal à flexão é obtida por:

$$
M_{n}=W_{e f} f_{c}=W_{e f} f_{y}
$$

onde $W_{\text {ef }}$ é o módulo de resistência elástico da seção efetiva, calculado de acordo com o conceito da largura efetiva, com tensão igual à tensão de escoamento $\left(f=f_{y}\right)$.

Quando a linha neutra estiver próxima à mesa comprimida, figura 3.1b, a máxima tensão ocorre na mesa tracionada, $f_{t}=f_{y}>f_{c}$.

A tensão na mesa comprimida é menor que a de escoamento e depende da localização da linha neutra. Então, um processo de tentativas é necessário para se obter a posição da linha neutra na seção efetiva. A resistência nominal à flexão da barra é obtida pelo menor valor entre:

$$
M_{n}=W_{e f} f_{c}
$$

ou

$$
M_{n}=W_{t} f_{y}
$$

sendo $W_{t} \circ$ módulo de resistência elástico da parte tracionada da seção transversal. 


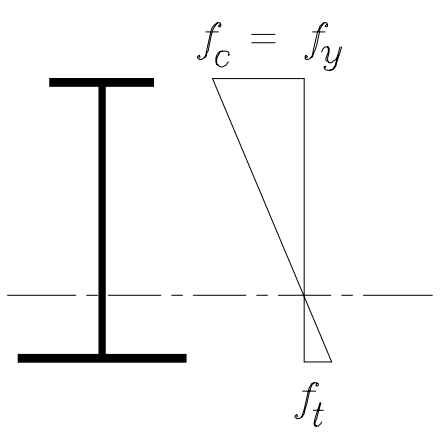

(a)

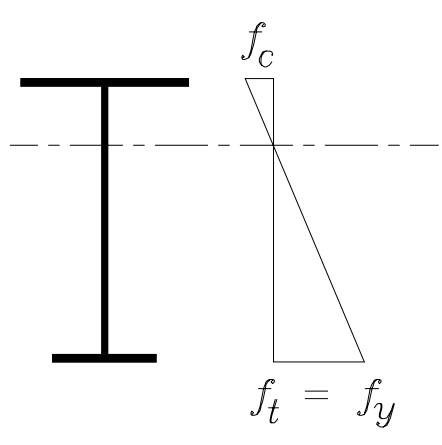

(b)

Figura 3.1: Distribuições de tensões em regime elástico para vigas contidas lateralmente.

\subsection{Flambagem local da alma (FLA)}

\subsubsection{Tensões normais}

A alma de uma viga é analisada como uma chapa retangular, em geral, apoiada nas bordas, sujeita às tensões normais devidas à flexão.

A tensão crítica de flambagem é determinada de acordo com a tensão de flambagem de chapa, equação (3.3):

$$
f_{c r}=\frac{k \pi^{2} E}{12\left(1-v^{2}\right)(h / t)^{2}}
$$

onde:

$k=$ coeficiente de flambagem de chapa.

$h=$ distância livre entre mesas.

$t=$ espessura da alma.

$v=$ coeficiente de Poisson. 
De maneira análoga ao tratamento dado às mesas, o problema da flambagem local da alma é analisado segundo o conceito da largura efetiva, a partir do qual determina-se o módulo de resistência elástico da seção efetiva e, como consequência, o momento resistente para a viga.

\subsubsection{Tensões de cisalhamento}

No projeto de vigas, a distribuição das tensões de cisalhamento na seção transversal, considerando-se os preceitos da Resistência dos Materiais, é obtida por:

$$
\tau=\frac{V M_{S}}{I t}
$$

onde:

$V=$ força cortante na seção transversal.

$M_{S}=$ momento estático.

$I=$ momento de inércia em relação ao eixo de flexão

$t=$ espessura, ou largura, da seção transversal na fibra em estudo.

$\mathrm{Na}$ aplicação da equação (3.4) às seções utilizadas em perfis metálicos constata-se que a maior parte das tensões de cisalhamento concentra-se na alma e tem sido prática geral em projeto o uso de um valor médio sobre a área bruta da alma, ou seja:

$$
\tau=\frac{V}{h t_{w}}
$$

Onde: 
$h=$ altura da alma, medida entre as faces internas das mesas dos perfis.

$t_{w}=$ espessura da alma.

Quando a espessura da alma é relativamente grande, $\left(h / t_{w} \leq 1,08 \sqrt{k E / f_{y}}\right)$, e está sujeita às tensões de cisalhamento, a falha darse-á através do escoamento da alma.

A tensão de escoamento devido a um estado de cisalhamento puro, segundo o critério da energia de distorção, pode ser escrita como:

$$
\tau_{y}=\frac{f_{y}}{\sqrt{3}}=0,577 f_{y}
$$

Para almas esbeltas, $\left(h / t_{w}>1,40 \sqrt{k E / f_{y}}\right)$, a resistência ao cisalhamento passa a ser governada pela flambagem elástica devida às tensões de cisalhamento atuantes.

A tensão crítica de flambagem elástica por cisalhamento pode ser também calculada pela equação (3.3), onde o coeficiente de flambagem $k$ varia de acordo com as condições de apoio e a relação $(a / h)$ da alma, Rockey (1967).

Para uma chapa longa, o valor de $k$ é igual a 5,34 para bordas simplesmente apoiadas e igual a 8,98 para bordas engastadas, como está apresentado na tabela 2.1. Para diferentes relações $(a / h)$, o valor de $k$ pode se obtido de acordo com as seguintes equações:

$$
\begin{array}{ll}
k=4+\frac{5,34}{(a / h)^{2}} & \text { para }(a / h)<1 \\
k=5,34+\frac{4}{(a / h)^{2}} & \text { para } 1 \leq(a / h)<3 \\
k=5,34 & \text { para }(a / h) \geq 3
\end{array}
$$


sendo a o comprimento da alma, ou a distância entre enrijecedores transversais, e $h$ a altura da alma.

Para almas medianamente esbeltas, o valor teórico da tensão crítica de flambagem inelástica é maior que a tensão limite de proporcionalidade no cisalhamento $\left(0,8 \tau_{y}\right)$.

Considerando a mudança no módulo de elasticidade (módulo tangente), Basler (1961) apresentou a equação (3.10) para a determinação da tensão crítica de flambagem inelástica por cisalhamento.

$$
\tau_{c r}=\sqrt{\tau_{p r} \tau_{c r e}}
$$

Onde:

$\tau_{p r}=$ tensão limite de proporcionalidade no cisalhamento $=0,8 \tau_{y}$.

$\tau_{\text {cre }}=$ tensão crítica de flambagem elástica por cisalhamento.

Substituindo-se os valores de $\tau_{p r}$ e $\tau_{c r e}$, obtém-se:

$$
\tau_{c r}=0,21 \pi \frac{\sqrt{k E f_{y}}}{h / t_{w}}
$$

Igualando-se as equações (3.6) e (3.11) obtém-se o valor limite para $\left(h / t_{w}\right), \lambda_{p}$, para o qual a falha ocorre por escoamento do aço, ou seja:

$$
\lambda_{p}=1,08 \sqrt{k E / f_{y}}
$$

Para valores superiores ao limite acima, a equação (3.11) é aplicável enquanto a tensão crítica, $\tau_{c r}$, é no máximo igual a tensão limite de proporcionalidade no cisalhamento, isto é: 


$$
\lambda_{\varphi}=1,40 \sqrt{k E / f_{y}}
$$

Para relações $\left(h / t_{w}\right)$ maiores que $\lambda_{r}$, a equação (3.3) fornece o valor da tensão crítica em regime elástico.

As equações anteriores podem ser escritas em termos da força cortante $V$, utilizando-se a equação (3.5) e os parâmetros de esbeltez $\lambda_{p} \mathrm{e}$ $\lambda_{r}$, da seguinte maneira:

- $\operatorname{para} \lambda \leq \lambda_{p} \quad \Rightarrow \quad V=V_{p l}$

- $\operatorname{para} \lambda_{p}<\lambda \leq \lambda_{r} \Rightarrow V=\frac{\lambda_{p}}{\lambda} V_{p l}$

- $\operatorname{para} \lambda>\lambda_{r} \Rightarrow V=1,28\left(\frac{\lambda_{p}}{\lambda}\right)^{2} V_{p l}$

onde $V_{p l}$ é o valor da força cortante correspondente à plastificação da alma por cisalhamento, equação (3.14).

$$
V_{p l}=0,6 A_{w} f_{y}
$$

sendo $A_{w}$ a área da alma $\left(A_{w}=h t_{w}\right)$.

\subsubsection{Tensões normais e de cisalhamento combinadas}

Tensões normais elevadas devidas à flexão muitas vezes combinamse com tensões de cisalhamento, principalmente em regiões de apoio para vigas em balanço e vigas contínuas.

Este caso foi estudado por Timoshenko, Gere (1961) para chapas retangulares. Observou-se que para pequenos valores de $\tau / \tau_{c r}$, menores 
que 0,4 aproximadamente, o efeito da tensão de cisalhamento no valor da tensão normal crítica devida à flexão é pequeno.

Da mesma forma, observou-se que para valores de $f / f_{c r}$ menores que 0,4 aproximadamente, o efeito da tensão normal da flexão no valor da tensão crítica de cisalhamento é pequeno.

A partir da figura 3.2, obtida para valores de $(a / h)$ entre 0,5 e 1,0, observa-se que a curva de interação entre $f / f_{c r}$ e $\tau / \tau_{c r}$ aproxima-se de um segmento de círculo:

$$
\left(\frac{f}{f_{c r}}\right)^{2}+\left(\frac{\tau}{\tau_{c r}}\right)^{2}=1
$$

onde:

$f=$ tensão devida à flexão.

$f_{c r}=$ tensão crítica de flambagem elástica na flexão pura.

$\tau=$ tensão de cisalhamento.

$\tau_{c r}=$ tensão crítica de flambagem elástica por cisalhamento puro.

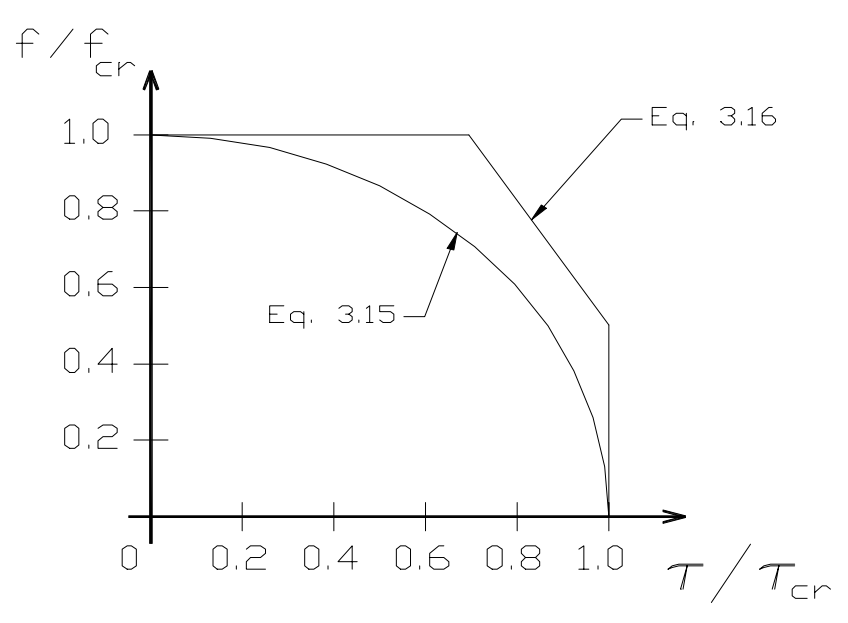

Figura 3.2: Relações de interação entre f e $\tau$. 
Através de resultados experimentais comprovou-se que a equação (3.15), desenvolvida originalmente para chapas individuais, fornece resultados conservativos para almas de vigas com enrijecedores transversais adequadamente projetados, nas quais o efeito do campo de tração pode ser desenvolvido.

A seguinte equação de interação foi obtida para alma de vigas com enrijecedores transversais:

$$
0,6\left(\frac{f}{f_{c r}}\right)+\left(\frac{\tau}{\tau_{c r}}\right) \leq 1,3
$$

A equação (3.16) é aplicada somente quando tem-se $\left(f / f_{c r}\right)>0,5$ e $\left(\tau / \tau_{c r}\right)>0,7$. Para outras condições, o projeto da alma é governado ou pela resistência à flexão ou pela resistência ao cisalhamento.

\subsection{Flambagem Lateral com torção (FLT)}

Um elemento fletido, quando carregado no plano da alma pode, além de deslocar-se verticalmente, girar e sofrer deslocamentos horizontais, atingindo assim um estado limite último denominado como flambagem lateral com torção (FLT). Este ocorre sem que o elemento venha a desenvolver toda a sua resistência à flexão, com tensões inferiores à tensão característica do material.

Os parâmetros estáticos e geométricos que influenciam a flambagem lateral com torção são: a rigidez à flexão e torção da seção transversal; a constante de empenamento; a posição do ponto de aplicação do carregamento em relação ao centro de cisalhamento; o comprimento lateralmente destravado da viga; o tipo de carregamento e as vinculações nos apoios. 


\subsubsection{Perfis com dupla simetria}

Quando uma viga simplesmente apoiada, com seção transversal duplamente simétrica, está solicitada por momentos fletores ' $M$ ' em suas extremidades, das equações (2.62), obtém-se:

$$
\begin{aligned}
& E I_{x} v^{i v}=0 \\
& E I_{y} u^{i v}+M \phi^{\prime \prime}=0 \\
& E C_{\omega} \phi^{i v}-G I_{t} \phi^{\prime \prime}+M u^{\prime \prime}=0
\end{aligned}
$$

onde:

$M=$ momento fletor.

$E=$ módulo de elasticidade.

$G=$ módulo de elasticidade transversal $=0,385 E$.

$I_{x}=$ momento de inércia em torno do eixo $x$.

$I_{y}=$ momento de inércia em torno do eixo $\mathrm{y}$.

$I_{t}=$ momento de inércia à torção.

$C_{\omega}=$ constante de empenamento da seção.

$v=$ deslocamento do centro de cisalhamento segundo $\mathrm{y}$.

$u=$ deslocamento do centro de cisalhamento segundo $\mathrm{x}$.

$\phi=$ ângulo de giro da seção.

Considerando-se as extremidades dessa viga com giro impedido, ou seja, vínculos de garfo nas extremidades, tem-se as seguintes condições de contorno:

$$
\begin{aligned}
& v(0)=v(L)=u(0)=u(L)=\phi(0)=\phi(L)=0 \\
& u^{\prime \prime}(0)=u^{\prime \prime}(L)=\phi^{\prime \prime}(0)=\phi^{\prime \prime}(L)=0 \\
& v^{\prime \prime}(0)=v^{\prime \prime}(L)=-\frac{M}{E I_{x}}
\end{aligned}
$$


A solução da equação (3.17) fornece a posição deslocada da viga no plano yz, dada por:

$$
v=\frac{M L^{2}}{2 E I_{x}}\left[\left(\frac{z}{L}\right)-\left(\frac{z}{L}\right)^{2}\right]
$$

A solução das equações (3.18) e (3.19), nas variáveis $u$ e $\phi$, fornece o valor do momento crítico de flambagem lateral com torção em regime elástico:

$$
M_{c r}=\frac{\pi}{L} \sqrt{E l_{y} G I_{t}\left(1+\frac{\pi^{2} E C_{\omega}}{G I_{t} L^{2}}\right)}
$$

A forma deslocada da viga é dada pelas funções $u$ e $\phi$, onde $c_{1}$ e $c_{2}$ são constantes indeterminadas:

$$
\begin{aligned}
& u=\frac{c_{1} M L^{2}}{\pi^{2} E I_{y}} \operatorname{sen}\left(\frac{\pi}{z L}\right) \\
& \phi=c_{2} \operatorname{sen}\left(\frac{\pi z}{L}\right)
\end{aligned}
$$

No caso partircular da viga simplesmente apoiada obtém-se $c_{1}=c_{2}$.

A solução dada pela equação (3.21) é adotada como um valor de referência e corrigida para diferentes situações de diagramas de momentos fletores através do coeficiente de modificação de momentos " $C_{b}$ ”, assim:

$$
M_{c r}=C_{b} \frac{\pi}{L_{b}} \sqrt{E I_{y} G I_{t}\left(1+\frac{\pi^{2} E C_{\omega}}{G I_{t} L_{t}{ }^{2}}\right)}
$$

onde $L_{b}$ representa o valor do comprimento do trecho sem contenção lateral. 


\subsubsection{Coeficiente de equivalência de momento na flexão}

Em situações normais de projeto, a distribuição de momento uniforme sobre a viga poucas vezes se verifica. A distribuição de momento não uniforme é frequente, porém, a solução das equações diferenciais da instabilidade por flexo-torção torna-se complexa, podendo ser solucionada para algumas situações específicas. Ainda assim, as soluções obtidas são expressões extensas e de aplicação prática restrita.

Os efeitos da distribuição de momento não uniforme e as diversas condições de apoio são ajustadas através de um fator de equivalência de momento, " $C_{b}$ ". Esta aproximação tem sido utilizada há, aproximadamente, 50 anos.

Fórmulas aproximadas para o coeficiente $C_{b}$ foram apresentadas por vários pesquisadores.

Segundo Massonnet (1976), o momento gradiente poderia ser afetado por um fator $\omega$ de maneira a se obter uma distribuição de momento fletor uniforme e de valor $M_{e q}=\omega M$, onde $M$ representa o maior momento fletor aplicado à extremidade, Figura 3.3.

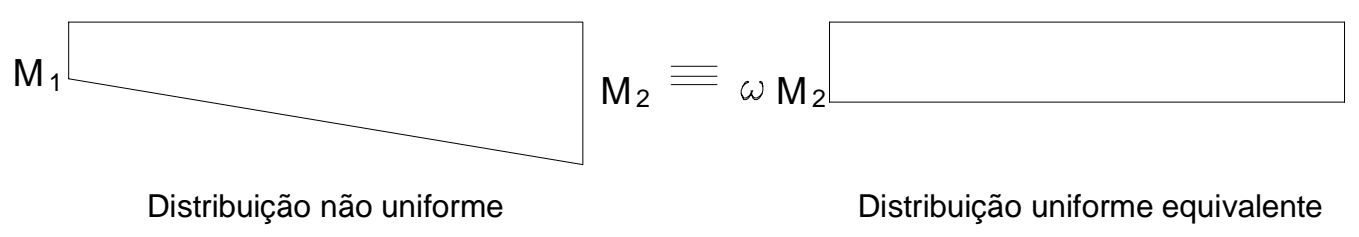

Figura 3.3: Coeficiente de equivalência de momento.

Dessa forma, através do método de Rayleigh-Ritz e assumindo-se que $\frac{\pi^{2} E C_{\omega}}{L^{2} G l_{t}}=1$, Massonnet obteve, em 1947, a expressão:

$$
\omega=\sqrt{0,27\left(1+r^{2}\right)+0,46 r}
$$


onde $r=M_{1} / M_{2}$ é a razão entre o menor momento fletor $\left(M_{1}\right)$ e o maior momento fletor $\left(M_{2}\right)$ aplicados às extremidades da viga. Esta razão é considerada positiva quando tem-se curvatura simples e negativa em caso contrário.

Posteriormente, assumindo $\frac{\pi^{2} E C_{\omega}}{L^{2} G I_{t}}=0$, Campus e Massonnet determinaram uma expressão mais conservativa para o coeficiente $\omega$ :

$$
\omega=\sqrt{0,30\left(1+r^{2}\right)+0,40 r}
$$

Salvadori (1955) resolveu o problema de uma viga tipo "l", sob momento fletor constante, também através do método de Raileigh-Ritz, considerando vários termos nas expressões dos deslocamento lateral e giro. Esses resultados foram aproximados pelo SSRC (Stability Steel Research Column) resultando na seguinte expressão:

$$
C_{b}=\frac{1}{\omega}=1,75+1,05 r+0,3 r^{2} \leq 2,3
$$

Austin (1961) observou que os valores do fator de momento equivalente usado para descrever a resistência de vigas no plano, aproximavam-se daqueles propostos por Massonnet e Salvadori, propondo uma aproximação linear:

$$
\omega=0,6+0,4 r \geq 0,4
$$

Ressalta-se que a expressão devida a Austin tem a sua determinação para a instabilidade no plano, sendo a sua aplicação na instabilidade lateral de vigas uma simplificação dos resultados.

Segundo Pandey, Sherbourne (1989) e Sherbourne, Pandey (1989), os resultados desses estudos têm sido similares por não incluírem, ou 
simplesmente aproximarem, a rigidez ao empenamento para simplicidade na análise. Sob este enfoque, o trabalho apresenta uma solução teórica para a flambagem lateral com torção de vigas "l”, em regime elástico, considerando o problema como uma superposição de dois casos hipotéticos: um correspondendo ao empenamento igual a zero e o outro, à rigidez torcional igual a zero.

Deve-se observar que os coeficientes de equivalência de momento obtidos acima podem ser aplicados para situações em que a distribuição de momento tem variação linear. Além disso, não é considerada a existência de forças transversais aplicadas entre os apoios ou pontos travados lateralmente.

Na Figura 3.4 estão apresentadas as diversas curvas referentes aos coeficientes de equivalência de momento apresentados acima. Para a apresentação destas curvas fez-se a correspondência inversa entre $C_{b}$ e $\omega$.

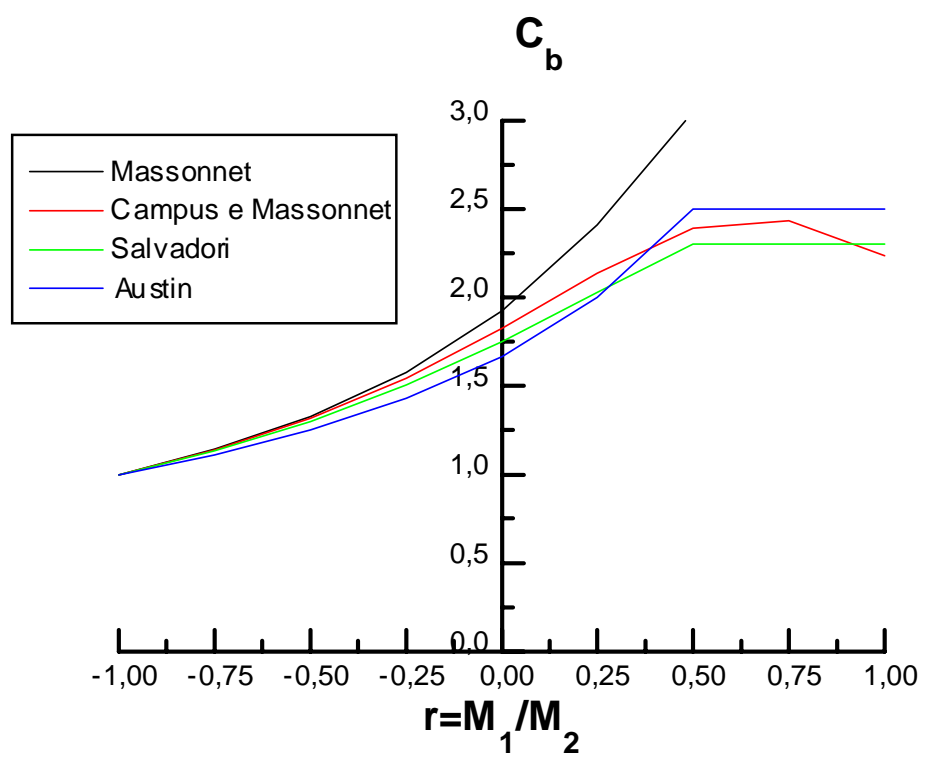

Figura 3.4: Valores de $C_{b}$ segundo alguns autores.

Quanto aos aspectos normativos referentes ao coeficiente de equivalência de momento, a expressão de $C_{b}$ devida a Salvadori, equação (3.27), teve maior utilização e é aplicada até os dias atuais, inclusive em normalizações nacionais. 
Em suas recentes edições, o Manual of Steel Construtction, LRFD Load and Resistance Factor Design (AISC-1994) e o AISI (1996), sugerem a utilização de uma nova expressão para $C_{b}$, baseada em estudos desenvolvidos por Kirby e Nethercot:

$$
C_{b}=\frac{12,5 M_{\max }}{2,5 M_{\max }+3 M_{A}+4 M_{B}+3 M_{c}}
$$

onde:

$M_{\max }=$ momento fletor máximo.

$M_{A}=$ momento fletor a um quarto do vão.

$M_{B}=$ momento fletor no meio do vão.

$M_{C}=$ momento fletor a três quartos do vão.

Esta expressão tem sua aplicação para distribuição de momento sob qualquer variação, Figura 3.5 .

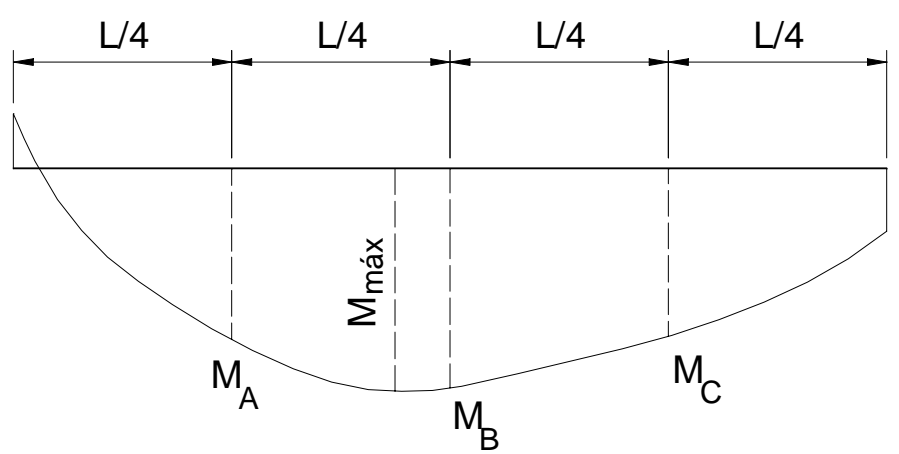

Figura 3.5: Diagrama de momento com variação não linear.

De maneira geral, os estudos anteriores referem-se a forças aplicadas no centro de cisalhamento da seção transversal da viga.

Havendo forças transversais aplicadas entre as extremidades da viga ou entre os pontos travados lateralmente, a posição do ponto de aplicação 
da força em relação ao centro de cisalhamento é uma consideração importante.

Para o caso de forças desestabilizantes, no sentido em que tendem a aumentar a torção, a equação (3.24) fornece valores superiores ao valor observado de $M_{c r}$, enquanto que, para forças estabilizantes, a equação fornece valores conservativos.

Nethercot (1983) apresenta os valores de $C_{b}$ já considerando a posição do ponto de aplicação da força em relação ao centro de cisalhamento da seção transversal da barra como sendo:

Força aplicada acima do centro de cisalhamento, ao nível da mesa superior:

$$
C_{b}=\frac{A}{B}
$$

Força aplicada no centro de cisalhamento:

$$
C_{b}=A
$$

Força aplicada abaixo do centro de cisalhamento, ao nível da mesa inferior:

$$
C_{b}=A B
$$

onde os coeficientes $A$ e $B$ são tomados a partir da tabela 3.1. 
Tabela 3.1 - Coeficientes $A$ e $B$ para forças transversais.

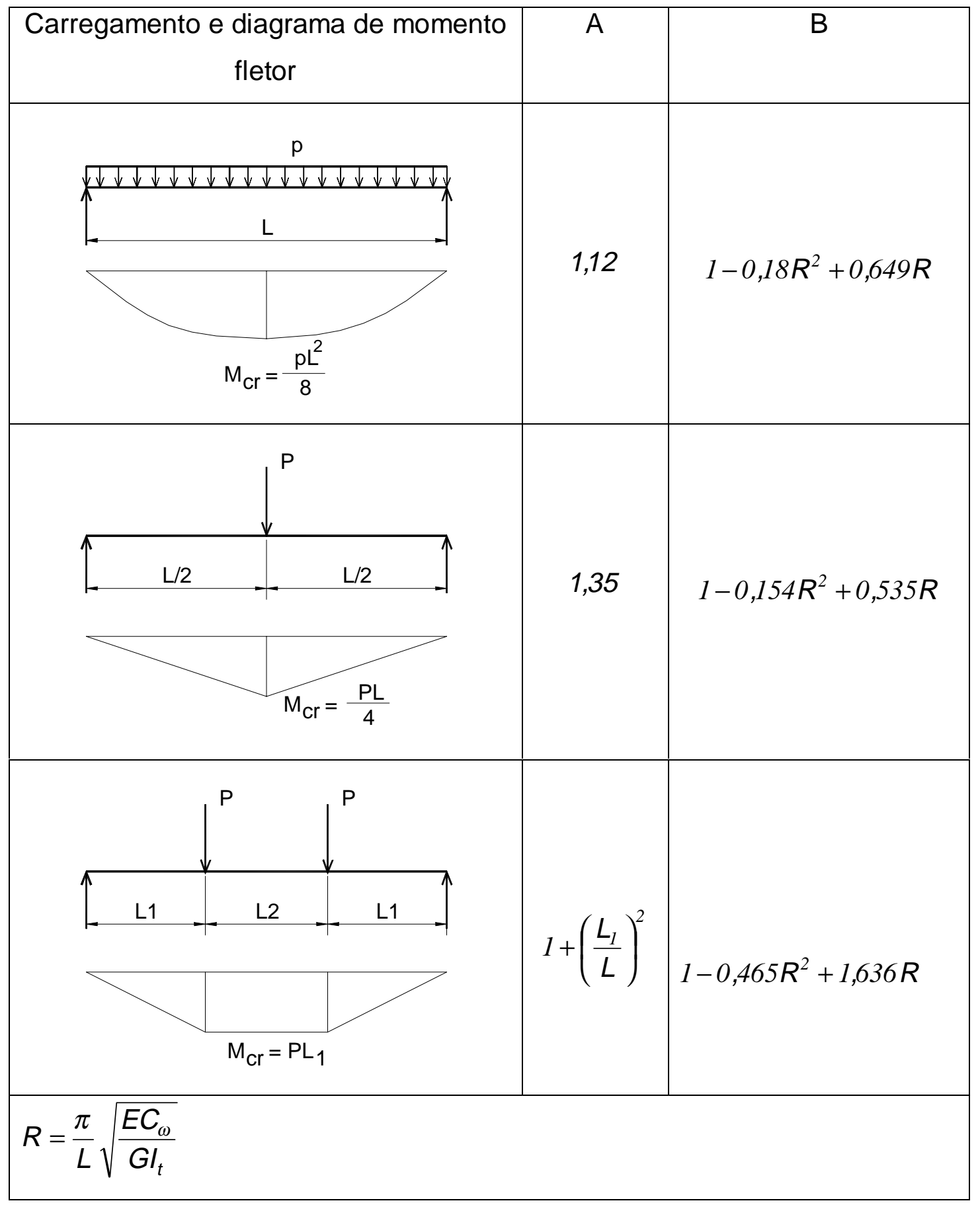

Já a influência da variação das condições de vínculos pode ser inserida na expressão (3.24) através dos fatores $K_{y}$ e $K_{t}$, obtendo-se: 


$$
M_{c r}=C_{b} \frac{\pi}{K_{y} L} \sqrt{E I_{y} G I_{t}\left(1+\frac{\pi^{2} E C_{\omega}}{G I_{t}\left(K_{t} L\right)^{2}}\right)}
$$

$K_{y}$ é o fator de comprimento efetivo de flambagem por flexão e $K_{t}$ é o fator correspondente ao comprimento efetivo de flambagem por torção.

Com algumas operações algébricas a equação (3.33) pode ser escrita como:

$$
M_{c r}=C_{b} A r_{0} \sqrt{\sigma_{e y} \sigma_{t}}
$$

sendo:

$$
\begin{aligned}
& A=\text { área da seção transversal da barra; } \\
& r_{o}=\text { raio de giração polar da seção transversal; } \\
& \sigma_{e y}=\frac{\pi^{2} E l_{y}}{\left(K_{y} L\right)^{2}} \\
& \sigma_{t}=\frac{1}{A r_{0}^{2}}\left[G I_{t}+\frac{\pi^{2} E C_{\omega}}{\left(K_{t} L\right)^{2}}\right]
\end{aligned}
$$

Os valores de $K_{y}$ e $K_{t}$ permitem a consideração das várias condições de contorno para " $u$ " e " $\phi$ ", respectivamente. Entretanto, a determinação precisa desses valores é difícil em razão das diversas formas possíveis de ligações, sugerindo a utilização de valores conservativos para os fatores.

Em geral, pode-se adotar para $K_{y}$ e/ou $K_{t} 0$ valor 1,0 se as extremidades são apoiadas, 0,70 se uma extremidade é apoiada e a outra engastada e 0,50 se as duas extremidades são engastadas. 


\subsubsection{Perfis monossimétricos}

Os perfis de simetria única, sendo "y" o eixo de simetria, apresentam duas situações distintas quanto à aplicação do carregamento em relação ao eixo de simetria.

Na primeira situação, flexão em relação ao eixo de simetria, o valor do momento crítico de flambagem lateral com torção é obtido através da equação (3.21).

Para a segunda situação, na qual tem-se flexão em relação ao eixo central perpendicular ao eixo de simetria, a não coincidência do centro de gravidade com o centro de cisalhamento altera o comportamento do perfil.

Nestas condições e para uma viga simplesmente apoiada com momentos fletores aplicados às extremidades encontra-se:

$$
\begin{aligned}
& E I_{x} v^{i v}=0 \\
& E I_{y} u^{i v}+M \phi^{\prime \prime}=0 \\
& E C_{\omega} \phi^{i v}-\left[G I_{t}+2 M\left(K_{y}-y_{0}\right)\right] \phi^{\prime \prime}+M u^{\prime \prime}=0
\end{aligned}
$$

Da equação (3.37), com as devidas condições de contorno, sem perda de estabilidade no plano, tem-se a posição deslocada da viga dada pela equação (3.20).

Das equações (3.38) e (3.39), nas variáveis " $u$ " e “ $\phi$ ", obtém-se 0 valor do momento crítico elástico de flambagem lateral com torção, já corrigido com o coeficiente $C_{b}$ :

$$
M_{c r}=C_{b} \frac{\pi E I_{y}}{L}\left[\frac{\pi}{L} j \pm \sqrt{\left(\frac{\pi j}{L}\right)^{2}+\frac{G I_{t}}{E l_{y}}+\left(\frac{\pi}{L}\right)^{2} \frac{C_{\omega}}{l_{y}}}\right]
$$

A grandeza $\left(j=K_{y}-y_{0}\right)$ é uma característica geométrica da seção transversal e pode ser tabelada para os perfis usuais de aço, sejam laminados, soldados ou formados a frio. 
Na expressão (3.40), efetuando-se as devidas operações algébricas, o valor do momento crítico pode ser expresso através da tensão crítica de flambagem de Euler em torno do eixo $y\left(\sigma_{e y}\right)$ e da tensão crítica de flambagem por torção $\left(\sigma_{t}\right)$, conforme equação (3.41).

$$
M_{c r}=C_{b} A_{g} \sigma_{e y}\left[j \pm \sqrt{j^{2}+r_{0}^{2}\left(\frac{\sigma_{t}}{\sigma_{e y}}\right)}\right]
$$

Em comparação aos perfis de dupla simetria, a influência da variação das condições de contorno e de carregamentos na instabilidade de perfis monossimétricos é de menor conhecimento. Entretanto, para fins de projeto, as expressões de $C_{b}$, equações (3.25) e (3.26) são utilizadas.

Nos perfis de aço formados a frio, as seções transversais tipo $U$ e tipo U enrijecido são de ampla utilização como elementos fletidos.

Como característica geral, possuem o eixo de menor inércia correspondente ao eixo de assimetria, portanto, quando da ocorrência da flambagem lateral com torção esta dar-se-á com flexão em torno do eixo de simetria.

Para fins de aplicação futura passa-se a analisar algumas situações de carregamento para os perfis tipo $U$, onde essas situações analisadas serão objetos de experimentação em laboratório possibilitando a comparação de resultados. 


\subsubsection{Perfis tipo U com trecho sob momento fletor constante}

Seja um perfil tipo $U$ sujeito ao carregamento indicado na figura 3.6.
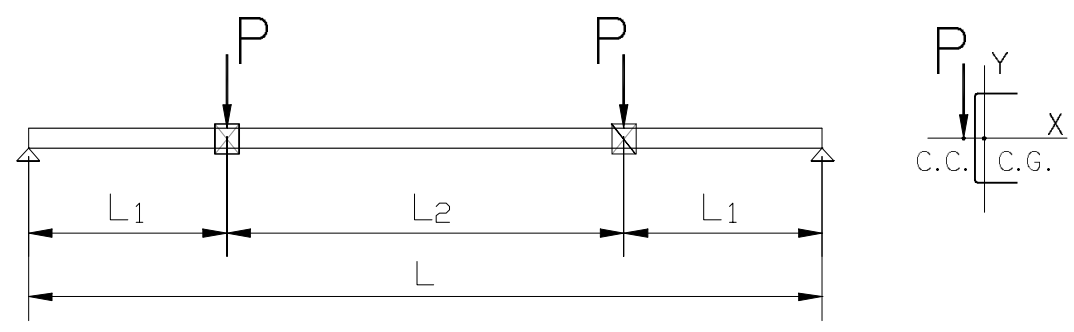

Figura 3.6: Esquema de carregamento para um perfil tipo U.

Aqui faz-se uma alteração com referência ao eixo de simetria. Passase a considerar o eixo ' $x$ ' como sendo o eixo de simetria, como usualmente é apresentado nas tabelas de características geométricas dos perfis de aço.

Considere-se que o perfil encontra-se travado lateralmente nos apoios, vínculos de garfo, e nos pontos de aplicação das forças $\mathrm{P}$.

\section{- Caso particular de $\mathrm{L}_{1}=\mathrm{L} / 3$ :}

Fazendo-se $L_{1}=L / 3$, das equações diferenciais da instabilidade por flexão e torção, equações (2.63), pode-se obter:

$$
\begin{aligned}
& E I_{x} v^{i v}=0 \\
& E I_{y} u^{i v}+\left(M_{x} \phi\right)^{\prime \prime}=0 \\
& E C_{\omega} \phi^{i v}-G l_{t} \phi^{\prime \prime}+M_{x} u^{\prime \prime}=0
\end{aligned}
$$

sendo que:

$$
\begin{array}{lll}
M_{x}=P z & \text { para } & 0 \leq z \leq \frac{L}{3} \\
M_{x}=\frac{P L}{3} & \text { para } & \frac{L}{3} \leq z \leq \frac{2 L}{3}
\end{array}
$$


Do sistema de equações diferenciais pode-se observar que a equação (3.42) é independente e estável no plano yz, fornecendo a equação da linha elástica para a viga esquematizada na Figura 3.3.

Integrando-se duas vezes a equação (3.43) e impondo-se as condições de contorno correspondentes pode-se obter:

$$
u^{\prime \prime}=-\frac{M_{x}}{E I_{y}} \phi
$$

Adotando-se para o giro $\phi$ a expressão (3.48), a qual atende as condições de contorno do problema, ou seja, giro impedido nos apoios e nos pontos de aplicação das forças:

$$
\phi=c \operatorname{sen}\left(\frac{3 \pi}{L} z\right)
$$

onde $c$ é uma constante e utilizando-se do processo de Ritz para a obtenção de um valor aproximado para $P_{c r}$ através do método da energia, tem-se:

$$
P_{c r}=\frac{3 \pi^{2}}{L^{2}} \sqrt{\frac{1}{2\left(\frac{5 \pi^{2}}{162}-\frac{1}{54}\right)}} \sqrt{E I_{y} G I_{t}\left(1+\frac{9 \pi^{2} E C_{\omega}}{G I_{t} L^{2}}\right)}
$$

sendo que o valor da constante $c$ permanece indeterminado.

Fazendo-se $L_{b}=L / 3$, comprimento lateralmente destravado, e observando-se que o máximo valor do momento fletor será dado por $M_{c r}=P_{c r} L_{b}$, pode-se escrever a seguinte relação:

$$
M_{c r}=1,3844 M_{0}
$$


onde $M_{0}$ é o valor do momento fletor crítico dado pela equação (3.21).

Deve-se observar que, para fins de projeto, o valor do momento fletor crítico seria determinado através da expressão (3.24) ou (3.34), propostas por Salvadori e por Kirby, Nethercot, respectivamente, com o valor de $C_{b}=1$, inferior ao valor obtido na equação (3.40).

Também, é intuitivo verificar que a situação analisada é favorável à viga quando em comparação com um diagrama de momento fletor constante em todo o vão. A parte comprimida da seção transversal possui os trechos de extremidade sob tensão de compressão variável e apenas o trecho central sob tensão de compressão constante.

\subsubsection{Perfis tipo U com trecho sob momento gradiente.}

Seja o caso de uma perfil tipo U simplesmente apoiado sujeito à uma força $P$ aplicada no meio do vão, figura 3.7.
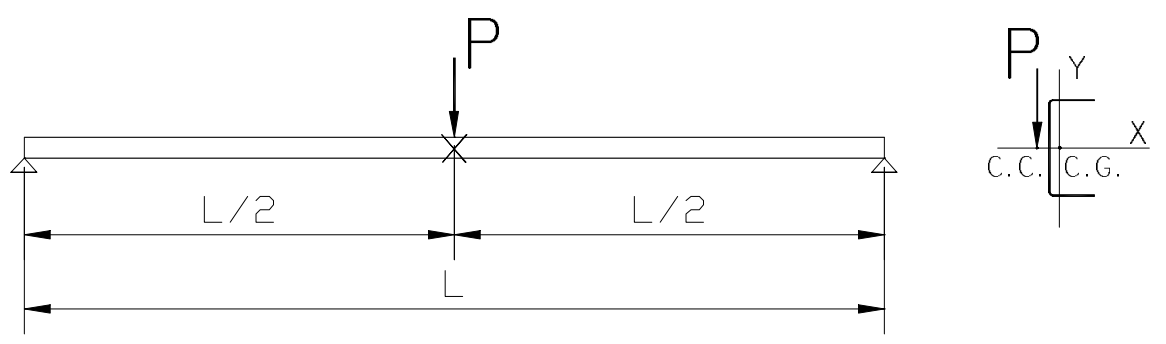

Figura 3.7: Perfil tipo U sob força concentrada no meio do vão.

A viga possui vínculos de garfo nas extremidades e está contida lateralmente no ponto de aplicação da força $P$.

Utilizando-se aqui também da relação dada em (3.47) e tomando-se para o giro $\phi$ a expressão (3.51):

$$
\phi=c \operatorname{sen}\left(\frac{2 \pi}{L} z\right)
$$


sendo c uma constante, da mesma forma que o procedimento anterior, a utilização do método da energia conduz a:

$$
P_{c r}=\frac{8 \pi}{L^{2}} \sqrt{\frac{1}{\left(\frac{1}{3}-\frac{1}{2 \pi^{2}}\right)}} \sqrt{E I_{y} G I_{t}\left(1+\frac{4 \pi^{2} E C_{\omega}}{G I_{t} L^{2}}\right)}
$$

Novamente, fazendo-se $L_{b}=L / 2$, comprimento lateralmente destravado e observando-se que o máximo valor do momento fletor será dado por $M_{c r}=P_{c r} L_{b} / 2$ pode-se escrever a seguinte relação:

$$
M_{c r}=1,8809 M_{0}
$$

onde $M_{0}$ é o valor do momento fletor crítico dado pela equação (3.21).

Para fins de projeto, a determinação do valor do momento fletor crítico é feita através da expressão de Salvadori, equação (3.24), com o valor de $C_{b}=1,75$, obtendo-se diferenças da ordem de $7,5 \%$ em relação ao valor dado por (3.52).

Com a finalidade de se verificar a utilização de contraventamento lateral na viga, seja o caso de uma seção retangular sem o travamento lateral. A solução das equações diferenciais fornece o valor teórico para a força crítica, equação (3.54):

$$
\left(P_{c r}\right)_{1}=16,9360 \frac{\sqrt{E I_{y} G I_{t}}}{L^{2}}
$$

Com a utilização do travamento lateral no ponto de aplicação da força, através da equação (3.52) encontra-se:

$$
\left(P_{c r}\right)_{2}=47,2713 \frac{\sqrt{E I_{y} G I_{t}}}{L^{2}}
$$


obtendo-se $\left(P_{c r}\right)_{2}=2,79\left(P_{c r}\right)_{1}$, mostrando a conveniência em se impedir a flambagem lateral com torção ou, pelo menos, reduzir o comprimento dos trechos entre pontos travados lateralmente para o projeto de vigas.

A integração da equação diferencial (3.19), utilizando-se a relação dada em (3.47), fornece, através das funções de Bessel, o seguinte resultado para uma viga de seção retangular:

$$
P_{c r}=44,4942 \frac{\sqrt{E I_{y} G I_{t}}}{L^{2}}
$$

valor este com variação de 5,87\% em relação ao valor aproximado obtido pela expressão dada em (3.55).

\subsubsection{Perfis tipo $U$ com força concentrada entre travamentos laterais}

Neste caso, o esquema de carregamento e os pontos de travamento lateral são aqueles apresentados na Figura 3.8. O ponto de aplicação da força $P$ é livre para deslocar-se lateralmente e girar.
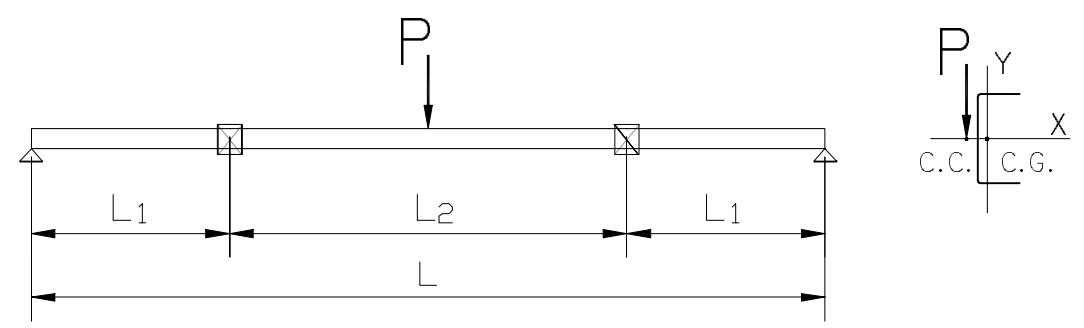

Figura 3.8: Perfil tipo U: força concentrada entre travamentos laterais. 
- Caso particular de $L_{1}=\mathrm{L} / 3$ :

Assumindo-se $L_{1}=L / 3$, a relação (3.47) e a função (3.48) para o giro $\phi$, pode-se obter a seguinte aproximação para o valor de $P_{c r}$ :

$$
P_{c r}=\frac{36 \pi}{L^{2}} \sqrt{\frac{1}{2\left(\frac{3}{2}+\frac{1}{\pi^{2}}\right)}} \sqrt{E I_{y} G I_{t}\left(1+\frac{9 \pi^{2} E C_{\omega}}{G I_{t} L^{2}}\right)}
$$

Fazendo-se $L_{b}=L / 3$, comprimento lateralmente destravado e observando-se que o máximo valor do momento fletor será dado por $M_{c r}=P_{c r} L / 4$ pode-se escrever a seguinte relação:

$$
M_{c r}=1,6764 M_{0}
$$

A tabela 3.2 apresenta um quadro comparativo entre os valores obtidos pelos diversos autores para as situações anteriormente analisadas.

Tabela 3.2: Valores comparativos de $\mathrm{C}_{\mathrm{b}}$.

\begin{tabular}{l|c|c|c|c}
\hline Carregamento & Salvadori & $\begin{array}{c}\text { Kirby, } \\
\text { Nethercot }\end{array}$ & Nethercot & $\begin{array}{c}\text { Soluçao } \\
\text { aproximada }\end{array}$ \\
\hline Esquema1 (fig. 3.6) & 1,00 & 1,00 & 1,00 & 1,38 \\
\hline Esquema 2 (fig 3.7) & 1,75 & 1,67 & 1,12 & 1,88 \\
\hline Esquema 3 (fig. 3.8) & 1,00 & 1,09 & 1,09 & 1,68 \\
\hline
\end{tabular}

Da tabela 3.2 pode-se observar que os valores propostos são conservadores, podendo-se obter melhores resultados com as soluções aproximadas, entretanto, soluções extensas para uso rotineiro. 


\subsubsection{Perfis tipo Z}

O perfil tipo Z caracteriza-se por possuir simetria em relação a um ponto e cujos eixos principais são inclinados em relação aos eixos paralelo e perpendicular à alma. Como geralmente o carregamento é aplicado segundo o plano da alma o problema envolve flexão oblíqua.

Hill, H. N. (1953) avaliou o momento crítico para seções em forma de Z com os momentos fletores aplicados paralelo e normal à alma, cujo desenvolvimento permite estabelecer uma expressão para o cálculo do momento crítico. Esta expressão é similar à equação (3.33).

Uma abordagem sistemática sobre o comportamento de perfis tipo $Z$ com as mesas enrijecidas, solicitados à flexão através de forças transversais aplicadas no plano da alma foi desenvolvida por Daltro (1989), acompanhada de um estudo experimental sobre esses perfis.

\subsection{Flambagem por distorção}

A flambagem por distorção deve ser considerada no projeto de perfis de chapa dobrada submetidos à flexão onde esse modo de falha pode ser crítico.

Como perfis isolados, o método australiano, proposto por Hancock, tem sido aceito no meio técnico, observando-se que todo o equacionamento desenvolvido, bem como a maioria dos estudos experimentais realizados, fez-se para perfis tipo $U$ e perfis tipo $Z$ enrijecidos, considerando-se sempre a presença do enrijecedor por virada simples de borda ou com dupla virada de borda.

No caso de perfis conectados às telhas, como no caso das terças e das longarinas, a flambagem lateral com torção não ocorre na seção transversal como um todo. Dois modelos de cálculo podem ser utilizados para a determinação da resistência nominal dos perfis. 
No primeiro deles, proposto por Peköz, Soroushian, apresentado no item 2.4.3, o comportamento do perfil é idealizado como a superposição de dois estágios de comportamento: um de deslocamento vertical e o outro de rotação. Este modelo serve de base para o procedimento de cálculo adotado no Eurocode, EC 3 Part 1.3 (1993).

O segundo modelo trata-se de um método empírico, onde LaBoube (1992, 1991) correlacionou os momentos fletores últimos observados em ensaios com o momento fletor de início de escoamento da seção transversal, propondo alguns valores para esta relação.

Faz-se aqui a determinação do momento crítico segundo o modelo de Hancock, deixando-se para o item seguinte a apresentação dos modelos que consideram o travamento lateral fornecido pelas telhas.

O cálculo do momento crítico correspondente ao modo de falha pela flambagem por distorção é obtidos a partir de Know, Hancock (1992); Hancock et al (1994), sendo que, a parábola de Johnston (1976) é utilizada para corrigir o valor desse momento crítico em regime inelástico, caso se faça necessário, conforme equações (3.59) e (3.60).

$$
\begin{array}{ll}
\sigma_{c}=f_{y}\left(1-\frac{f_{y}}{4 \sigma_{e d}}\right) & \text { para } \sigma_{e d}>\frac{f_{y}}{2} \\
\sigma_{c}=\sigma_{e d} & \text { para } \sigma_{e d} \leq \frac{f_{y}}{2}
\end{array}
$$

onde $\sigma_{c}$ é a tensão crítica de flambagem por distorção e $\sigma_{e d}$ é a tensão crítica de flambagem elástica por distorção.

Com o objetivo de estimar a capacidade última de chapas comprimidas considerando a sua resistência pós-flambagem, a formulação de Winter para o conceito da largura efetiva, em sua forma usual, é escrita como: 


$$
\frac{b_{e f}}{b}=\sqrt{\frac{\sigma_{e}}{f_{y}}}\left(1-0,22 \sqrt{\frac{\sigma_{e}}{f_{y}}}\right)
$$

sendo $b$ a largura da chapa, $b_{\text {ef }}$ a sua largura efetiva calculada para $a$ tensão de flambagem elástica da chapa $\sigma_{e}$.

Simplesmente substituindo-se $\sigma_{e}$ por $\sigma_{e d}$ e rescrevendo-se a equação (3.61) obtém-se:

$$
\begin{array}{ll}
\frac{b_{e f}}{b}=1 & \text { para } \lambda \leq 0,673 \\
\frac{b_{e f}}{b}=\sqrt{\frac{\sigma_{e d}}{f_{y}}}\left(1-0,22 \sqrt{\frac{\sigma_{e d}}{f_{y}}}\right) & \text { para } \lambda>0,673
\end{array}
$$

onde:

$$
\lambda=\sqrt{\frac{f_{y}}{\sigma_{e d}}}
$$

Dessa forma, para barras comprimidas, assumindo-se que todos os elementos de chapa que compõe a seção são reduzidos na mesma proporção:

$$
\frac{A_{e f}}{A}=\sqrt{\frac{\sigma_{e}}{f_{y}}}\left(1-0,22 \sqrt{\frac{\sigma_{e}}{f_{y}}}\right)
$$

sendo $A_{\text {ef }}$ a área efetiva da seção transversal da barra.

Da mesma forma a aproximação acima é aplicada às barras fletidas, encontrando-se: 


$$
\frac{W_{e f}}{W}=\sqrt{\frac{\sigma_{e}}{f_{y}}}\left(1-0,22 \sqrt{\frac{\sigma_{e}}{f_{y}}}\right)
$$

sendo $W_{\text {ef }}$ o módulo de resistência elástica da seção transversal efetiva da barra.

Assim, as equações para determinação do momento crítico para a flambagem distorcional podem ser escritas como:

$$
\begin{array}{ll}
M_{c}=M_{y} & \text { para } M_{e d} \geq 2,2 M_{y} \\
M_{c}=M_{y} \sqrt{\frac{M_{e d}}{M_{y}}}\left(1-0,22 \sqrt{\frac{M_{e d}}{M_{y}}}\right) & \text { para } M_{e d}<2,2 M_{y}
\end{array}
$$

$M_{e d}$ é o momento crítico elástico de flambagem por distorção, obtido a partir das equações (2.75). Dividindo-se a equação (2.75a) pela área da seção transversal da barra obtém-se $\sigma_{e d}$, ou seja:

$$
\sigma_{e d}=\frac{E}{2 A}\left[\left(\alpha_{1}+\alpha_{2}\right) \pm \sqrt{\left(\alpha_{1}+\alpha_{2}\right)^{2}-4 \alpha_{3}}\right]
$$

Portanto, $M_{e d}=W \sigma_{e d}$, sendo a resistência nominal ao momento fletor por flambagem distorcional dada por:

$$
M_{n}=W_{e f} \frac{M_{c}}{W}
$$

onde:

$W=$ módulo de resistência elástico da seção transversal da barra. 


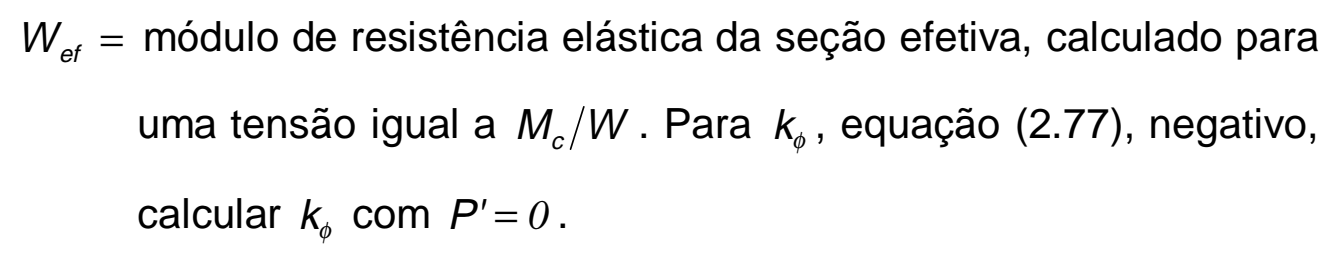

\subsection{Cálculo das forças críticas para os ensaios dos perfis isolados}

Procurando-se prever as forças últimas para os modelos ensaiados, determinam-se os momentos fletores críticos de flambagem para todos os estados limites últimos associados, onde o menor valor encontrado caracteriza o modo de falha e o momento crítico. A esse momento crítico calculam-se, com as tensões correspondentes, as propriedades efetivas da seção transversal.

Dessa forma, o momento fletor resistente, nominal, será dado por:

$$
M_{n}=W_{e f} \frac{M_{c}}{W}
$$

Para a determinação do momento fletor crítico, consequentemente da força última teórica, serão utilizados os procedimentos adotados na norma americana (AISI) e européia (Eurocode). Assim, o momento fletor crítico é dado por:

\section{AISI (1996)}

$$
\begin{array}{ll}
M_{c}=M_{y} & \text { para } M_{e} \geq 2,78 M_{y} \\
M_{c}=\frac{10}{9} M_{y}\left(1-\frac{10 M_{y}}{36 M_{e}}\right) & \text { para } 0,56<M_{e}<2,78 M_{y} \\
M_{c}=M_{e} & \text { para } M_{e} \leq 0,56 M_{y}
\end{array}
$$




\section{EUROCODE (1993)}

$$
M_{c}=\chi_{L T} W_{e f} f_{y}
$$

$$
\chi_{L T}=\frac{1}{\phi_{L T}+\sqrt{\left(\phi_{L T}\right)^{2}-\left(\bar{\lambda}_{L T}\right)^{2}}} \leq 1
$$

$$
\phi_{L T}=0,5\left[1+\alpha_{L T}\left(\bar{\lambda}_{L T}-0,2\right)+\left(\bar{\lambda}_{L T}\right)^{2}\right]
$$

$$
\bar{\lambda}_{L T}=\sqrt{\frac{W_{e f} f_{y}}{M_{e}}}
$$

$$
\alpha_{L T}=0,21 \quad \text { (para perfis de chapa dobrada) }
$$

$M_{y}$ é o valor do momento fletor correspondente ao início de escoamento da seção transversal bruta e $M_{e}$ é o momento fletor de flambagem lateral com torção, em regime elástico, calculado para uma barra sob momentos aplicados às suas extremidades.

$W_{e f}$ é o módulo de resistência elástico da seção efetiva calculado com tensão $\sigma=M_{c} / W_{x}$.

A força crítica correspondente pode ser calculada diretamente a partir da resolução das equações diferenciais, conforme os resultados obtidos anteriormente.

Esses resultados estão apresentados na Tabela 3.3 e no capítulo 4, em conjunto com os resultados obtidos nos ensaios realizados. 
Tabela 3.3 - Valores previstos para as forças críticas correspondentes.

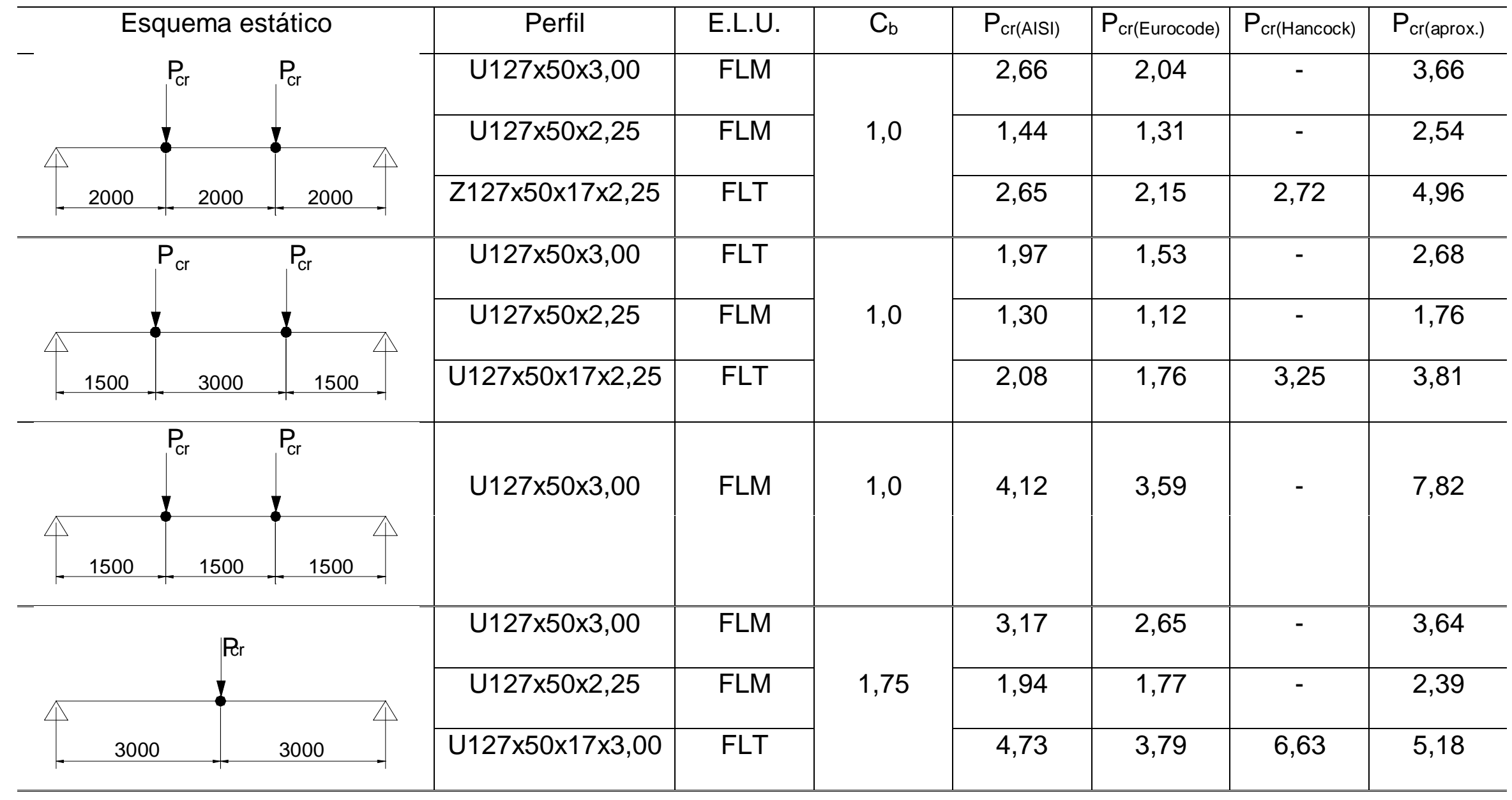


Tabela 3.3 - Valores previstos para as forças críticas correspondentes (continuação).

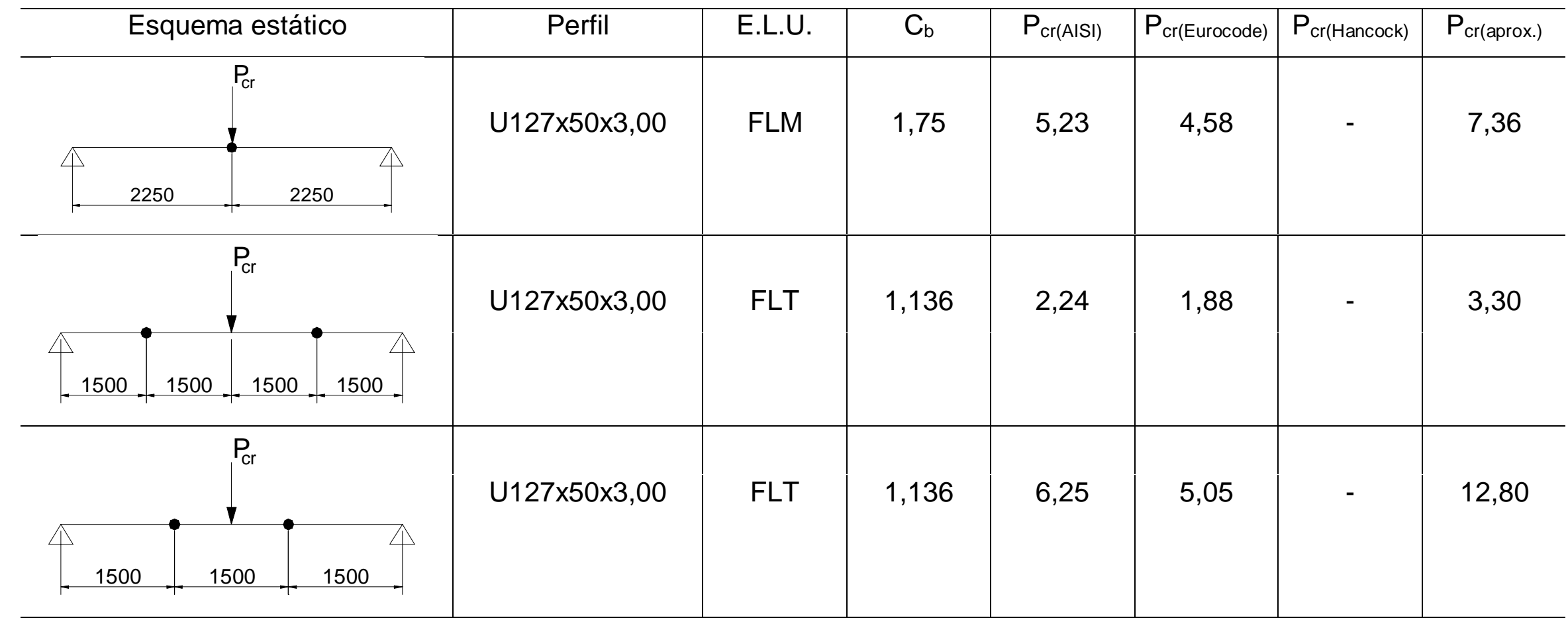

Notas: a) E.L.U: estado limite último previsto. b) $\mathrm{P}_{\text {cr }}$ em kN. c) • pontos travados lateralmente. d) $P_{\text {cr(aprox.) }}$ corresponde aos valores aproximados obtidos através das soluções aproximadas das equações diferenciais, especificamente para o estado limite último de flambagem lateral com torção. 


\subsection{Sobre o dimensionamento dos perfis conectados às telhas}

Entre as mais diversas aplicações dos perfis tipo $U$ nas construções metálicas, a utilização como terças e longarinas é de grande frequência.

Como parte do sistema de fechamento, estes perfis são conectados, ao longo de uma aba pelas telhas e, em pontos discretos ao longo de seu vão, por tirantes (correntes).

Portanto, as terças apresentam algum grau de restrição contra deslocamentos laterais e rotacionais quando os perfis são solicitados à flexão. A região tracionada da seção transversal, principalmente se conectada em telhas de aço, permanece reta e a flambagem lateral não mais ocorre na seção como um todo. Esta situação é típica para terças e longarinas submetidas à ação de sucção devida ao efeito do vento.

Como esquema estático para esses elementos o de viga apoiada é o mais utilizado. Com isso, permite-se uma padronização das terças para todos os vãos, de fácil transporte e ligação simples com os demais elementos estruturais.

De outra forma, pode-se dimensionar as terças como vigas contínuas, obtendo-se perfis mais econômicos, porém, exigindo-se a execução de emendas nos perfis, em oficina ou em campo, encarecendo o seu custo, nem sempre contribuindo para a redução do custo final da edificação.

Alternativamente, as emendas podem ser feitas por traspasse com 0 objetivo de recompor a continuidade das peças e garantir um menor comprimento, evitando-se problemas de transporte e garantindo uma padronização para toda a obra.

Para os perfis tipo $U$, esse traspasse pode ser feito superpondo-se os perfis costa a costa, alternando-se para cada vão. Como desvantagem, ocorre o desalinhamento da fixação das telhas às terças.

Neste caso, as seções tipo Z podem resultar em um sistema de traspasse mais vantajoso. Pela sua forma, o traspasse pode ser feito pela simples superposição das seções transversais, alinhadas ao longo de todo o comprimento da edificação. 
Na figura 3.9 estão ilustrados os dois tipos de seções transversais com os respectivos traspasse.

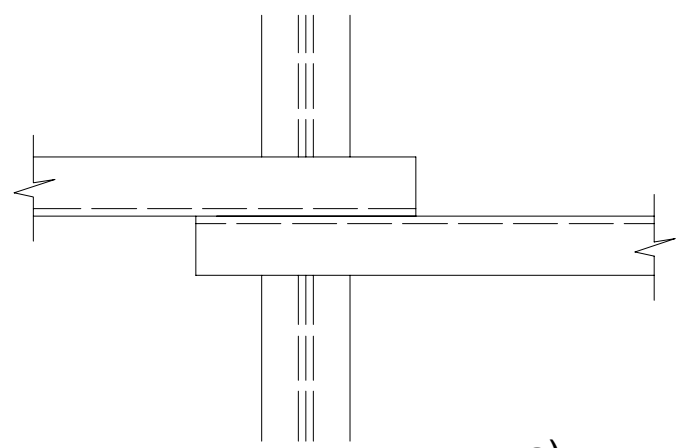

a)

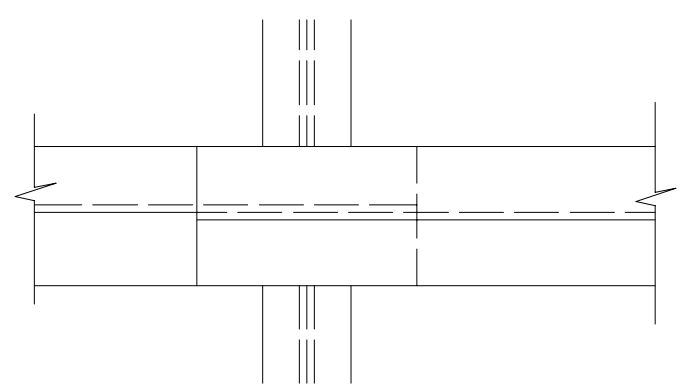

b)
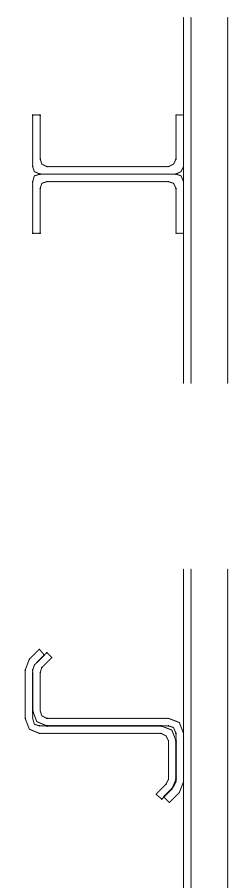

Figura 3.9: Detalhe do traspasse dos perfis. a) Perfis tipo U. b) Perfis tipo Z.

A presença das telhas de cobertura fixadas às terças confere a este elemento uma certa restrição lateral, dependendo de características da seção transversal do perfil, dos vãos dos painéis e dos elementos e formas de fixação dos painéis às terças.

O dimensionamento desses perfis tem-se baseado, em geral, no modelo de colunas sob base elástica, onde a coluna consiste de uma parte da seção transversal, mesa comprimida e região comprimida da alma, e a base elástica é formada pela região tracionada da seção transversal e pelo painel.

Hausller (1964) apresentou um método rigoroso para a determinação da resistência de vigas estabilizadas elasticamente, considerando a região comprimida como uma coluna sob fundação elástica. A solução da equação 
diferencial resultante é dada de forma a permitir a avaliação numérica direta da tensão crítica.

Peköz (1983) apresenta um método simples para o cálculo da resistência nominal à flexão de perfis tipo $Z$ enrijecido e tipo $U$ enrijecido. Utilizando-se desse método, com um número limitado de ensaios, observou que os perfis $U$ enrijecidos fletem lateralmente duas a três vezes mais que os perfis $Z$ enrijecidos, de mesma altura e perímetro. Como deficiência, o método exige conhecimentos de dados experimentais do conjunto vigapainel.

Estudos analíticos, através de métodos numéricos, e estudos experimentais de perfis $U$ e $Z$, incluindo-se o efeito da restrição à torção pelo uso de tirantes, são apresentados, entre outros, por Kemp et. al. (1995), Polyzois (1987), Polyzois, Birkemoe (1985), Polyzois, Guillory (1991), Willis e Wallace (1990).

Os resultados observados indicam que os painéis em aço podem fornecer, em muitos casos, restrições à rotação e ao deslocamento lateral suficientes para se considerar somente o efeito da flexão simples na viga.

Em vista dos aspectos normativos aqui abordados, serão apresentados e discutidos os métodos de dimensionamento do AISI (1996) e do Eurocode (1993).

\subsubsection{Procedimento do AISI (1996)}

Baseado em resultados experimentais, LaBoube (1992, 1991) apresentou uma formulação empírica para a determinação da resistência nominal à flexão em perfis cuja mesa tracionada encontra-se fixada à telhas de cobertura:

$$
M_{n}=R M_{y}
$$

onde: 


$$
\begin{array}{ll}
M_{n} & =\text { resistência nominal ao momento fletor. } \\
R & =\text { fator de redução. } \\
M_{y} & =W_{e f} f_{y} \\
W_{e f} & =\text { módulo de resistência efetivo, elástico. } \\
f_{y} & =\text { tensão limite de escoamento do aço. }
\end{array}
$$

O fator $R$ é um fator empírico, com valor dado pela razão entre o momento fletor último observado em ensaio e o momento fletor que causa o escoamento inicial da seção transversal $\left(M_{y}\right)$.

Os valores de $R$, obtidos para perfis tipo $U$ enrijecido e tipo $Z$ enrijecido são, respectivamente, 0,40 e 0,50 para vigas simplesmente apoiadas e 0,60 e 0,70 para vigas contínuas.

Esse procedimento proposto por LaBoube foi adotado pelo AISI (1996, 1991).

\subsubsection{Procedimento do Eurocode (1993)}

O Eurocode 3 (1993) traz um modelo de cálculo para a verificação de terças sujeitas às ações gravitacionais ou de sucção, sendo tal procedimento similar ao idealizado por Peköz, Soroushian.

No caso das ações gravitacionais, as tensões devidas à força lateral fictícia atuando na mesa livre podem ser desprezadas. Portanto, somente as forças verticais são consideradas. Isto porque tem-se a mesa comprimida travada lateralmente pelo painel de cobertura. Assim, a tensão máxima será obtida através de:

$$
\sigma_{\text {max }}=\frac{M_{x}}{W_{e f, x}}
$$

onde: 


$$
\begin{aligned}
M_{x}= & \text { momento fletor em torno do eixo } x \\
W_{e f, x}= & \text { módulo de resistência elástico efetivo da seção transversal } \\
& \text { em torno do eixo } x
\end{aligned}
$$

Para as ações de sucção, onde a mesa comprimida encontra-se lateralmente destravada, a tensão de compressão é obtida pela superposição da tensão devida à flexão vertical e de uma tensão fictícia dada por um carregamento lateral fictício. Duas situações devem ser verificadas:

- Mesa com restrição lateral (tracionada):

$$
\sigma_{\text {max }}=\frac{M_{x}}{W_{e f, x}}
$$

- Mesa livre (comprimida):

$$
\sigma_{\max }=\frac{1}{\chi} \frac{M_{\chi}}{W_{e f, x}}+\frac{M_{f z}}{W_{f}}
$$

onde:

$M_{f z} \quad=$ momento fletor em torno do eixo $y$, na mesa livre, devido ao carregamento lateral fictício $q_{x}(z)$, sendo que:

$M_{t z}=\beta_{R} M_{y}$, onde $M_{y}$ é o momento fletor na mesa livre, desprezando-se o apoio elástico.

$q_{x}(z)=$ carregamento lateral fictício, conforme equação 2.96 .

$$
\beta_{R}=\frac{1-0,0225 R}{1+1,013 R}
$$




$$
R=\frac{K L^{4}}{\pi^{4} E I_{f z}}
$$

$L=$ a distância entre linhas de corrente ou, na ausência destas, o vão da terça.

$K=$ rigidez da mola lateral.

$I_{f z}=$ momento de inércia da mesa livre mais $1 / 6$ da altura da alma, onde o eixo z é um eixo paralelo à alma da seção passando através do C.G. da mesa livre.

$W_{f z}=$ módulo de resistência elástico da mesa livre mais 1/6 da altura da alma.

$\chi \quad=$ coeficiente de flambagem, de acordo com o Eurocode:

$\chi \quad=\frac{1}{\phi+\sqrt{\phi^{2}-\lambda^{2}}} \leq 1$

$\phi \quad=0,5\left[1+0,21\left(\bar{\lambda}_{t z}-0,2\right)+\bar{\lambda}_{t z}^{2}\right]$

$\lambda_{f z}=\frac{1}{\pi} \frac{L_{f z}}{r_{f z}} \sqrt{\frac{f_{y}}{E}}$

$i_{f z} \quad=$ raio de giração da mesa livre mais $1 / 6$ da altura da alma:

$$
=\sqrt{\frac{I_{f z}}{A_{f}}}
$$

$A_{f} \quad=$ área da mesa livre mais $1 / 6$ da altura da alma.

$L_{f z} \quad=$ comprimento efetivo de flambagem para a mesa livre.

$=0,526 L\left(1+22,8 R^{2,12}\right)^{-0,108}$, sendo que $0 \leq R \leq 200$.

A rigidez da mola lateral $K$ por unidade de comprimento deve ser determinada a partir de procedimento experimental ou de forma analítica obtida por:

$$
\frac{1}{k}=\frac{1}{k_{A}}+\frac{1}{k_{B}}+\frac{1}{k_{C}}
$$


sendo que:

$K_{A}$ é a rigidez lateral correspondente a rigidez rotacional da conexão entre o painel e a terça;

$K_{B}$ é a rigidez lateral devido a distorção da seção transversal da terça;

$K_{c}$ é a rigidez lateral devido a rigidez à flexão do painel.

Em geral, pode-se desprezar o termo $1 / K_{c}$ porque $K_{c}$ é muito maior que $K_{A}$ e $K_{B}$.

O valor de $K$ pode ser calculado pela expressão:

$$
\frac{1}{k}=\frac{4\left(1-v^{2}\right) h^{2}(h+2 a+b)}{E t^{3}}+\frac{h^{2}}{C_{D}}
$$

onde:

$$
\begin{array}{ll}
a & =\text { distância do centro do parafuso à alma; } \\
b & =\text { largura da mesa conectada ao painel; } \\
C_{D} & =\text { rigidez rotacional; } \\
h & =\text { altura total da terça; } \\
v & =\text { coeficiente de Poisson }(v=0,3)
\end{array}
$$

A restrição à rotação dada à terça pelo painel ao qual está conectada deve ser modelada como uma mola rotacional atuando na mesa. A rigidez à rotação $C_{D}$ deve ser determinada a partir de:

$$
C_{D}=\frac{1}{\left(1 / C_{D, A}+1 / C_{D, C}\right)}
$$

Onde: 


$$
\begin{aligned}
& C_{D, A}=\text { rigidez à rotação da conexão entre o painel e a terça; } \\
& C_{D, C}=\text { rigidez rotacional devida à rigidez à flexão do painel. }
\end{aligned}
$$

Um valor conservativo para $C_{D, C}$ pode ser obtido por:

$$
C_{D, C}=\frac{k E I_{e f}}{s}
$$

onde:

$k$ = coeficiente numérico cujos valores são:

- Para telhas de vão simples: $k=2$;

- Para painel contínuo com dois ou mais vãos: $k=4$.

$S=$ espaçamento entre terças;

$I_{e f}=$ momento de inércia do painel por unidade de largura.

Para a rigidez à rotação da conexão entre o painel e a terça, $C_{D, A}$, para painéis trapezoidais e parafusos posicionados no centro da mesa, pode-se fazer:

- Para $b \leq 125 \mathrm{~mm}$ :

$$
C_{D, A}=1,7\left(\frac{b}{100}\right)^{2}
$$

- Para $125 \mathrm{~mm}<b \leq 200 \mathrm{~mm}$ :

$$
C_{D, A}=2,125\left(\frac{b}{100}\right)
$$


onde $b$ é a largura da mesa conectada às telhas, em milímetros.

\subsection{Comentários}

Neste capítulo foram apresentados os procedimentos para determinação da resistência nominal ao momento fletor para os perfis de chapa, tendo como objetivo determinar os resultados teóricos para os modelos apresentados, preparando-os para comparações futuras com os resultados experimentais.

Para os perfis fletidos, pode-se verificar que o seu dimensionamento é relativamente trabalhoso quando se trata de obter as propriedades efetivas da seção transversal, principalmente quando ocorre problemas de flambagem local na alma, onde o processo de determinação da largura efetiva torna-se interativo.

Observando-se a tabela 3.3 pode-se constatar que os valores obtidos através das especificações do AISI são superiores aos valores obtidos por meio do Eurocode. Enquanto o Eurocode se utiliza da tensão básica do material para o cálculo da largura efetiva, o AISI trabalha com uma tensão correspondente ao momento crítico de flambagem lateral com torção.

Os valores da força crítica correspondentes à solução aproximada das equações diferenciais são válidas somente em regime elástico linear. As expressões utilizadas são extensas e o seu uso corrente em projeto fica prejudicado.

O modo de flambagem por distorção não é, usualmente, levado em consideração pelos projetistas como um estado limite no dimensionamento, apesar de ser previsto em várias especificações de projeto.

Nas especificações do AISI, esse modo de falha é tratado como sendo um modo de instabilidade do enrijecedor de borda, instabilidade esta que induz a flambagem do elemento ao qual deveria dar apoio. Por isso, no conceito de largura efetiva procura-se obter um valor correspondente ao coeficiente de flambagem de chapa para a consideração desse fator. Para 
os perfis de chapa dobrada de uso corrente em projetos, os enrijecedores possuem, na sua grande maioria, condições de rigidez suficiente para fornece apoio ao elemento a ser enrijecido.

De forma similar, o Eurocode dispensa a verificação da flambagem por distorção, reduzindo-se a área efetiva do enrijecedor.

Os valores obtidos através do modelo de Hancock são válidos para os perfis tipo $U$ enrijecido e tipo $Z$ enrijecido e, conforme verificou-se, não devem ser o modo de falha para os modelos analisados.

Rogers, Schuster (1997) fazem uma análise de resultados obtidos por vários pesquisadores, comparando-os com alguns modelos matemáticos para a flambagem por distorção. Curiosamente, dos 59 ensaios desenvolvidos para o estudo, apenas 4 apresentaram este modo de falha.

Quanto ao perfis fletidos com a mesa tracionada conectada às telhas, aqui especificamente as terças de cobertura, tem sido objeto de estudos por vários pesquisadores.

O método proposto por Laboube (1992) trata-se de um método empírico, sem um modelo matemático formal.

Seguindo este procedimento empírico, Jonhston e Hancock (1994) desenvolveram um programa de testes para terças em perfis $Z$ enrijecido, dividido em três séries: terças simplesmente apoiadas e terças contínuas com dois e três vãos. O número de linhas de correntes variou de zero a dois, por vão. Os resultados obtidos permitiram a recomendação de novos valores para o fator de redução $R$ para situações distintas daquelas utilizadas por LaBoube.

Segundo dados coletados a partir de 10 laboratórios de Engenharia nos Estados Unidos, Murray e Elhouar (1994) analisaram os resultados de ensaios em 24 sistemas de terças. Desses, 17 foram ensaiados simulandose ações gravitacionais e o restante, ações devidas ao vento. Os sistemas eram constituídos por terças contínuas de dois e três vãos com duas linhas de terças. Os vãos variaram entre $6,10 \mathrm{~m}$ e 8,54 m. 
Este procedimento é bastante simples do ponto de vista de aplicação, entretanto, possui condições de aplicação restritas às condições experimentadas no desenvolvimento dos ensaios.

O modelo do Eurocode está em acordo com aquele apresentado por Peköz, Souroshian (1983) e tem como certa dificuldade a determinação da rigidez rotacional oferecida pelo paínel, cuja avaliação experimental é a indicada. Dentro de certas condições, pode-se utilizar as expressões teóricas apresentadas. Ainda, como dificuldade adicional, esta rigidez pode apresentar muita variação em função da locação do parafuso na mesa, do seu diâmentro, da quantidade de parafusos, etc.

Tomà, Wittemann (1994) compararam os resultados de ensaios e os resultados obtidos através desse procedimento para situações de carregamento gravitacional e carregamento de sucção. A comparação mostrou que o procedimento do Eurocode é conservador.

Leach, Robinson (1993) também comparam os resultados de ensaios com os obtidos de acordo com o Eurocode e conclui que os valores calculados são de $20 \%$ a $25 \%$ inferiores aos de ensaio.

Lin (1983), analisa a influência de diversos tipos de restrição elástica, discreta e contínua, no comportamento dos perfis de chapa dobrada fletidos. As equações diferenciais são resolvidas através do método das diferenças finitas. Os resultados demonstram a influência das restrições elásticas, podendo alterar significativamente o valor da carga crítica. No caso de restrição elástica contínua pode-se considerar impedido o estado limite último de flambagem lateral com torção.

As linhas de corrente, além de serem elementos que podem ser utilizados para o alinhamento das terças durante a fase de montagem, também têm influência no comportamento das terças.

Polyzois,Birkmoe (1987), Polyzois (1987), Lin (1983) observaram que a efetividade dos tirantes depende de sua localização, sendo mais efetivo quando conectados o mais próximo possível da mesa comprimida. Isto torna-se mais evidente quanto menor a rigidez do tirante. 


\section{ENSAIOS EM PERFIS FLETIDOS ISOLADOS}

\subsection{Introdução}

O presente capítulo tem como finalidade apresentar e discutir os resultados obtidos nos ensaios à flexão realizados com os perfis tipo $U, U$ enrijecido e $Z$ enrijecido. Os perfis são biapoiados, sujeitos às forças concentradas e travados lateralmente nos apoios e em pontos intermediários.

Descrevem-se a metodologia empregada nos ensaios de flexão, os modelos ensaiados e os resultados obtidos.

Contrariamente ao que se verifica nos países da América do Norte e Europa, no Brasil os programas de ensaios com os perfis de aço formados a frio ainda são modestos e a necessidade em se dispor de resultados experimentais sobre os mesmos levou à realização deste programa experimental.

Como objetivo procura-se obter resultados experimentais referentes aos modos de falha característicos para os perfis, especialmente os perfis tipo U, amplamente utilizados no Brasil. Pretende-se investigar o comportamento desses perfis sob a ação de forças transversais e a 
verificação dos resultados teóricos em comparação com os obtidos nesses ensaios.

Os ensaios foram desenvolvidos no Laboratório de Estruturas do Departamento de Engenharia de Estruturas da Escola de Engenharia de São Carlos. Apenas os ensaios referentes à caracterização do aço foram realizados no Laboratório de Ensaios Mecânicos do Departamento de Materiais da EESC/USP.

\subsection{Seções transversais e processo de fabricação dos perfis}

As seções transversais dos perfis analisados são do tipo $U, U$ enrijecido e $Z$ enrijecido. Para as seções tipo $Z$ enrijecido foram realizados 4 ensaios com o objetivo de verificar o seu comportamento em caráter exploratório.

$\mathrm{Na}$ figura 4.1 está indicada a nomenclatura utilizada para as dimensões geométricas das seções transversais dos perfis.

A altura $h$ permaneceu constante em todas as seções e igual a 127 $\mathrm{mm}$. Da mesma forma, a largura da mesa $b$ foi mantida constante e igual a $50 \mathrm{~mm}$.
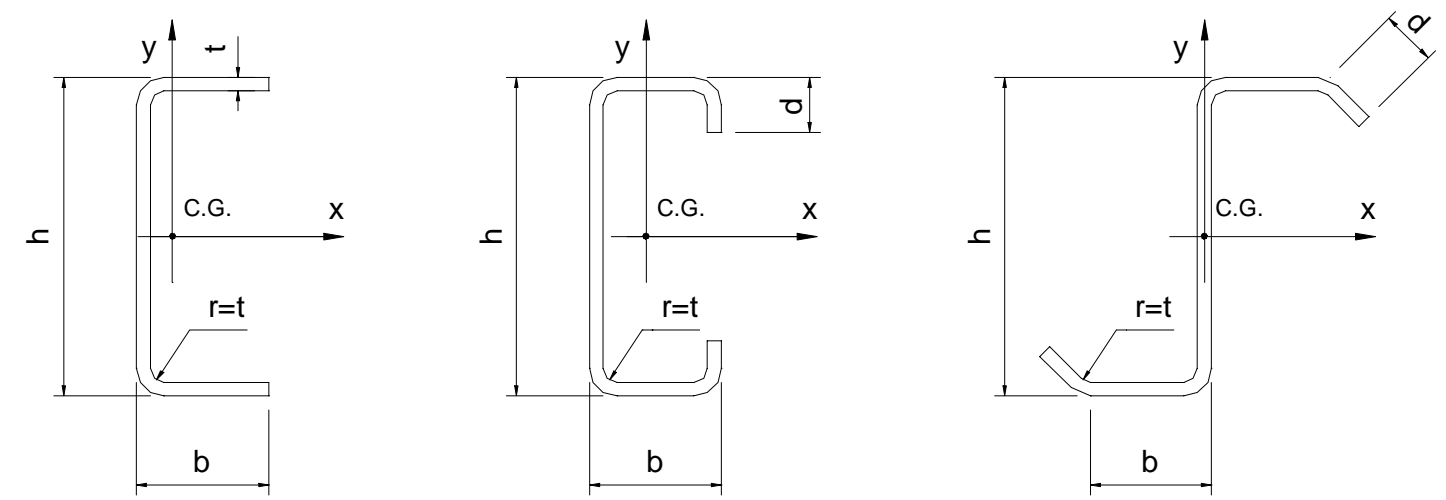

Figura 4.1: Seções transversais e nomenclatura. 
Os enrijecedores de borda são formados por virada simples de borda a $90^{\circ}$ para os perfis tipo $U$ enrijecido e por virada de borda a $45^{\circ}$ para os perfis tipo $Z$ enrijecido. Para estes últimos, o ângulo de $45^{\circ}$ facilita o seu transporte e armazenamento.

Para os perfis utilizados no programa experimental, as chapas de aço foram obtidas através de doação da USIMINAS para serem dobradas a frio na Indústria Comércio Ferro Soufer, em São João da Boa Vista (SP).

O dobramento deu-se por prensagem, em perfis com 6 metros de comprimento. O processo de prensagem foi escolhido dado o seu grande emprego na conformação de perfis em nossa região.

As propriedades geométricas das seções transversais para os vários perfis utilizados estão apresentadas na tabela 4.1. Estas propriedades estão referidas às dimensões nominais da seção transversal e aos eixos indicados na Figura 4.1.

Tabela 4.1: Propriedades geométricas das seções transversais estudadas.

\begin{tabular}{c|c|c|c|c|c|c|c|c|c|c|c}
\hline Perfil & $\begin{array}{c}\mathrm{A} \\
\left(\mathrm{cm}^{2}\right)\end{array}$ & $\begin{array}{c}\mathrm{I}_{\mathrm{x}} \\
\left(\mathrm{cm}^{4}\right)\end{array}$ & $\begin{array}{c}\mathrm{W}_{\mathrm{x}} \\
\left(\mathrm{cm}^{3}\right)\end{array}$ & $\begin{array}{c}\mathrm{r}_{\mathrm{x}} \\
(\mathrm{cm})\end{array}$ & $\begin{array}{c}\mathrm{I}_{\mathrm{y}} \\
\left(\mathrm{cm}^{4}\right)\end{array}$ & $\begin{array}{c}\mathrm{r}_{\mathrm{y}} \\
(\mathrm{cm})\end{array}$ & $\begin{array}{c}\mathrm{I}_{\mathrm{t}} \\
\left(\mathrm{cm}^{4}\right)\end{array}$ & $\begin{array}{c}\mathrm{r}_{0} \\
(\mathrm{~cm})\end{array}$ & $\begin{array}{c}\mathrm{C}_{\mathrm{w}} \\
\left(\mathrm{cm}^{6}\right)\end{array}$ & $\begin{array}{c}\mathrm{X} \\
(\mathrm{cm})\end{array}$ & $\begin{array}{c}\mathrm{x}_{0} \\
(\mathrm{~cm})\end{array}$ \\
\hline $\mathrm{U} 127 \times 50 \times 2,25$ & 4,94 & 118,8 & 18,7 & 4,90 & 11,7 & 1,54 & 0,083 & 5,88 & 322,8 & 1,20 & 2,85 \\
\hline $\mathrm{U} 127 \times 50 \times 3,00$ & 6,51 & 153,6 & 24,2 & 4,86 & 15,1 & 1,53 & 0,195 & 5,83 & 415,8 & 1,24 & 2,85 \\
\hline $\mathrm{U} 127 \times 50 \times 17 \times 2,25$ & 5,54 & 135,2 & 21,3 & 4,94 & 18,9 & 1,85 & 0,093 & 6,57 & 672,9 & 1,48 & 3,92 \\
\hline $\mathrm{U} 127 \times 50 \times 17 \times 3,00$ & 7,24 & 171,9 & 27,1 & 4,87 & 23,6 & 1,80 & 0,217 & 6,49 & 839,3 & 1,44 & 3,88 \\
\hline $\mathrm{Z127 \times 50 \times 17 \times 2,25}$ & 5,72 & 152,4 & 24,0 & 5,16 & 38,5 & 2,59 & 0,096 & 5,77 & 1032,8 & 0 & 0 \\
\hline $\mathrm{Z} 127 \times 50 \times 17 \times 3,00$ & 7,56 & 188,2 & 29,6 & 4,99 & 49,5 & 2,56 & 0,227 & 5,61 & 1316,0 & 0 & 0 \\
\hline
\end{tabular}

\subsection{Metodologia empregada}

Os ensaios à flexão foram realizados em perfis tipo $U, U$ enrijecido e, em caráter exploratório, Z enrijecido, utilizando-se duas diferentes espessuras de chapas: $2,25 \mathrm{~mm}$ e $3,00 \mathrm{~mm}$. 
Os vãos, carregamentos e travamentos laterais foram escolhidos prevendo-se os modos de falha de flambagem local e flambagem global para os perfis de aço formados a frio sujeitos à flexão.

Os perfis foram submetidos a dois diferentes vãos sob três diferentes tipos de situações de carregamento, conforme ilustra-se na figura 4.2. Os travamentos laterais intermediários estão indicados através de um $\mathrm{x}$.

Os pontos travados lateralmente, tanto nos apoios quanto os intermediários, foram obtidos através do ensaio dos perfis aos pares, possibilitando a ligação entre os mesmos, conforme esquema ilustrado na figura 4.3.

As forças foram aplicadas através de atuador hidráulico acionado manualmente. A intensidade da força foi aferida através da utilização de células de carga devidamente calibradas.

\section{Carregamento 1}
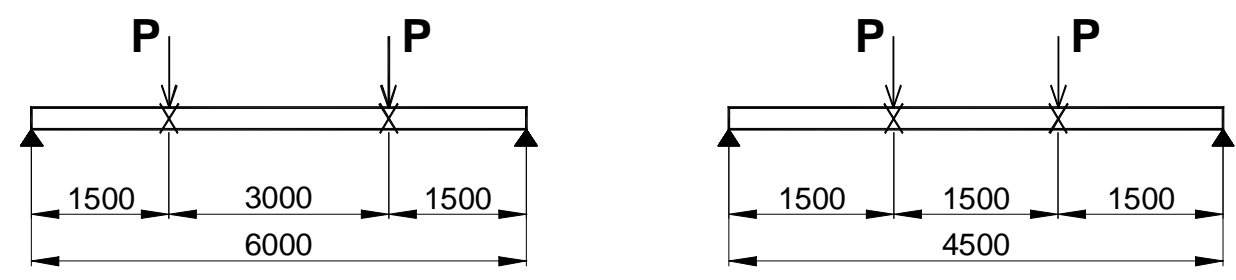

Carregamento 2
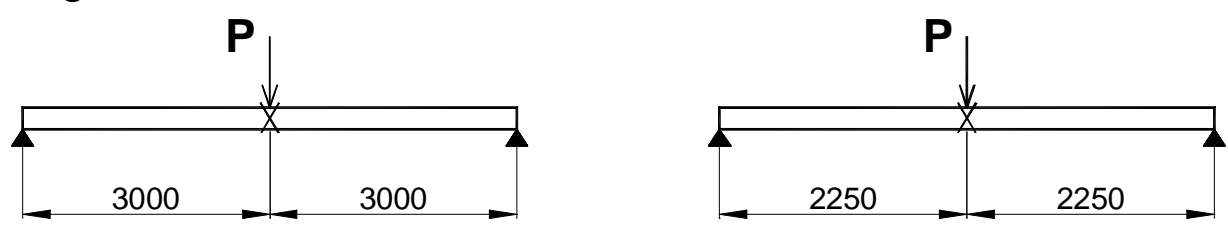

Carregamento 3
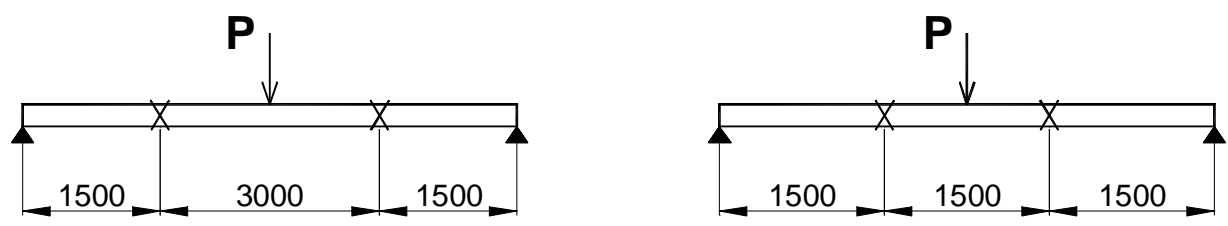

Figura 4.2: Esquemas de carregamentos para os ensaios à flexão. 


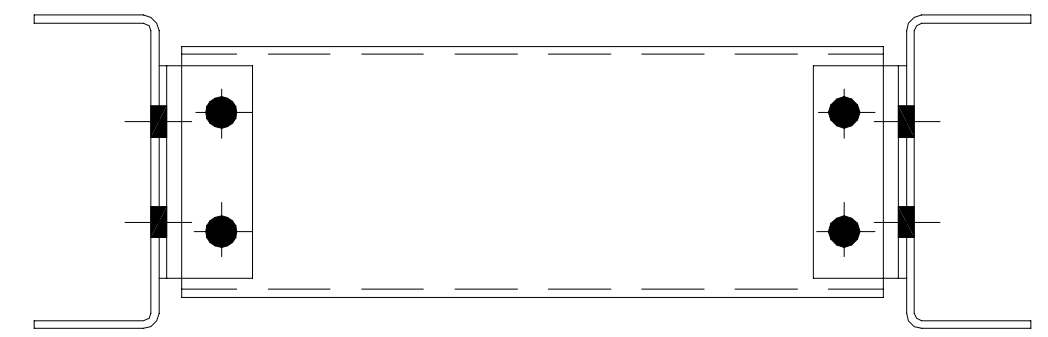

Figura 4.3: Detalhe do travamento lateral entre perfis.

Foram medidos os deslocamentos verticais ao longo do vão através de transdutores de deslocamento linear, marca Kyowa, posicionados a 1,5 metros de cada apoio e no meio do vão. Já os deslocamentos horizontais das mesas superior e inferior foram medidos na seção transversal no meio do vão para os esquemas de carregamentos 1 e 3 indicados na figura 4.2.

As deformações ocorridas foram medidas através de extensômetros elétricos de resistência posicionados nas mesas superior e inferior do perfil, na seção transversal no meio do vão, como ilustrado na figura 4.4.

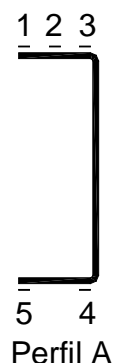

Perfil A

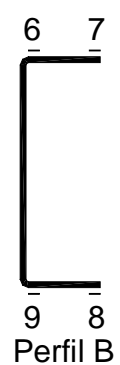

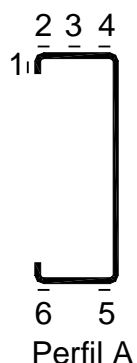

Perfil A

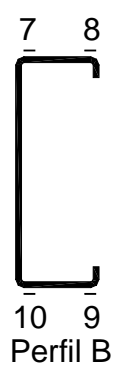

Perfil B

Figura 4.4: Posição dos extensômetros nas seções transversais dos perfis tipo U e U enrijecido.

Todas as leituras dos dados de força aplicada, de deslocamentos e de deformações ocorridas foram obtidas automaticamente por meio do sistema de aquisição de dados WIN5000 da Measurements Group, Inc. 
A aplicação das forças, de acordo com os dispositivos de ensaios utilizados, fez-se, aproximadamente, no centro de cisalhamento da seção transversal.

Na figura 4.5.a pode ser observada a aplicação das forças em pontos travados lateralmente, correspondente aos carregamentos 1 e 2, o atuador hidráulico, a célula de carga e os transdutores de deslocamentos posicionados.

$\mathrm{Na}$ figura 4.5.b ilustra-se a aplicação das forças através de cantoneiras fixadas às almas dos perfis, correspondendo ao esquema de carregamento 3 .

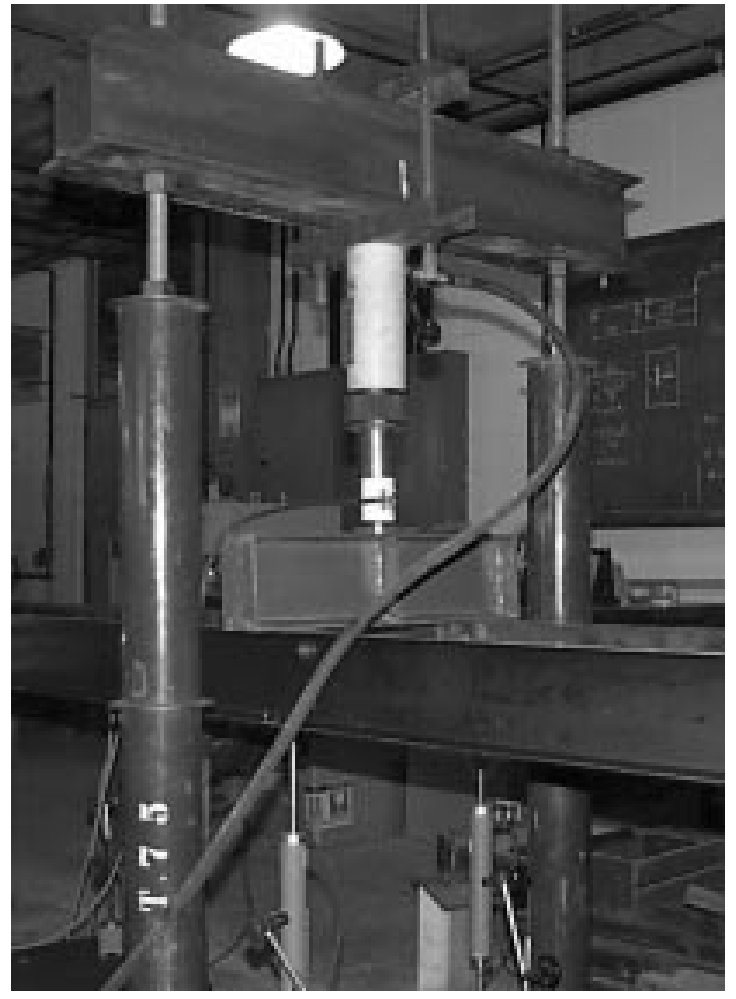

a)

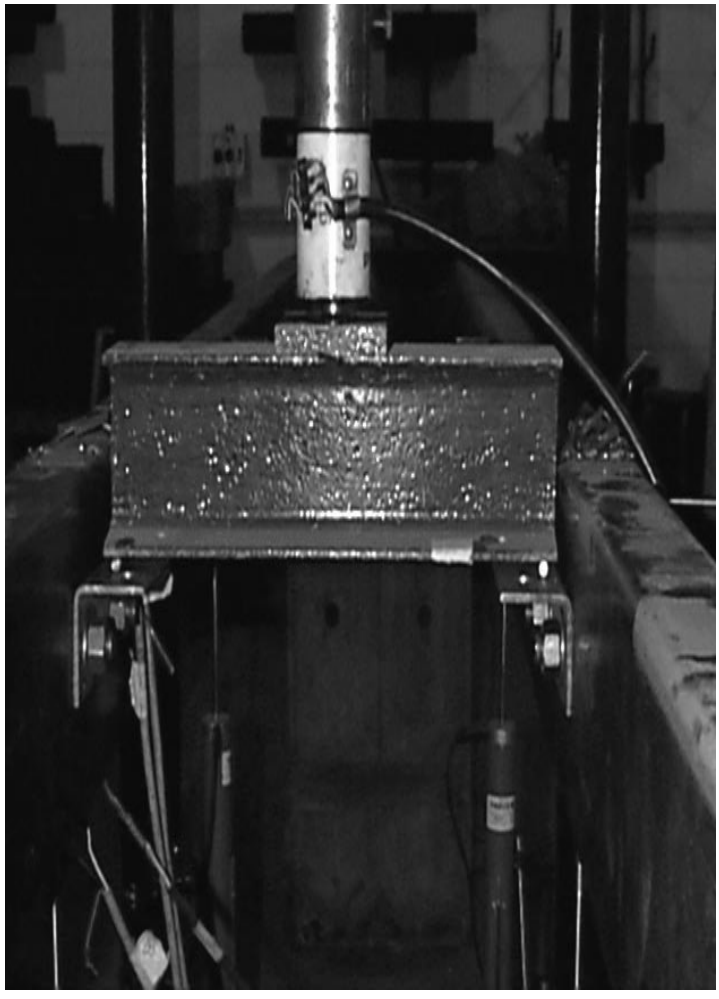

b)

Figura 4.5: Aplicação de forças e dispositivos de ensaios para os carregamentos utilizados. 
$\mathrm{Na}$ figura 4.6, a fotografia apresentada ilustra uma vista geral do ensaio podendo-se observar os pórticos de reação e o posicionamento dos transdutores de deslocamento.

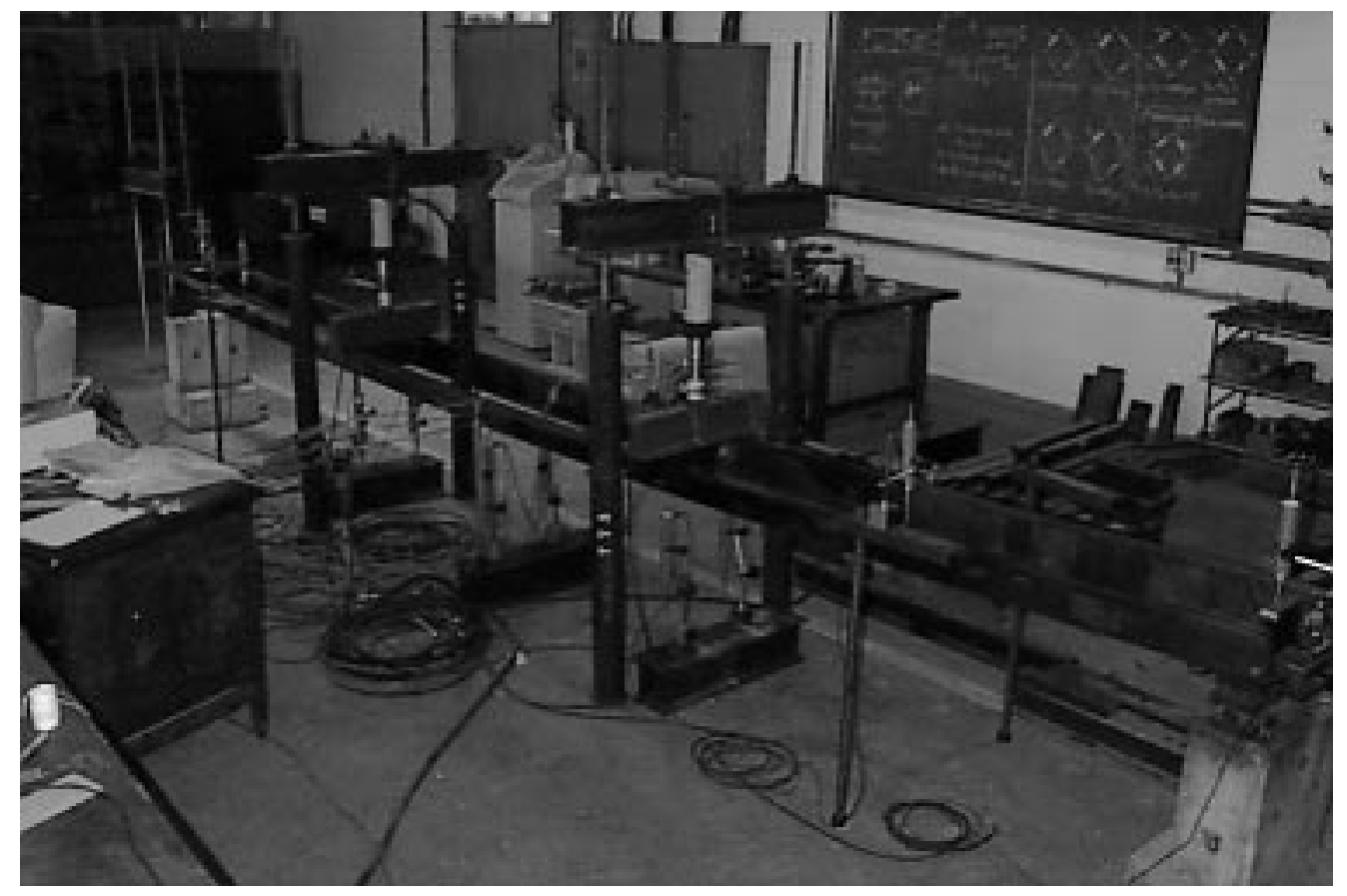

Figura 4.6: Vista geral de um ensaio em andamento.

\subsection{Caracterização do aço}

Para a determinação das propriedades mecânicas de interesse do aço empregado na confecção dos perfis, denominado comercialmente como USI-SAC 41, foram realizados ensaios à tração em 12 (doze) corpos de prova. Nesses ensaios foram obtidas a tensão limite de escoamento $\left(f_{y}\right)$ e a tensão limite de ruptura à tração $\left(f_{u}\right)$.

Os corpos de prova foram retirados de quatro chapas de aço antes da operação de dobramento (aço virgem), sendo duas chapas de espessura de 2,25 mm e as outras duas com espessura de 3,00 mm. Para cada chapa retirou-se três corpos de prova, em um total de 12. As dimensões nominais para esses corpos de prova estão indicadas na figura 4.7. 
Os ensaios à tração foram realizados em máquina universal de ensaio, junto ao Departamento de Materiais da Escola de Engenharia de São Carlos, da Universidade de São Paulo.

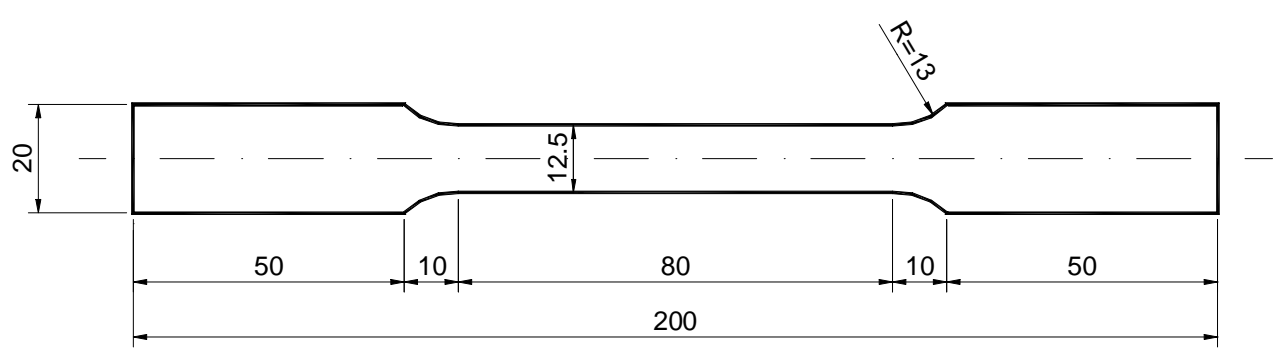

Figura 4.7: Dimensões nominais do corpo de prova para ensaio à tração.

Na tabela 4.2 estão apresentados os resultados obtidos na realização dos ensaios, cujos procedimentos utilizados foram aqueles preconizados pela norma ASTM 370-95 da American Society for Testing and Materials (ASTM). As chapas estão numeradas de 1 a 4 e os três corpos de prova correspondentes a mesma chapa são identificados pelas letras A, B e C.

O alongamento foi medido sobre a base de medida de $50 \mathrm{~mm}$ e todos os corpos de prova apresentaram patamar de escoamento definido, sendo o valor do módulo de elasticidade (E) admitido igual a $205.000 \mathrm{MPa}$, valor este normalizado para o aço.

Para fins de utilização futura, na determinação dos valores de resistência nominal da barra, serão utilizados os valores médios obtidos dos ensaios. 
Tabela 4.2: Características mecânicas obtidas no ensaio à tração.

\begin{tabular}{|c|c|c|c|c|c|c|}
\hline C.P. & $\begin{array}{c}\text { A } \\
\left(\mathrm{mm}^{2}\right)\end{array}$ & $\begin{array}{l}\text { Along. } \\
(\mathrm{mm})\end{array}$ & $\begin{array}{c}\text { Along. } \\
(\%)\end{array}$ & $\begin{array}{c}f_{y} \\
(\mathrm{Mpa})\end{array}$ & $\begin{array}{c}\mathrm{f}_{\mathrm{u}} \\
(\mathrm{MPa})\end{array}$ & $\bar{f} / f_{y}$ \\
\hline $1 \mathrm{~A}$ & 38,130 & 68,42 & 36,84 & 351,43 & 457,64 & 1,30 \\
\hline $1 \mathrm{~B}$ & 37,324 & 67,15 & 34,30 & 348,30 & 455,47 & 1,31 \\
\hline $1 \mathrm{C}$ & 38,440 & 66,75 & 33,50 & 340,79 & 450,05 & 1,32 \\
\hline $2 \mathrm{~A}$ & 28,125 & 66,56 & 33,12 & 34,44 & 4744,67 & 1,36 \\
\hline $2 B$ & 27,630 & 64,95 & 29,90 & 356,50 & 470,50 & 1,32 \\
\hline $2 \mathrm{C}$ & 27,540 & 64,45 & 28,90 & 357,66 & 475,67 & 1,33 \\
\hline $3 \mathrm{~A}$ & 28,409 & 66,85 & 33,70 & 332,64 & 461,12 & 1,39 \\
\hline 3B & 27,725 & 65,96 & 31,92 & 335,44 & 463,48 & 1,38 \\
\hline $3 C$ & 28,181 & 65,91 & 31,82 & 338,88 & 464,86 & 1,37 \\
\hline $4 \mathrm{~A}$ & 39,122 & 68,43 & 36,86 & 342,52 & 4454,99 & 1,33 \\
\hline $4 \mathrm{~B}$ & 38,626 & 66,08 & 32,16 & 328,79 & 450,47 & 1,37 \\
\hline $4 \mathrm{C}$ & 38,440 & 65,12 & 30,24 & 338,19 & 457,86 & 1,35 \\
\hline \multicolumn{3}{|c|}{ Média } & 32,77 & 343,30 & 461,40 & 1,34 \\
\hline \multicolumn{3}{|c|}{ Desvio Padrão } & 2,50 & 9,23 & 8,69 & 0,03 \\
\hline
\end{tabular}




\subsection{Imperfeições geométricas iniciais}

A medida das imperfeições longitudinais dos perfis exigiu 0 desenvolvimento de dispositivos específicos para este fim.

Para este estudo foi projetado e construído uma bancada consistindo de um mancal devidamente ajustado sobre um perfil tipo I, com $200 \mathrm{~mm}$ de altura, figura 4.8 .

Com o mancal desloca-se um transdutor de deslocamento linear a fim de se obter as leituras nos pontos de interesse, como se apresenta em detalhe na figura 4.9 .

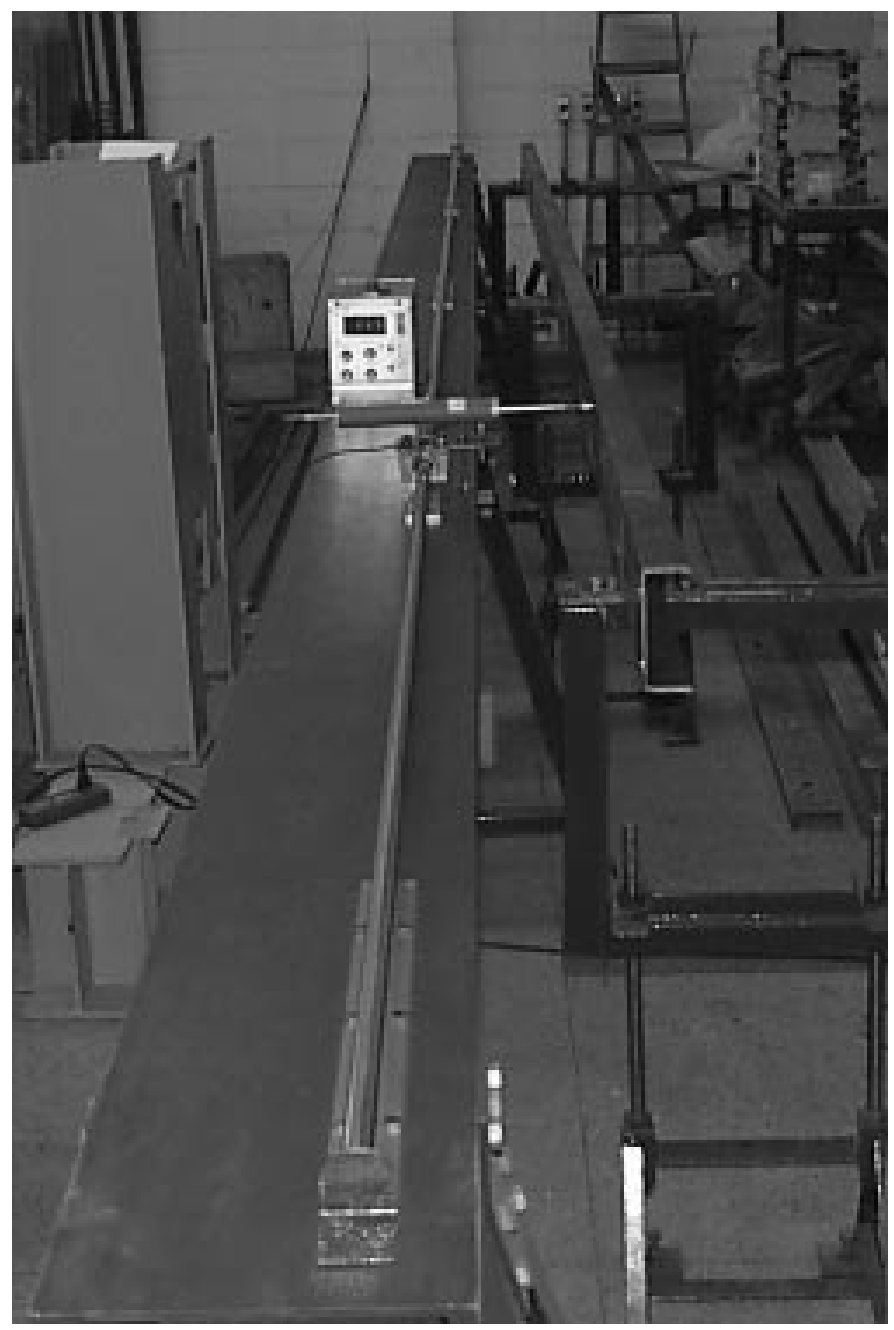

Figura 4.8: Dispositivo para leitura das imperfeições geométrica longitudinais. 


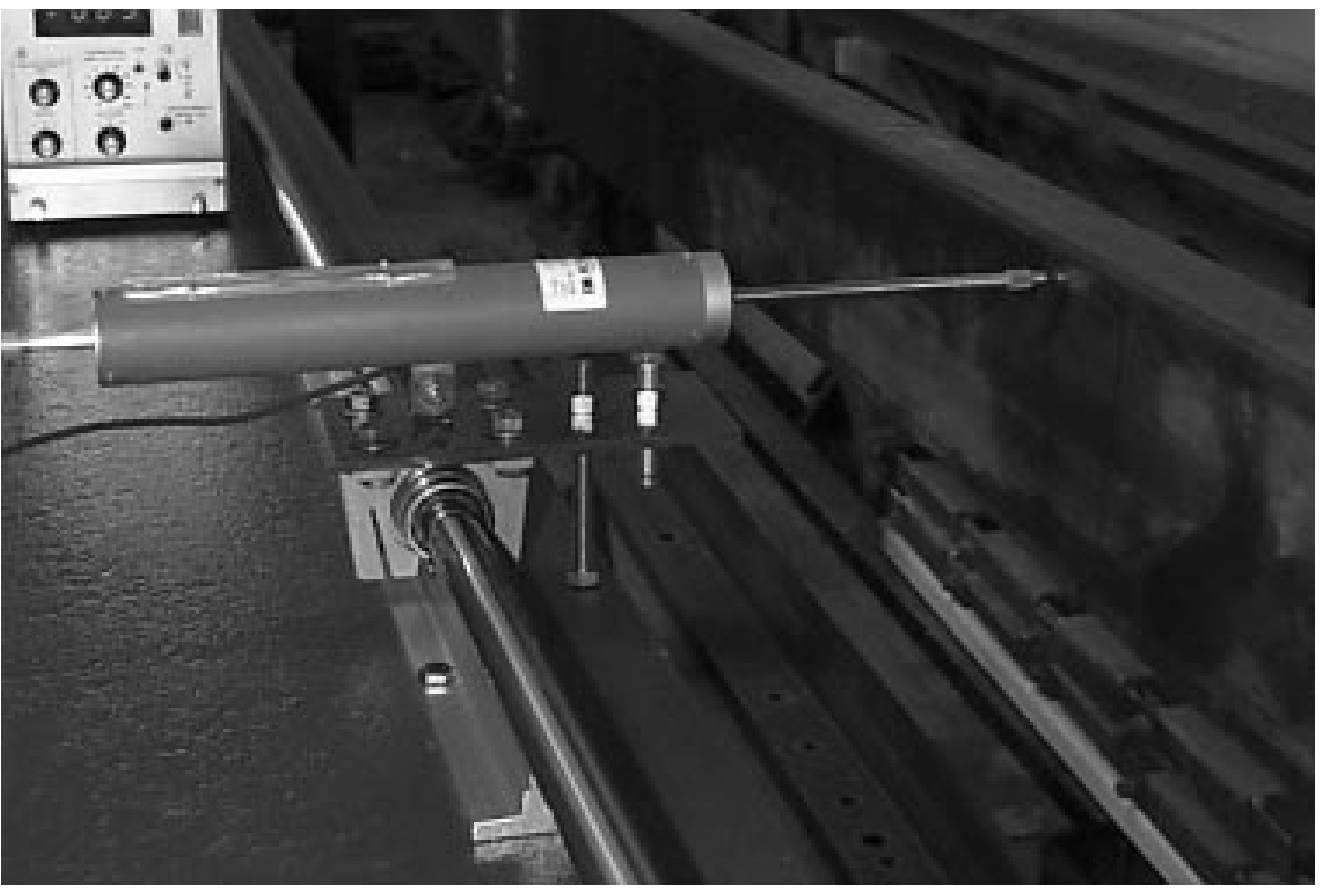

Figura 4.9: Detalhe da realização de medida da deslocada inicial do perfil.

O perfil foi posicionado de tal forma que as suas extremidades possuíam iguais distâncias aos eixos, constituindo um segmento de reta para referência das medidas.

Foram realizadas medições da forma deslocada longitudinal em dois perfis sendo um perfil tipo $U$ e outro um perfil tipo $Z$ enrijecido.

Nesta etapa do trabalho tinha-se como objetivo o desenvolvimento do dispositivo para uso em trabalhos futuros e uma verificação exploratória da forma da deslocada inicial para os perfis em questão.

Foram realizadas medidas em três linhas ao longo da alma e nas extremidades das mesas superior e inferior do perfil, figura 4.10. Essas medidas foram feitas a cada $300 \mathrm{~mm}$, sendo o transdutor de deslocamento posicionado manualmente ao longo de cada ponto. 

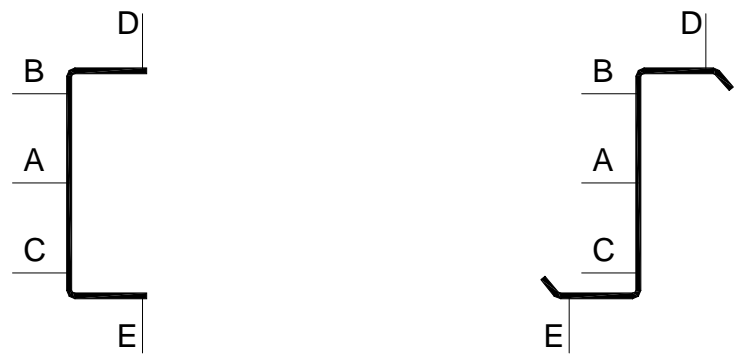

Figura 4.10: Posições para medidas das deslocadas longitudinais

A figura 4.11 apresenta formas deslocadas referentes ao perfil tipo $U$. Pode-se observar que as imperfeições geométricas mostram-se na forma de uma ou mais semi-ondas. O valor máximo medido foi de $6,8 \mathrm{~mm}$, na geratriz segundo a linha $B$.

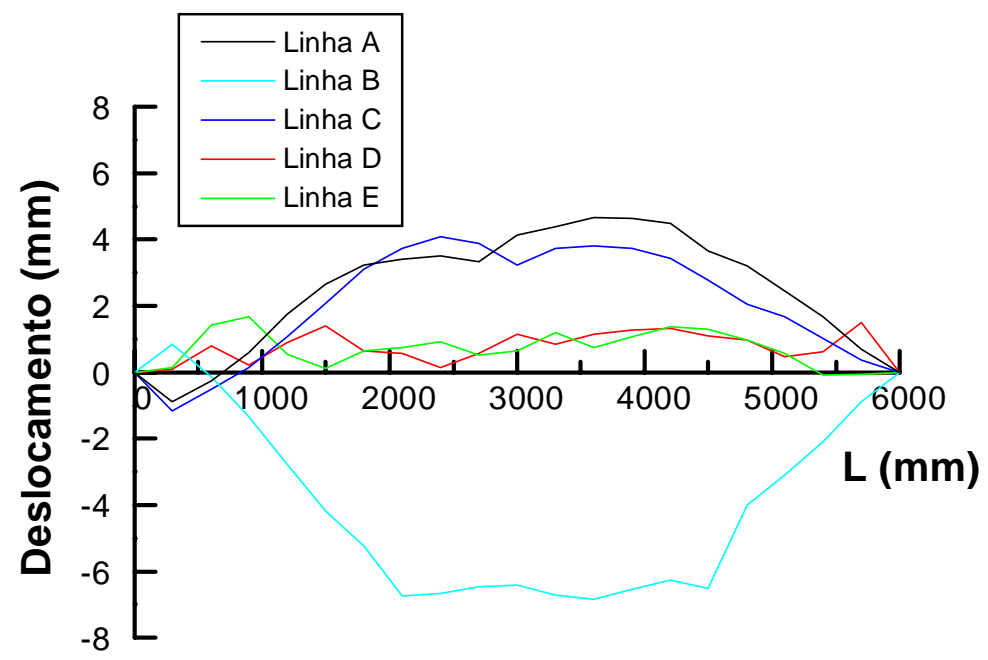

Figura 4.11: Imperfeições geométricas para o perfil tipo U.

Na figura 4.12 pode-se observar os valores encontrados para o perfil tipo Z enrijecido.

Como observado para o perfil tipo $U$, também observar-se a presença de uma ou mais semi-ondas na forma das imperfeições geométricas. O valor máximo medido foi de $3,8 \mathrm{~mm}$, na geratriz segundo a linha $E$. 


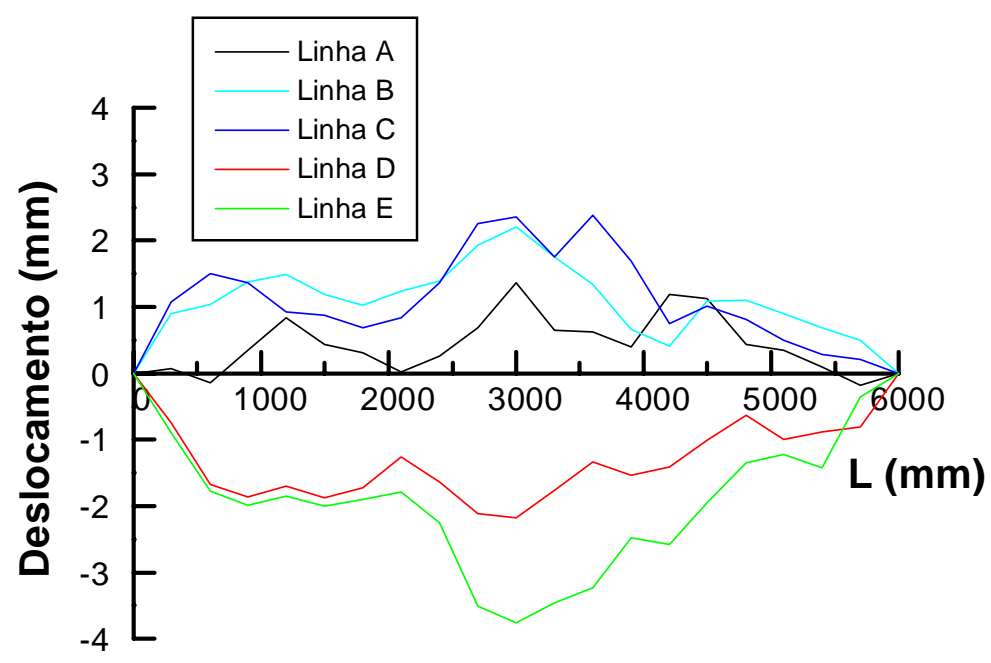

Figura 4.12: Imperfeições geométricas para o perfil tipo Z.

Analisando-se os resultados obtidos pode-se verificar que os valores das imperfeições geométricas longitudinais não ultrapassam, aproximadamente, a relação $1 / 1300$ do seu comprimento, tendo como exceção a linha $B$ do perfil tipo $U$ para o qual encontrou-se a relação aproximada de $1 / 880$.

A relação de $1 / 1000$ do comprimento é o limite estabelecido em diversas normas de dimensionamento e em catálogos de fabricantes.

Comparativamente ao perfil tipo $\mathrm{U}$, o perfil tipo $\mathrm{Z}$ apresentou maiores deslocamentos nas bordas enrijecidas, o que deve-se ao fato de ali ocorrer mais um dobra e esta a $45^{\circ}$. Esses valores obtidos estão em acordo com aqueles obtidos por Rodrigues (1993).

Dessa forma, o dispositivo desenvolvido para as medidas das imperfeições geométricas iniciais mostrou-se adequado ao fim proposto e presta-se ao levantamento das imperfeições iniciais de perfis metálicos em geral. Como desenvolvimento futuro, torna-se interessante a automatização da aquisição dos dados, permitindo a execução das medidas de forma mais rápida e com o devido tratamento estatístico realizado imediatamente após a aquisição dos dados. 
Previamente à realização dos ensaios, foram realizadas as medidas para a obtenção das dimensões características dos perfis, verificando-se as variações das medidas reais com as dimensões nominais.

As dimensões da seção transversal do perfil foram obtidas através de paquímetro com precisão de $0,01 \mathrm{~mm}$. As medidas foram realizadas nas seções transversais das extremidades, próximas aos apoios, e na seção transversal no meio do vão.

$\mathrm{Na}$ tabela 4.3 encontram-se os valores médios obtidos para os perfis tipo $U$ e $U$ enrijecido. Pode-se observar que as maiores variações encontram-se nas mesas e nos enrijecedores, sendo que, para esses a dimensão real ficou sempre abaixo da dimensão nominal (17 mm).

Tabela 4.3: Variações dimensionais para os perfis

\begin{tabular}{l|c|c|c|c|c}
\hline & $\begin{array}{c}\text { Altura } \\
(\mathrm{mm})\end{array}$ & $\begin{array}{c}\text { Mesa Sup. } \\
(\mathrm{mm})\end{array}$ & $\begin{array}{c}\text { Mesa Inf. } \\
(\mathrm{mm})\end{array}$ & $\begin{array}{c}\text { Enrijecedor } \\
\text { Sup. (mm) }\end{array}$ & $\begin{array}{c}\text { Enrijecedor } \\
\text { Inf. (mm) }\end{array}$ \\
\hline $\mathrm{N}^{0}$ de Perfis & 60 & 60 & 60 & 8 & 8 \\
\hline Média & 127,809 & 50,078 & 50,144 & 16,075 & 15,920 \\
\hline Desv. Padrão & 0,287 & 0,838 & 1,524 & 1,016 & 1,395 \\
\hline
\end{tabular}




\subsection{Modelos ensaiados}

Os ensaios foram realizados em 32 conjuntos, correspondendo a um total de 64 perfis, cuja distribuição entre os 3 esquemas de carregamento previstos está apresentada na tabela 4.4.

Tabela 4.4: Perfis ensaiados à flexão.

\begin{tabular}{|c|c|c|c|}
\hline Perfil & $\begin{array}{l}\text { Vão } \\
\text { (m) }\end{array}$ & $\begin{array}{c}\text { Esquema de } \\
\text { Carregamento } \\
\text { (figura 4.1) }\end{array}$ & $\begin{array}{c}\text { Total de Ensaios } \\
\text { Realizados }\end{array}$ \\
\hline \multirow{3}{*}{ U127x50×3,00 } & \multirow{3}{*}{6,0} & 1 & $10^{(*)}$ \\
\hline & & 2 & 6 \\
\hline & & 3 & 6 \\
\hline \multirow{3}{*}{ U127x50×3,00 } & \multirow{3}{*}{4,5} & 1 & 6 \\
\hline & & 2 & 6 \\
\hline & & 3 & 6 \\
\hline \multirow[t]{2}{*}{ U127×50x2,25 } & \multirow[t]{2}{*}{6,0} & 1 & $8^{(*)}$ \\
\hline & & 2 & 4 \\
\hline U127x50x17×3,00 & 6,0 & 2 & 4 \\
\hline U127×50x17×2,25 & 6,0 & 1 & 4 \\
\hline $\mathrm{Z127 \times 50 \times 17 \times 2,25}$ & 6,0 & 1 & $4^{(*)}$ \\
\hline \multicolumn{3}{|l|}{ TOTAL } & 64 \\
\hline
\end{tabular}

Os perfis foram simplesmente apoiados em blocos rígidos de concreto sobre os quais foram posicionadas chapas e cilindros de aço, figura 4.13, permitindo-se, assim, assumir a hipótese de viga simplesmente apoiada. 


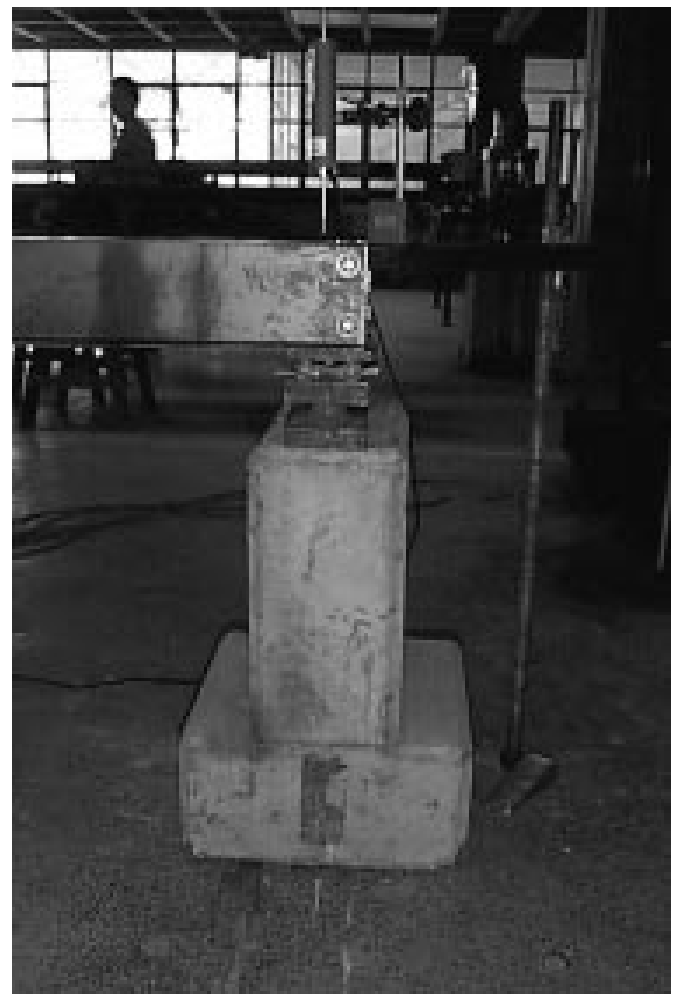

a)

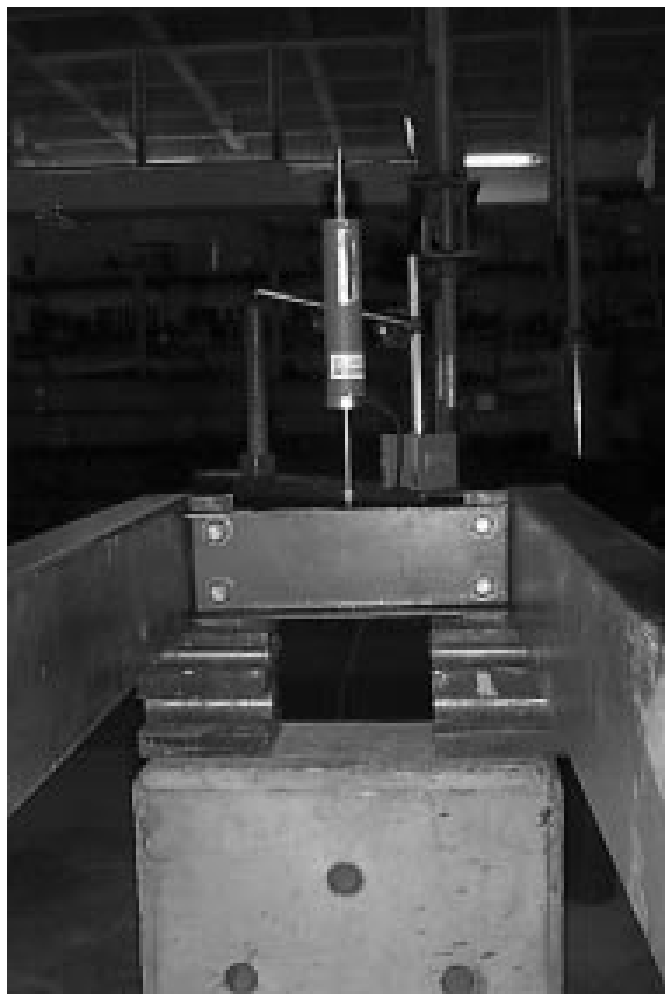

b)

Figura 4.13: Vista do apoio. a) Vista lateral. b)Vista frontal, interna.

Os transdutores de deslocamento linear foram posicionados como ilustrado na figura 4.14, correspondentes aos números de 3 até 13. As células de carga correspondem aos números 1 e 2, enquanto que, os extensômetros elétricos de resistência receberam os números a partir do 21 , crescendo conforme sequência indicada na figura 4.4.

Essa numeração é correspondente aos números dos canais utilizados no sistema para aquisição de dados.

Os deslocamentos horizontais indicados na figura 4.14.b, foram medidos com o auxílio de fios de aço longos presos em uma extremidade à alma do perfil e ligados aos transdutores em sua outra extremidade. Assim, a influência do deslocamento vertical do conjunto pode ser minimizada.

Esses deslocamentos horizontais permitiram o cálculo da rotação da seção transversal em torno do seu centro de torção. A diferença entre os deslocamentos dividida pela distância entre os pontos de medidas fornece $o$ valor da rotação desejada. 
A aplicação de forças fez-se através do incremento de carga de valor aproximadamente igual a $10 \%$ da força última prevista. A cada acréscimo era feita a leitura dos deslocamentos e deformações ocorridas. Previamente, era feita a escorva, de valor igual a $10 \%$ da força última prevista, para posterior início do ensaio propriamente dito.

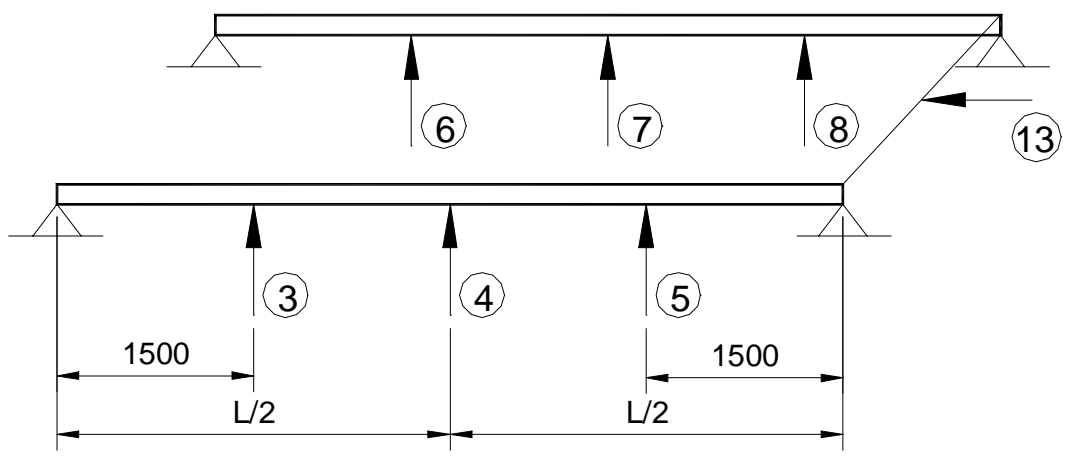

(a)
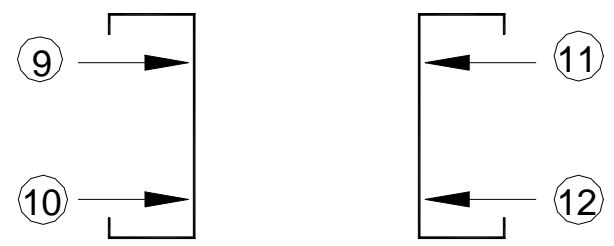

(b)

Figura 4.14: Transdutores de deslocamento. a) Verticais. b) Horizontais no meio do vão.

Os conjuntos (pares de perfis) ensaiados receberam a identificação correspondente ao número da sequência do ensaio realizado. Os perfis pertencentes ao mesmo conjunto receberam a letra $A$ correspondente ao perfil da esquerda, e a letra $B$ para o perfil da direita, referenciando-se à figura 4.14b.

Inicialmente foram realizados ensaios em 6 conjuntos, sendo quatro conjuntos de perfis tipo $U$ e dois de perfis tipo $Z$ enrijecido, totalizando 12 perfis ensaiados. Esses ensaios preliminares tiveram como objetivo a verificação da funcionabilidade dos dispositivos e instrumentação adotados.

Posicionados os perfis pertencentes ao conjunto eram efetuadas as medidas da sua altura, da sua largura e da altura do enrijecedor para os 
perfis enrijecidos. Essas medidas foram feitas nas extremidades dos perfis e na sua seção transversal central, junto aos pontos onde estavam colados os extensômetros elétricos de resistência.

Durante a fase de escorvamento do conjunto foram observados os deslocamentos transversais dos pontos instrumentados, verificando-se os valores obtidos. Dessa forma, pela simetria de posição e carregamento, verificava-se a necessidade ou não de ajustes preliminares à realização do ensaio. Confirmada a posição correta do conjunto e dos dispositivos necessários, o ensaio tinha seu início.

De acordo com os esquemas de carregamentos e travamentos laterais definidos, pode-se determinar previamente as forças últimas teóricas para os perfis ensaiados, bem como o provável modo de falha.

Em ordem de tratar este problema, vários procedimentos alternativos, normalizados ou não, podem ser utilizados. Em vista disso, os procedimentos de projeto empregados para o dimensionamento dos perfis de aço formados a frio são aqueles utilizados em normas estrangeiras, principalmente a norma do AISI e o Eurocode, com predominância de emprego da primeira. Esses resultados estão apresentados no capítulo anterior, tabela 3.1.

Além disso, a força crítica correspondente pode ser calculada diretamente a partir da resolução das equações diferenciais, conforme os resultados obtidos no capítulo 3.

\subsection{Apresentação dos resultados}

$\mathrm{Na}$ tabela 4.5 apresentam-se os resultados correspondentes à força última $\left(\mathrm{P}_{\text {último}}\right)$ obtida e o modo de falha ocorrido para todos os conjuntos ensaiados.

As forças últimas $\left(\mathrm{P}_{\text {último }}\right)$ apresentadas na tabela 4.5 referem-se aos valores médios dos resultados observados para os conjuntos ensaiados. 
Tabela 4.5: Resultados obtidos nos ensaios à flexão.

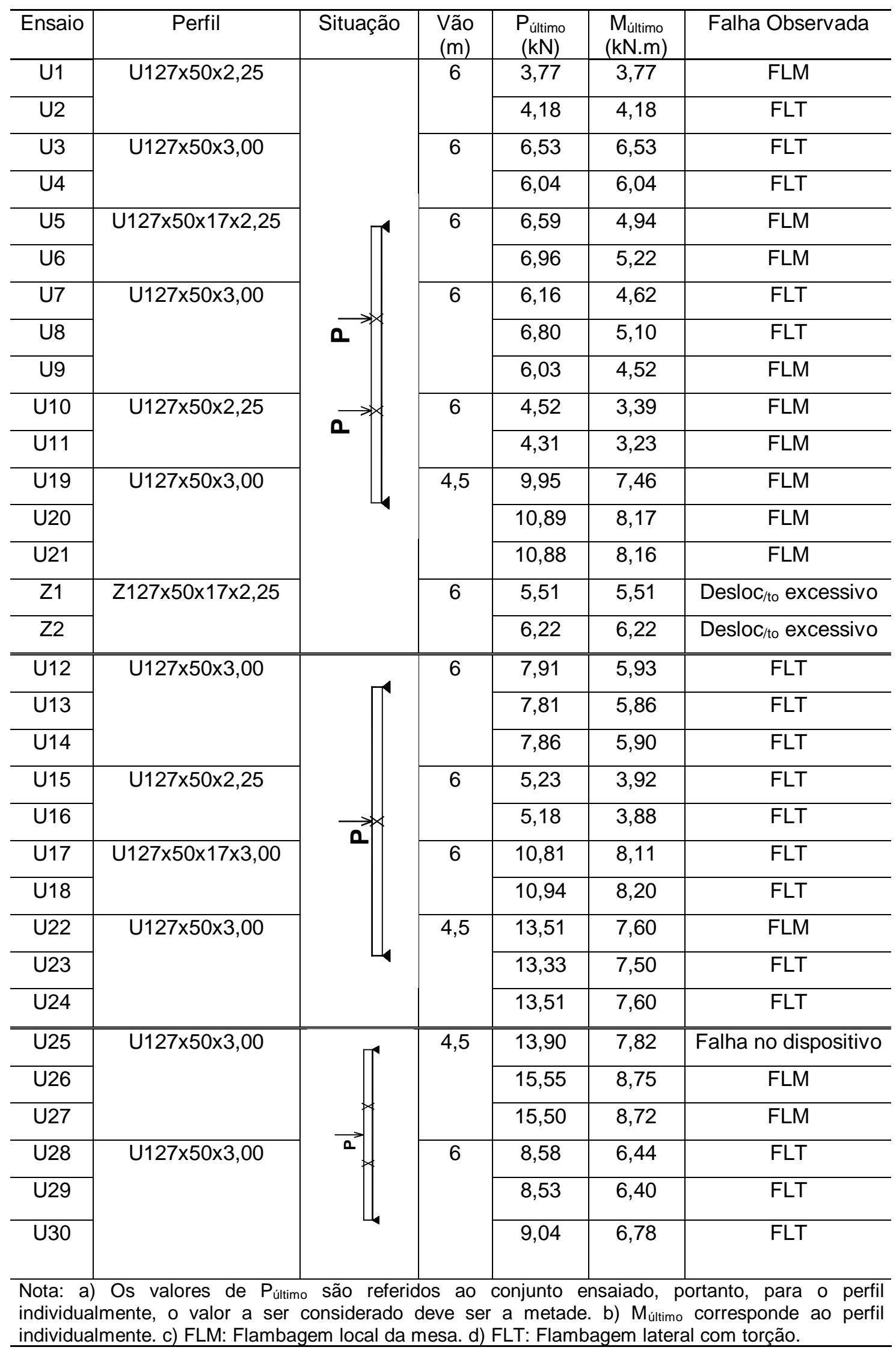


Por força última entende-se aquela para a qual verificou-se a ruína total ou parcial do conjunto ensaiado. Assim, quando da ocorrência do estado limite de flambagem local da mesa (FLM), o perfil perde a sua posição original e não mais pode ser carregado, caracterizando a sua ruína e como consequência, o valor de $\left(P_{\text {útimo }}\right)$.

Em se tratando do estado limite último de flambagem lateral com torção, o deslocamento lateral e o giro excessivos foram tomados como limites para o fim do carregamento, ou seja, para pequenos acréscimos da força aplicada observava-se um grande acréscimo nas grandezas medidas. Isto ficou evidenciado pelo processo de aplicação de forças e acompanhamento dos valores correspondentes através do sistema de aquisição de dados.

$\mathrm{Na}$ tabela 4.5 encontram-se os valores do momento fletor máximo $\left(M_{\text {útitimo }}\right)$ correspondente ao valor medido de $\left(P_{\text {útimo }}\right)$ tendo-se em vista o esquema de carregamento utilizado. Note-se que o valor de $P_{\text {último }}$ corresponde ao conjunto, enquanto que, o valor correspondente de $\mathrm{M} u ́$ útimo está referido ao perfil individualmente.

A similaridade dos resultados obtidos para os conjuntos de mesmas características indicam uma boa condução dos ensaios realizados e o bom comportamento do material sob as condições dos ensaios.

A figura 4.15 ilustra o modo de falha devido a flambagem local da mesa ocorrida para o conjunto $\mathrm{U} 2$, perfil $B$. Observa-se que a sua ocorrência dá-se no meio do vão, na seção transversal instrumentada.

$\mathrm{Na}$ figura 4.16 pode ser observado o modo de falha devido à flambagem lateral com torção ocorrido para os conjuntos U3 e U13. No primeiro tem-se as forças $P$ aplicadas a cada um terço de vão, enquanto no conjunto U13 a aplicação da força $P$ ocorre somente no meio do vão. Nesses casos, os travamentos laterais, além daqueles nos apoios, ocorrem nos pontos de aplicação da força.

As figuras anteriormente mencionadas são ilustrativas dos dois modos de falhas que caracterizaram o desenvolvimento dos ensaios. 


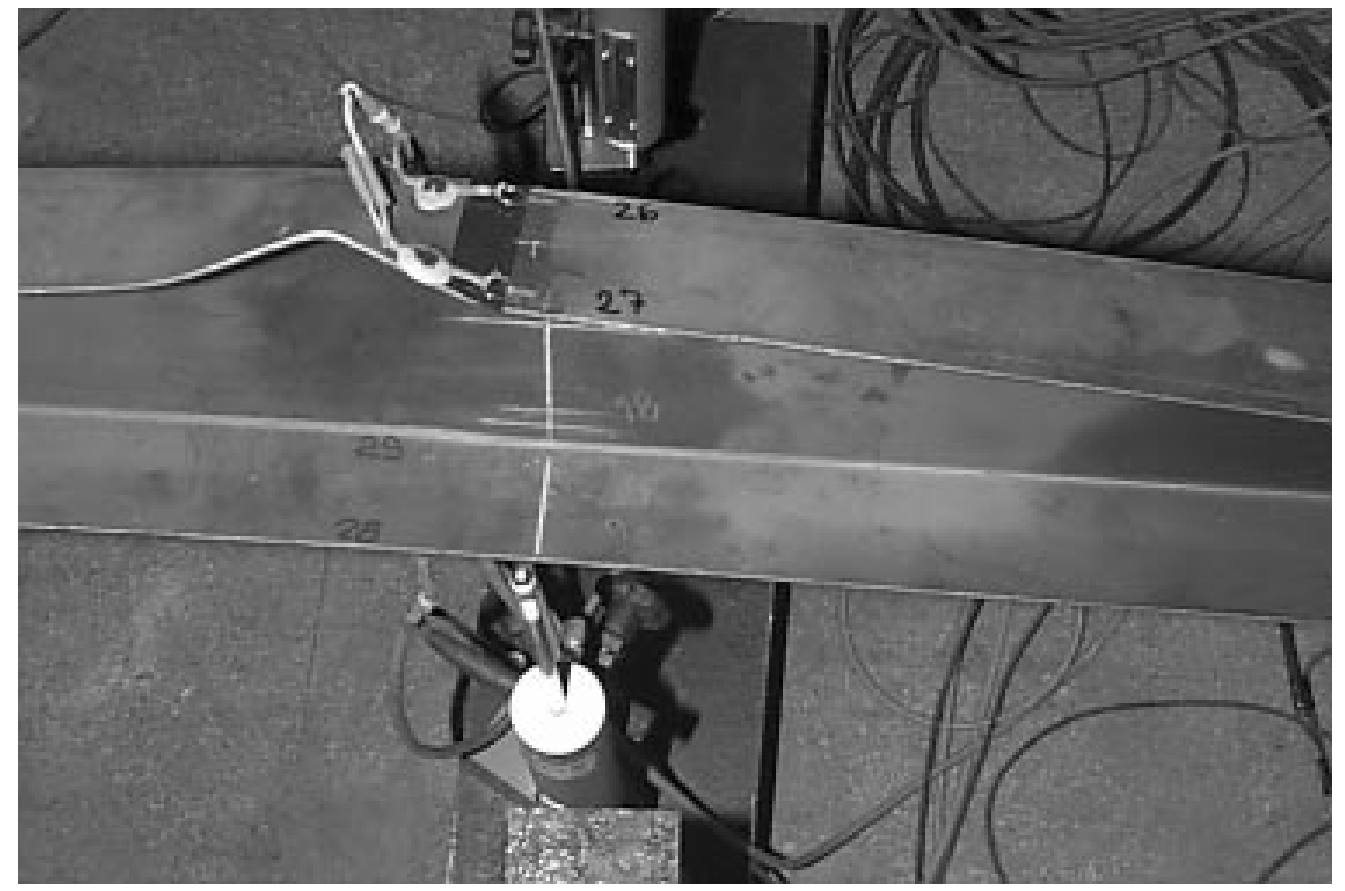

Figura 4.15: Flambagem Local da Mesa (FLM) para o perfil U2B.

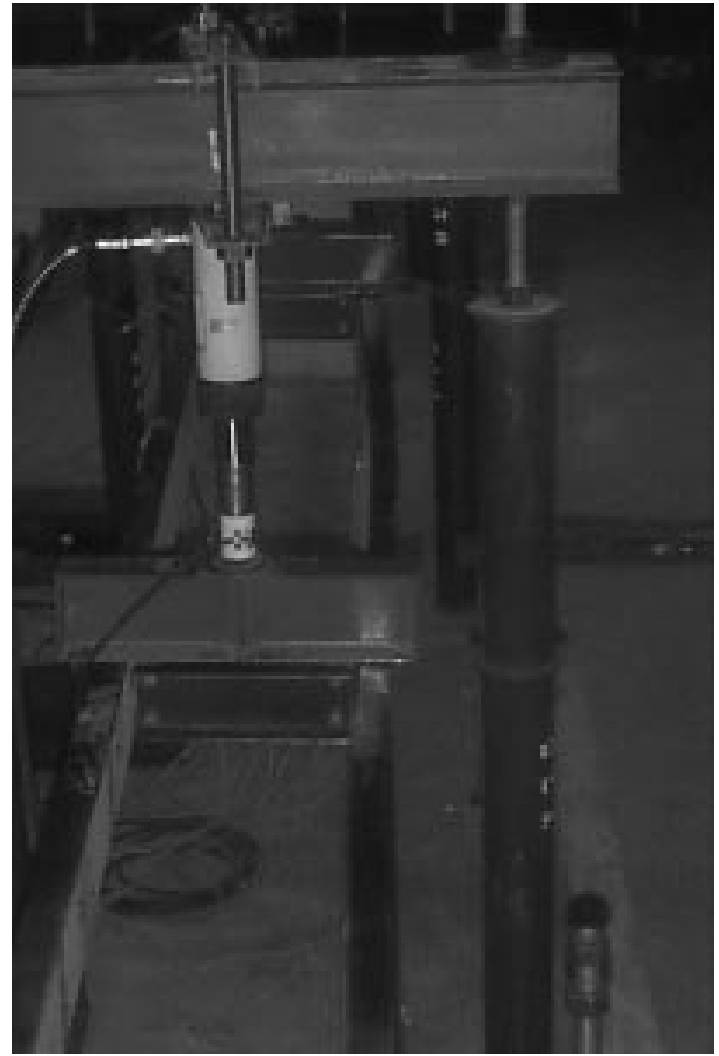

a)

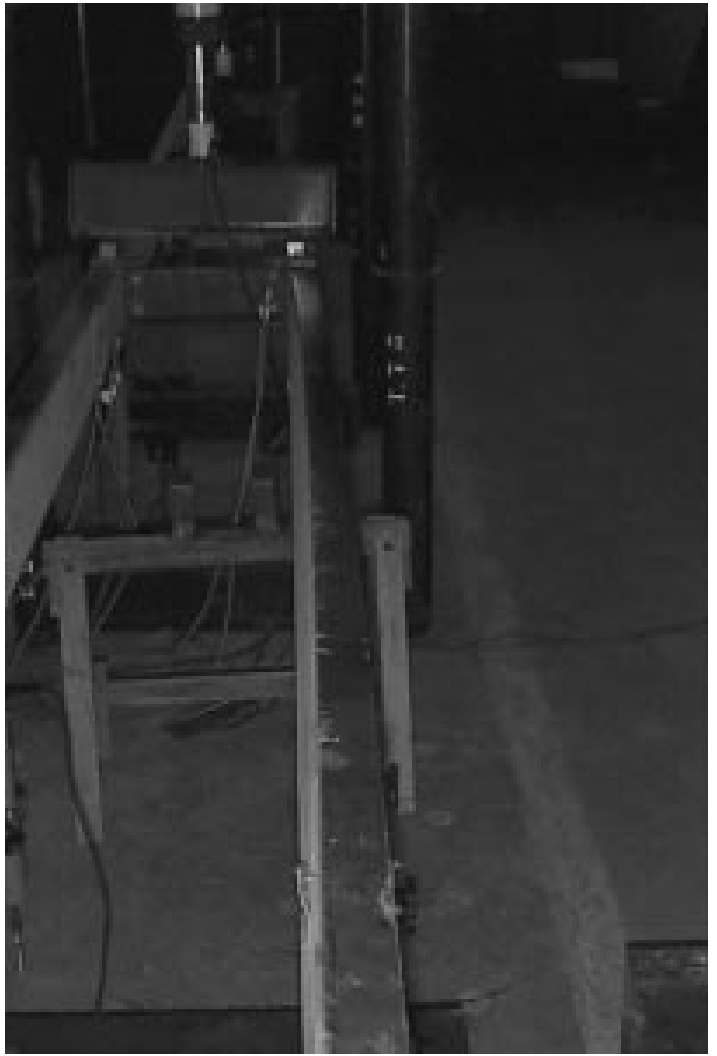

b)

Figura 4.16: Flambagem lateral com torção.
a) Conjunto U3.
b) Conjunto U13 
No caso dos perfis tipo $Z$ enrijecido, os ensaios foram interrompidos em função dos deslocamentos sofridos pelo conjunto, embora, como poderá ser verificado adiante, já caracterizando-se o início de flambagem lateral com torção. Ressalta-se, mais uma vez, que os ensaios nos perfis tipo $Z$ enrijecido foram tidos como exploratórios, com a finalidade de se obter alguns resultados preliminares sobre o comportamento de tais perfis para usos futuros.

Os principais resultados obtidos nos ensaios estão apresentados sobre a forma de gráficos relacionando força aplicada contra deformações e força aplicada contra deslocamentos. Esses gráficos são representativos dos esquemas de carregamento e tipos de perfis utilizados nos ensaios.

\subsubsection{Esquema de carregamento 1}

$\mathrm{Na}$ tabela 4.6 apresentam-se os modos de falha previstos contra aqueles observados nos ensaios referentes a este esquema de carregamento.

Tabela 4.6: Modos de falha previstos e observados (carregamento 1).

\begin{tabular}{|c|c|c|c|c|c|}
\hline Ensaio & Perfil & Situação & Vão $(m)$ & Falha Prevista & Falha Observada \\
\hline U1 & \multirow[t]{2}{*}{ U127×50x2,25 } & \multirow{4}{*}{$\Gamma$} & \multirow[t]{2}{*}{6} & \multirow[t]{2}{*}{ FLM } & FLM \\
\hline $\mathrm{U} 2$ & & & & & FLT \\
\hline U3 & \multirow[t]{2}{*}{ U127×50×3,00 } & & \multirow[t]{2}{*}{6} & \multirow[t]{2}{*}{ FLM } & FLT \\
\hline U4 & & & & & FLT \\
\hline U5 & \multirow[t]{2}{*}{ 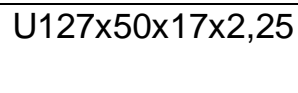 } & \multirow{5}{*}{ 口 } & \multirow[t]{2}{*}{6} & \multirow[t]{2}{*}{ FLT } & FLM \\
\hline U6 & & & & & FLM \\
\hline U7 & \multirow[t]{3}{*}{ U127×50x3,00 } & & \multirow[t]{3}{*}{6} & \multirow[t]{3}{*}{ FLT } & FLT \\
\hline U8 & & & & & FLT \\
\hline U9 & & & & & FLM \\
\hline U10 & \multirow[t]{2}{*}{ U127×50x2,25 } & & \multirow[t]{2}{*}{6} & \multirow[t]{2}{*}{ FLM } & FLM \\
\hline U11 & & & & & FLM \\
\hline U19 & \multirow[t]{3}{*}{ U127×50×3,00 } & 4 & \multirow[t]{3}{*}{4,5} & \multirow[t]{3}{*}{ FLM } & FLM \\
\hline U20 & & & & & FLM \\
\hline U21 & & & & & FLM \\
\hline $\mathrm{Z1}$ & \multirow[t]{2}{*}{ Z127×50x17×2,25 } & & \multirow[t]{2}{*}{6} & \multirow[t]{2}{*}{ FLT } & 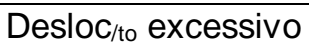 \\
\hline $\mathrm{Z2}$ & & & & & Desloc/to excessi $_{\text {to }}$ \\
\hline
\end{tabular}


Nessa tabela pode-se observar que os modos de falha previsto e ocorrido não são os mesmos para alguns conjuntos ensaiados, sendo que, enquanto era esperado a ocorrência da flambagem local da mesa (FLM) foi observado a ocorrência da flambagem lateral com torção (FLT), especificamente para o conjunto U2.

Como justificativa para a ocorrência deste fato deve ser observado o gráfico apresentado na figura 4.17, correspondente ao conjunto U2.

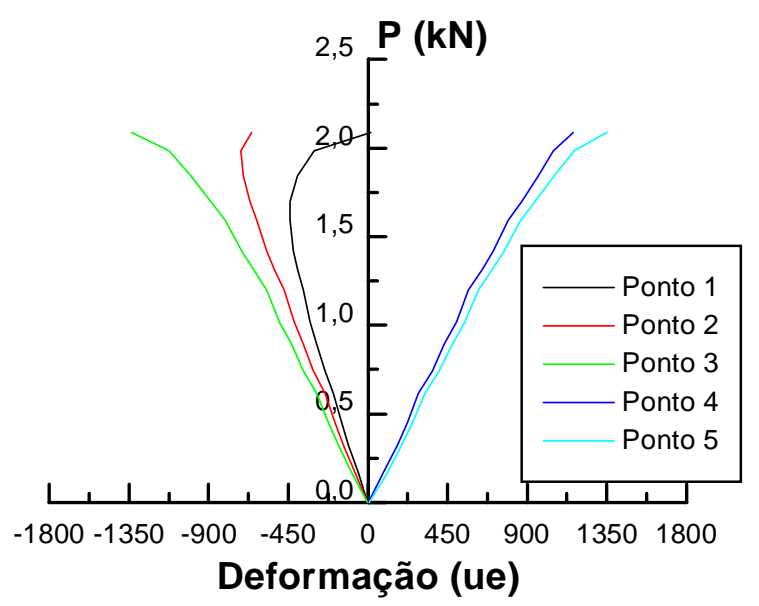

a)

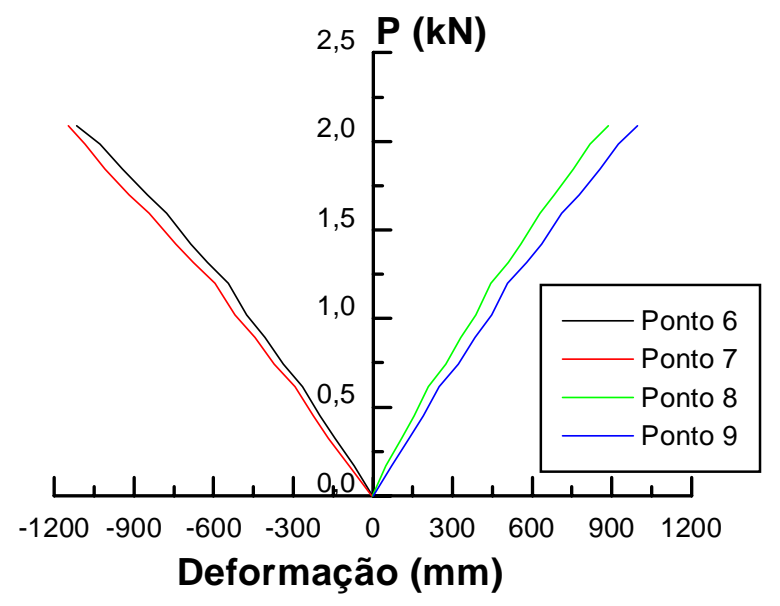

b)
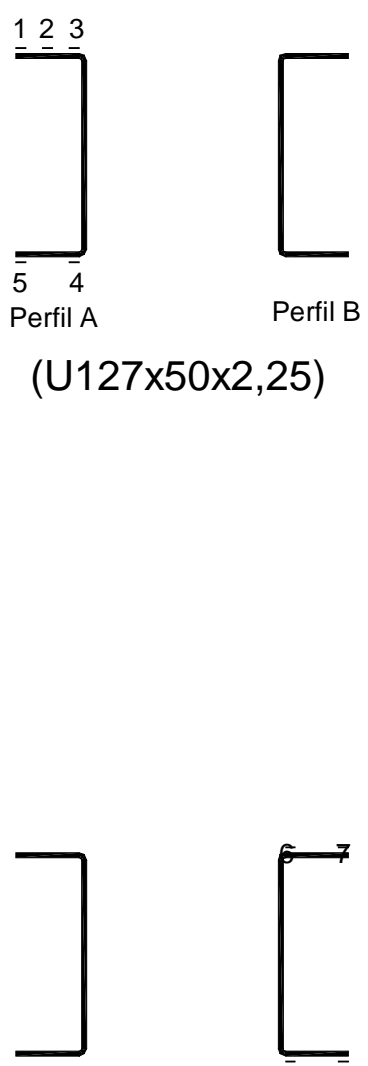

Perfil A Perfil B

(U127x50x2,25)

Figura 4.17: Gráficos força aplicada x deformação: Conjunto U2.
a) Perfil U2A.
b) Perfil U2B. 
Este conjunto teve como falha a ocorrência da flambagem lateral com torção, evidenciada no perfil A.

Note-se que a ocorrência da FLT está condicionada a deslocamentos horizontais e giro em torno do centro de torção da seção transversal. Assim, na seção transversal surgem tensões que superpõe-se às tensões da flexão vertical e com isso, a tensão de compressão na mesa deixa de ser uniforme, consequentemente, o coeficiente de flambagem utilizado no cálculo da largura efetiva $(k=0,43)$ passa a ter novo valor, sendo superior ao adotado.

Uma discussão mais detalhada destes resultados é apresentada no final do capítulo, em conjunto com os demais esquemas de carregamento utilizados.

A figura 4.18 ilustra a relação entre força aplicada e giro da seção transversal no meio do vão para o perfil U2A, onde pode-se observar o aparecimento de giro na seção transversal desde o início da aplicação do carregamento.

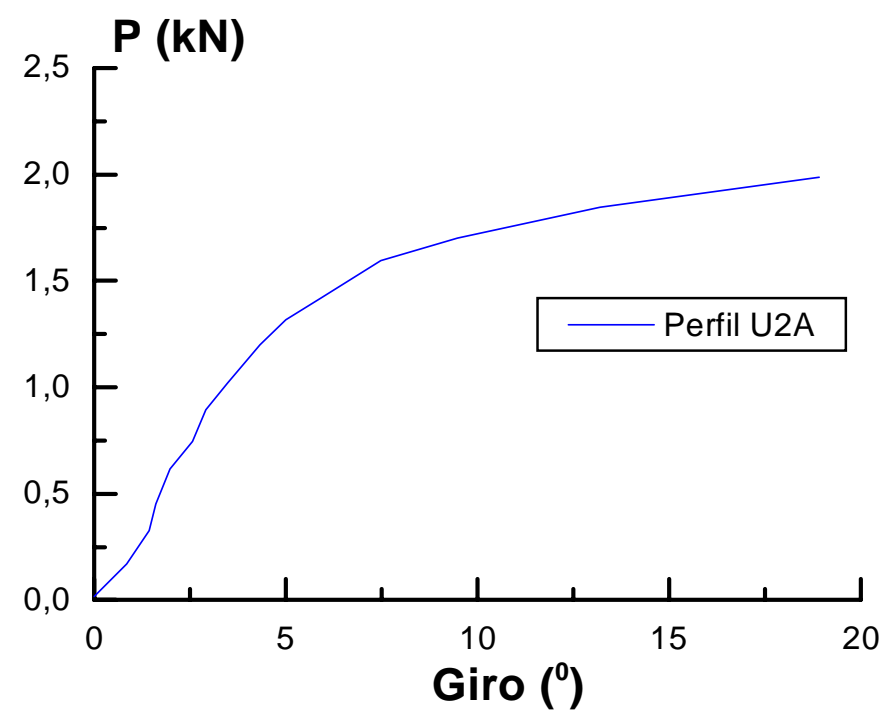

Figura 4.18: Gráfico força aplicada x giro: Perfil U2A.

$\mathrm{Na}$ sequência de carregamento para este conjunto, com travamentos laterais a cada $1 / 3$ do vão $(2,0 \mathrm{~m})$, após a ocorrência da FLT na seção transversal central verificou-se a flambagem local da mesa para as seções 
transversais situadas a aproximadamente 1,5 $\mathrm{m}$ dos apoios, de forma simultânea e simétrica, ilustrada nas fotos da figura 4.19.

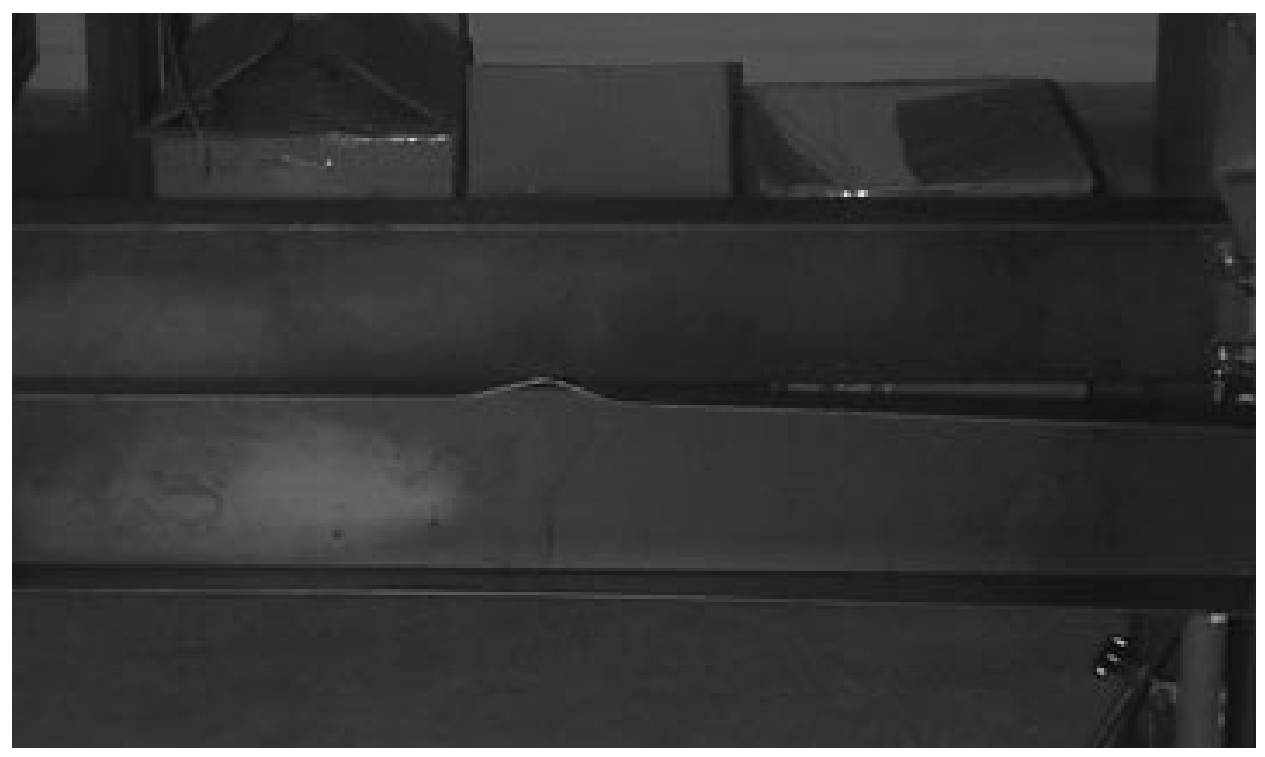

a)

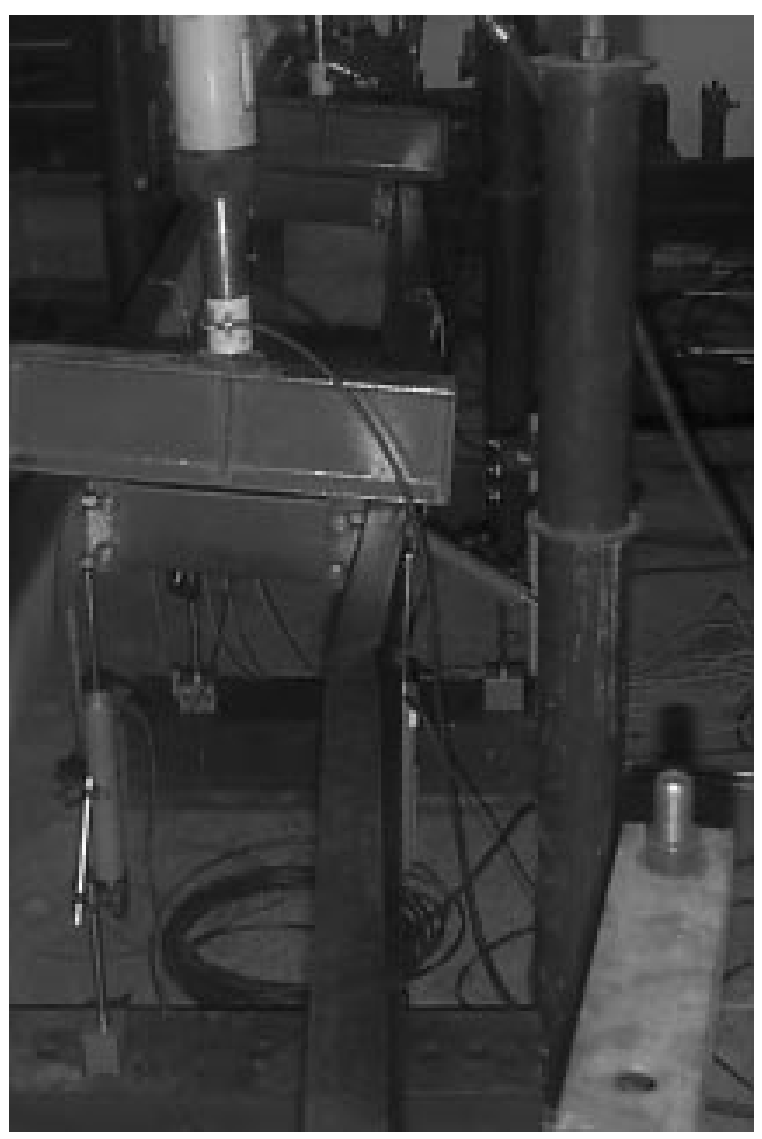

b)

Figura 4.19: Falha para o conjunto U2: a) FLM. b) Vista frontal. 
$\mathrm{Na}$ figura 4.20 apresentam-se os diagramas força aplicada $x$ deformação para o conjunto U21, constituído de 2 perfis U127×50×3,00.

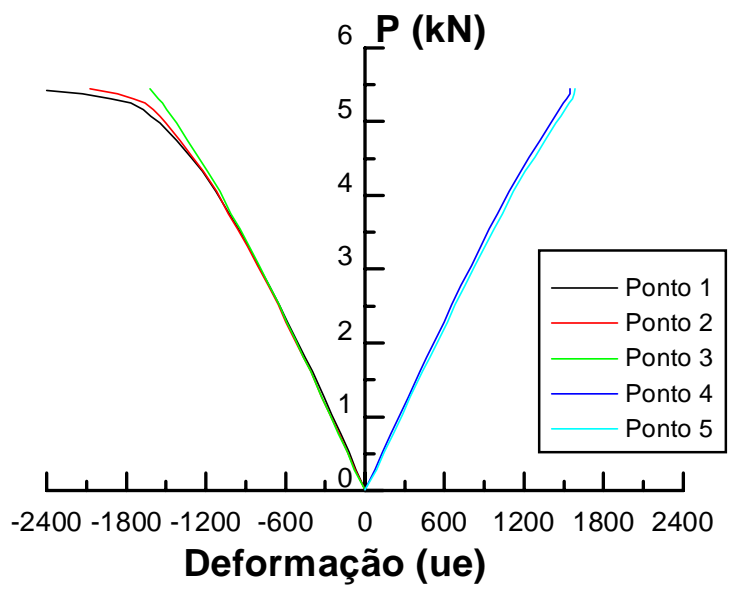

a)

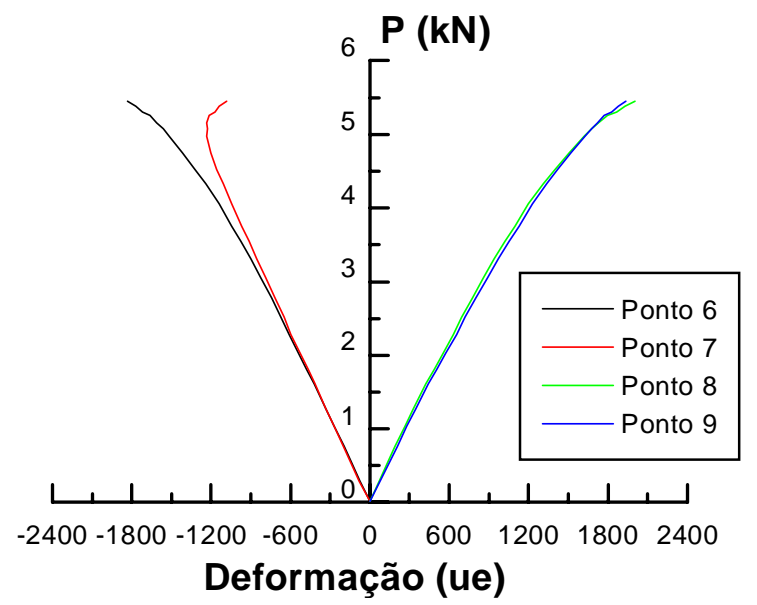

b)
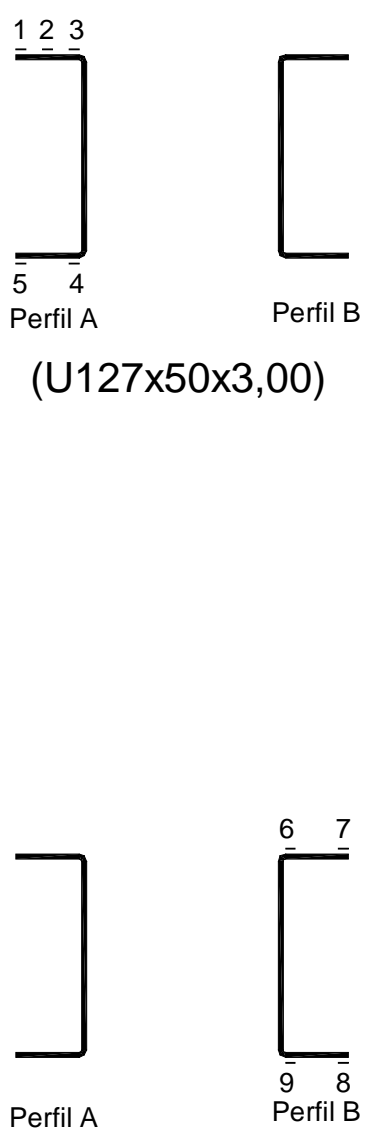

(U127x50×3,00)

Figura 4.20: Gráficos força aplicada x deformação: Conjunto U21.
a) Perfil U21A.
b) Perfil U21B.

Acompanhando-se o histórico de carregamento realizado pode-se observar que as deformações, consequentemente as tensões, permanecem praticamente iguais ao longo da largura da mesa tracionada até valores da força aplicada praticamente iguais ao valor da força última. 
O gráfico dos deslocamentos ocorridos no meio do vão contra a força aplicada está representado na figura 4.21. Mostra-se também os deslocamentos teóricos calculados a partir da equação da linha elástica correspondente ao esquema de carregamento da viga.

Novamente, pode-se concluir pela relação linear entre força aplicada e deslocamento ocorrido, bem como uma boa correlação entre os valores teóricos e os medidos, ressaltando-se que os deslocamentos nos perfis $\mathrm{A}$ e B são praticamente iguais.

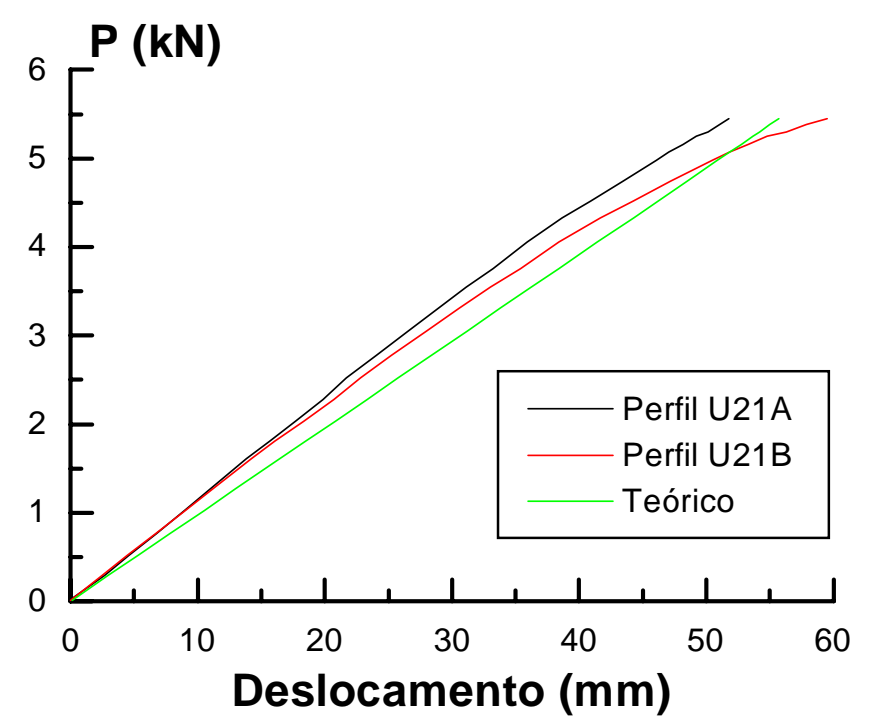

Figura 4.21: Gráfico força x deslocamento: Conjunto U21.

O gráfico apresentado na figura 4.22 ilustra o valor do giro ocorrido na seção transversal do meio do vão. Para a sua obtenção foram medidos os deslocamentos horizontais das faces internas das mesas superior e inferior.

Nota-se que o giro começa a ocorrer já para pequenos valores da força aplicada. Próximo da força última, os valores do giro crescem bastante para pequenos acréscimos de força aplicada.

Este comportamento mostrou-se presente em vários modelos deste esquema de carregamento, onde notou-se a iminência da flambagem lateral com torção, sendo esta superada pela flambagem local da mesa. Esta 
ocorrência se caracterizou por não possuir praticamente nenhuma reserva de resistência, em contrário ao observado para a flambagem lateral com torção.

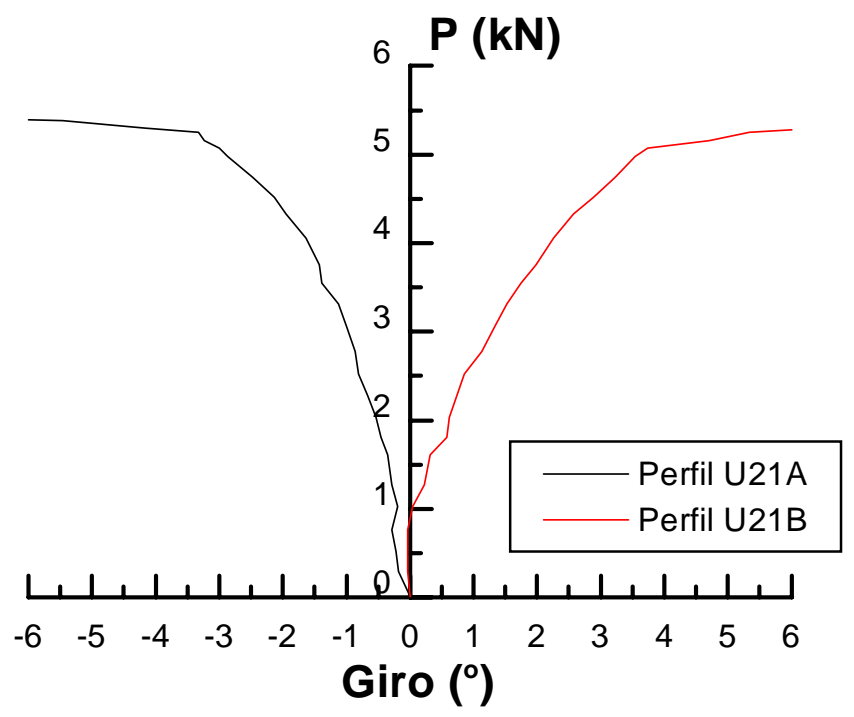

Figura 4.22: Gráfico força x giro: Conjunto U21.

As observações anteriores podem ser estendidas também para os perfis tipo $U$ enrijecido, onde os gráficos força aplicada $x$ deformações, força aplicada $x$ deslocamentos e força aplicada $x$ giro são apresentados nas figuras 4.23 a 4.25 .

O gráfico da figura 4.23 ilustra o comportamento do perfil com relação à distribuição de tensões ao longo das mesas. As deformações são praticamente as mesmas ao longo da largura da mesa até valores da força aplicada próximos ao valor da força correspondente à falha do conjunto.

O giro, figura 4.24, mostra que o perfil enrijecido comporta-se de melhor forma sob a ação do carregamento em relação ao perfil sem enrijecedor de borda. Nota-se, neste caso, que o perfil permanece sem girar até aproximadamente $80 \%$ do valor da força última e, após, tem grande acréscimo da rotação da seção transversal para pequeno incremento na força aplicada. 
Embora a flambagem local da alma tenha ocorrido pode-se notar que houve uma interação entre esta e a flambagem lateral com torção, sendo esta última a prevista como falha do conjunto

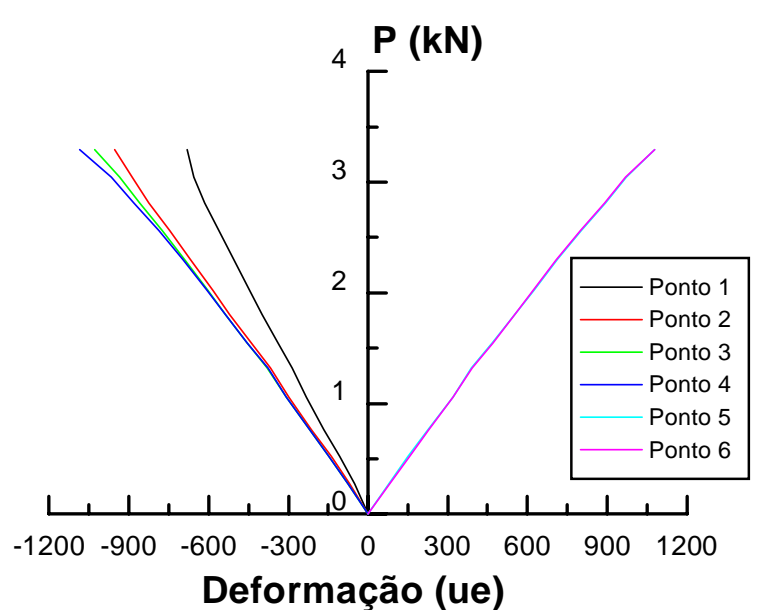

a)

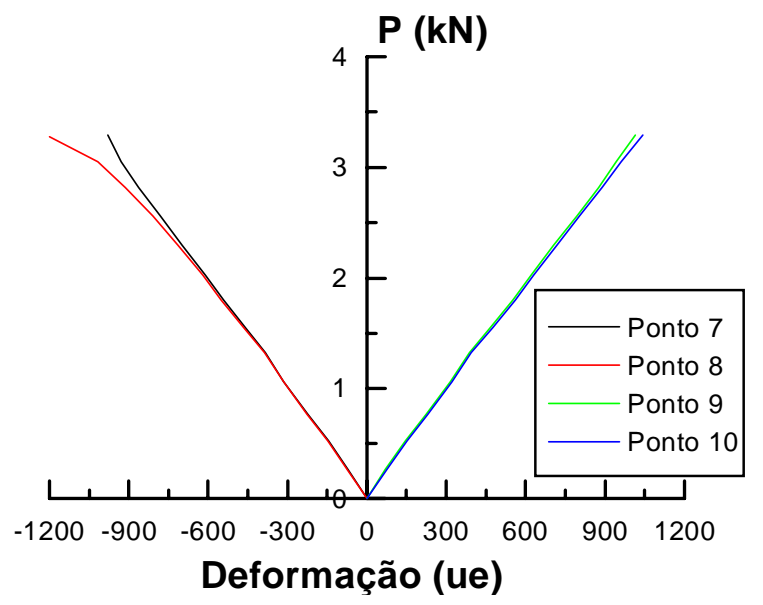

b)
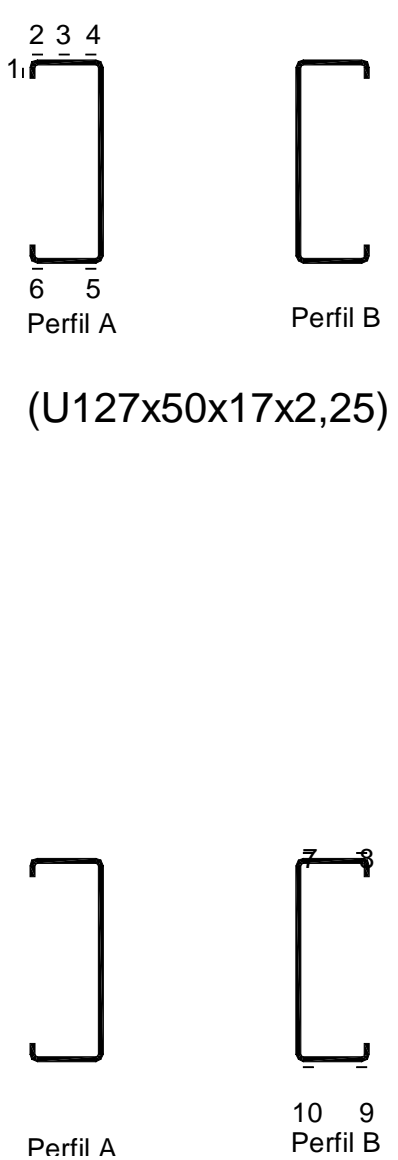

(U127x50x17×2,25)

Figura 4.23: Gráficos força aplicada x deformação: Conjunto U5.

a) Perfil U5A. b) Perfil U5B. 


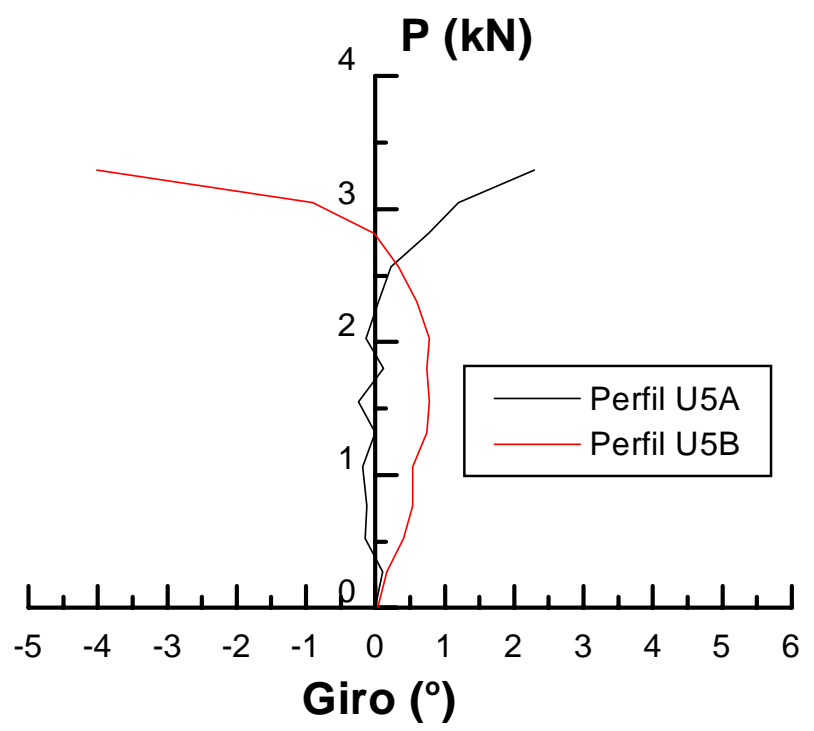

Figura 4.24: Gráfico força aplicada x giro: Conjunto U5.

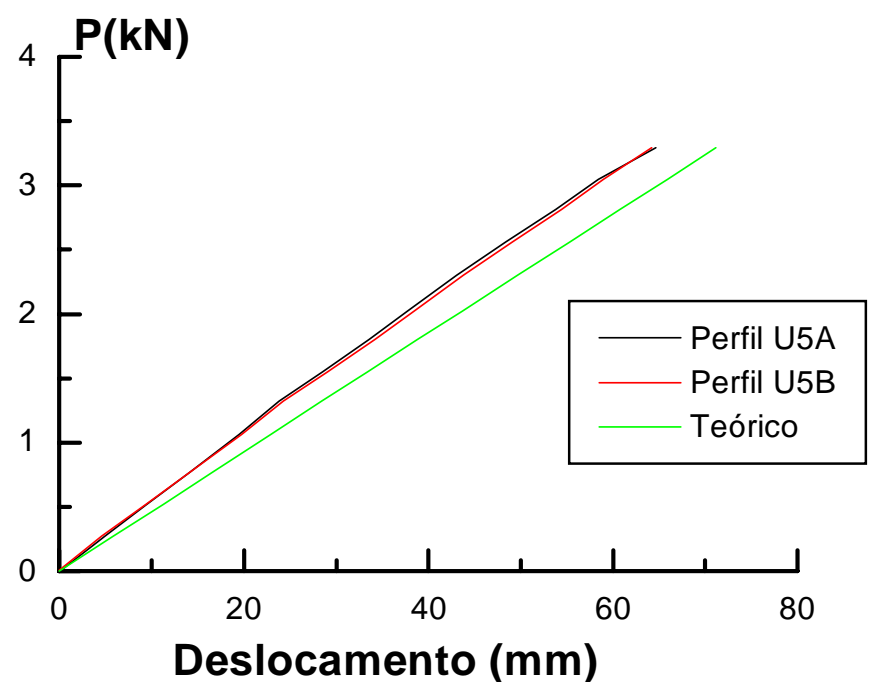

Figura 4.25: Gráfico força aplicada x deslocamento: Conjunto U5.

O gráfico correspondente aos deslocamentos do centro do vão (flecha), figura 4.25, indicam o comportamento linear para os perfis, bem como, uma igualdade na distribuição das forças aplicadas para ambos os perfis.

Quanto aos perfis tipo Z enrijecido, estes tiveram a aplicação da força cessada em vista dos grandes deslocamentos sofridos. Entretanto, como 
indica a figura 4.26, os perfis estavam na iminência da flambagem lateral com torção.

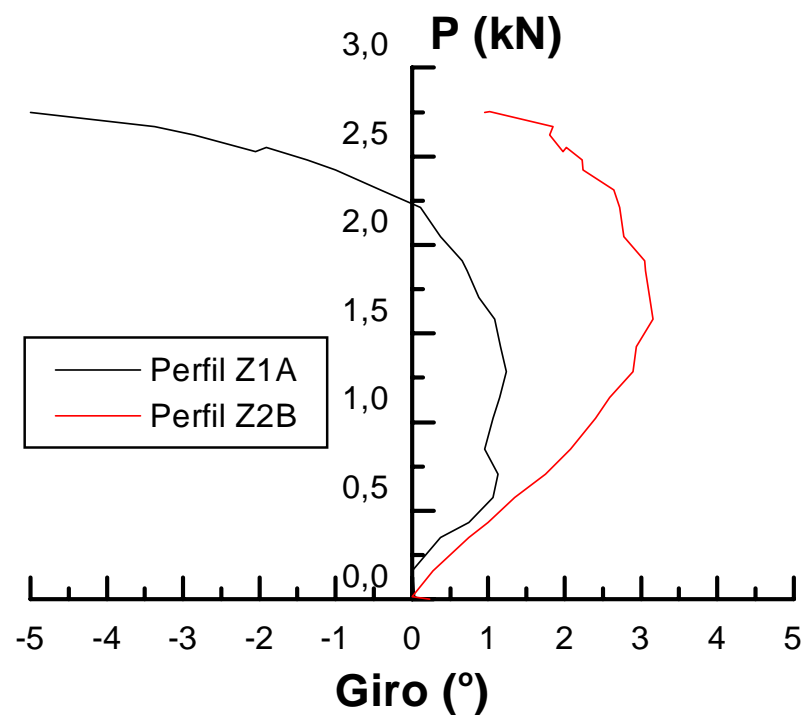

Figura 4.26: Gráfico força aplicada x giro: Conjunto Z1.

\subsubsection{Esquema de carregamento 2}

Neste esquema de carregamento a aplicação da força deu-se no meio do vão, com diagrama de momentos fletores variando linearmente entre os pontos travados lateralmente.

Pode-se observar a predominância do modo de falha devido à flambagem lateral com torção, sendo apresentados na tabela 4.7 os modos de falha previstos contra aqueles observados nos ensaios desenvolvidos.

Da tabela nota-se que os conjuntos U22 e U24 apresentaram, além do estado limite de flambagem lateral com torção, flambagem local da mesa a uma distância de aproximadamente $1,5 \mathrm{~m}$ dos apoios.

Este fato pode ser explicado pelo giro ocorrido devido à FLT. Como tem-se apenas um travamento intermediário, a flambagem lateral com torção ocorre com duas semi-ondas, onde uma dessas ocasiona acréscimos de 
tensões de compressão na mesa comprimida, atingindo o colapso por flambagem local desse elemento.

Tabela 4.7: Modos de falha previstos e observados (carregamento 2).

\begin{tabular}{|c|c|c|c|c|c|}
\hline Ensaio & Perfil & Situação & Vão (m) & Falha Prevista & Falha Observada \\
\hline U12 & \multirow[t]{3}{*}{ U127×50×3,00 } & \multirow{5}{*}{ 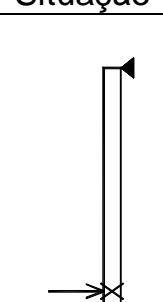 } & \multirow[t]{3}{*}{6} & \multirow[t]{3}{*}{ FLT } & FLT \\
\hline U13 & & & & & FLT \\
\hline U14 & & & & & FLT \\
\hline U15 & \multirow[t]{2}{*}{ U127x50x2,25 } & & \multirow[t]{2}{*}{6} & \multirow[t]{2}{*}{ FLT } & FLT \\
\hline U16 & & & & & FLT \\
\hline U17 & \multirow[t]{2}{*}{ U127x50x17×3,00 } & \multirow{5}{*}{$\mathbf{0}$} & \multirow[t]{2}{*}{6} & \multirow[t]{2}{*}{ FLT } & FLT \\
\hline U18 & & & & & FLT \\
\hline U22 & \multirow[t]{3}{*}{ U127x50x3,00 } & & \multirow[t]{3}{*}{4,5} & \multirow[t]{3}{*}{ FLT } & FLT(FLM) \\
\hline U23 & & & & & FLT \\
\hline U24 & & & & & FLT(FLM) \\
\hline
\end{tabular}

$\mathrm{Na}$ figura 4.27 apresentam-se os gráficos força aplicada contra deformação para os perfis do conjunto, onde a flambagem local da mesa ocorreu primeiramente para o perfil B.

A correspondência entre forças aplicadas e deslocamentos ocorridos mostrou-se de forma linear e com boa correlação com os valores teóricos obtidos a partir da equação da linha elástica para este esquema de carregamento, figura 4.28 . 


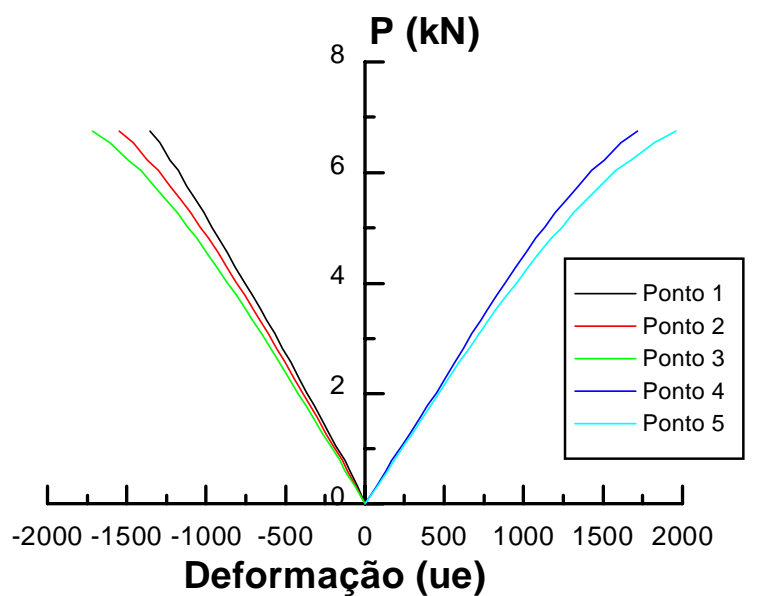

a)

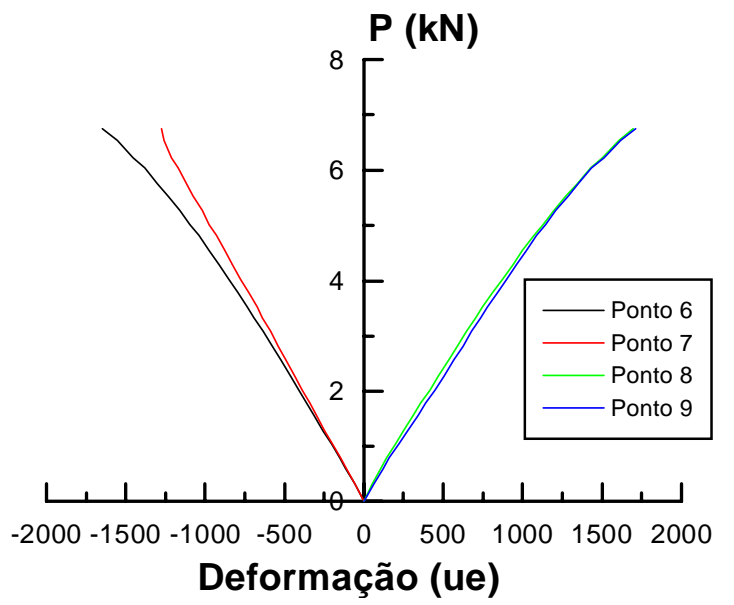

b)
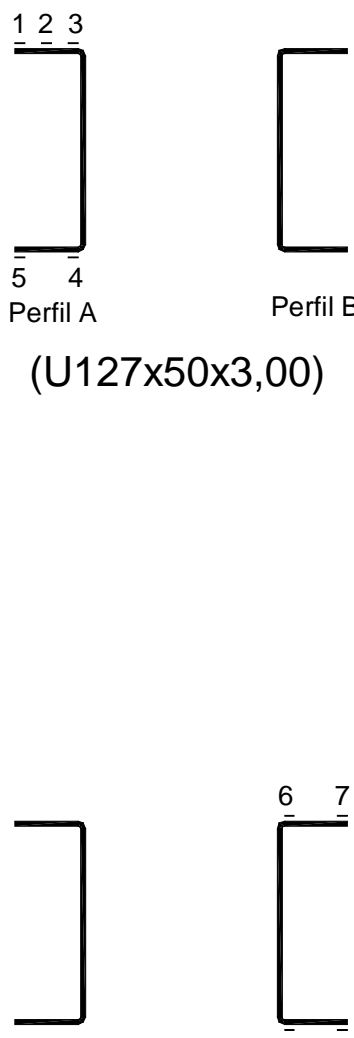

Perfil A

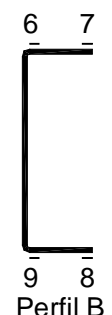

(U127x50x3,00)

Figura 4.27: Gráficos força aplicada x deformação: Conjunto U22.

a) Perfil U22A. b) Perfil U22B. 


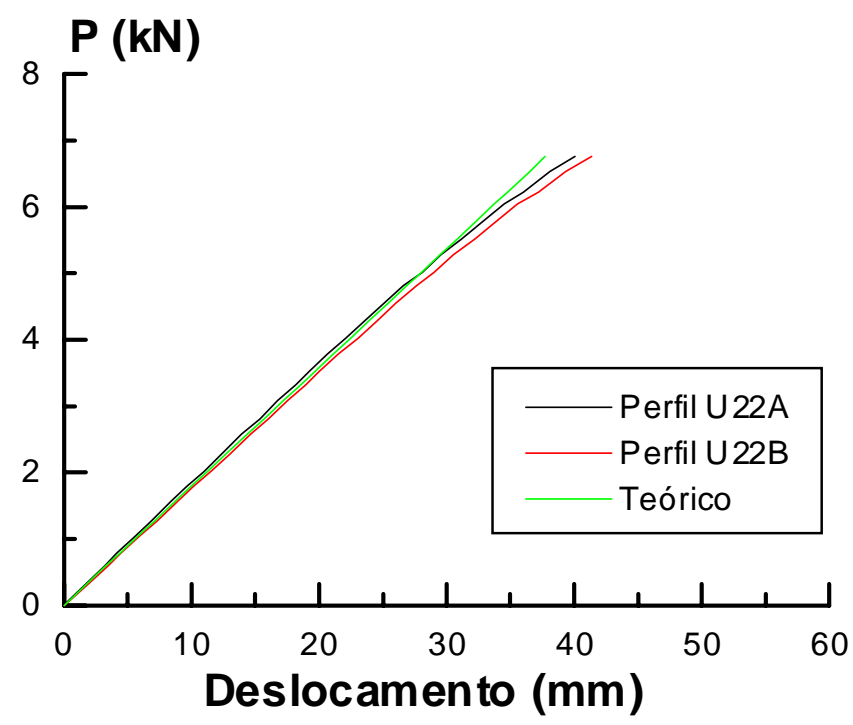

Figura 4.28: Gráfico força aplicada x deslocamento: Conjunto U22.

\subsubsection{Esquema de carregamento 3}

Neste esquema de carregamento a força foi aplicada em pontos não travados lateralmente, onde os modos de falha do ensaio foram os mesmos que os previstos.

Para os perfis U26 e U27 foram claras as falhas devidas à flambagem local da mesa. No caso do perfil U25 a falha ocorreu na cantoneira utilizada para a aplicação da força, não caracterizando a falha do perfil propriamente dita.

Na figura 4.29 estão apresentadas as fotografias da ruína observada para o perfil U26.

$\mathrm{Na}$ figura 4.30 apresenta-se o gráfico do giro medido na seção transversal central para o conjunto U26 onde a falha observada deu-se por flambagem local da mesa.

$\mathrm{Na}$ figura 4.31 apresenta-se o giro medido na seção transversal central para o conjunto U28 onde o colapso ocorreu por flambagem lateral com torção. A comparação entre os gráficos permite verificar as diferenças entre esses modos de instabilidade. 


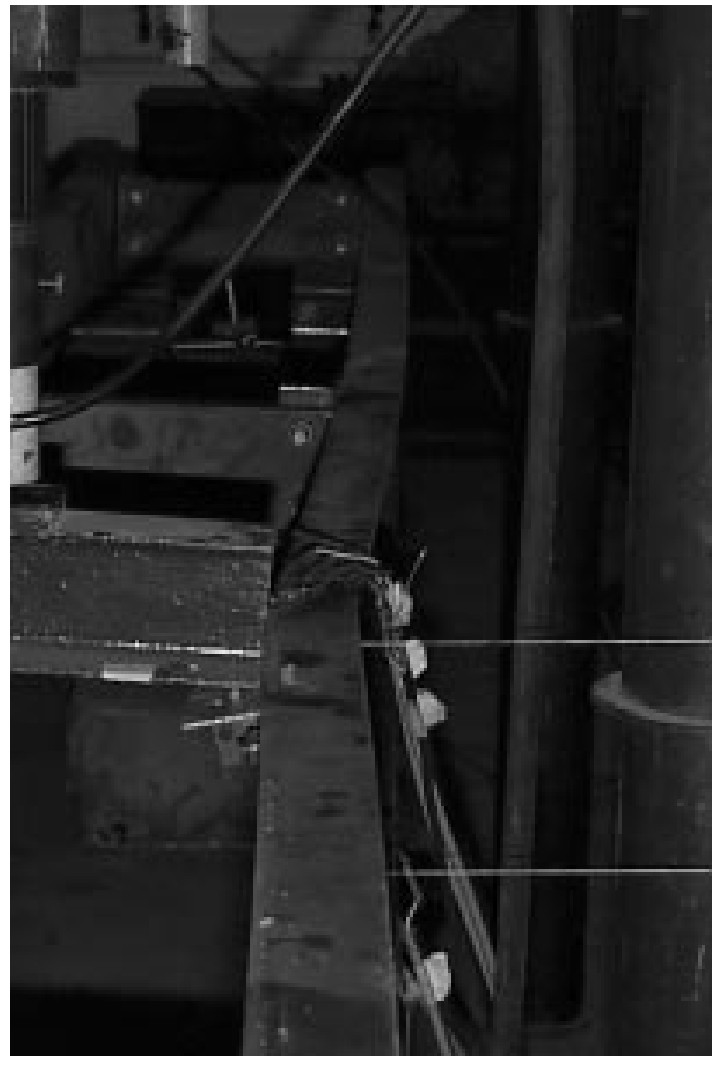

(a)

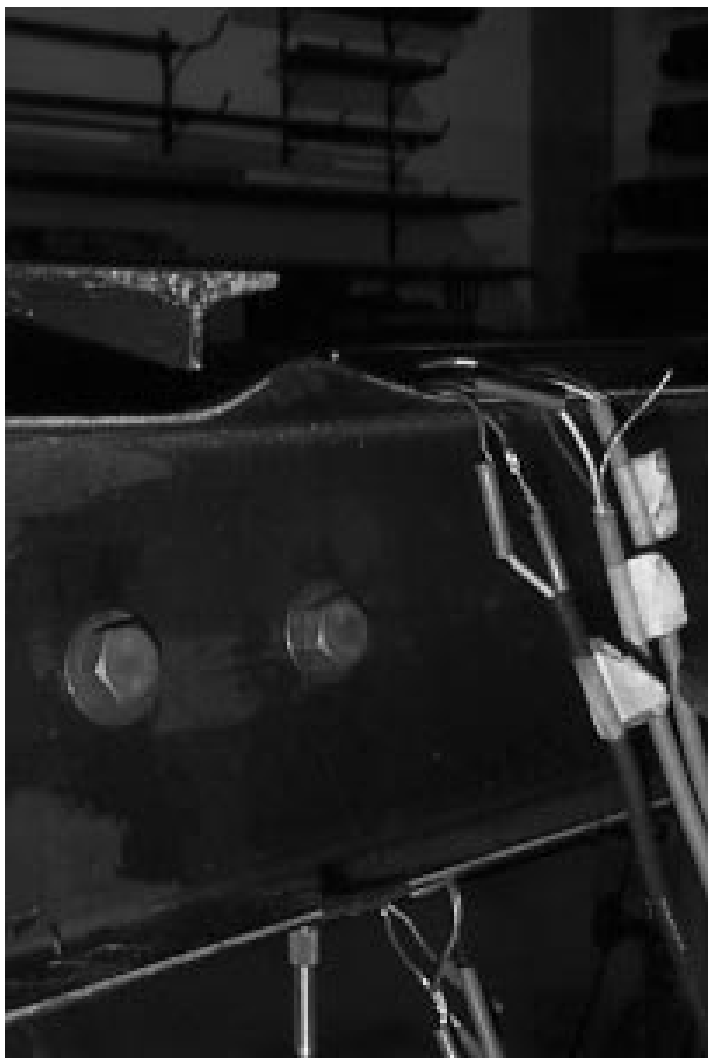

(b)

Figura 4.29: Flambagem local da mesa: conjunto U26.

a) Vista geral do Perfil A. b) Detalhe da falha.

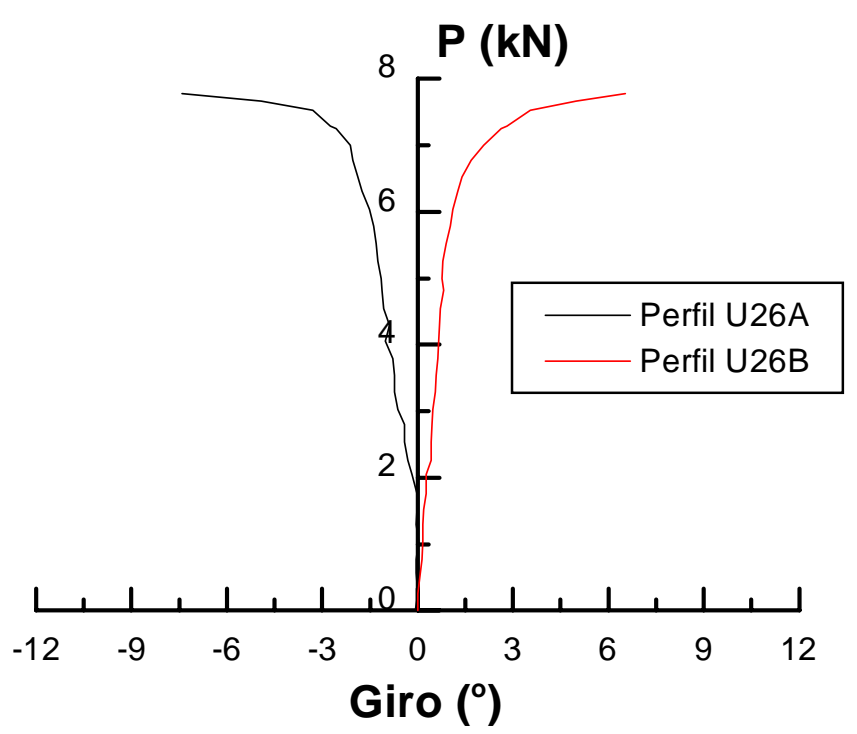

Figura 4.30: Gráfico força aplicada x giro - conjunto U26: Flambagem local da mesa. 


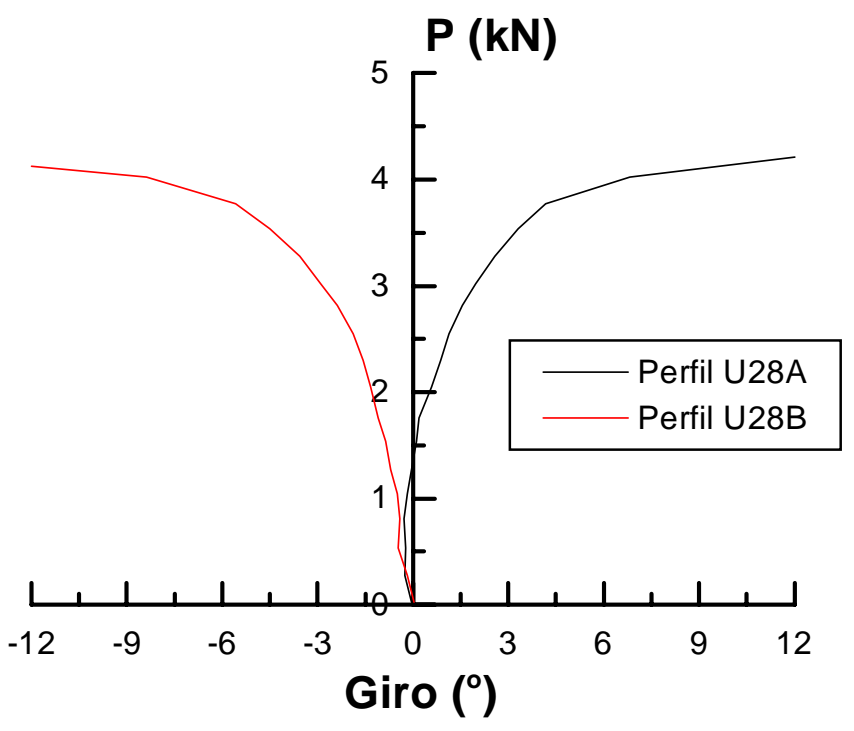

(b)

Figura 4.31: Gráfico força aplicada x giro - conjunto U28: Flambagem lateral com torção.

\subsection{Análise dos resultados}

Em todos os ensaios o colapso das vigas foi caracterizado pelo modo de instabilidade local da mesa ou pelo modo de instabilidade global, a flambagem lateral com torção.

Da execução dos ensaios pode-se observar que o modo de instabilidade local da mesa não apresentou prévio aviso de ruína, praticamente sem nenhuma reserva de resistência, induzindo o perfil a sair de sua posição original, cessando o carregamento.

Quando a falha dos perfis deveu-se à flambagem lateral com torção, esta foi acompanhada de grandes deslocamentos, permitindo-se inclusive o descarregamento dos perfis de forma gradual.

Os resultados experimentais estão comparados com os resultados obtidos através da solução das equações diferenciais, apresentada no capítulo anterior, através dos procedimentos do AISI (1996) e através do Eurocode (1993), os quais são adotados normalmente em projetos de 
estruturas de aço constituídas por perfis de aço formados a frio. Também são comparados com os resultados do modelo de flambagem por distorção proposto por Hancock (1997).

Esses valores comparativos estão apresentados e discutidos nas tabelas seguintes para cada caso de esquema de carregamento ensaiado, proporcionando uma maior clareza na sua análise.

$\mathrm{Na}$ determinação das forças críticas foram considerados $\mathrm{K}_{\mathrm{y}}=\mathrm{K}_{t}=1,0$ e os valores de $P_{\text {cr(aprox.) }}$ são aqueles obtidos no capítulo 3 por meio das equações aproximadas desenvolvidas.

Os valores de $C_{b}$ utilizados foram 1,0; 1,75 e 1,136 para os esquemas de carregamento 1, 2 e 3, respectivamente.

Deve-se lembrar que as equações diferenciais consideram o material com comportamento elástico linear, enquanto os demais modelos apresentam curvas correspondentes ao regime não elástico.

Da mesma forma, as equações diferenciais não consideram a possibilidade da ocorrência simultânea da flambagem local da mesa. Além disso, os modelos para a flambagem por distorção $\left(P_{\text {cr(Hancock })}\right)$ são aplicados para perfis com enrijecedores de borda.

$\mathrm{Na}$ tabela 4.8 indica-se o valor de $\mathrm{P}_{\mathrm{cr}}$ para os diversos procedimentos utilizados no dimensionamento dos perfis de aço formados a frio correspondentes ao esquema de carregamento 1. Para cada valor de $P_{c r}$ indica-se o modo de falha associado.

Da análise da tabela 4.8 pode-se observar que os valores obtidos através dos resultados teóricos são pouco superiores aqueles obtidos em ensaios para os quais a falha ocorrida correspondeu ao estado limite último de flambagem lateral com torção. No entanto, deve-se ressaltar que este estado limite último ficou caracterizado para o esquema de carregamento 2 , onde os resultados teóricos apresentam-se próximos aos resultados observados nos ensaios. 
Tabela 4.8: Valores comparativos da força $P$.

\begin{tabular}{|c|c|c|c|c|c|c|c|}
\hline Ensaio & Perfil & $\begin{array}{l}\text { Vão } \\
(\mathrm{m})\end{array}$ & $P_{\text {último }}(\mathrm{kN})$ & $\begin{array}{c}P_{\text {cr(AISI) }} \\
(\mathrm{kN})\end{array}$ & $\begin{array}{l}P_{\text {cr(Euroc. }} \\
(\mathrm{kN})\end{array}$ & $\begin{array}{l}\mathrm{P}_{\text {er(Hancoock) }} \\
(\mathrm{kN})\end{array}$ & $\begin{array}{l}P_{\text {cr(aprox.) }} \\
(\mathrm{kN})\end{array}$ \\
\hline U1 & \multirow[t]{2}{*}{ U127×50×2,25 } & \multirow[t]{2}{*}{6} & 3,77 (FLM) & \multirow{2}{*}{$\begin{array}{c}2,90 \\
\text { (FLM) }\end{array}$} & \multirow{2}{*}{$\begin{array}{c}2,62 \\
(F L M)\end{array}$} & \multirow[t]{2}{*}{1,} & \multirow{2}{*}{$\begin{array}{l}5,08 \\
(\mathrm{FLT})\end{array}$} \\
\hline U2 & & & 4,18 (FLT) & & & & \\
\hline U3 & \multirow[t]{2}{*}{ U127×50x3,00 } & \multirow[t]{2}{*}{6} & 6,53 (FLT) & \multirow{2}{*}{$\begin{array}{c}4,52 \\
\text { (FLM) }\end{array}$} & \multirow{2}{*}{$\begin{array}{c}4,08 \\
(F L M)\end{array}$} & \multirow[t]{2}{*}{ 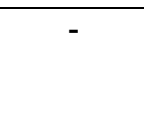 } & \multirow{2}{*}{$\begin{array}{l}7,32 \\
(\mathrm{FLT})\end{array}$} \\
\hline $\mathrm{U} 4$ & & & $6,04(\mathrm{FLT})$ & & & & \\
\hline U5 & \multirow[t]{2}{*}{ U127x50x17x2,25 } & \multirow[t]{2}{*}{6} & 6,59 (FLM) & \multirow{2}{*}{$\begin{array}{c}4,12 \\
(\mathrm{FLT})\end{array}$} & \multirow{2}{*}{$\begin{array}{c}3,53 \\
(\mathrm{FLT})\end{array}$} & \multirow{2}{*}{$\begin{array}{c}6,50 \\
\text { (DIST.) }\end{array}$} & \multirow{2}{*}{$\begin{array}{c}7,62 \\
(\mathrm{FLT})\end{array}$} \\
\hline U6 & & & 6,96 (FLM) & & & & \\
\hline $\mathrm{U} 7$ & \multirow[t]{3}{*}{ U127×50x3,00 } & \multirow[t]{3}{*}{6} & $6,16(\mathrm{FLT})$ & \multirow{3}{*}{$\begin{array}{c}3,46 \\
(\mathrm{FLT})\end{array}$} & \multirow{3}{*}{$\begin{array}{l}3,06 \\
(\mathrm{FLT})\end{array}$} & \multirow[t]{3}{*}{ - } & \multirow{3}{*}{$\begin{array}{l}5,36 \\
(\mathrm{FLT})\end{array}$} \\
\hline U8 & & & 6,80 (FLT) & & & & \\
\hline U9 & & & 6,03 (FLM) & & & & \\
\hline U10 & \multirow[t]{2}{*}{ U127x50x2,25 } & \multirow[t]{2}{*}{6} & 4,52 (FLM) & \multirow{2}{*}{$\begin{array}{c}2,30 \\
(\mathrm{FLM})\end{array}$} & \multirow{2}{*}{$\begin{array}{c}2,23 \\
(F L M)\end{array}$} & \multirow[t]{2}{*}{-} & \multirow{2}{*}{$\begin{array}{c}3,51 \\
(\mathrm{FLT})\end{array}$} \\
\hline U11 & & & 4,31 (FLM) & & & & \\
\hline U19 & \multirow[t]{3}{*}{ U127×50x3,00 } & \multirow[t]{3}{*}{4,5} & 9,95 (FLM) & \multirow{3}{*}{$\begin{array}{c}7,48 \\
(\mathrm{FLM})\end{array}$} & \multirow{3}{*}{$\begin{array}{c}7,18 \\
(\mathrm{FLM})\end{array}$} & \multirow[t]{3}{*}{-} & \multirow{3}{*}{$\begin{array}{l}15,64 \\
(F L T)\end{array}$} \\
\hline U20 & & & 10,89 (FLM) & & & & \\
\hline U21 & & & 10,88 (FLM) & & & & \\
\hline Z1 & \multirow[t]{2}{*}{ Z127x50x17x2,25 } & 6 & 5,51 & 5,30 & 4,29 & 5,44 & 9,91 \\
\hline Z2 & & & 6,22 & $(\mathrm{FLT})$ & $(\mathrm{FLT})$ & (DIST.) & $(\mathrm{FLT})$ \\
\hline
\end{tabular}

Como já observado, para o conjunto U2 verificou-se a ocorrência da flambagem lateral com torção sendo que, previu-se como estado limite último a flambagem local da mesa.

O giro da seção transversal e os deslocamentos horizontais modificam a distribuição de tensões na mesa deixando de ser uniforme e passa a apresentar uma distribuição com variação linear.

Através dos extensômetros elétricos posicionados na seção transversal do meio do vão pode-se avaliar a distribuição de tensão na mesa comprimida, obtendo-se uma distribuição conforme indicado na figura 4.32 para o perfil A do conjunto U2. 


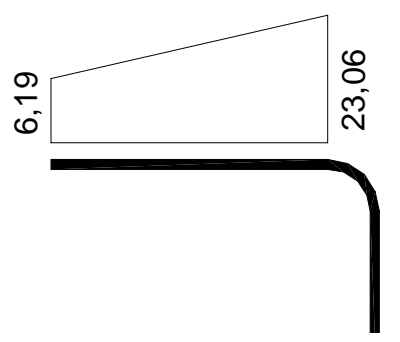

Figura 4.32: Tensões normais na mesa comprimida - perfil U2A

Sob esta distribuição de tensões pode-se avaliar a largura efetiva da mesa comprimida sendo o coeficiente de flambagem de placa obtido através da seguinte expressão:

$$
k=\frac{0,578}{\sigma_{2} / \sigma_{1}+0,34}=0,95
$$

onde $\sigma_{1}$ é a menor e $\sigma_{2}$ é a maior tensão normal no elemento não enrijecido.

Analisando-se as deformações ocorridas ao longo de todo o processo de carregamento verifica-se que a distribuição de tensões deixa de ser uniforme para valores correspondente a aproximadamente $25 \%$ da força última, obtendo-se nessa situação a relação $\sigma_{1} / \sigma_{2}=0,67$.

Em função dessa variação de tensões de compressão, o cálculo da largura efetiva para o elemento passa a ser efetuado com $k=0,95$, contra 0 valor de 0,43 para elemento não enrijecido sobre compressão uniforme. Dessa forma pode-se obter $\lambda=0,732$ e, embora maior que 0,673, deve-se observar que $\lambda$ foi obtido para a tensão indicada na figura 4.32 cujo valor não reproduz a relação linear entre tensão e deformação, o que deve proporcionar um valor de $\lambda$ menor que o calculado anteriormente.

Em contrapartida, da mesma forma que o giro alterou a distribuição de tensões ao longo da mesa na seção transversal do meio do vão, o giro nos trechos de extremidades dá-se em sentido contrário, neste caso, 
aumentando a tensão de compressão na borda livre. Então, para seções contidas nesse trecho, o coeficiente de flambagem de $K$ pode ser admitido próximo ao valor de 0,45 , justificando-se a ocorrência da flambagem local da mesa nesse trecho, onde o momento fletor, consequentemente a tensão normal correspondente, é menor.

O fato da flambagem local da mesa ocorrer a uma distância de 1,5 metros do apoio justifica-se pelos dispositivos de travamento utilizado. Estes dispositivos não permitem a rotação da seção transversal, podendo-se atribuir a eles uma determinada restrição à rotação da seção transversal, indicando um coeficiente de flambagem por torção $\left(K_{t}\right)$ inferior a 1.

Como a ocorrência da flambagem local da mesa deu-se a aproximadamente 0,5 metro do ponto contraventado, obtém-se como comprimento efetivo de flambagem por torção 1 metro resultando, portanto, em um valor de $K_{t} \cong 0,5$. Isto justifica-se pelo próprio detalhe do dispositivo de travamento, o qual sugere um engastamento ao giro no ponto travado lateralmente.

Com referência aos ensaios correspondentes aos conjuntos U5 e U6 previa-se a ocorrência da flambagem lateral com torção, observando-se no ensaio o colapso por flambagem local da mesa. Ao analisar-se o comportamento da seção transversal no meio do vão pode-se notar que o início da flambagem lateral com torção, indicando-se uma interação entre os dois estados limites.

Da tabela 4.8 também pode-se notar que 0 valor de $P_{c r}$ correspondente à flambagem por distorção é próximo ao valor obtido em ensaio, indicando a distorção da seção segundo preconizado no modelo de Hancock.

A tabela 4.9 indica o valor de $\mathrm{P}_{\mathrm{cr}}$ para os diversos procedimentos utilizados no dimensionamento dos perfis de aço formados a frio correspondentes ao esquema de carregamento 2 (força aplicada no meio do vão). Como se fez anteriormente, para cada valor de $P_{c r}$ indica-se o modo de falha associado. 
Tabela 4.9: Valores comparativos da força $\mathrm{P}$ (carregamento 2).

\begin{tabular}{|c|c|c|c|c|c|c|c|}
\hline Ensaio & Perfil & $\begin{array}{l}\text { Vão } \\
\text { (m) }\end{array}$ & $P_{\text {último }}(\mathrm{kN})$ & $\begin{array}{c}P_{\text {cr(AISI) }} \\
(\mathrm{kN})\end{array}$ & $\begin{array}{c}P_{\text {cr(Euroc. })} \\
(\mathrm{kN})\end{array}$ & $\begin{array}{c}P_{\text {cr(Hancock })} \\
(\mathrm{kN})\end{array}$ & $\begin{array}{l}P_{\text {cr(aprox.) }} \\
\text { (kN) }\end{array}$ \\
\hline U12 & \multirow[t]{3}{*}{ U127×50x3,00 } & \multirow[t]{3}{*}{6} & 7,91 (FLT) & \multirow{3}{*}{$\begin{array}{c}5,86 \\
(\mathrm{FLT})\end{array}$} & \multirow{3}{*}{$\begin{array}{l}5,30 \\
(F L T)\end{array}$} & \multirow[t]{3}{*}{ 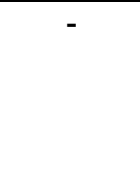 } & \multirow{3}{*}{$\begin{array}{c}7,28 \\
(F L T)\end{array}$} \\
\hline U13 & & & $7,81(\mathrm{FLT})$ & & & & \\
\hline U14 & & & 7,86 (FLT) & & & & \\
\hline U15 & \multirow[t]{2}{*}{$U 127 \times 50 \times 2,25$} & \multirow[t]{2}{*}{6} & $5,23(\mathrm{FLT})$ & \multirow{2}{*}{$\begin{array}{c}3,54 \\
(\mathrm{FLT})\end{array}$} & \multirow{2}{*}{$\begin{array}{c}3,54 \\
(\mathrm{FLT})\end{array}$} & \multirow[t]{2}{*}{-} & \multirow{2}{*}{$\begin{array}{c}4,78 \\
(\mathrm{FLT})\end{array}$} \\
\hline U16 & & & $5,18(\mathrm{FLT})$ & & & & \\
\hline U17 & \multirow[t]{2}{*}{ U127x50x17×3,00 } & \multirow[t]{2}{*}{6} & 10,81 (FLT) & \multirow[t]{2}{*}{8,62} & \multirow{2}{*}{$\begin{array}{c}7,58 \\
(\mathrm{FLT})\end{array}$} & \multirow{2}{*}{$\begin{array}{c}13,26 \\
\text { (DIST.) }\end{array}$} & \multirow{2}{*}{$\begin{array}{l}10,36 \\
(F L T)\end{array}$} \\
\hline U18 & & & 10,94 (FLT) & & & & \\
\hline U22 & \multirow[t]{3}{*}{ U127×50x3,00 } & \multirow[t]{3}{*}{4,5} & 13,51 (FLM) & \multirow{3}{*}{$\begin{array}{c}9,64 \\
(\mathrm{FLT})\end{array}$} & \multirow{3}{*}{$\begin{array}{l}9,15 \\
(\mathrm{FLT})\end{array}$} & \multirow[t]{3}{*}{ - } & \multirow{3}{*}{$\begin{array}{l}14,72 \\
(F L T)\end{array}$} \\
\hline U23 & & & 13,33 (FLT) & & & & \\
\hline U24 & & & 13,51 (FLM) & & & & \\
\hline
\end{tabular}

Da análise da tabela 4.9 observa-se que o modo de falha previsto (FLT) foi o modo de falha ocorrido, exceto para o conjunto U22 e U24. A justificativa para tal ocorrência é a mesma já discutida anteriormente, ou seja, a superposição de tensões normais advindas do giro e dos deslocamentos horizontais nas proximidades dos pontos travados lateralmente.

Novamente, a flambagem local da mesa ocorreu aproximadamente a 1,5 metros do apoio, indicando valores de $K_{t} \cong 0,5$.

Também observa-se que os valores de $P_{c r}$ obtidos pelas soluções aproximadas fornecem bom resultados quando comparados com os valores dos ensaios. Isto deve-se ao fato de ter-se o comportamento do perfil em regime elástico, reproduzindo-se as hipóteses adotadas nessas equações.

Quanto ao esquema de carregamento 3, com já observado, os modos de falha ocorridos e previstos foram os mesmos.

$\mathrm{Na}$ tabela 4.10 estão indicados os valores previstos bem como aqueles obtidos nos ensaios. 
Tabela 4.10: Valores comparativos da força P (carregamento 3).

\begin{tabular}{|c|c|c|c|c|c|c|c|}
\hline Ensaio & Perfil & $\begin{array}{l}\text { Vão } \\
\text { (m) }\end{array}$ & $P_{\text {último }}(\mathrm{kN})$ & $\begin{array}{c}P_{\text {cr(AISI) }} \\
(\mathrm{kN})\end{array}$ & $\begin{array}{l}P_{\text {cr(Euroc. }} \\
(\mathrm{kN})\end{array}$ & $\begin{array}{l}P_{\text {crithancock) }} \\
(\mathrm{kN})\end{array}$ & $\begin{array}{l}P_{\text {cr(aprox. })} \\
(\mathrm{kN})\end{array}$ \\
\hline U25 & \multirow[t]{3}{*}{ U127x50×3,00 } & \multirow[t]{3}{*}{4,5} & 13,90 ( FLM) & \multirow{3}{*}{$\begin{array}{c}9,97 \\
\text { (FLM) }\end{array}$} & \multirow{3}{*}{$\begin{array}{c}9,57 \\
\text { (FLM) }\end{array}$} & \multirow[t]{3}{*}{1} & \multirow{3}{*}{$\begin{array}{l}25,60 \\
(F L T)\end{array}$} \\
\hline U26 & & & 15,55 (FLM) & & & & \\
\hline U27 & & & 15,50 (FLM) & & & & \\
\hline U28 & \multirow[t]{3}{*}{$\mathrm{U} 127 \times 50 \times 3,00$} & \multirow[t]{3}{*}{6} & $8,58(\mathrm{FLT})$ & \multirow{3}{*}{$\begin{array}{c}3,47 \\
(\mathrm{FLT})\end{array}$} & \multirow{3}{*}{$\begin{array}{c}3,06 \\
(\mathrm{FLT})\end{array}$} & \multirow[t]{3}{*}{ - } & \multirow{3}{*}{$\begin{array}{c}6,60 \\
(\mathrm{FLT})\end{array}$} \\
\hline U29 & & & $8,53(\mathrm{FLT})$ & & & & \\
\hline U30 & & & 9,04 (FLT) & & & & \\
\hline
\end{tabular}

Em vista dos coeficientes de flambagem sugeridos pelos próprios resultados dos ensaios, na tabela 4.11 apresentam-se as forças previstas calculadas de acordo com o procedimento do AISI (1996) para os valores de $K_{t}=0,5$ e $K_{y}=1,0$.

Tabela 4.11: - Comparação entre os resultados obtidos $\left(K_{t}=0,5 ; K_{y}=1,0\right)$.

\begin{tabular}{|c|c|c|c|c|c|}
\hline Perfil & $\begin{array}{l}\text { Vão } \\
\text { (m) }\end{array}$ & $\begin{array}{c}\text { Esquema } \\
\text { Carregamento }\end{array}$ & $\begin{array}{c}P_{\text {último }} \\
(\mathrm{kN})\end{array}$ & $\begin{array}{l}P_{\text {AISI }} \\
(k N)\end{array}$ & $\begin{array}{c}\mathrm{P}_{\text {último }} / \mathrm{P}_{\text {AISI }} \\
(\mathrm{kN})\end{array}$ \\
\hline \multirow{3}{*}{ U127x50×3,00 } & \multirow{3}{*}{6,0} & 1 & 6,32 & 5,73 & 1,103 \\
\hline & & 2 & 7,86 & 7,84 & 1,003 \\
\hline & & 3 & 7,99 & 6,05 & 1,321 \\
\hline \multirow{3}{*}{ U127x50×3,00 } & \multirow{3}{*}{4,5} & 1 & 10,57 & 9,44 & 1,120 \\
\hline & & 2 & 13,45 & 11,11 & 1,211 \\
\hline & & 3 & 15,17 & 12,83 & 1,182 \\
\hline \multirow[t]{2}{*}{ U127x50x2,25 } & \multirow[t]{2}{*}{6,0} & 1 & 4,39 & 3,60 & 1,219 \\
\hline & & 2 & 5,20 & 5,37 & 0,968 \\
\hline U127x50x17×2,25 & 6,0 & 1 & 6,78 & 7,18 & 0,944 \\
\hline U127×50x17×3,00 & 6,0 & 2 & 10,87 & 10,28 & 1,057 \\
\hline U127x50×3,00 & 6,0 & $1^{*}$ & 6,28 & 5,85 & 1,073 \\
\hline U127×50×2,25 & 6,0 & 1 & 4,12 & 3,84 & 1,073 \\
\hline Z127x50x17×2,25 & 6,0 & $1^{*}$ & 5,86 & 5,30 & 1,106 \\
\hline
\end{tabular}


Com os novos valores calculados pode-se observar que a razão entre os resultados teóricos e os experimentais apresentam melhor correlação aproximando-se do valor unitário.

As falhas para as quais o modo previsto não correspondeu ao observado deveu-se a superposição dos efeitos de deslocamento lateral e rotação da seção transversal, alterando a distribuição uniforme de tensões de compressão na mesa superior. Dessa forma, a flambagem local da mesa comprimida não ocorreu na posição de máximo momento fletor.

Quanto ao modelo de flambagem por distorção devido a Hancock, os modos de falha ocorridos não permitiram a sua avaliação. Entretanto, observa-se que os valores obtidos para os conjuntos U5 e U6 estão próximos aos dos ensaios, podendo justificar a diferença entre os modos de falha observado e o ocorrido, conforme tabela. Ressalta-se também que o efeito distorcional é mais relevante quando a relação largura e espessura dos elementos do perfil (mesa e alma) é superior aos utilizados nos ensaios aqui desenvolvidos.

Para os valores do coeficiente de flambagem lembra-se que os mesmos irão depender do detalhe dado ao travamento. Como realizado aqui, proporcionou-se uma restrição ao giro na seção travada lateralmente, podendo-se adotar valores de $K$ menores que 1. Por outro lado, imaginando-se esse travamento realizado através de barra redonda certamente não poderia ser adotado $K_{t}=0,5$. Cabe ao engenheiro a avaliação desses parâmetros, observando-se que a sua influência na determinação da resistência do perfil é significativa. 


\section{ENSAIOS EM PERFIS CONECTADOS ÀS TELHAS DE AÇO}

\subsection{Introdução}

Neste capítulo descrevem-se os ensaios realizados em perfis conectados às telhas de aço, simulando o efeito de sucção devido à ação do vento em terças de coberturas. Os perfis são do tipo $U, U$ enrijecido e $Z$ enrijecido, biapoiados.

Como nos ensaios à flexão, esta etapa do trabalho tem como objetivo a obtenção de resultados experimentais referentes às terças submetidas ao efeito de sucção devido ao vento, bem como a verificação dos modos de falha possíveis e a verificação dos resultados teóricos em comparação com os obtidos nesses ensaios.

As seções transversais escolhidas e as suas dimensões devem-se ao fato de serem as de uso frequente nas construções em aço.

Para a execução desses ensaios foi projetada e construída uma, assim denominada, caixa de sucção, executada em módulos com 1 metro de largura e 6 metros de comprimento. Dessa forma, é possível o ensaio de painéis com dimensões em planta de $3 \mathrm{~m} \times 6 \mathrm{~m}$ até painéis com $6 \mathrm{~m} \times 12 \mathrm{~m}$. 
A simulação do efeito de sucção fez-se através da diferença entre a pressão externa e a pressão interna. Para tanto, o ar contido no interior da caixa de sucção foi retirado de maneira gradual por meio de um aspirador.

Essa retirada de ar do interior da caixa de pressão, esta devidamente vedada para impedir a reposição do ar retirado, implica em uma diminuição da pressão interna em relação à pressão externa, a pressão atmosférica, proporcionando a diferença de pressão desejada.

A ação do vento sobre coberturas, em situações correntes de projeto, é da ordem de $1,0 \mathrm{kN} / \mathrm{m}^{2}$, enquanto que, a pressão atmosférica padrão é de $101 \mathrm{kN} / \mathrm{m}^{2}$. Pode-se assim, retirando-se pequena quantidade do ar interno à caixa, conseguir reproduzir situações de carregamento equivalentes à ação do vento em coberturas, observando-se que esse efeito de diferença de pressão sobre o painel formado pelas telhas de aço ocorre de maneira gradual e uniforme, ao contrário da ação do vento caracterizada por picos.

Os ensaios foram realizados em perfil tipo $U, U$ enrijecido e $Z$ enrijecido com comprimento total de $5.740 \mathrm{~mm}$. Desses ensaios, uma primeira série foi realizada sem linhas de correntes e, em uma segunda série, as terças foram executadas com 2 linhas de correntes a cada terço de vão.

As telhas de aço utilizadas têm seção trapezoidal com altura de 40 $\mathrm{mm}$ e espessura de chapa de $0,65 \mathrm{~mm}$, conectadas aos perfis de chapa dobrada por meio de parafusos auto-brocantes. A opção de uma telha com essa espessura e devidamente conectada às terças deve-se ao fato de não se desejar a ocorrência precoce de falhas na telha ou na sua fixação.

Esses ensaios foram desenvolvidos no Laboratório de Estruturas do Departamento de Engenharia de Estruturas da Escola de Engenharia de São Carlos. 


\subsection{Seções transversais e processo de fabricação dos perfis}

As seções transversais dos perfis analisados são do tipo $U, U$ enrijecido e $Z$ enrijecido.

$\mathrm{Na}$ figura 5.1 apresenta-se a nomenclatura utilizada para as dimensões geométricas das seções transversais dos perfis.

Como nos ensaios relativos aos perfis fletidos, a altura $h$ da seção transversal permaneceu constante em todas as seções e igual a $127 \mathrm{~mm}$ e a largura da mesa $b$ foi mantida constante e igual a $50 \mathrm{~mm}$.

As chapas de aço utilizados na fabricação dos perfis pertencem ao mesmo lote de chapas de aço utilizadas na fabricação dos perfis para os ensaios de flexão.

Esses perfis também foram dobrados por prensagem em dobradeiras, em perfis com 6 metros de comprimento, juntamente com os perfis utilizados nos ensaios de flexão
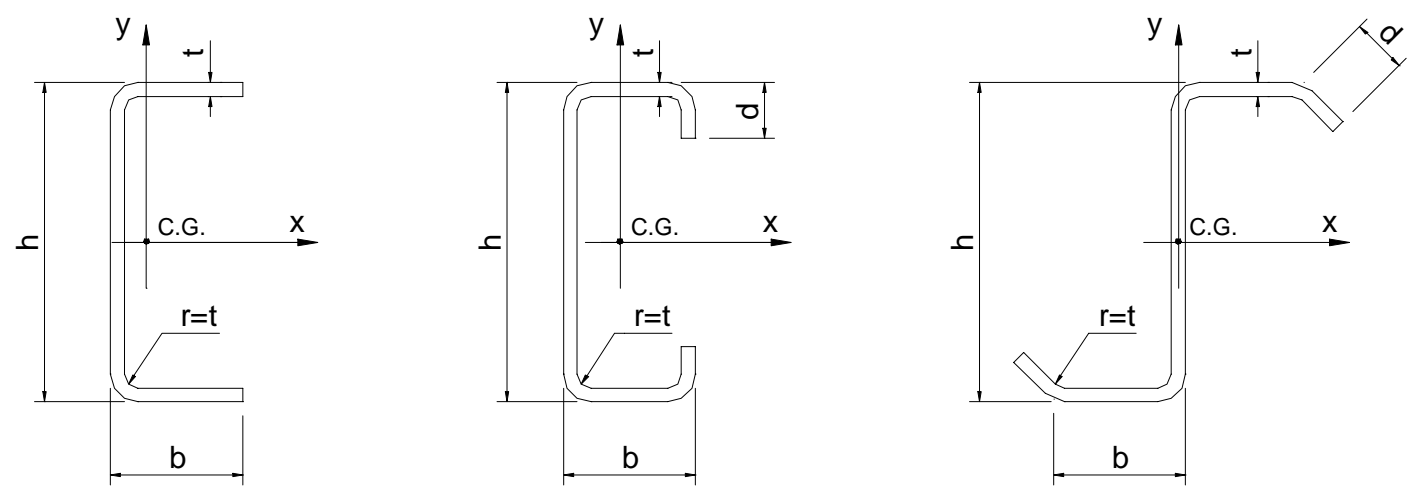

Figura 5.1: Seções transversais e nomenclatura dos perfis conectados às telhas de aço. 


\subsection{Metodologia empregada}

Para a execução dos ensaios fez-se necessário o projeto e execução de um dispositivo que permitisse a simulação do efeito de sucção devido à ação do vento em coberturas.

Este dispositivo, denominado de caixa de sucção, consiste em uma caixa de dimensões em planta que podem variar de $3 \mathrm{~m} \times 6 \mathrm{~m}$ até $12 \mathrm{~m} \times 6$ $\mathrm{m}$, em módulos de $1 \mathrm{~m} \times 6 \mathrm{~m}$. As suas faces laterais e o seu fundo são de chapas madeirit de $21 \mathrm{~mm}$ de espessura. A estrutura portante é feita em perfis de aço formados a frio.

A parte superior da caixa é composta pelo conjunto telha-terça que se deseja ensaiar, disposto em posição invertida à aquela dos telhados convencionais, de tal modo que, ao ser retirado o ar contido dentro da caixa, a diferença entre as pressões interna e externa forneça uma sobrepressão no conjunto, simulando o efeito de sucção devido à ação do vento. Esta diferença entre pressões distribuí-se de maneira uniforme em toda a superfície do painel formado pelas telhas.

A montagem na posição invertida permite o acompanhamento visual do comportamento do perfil e facilita a colocação da instrumentação e aquisição dos dados.

O projeto da caixa de sucção está ilustrado na figura 5.2 onde podese notar as suas dimensões gerais e os módulos de $1 \mathrm{~m} \times 6 \mathrm{~m}$, compondo uma caixa de $4 \mathrm{~m}$ de largura. Os pórticos são feitos em perfis tipo I formado pela união de dois perfis tipo $U$ e as barras transversais em perfis tipo $U$.

A figura 5.3 ilustra a caixa de sucção em fase de montagem e na figura 5.4 pode-se observar o conjunto telha-terça já montado, a caixa envolta por uma lona plástica, o aspirador e o perfil a ser ensaiado no centro da caixa com a sua instrumentação posicionada.

A lona plástica observada, figura 5.4, tem a função de impedir a entrada de ar de fora para dentro através das possíveis frestas entre as chapas de madeirit quando da aspiração do ar interno. Esta vedação é de 
grande importância no desenvolvimento do ensaios e torna-se indispensável para a obtenção dos valores de diferença de pressão desejados.
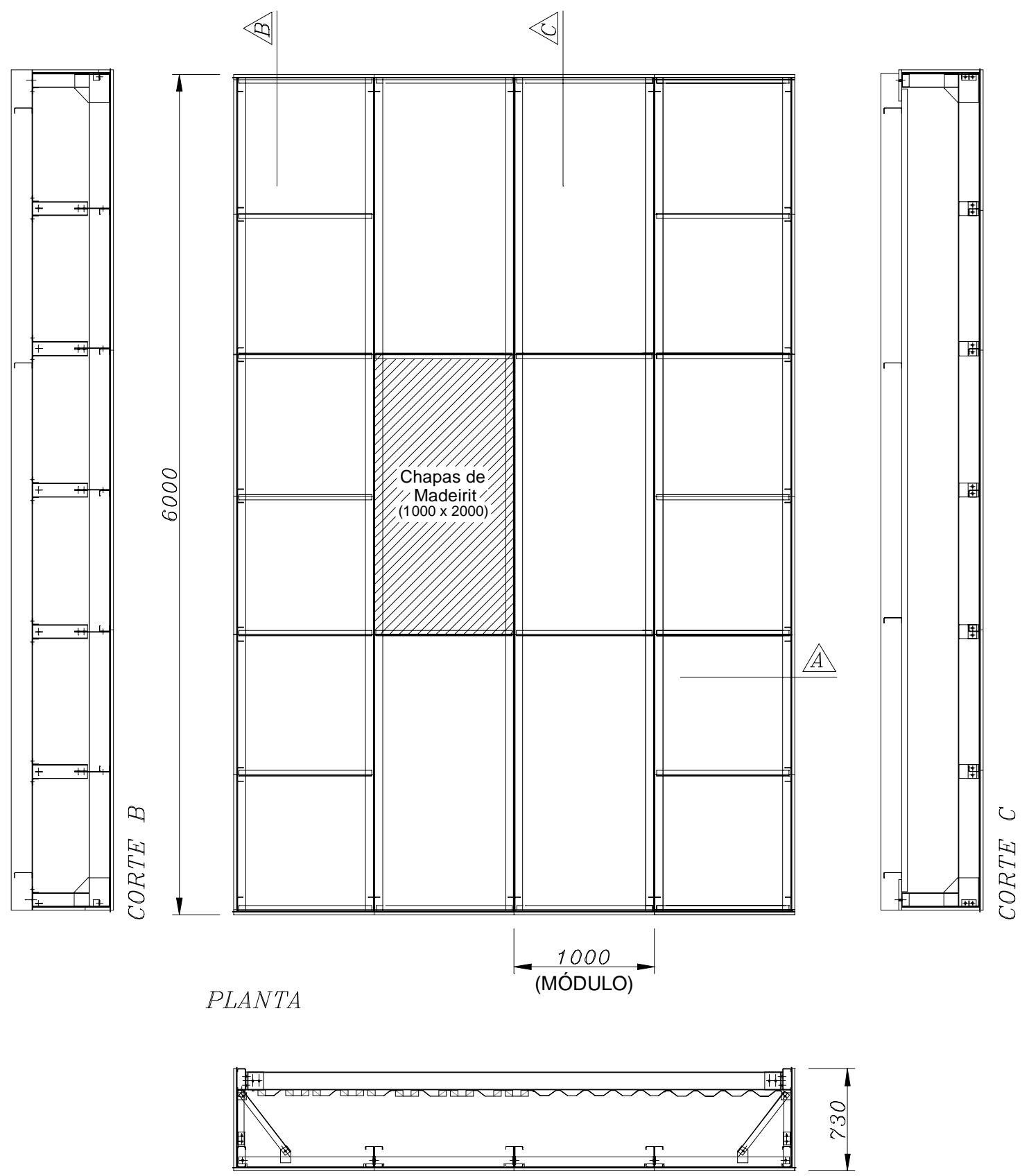

CORTE A

Figura 5.2: Caixa de sucção: Dimensões gerais 


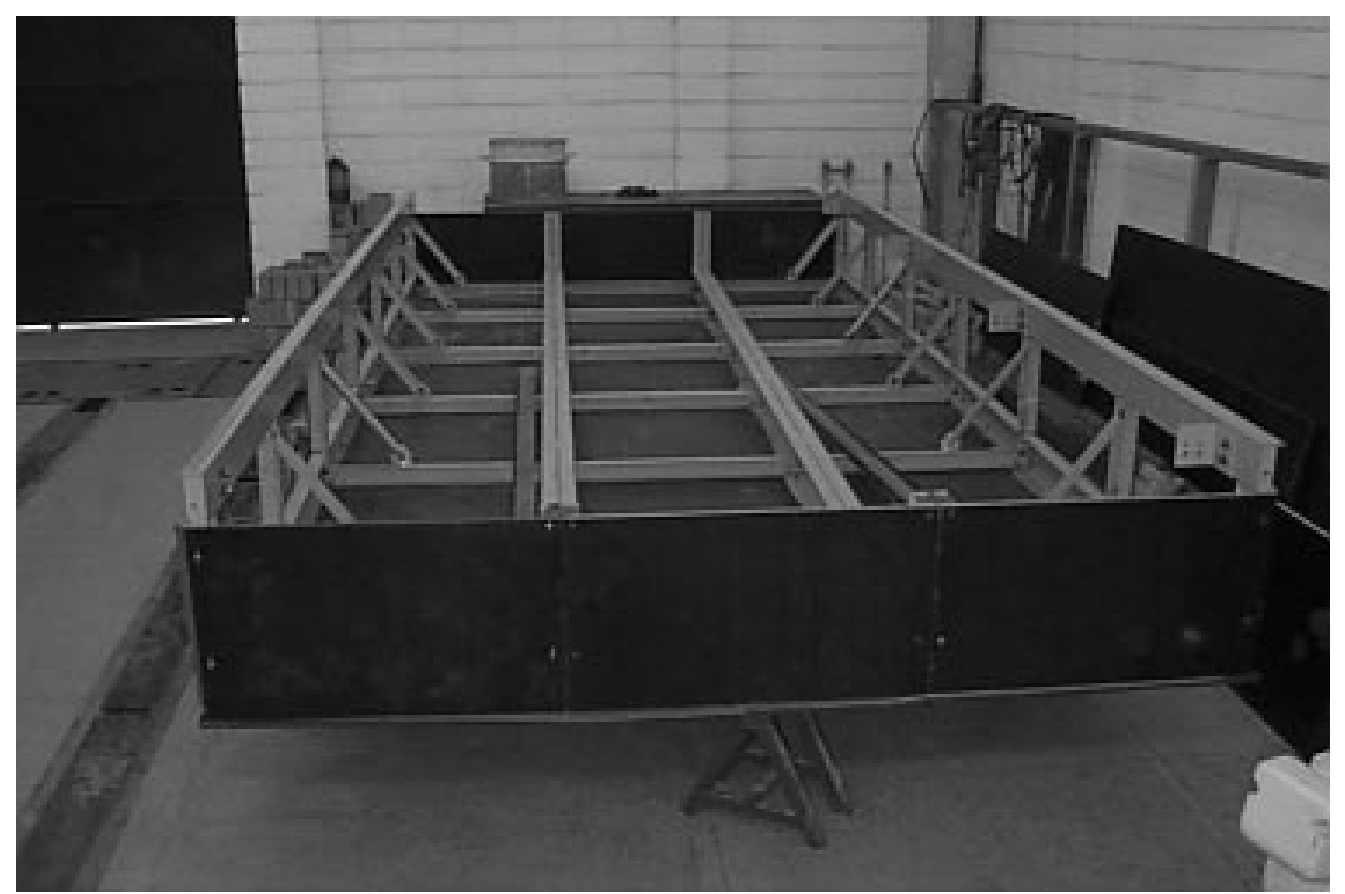

Figura 5.3: Caixa de sucção em fase de montagem.

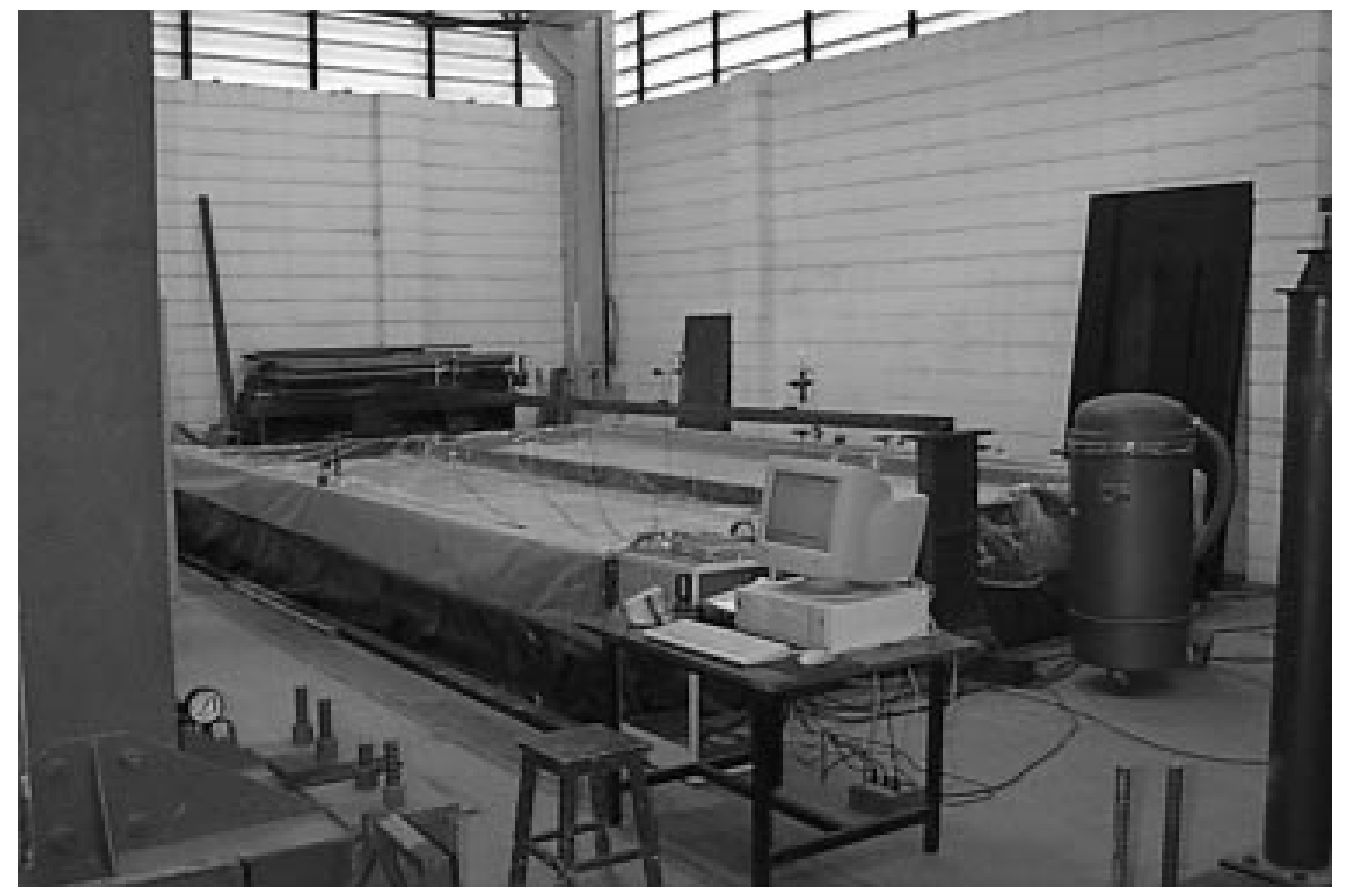

Figura 5.4: Caixa de sucção preparada para o início de um ensaio. 
$\mathrm{Na}$ figura 5.5 estão apresentados o arranjo geral dos dispositivos de ensaios e as dimensões de vão e espaçamento entre as terças utilizadas. A instrumentação foi realizada no perfil central e os perfis das extremidades tiveram apenas os deslocamentos no meio do vão medidos para controle.

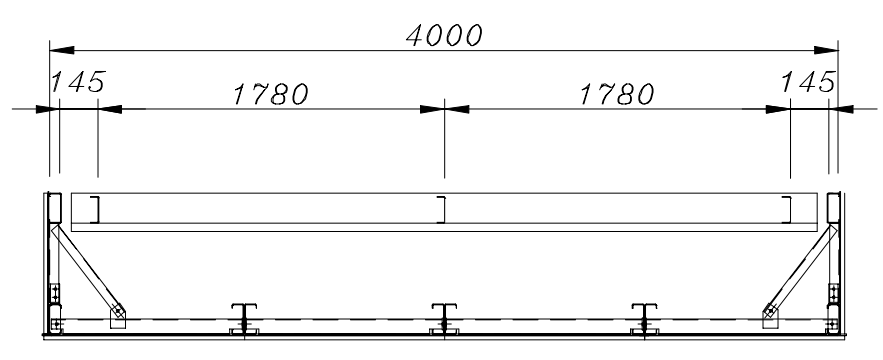

a)

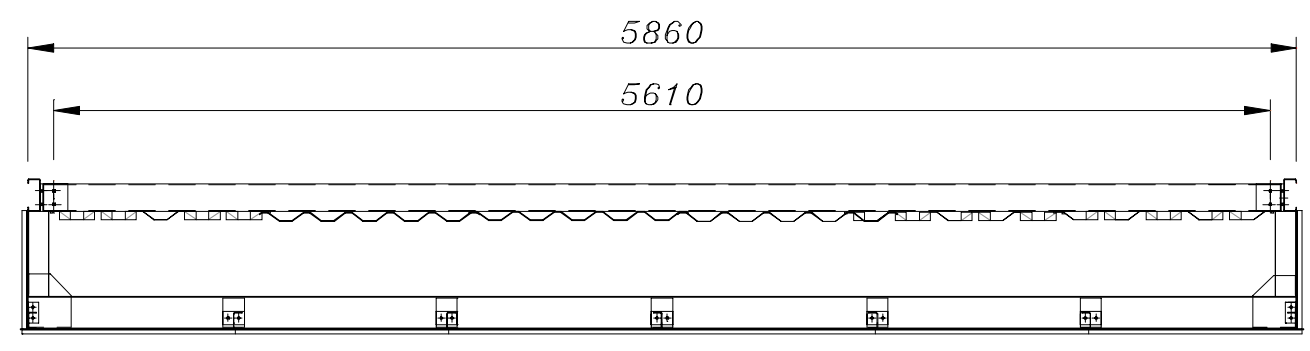

b)

Figura 5.5: Caixa de sucção - dimensões gerais:

(a) Corte transversal. (b) Corte longitudinal.

Os ensaios das terças foram realizados em perfis tipo $U, U$ enrijecido e $Z$ enrijecido, utilizando-se duas diferentes espessuras de chapas: 2,25 mm e $3,00 \mathrm{~mm}$.

A intensidade da pressão negativa foi medida através de um transdutor de pressão negativa, marca Kyowa, e também verificada por meio de um vacuômetro analógico.

Para a leitura dos deslocamentos verticais ao longo do vão do perfil instrumentado utilizou-se de transdutores de deslocamento linear, marca 
Kyowa. Os deslocamentos horizontais foram medidos na mesa superior do perfil, também através de transdutores de deslocamento linear. Na figura 5.6 pode-se obter as posições dos transdutores de deslocamento linear utilizados.

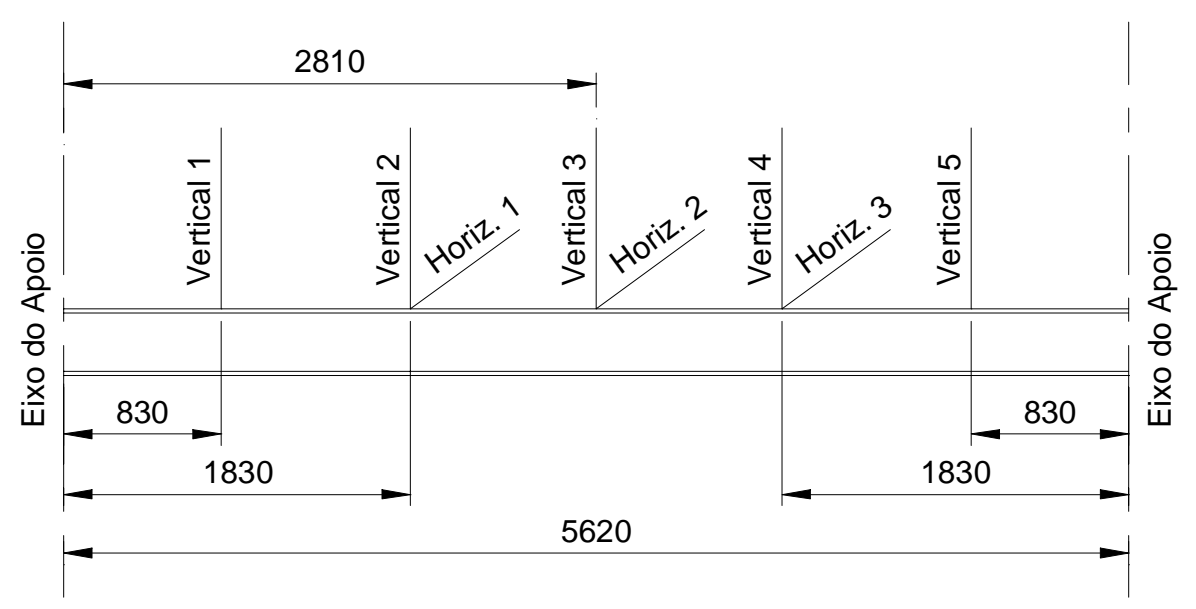

Figura 5.6: Posicionamento dos transdutores de deslocamentos.

Para a medida dos deslocamentos horizontais utilizou-se de fios de aço dispostos horizontalmente, fixados aos transdutores de deslocamento, os quais foram posicionados sobre uma base externa à caixa de sucção.

Quanto aos deslocamentos verticais, dispôs-se de um perfil de aço laminado, tipo I, onde foram posicionados os transdutores e fixados à terça através dos fios de aço. O perfil de aço laminado foi apoiado sobre outra base externa à caixa de sucção.

Isto possibilitou minimizar a influência do giro da seção transversal na leitura dos deslocamentos verticais da terça ensaiada.

$\mathrm{Na}$ figura 5.7 pode-se observar o arranjo realizado para a colocação dos transdutores de deslocamento linear. 


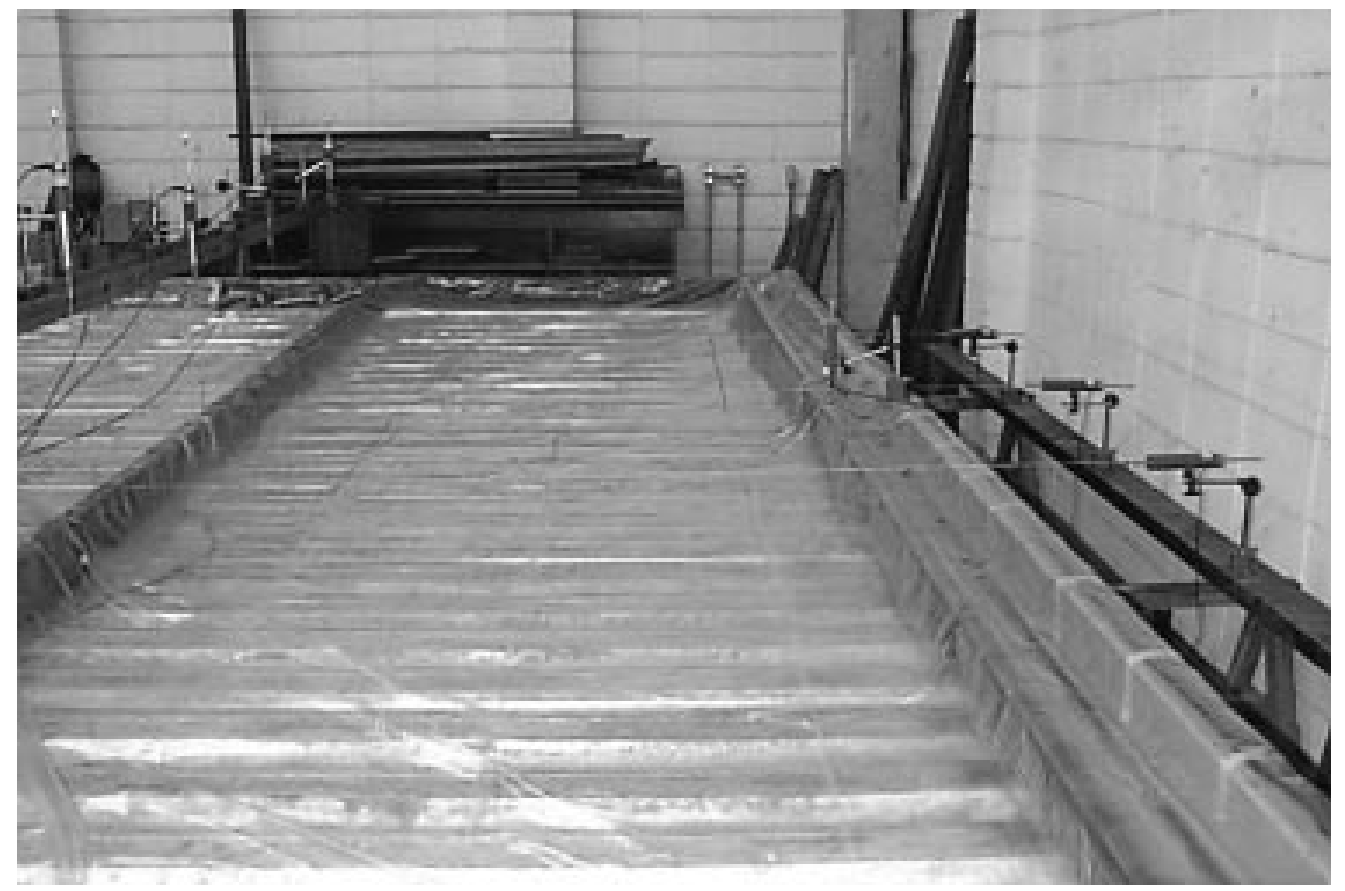

Figura 5.7: Disposição dos transdutores de deslocamento linear.

Os extensômetros elétricos de resistência foram colocados no perfil central, na seção transversal no meio do vão, nas mesas superior e inferior, conforme indicado na figura 5.8.
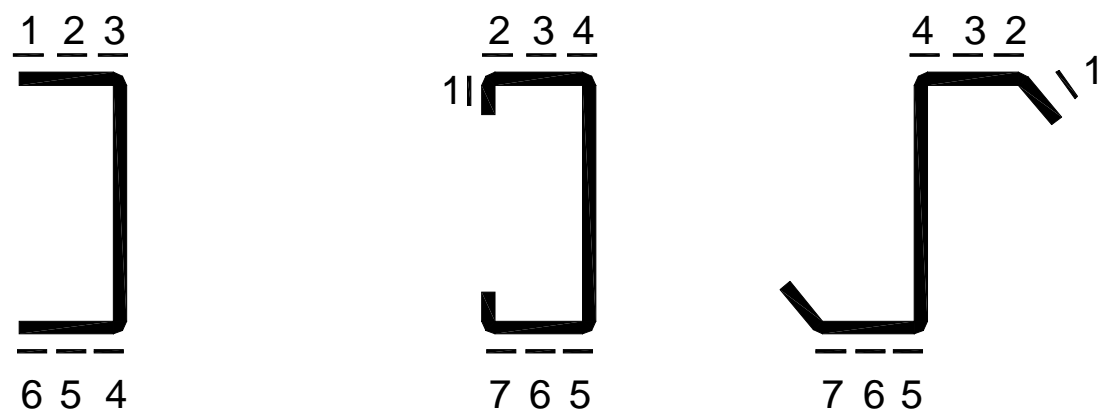

Figura 5.8: Posição dos extensômetros nas seções transversais ensaiadas.

Entre os perfis ensaiados, alguns tiverem extensômetros elétricos de resistência posicionados na alma com o objetivo de verificar a distribuição 
das tensões normais e a posição da linha neutra, bem como uma possível variação dessa posição durante o carregamento, figura 5.9.

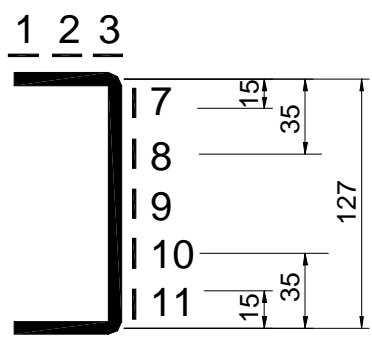

$\overline{6} \overline{5} \overline{4}$

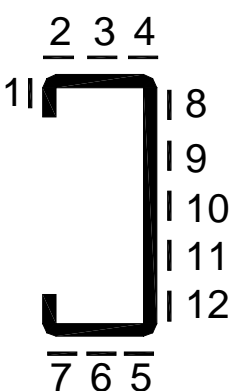

$\overline{7} \overline{6} \overline{5}$

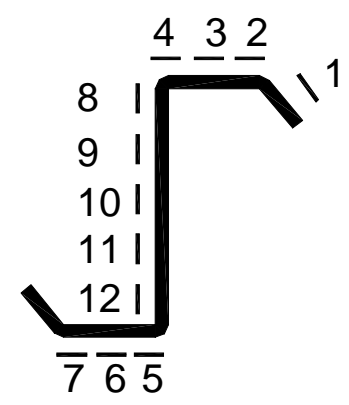

Figura 5.9: Posição dos extensômetros na alma.

$\mathrm{Na}$ figura 5.10 pode-se observar a seção transversal de um perfil com os extensômetros posicionados nas mesas e na alma.

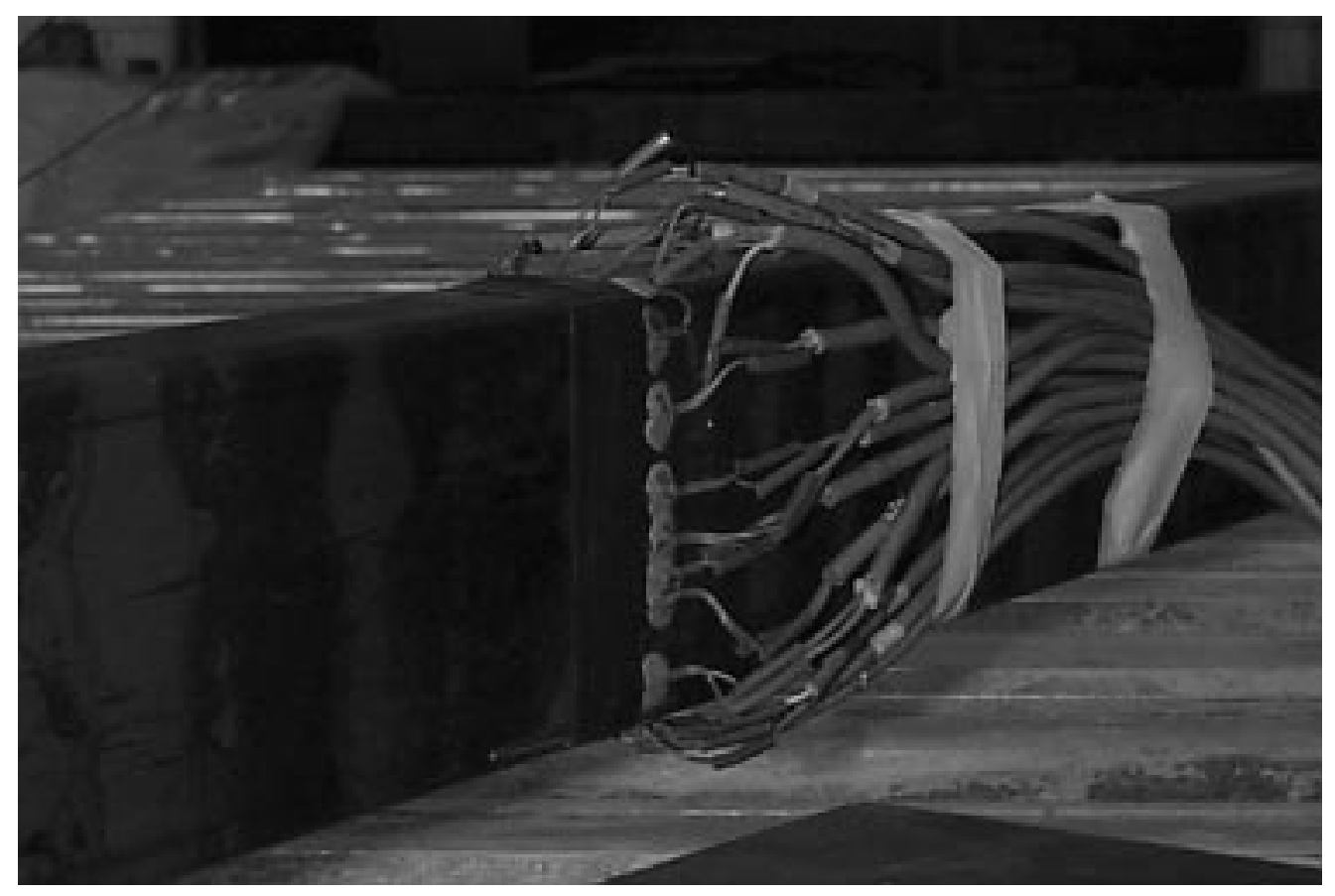

Figura 5.10: Seção transversal com extensômetros posicionados. 
As telhas de aço utilizadas possuíam seção transversal trapezoidal, cujas dimensões características estão indicadas na figura 5.11. O comprimento das telhas é de $4.010 \mathrm{~mm}$.

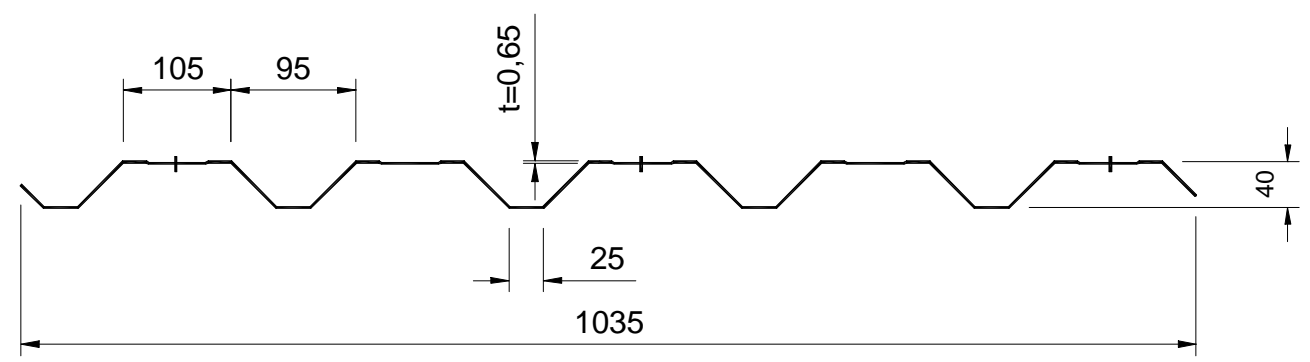

Figura 5.11: Seção transversal da telha de aço na posição de montagem.

A fixação das telhas às terças foi executada por meio de parafusos auto-brocantes, sendo executada de duas maneiras distintas. Nos três primeiros ensaios a fixação deu-se em todas as ondas das telhas. Para os ensaios restantes, a fixação foi realizada da forma convencional, $1^{\mathrm{a}}, 3^{\mathrm{a}}$ e $5^{\mathrm{a}}$ ondas, indicadas na Figura 5.11, conforme recomendações do fabricante da telha (Emesa S.A).

$\mathrm{Na}$ figura 5.12, cuja fotografia foi registrada após a execução de um teste piloto, pode-se observar o detalhe da fixação das telhas à terça, além da falha observada para a terça ensaiada.

Os apoios para as terças foram realizados através de cantoneiras fixadas aos perfis laterais da caixa de sucção através de parafusos de alta resistência (ASTM A-325). Nas cantoneiras foram fixadas as terças por meio de dois parafusos comuns. Esses apoios podem ser observados na fotografia apresentada na figura 5.12. Esse detalhe procurou reproduzir o detalhe convencional de fixação das terças em obras correntes.

As medidas da diferença entre as pressões interna e externa, os deslocamentos ocorridos e as deformações nos perfis foram realizadas em intervalos de tempos regulares. Isto deveu-se ao fato da retirada do ar interno ocorrer de forma contínua e relativamente rápida. A aquisição 
desses dados foi, então, realizada automaticamente por meio do sistema de aquisição de dados WIN5000 da Measurements Group Inc, em intervalos regulares de 5 segundos.

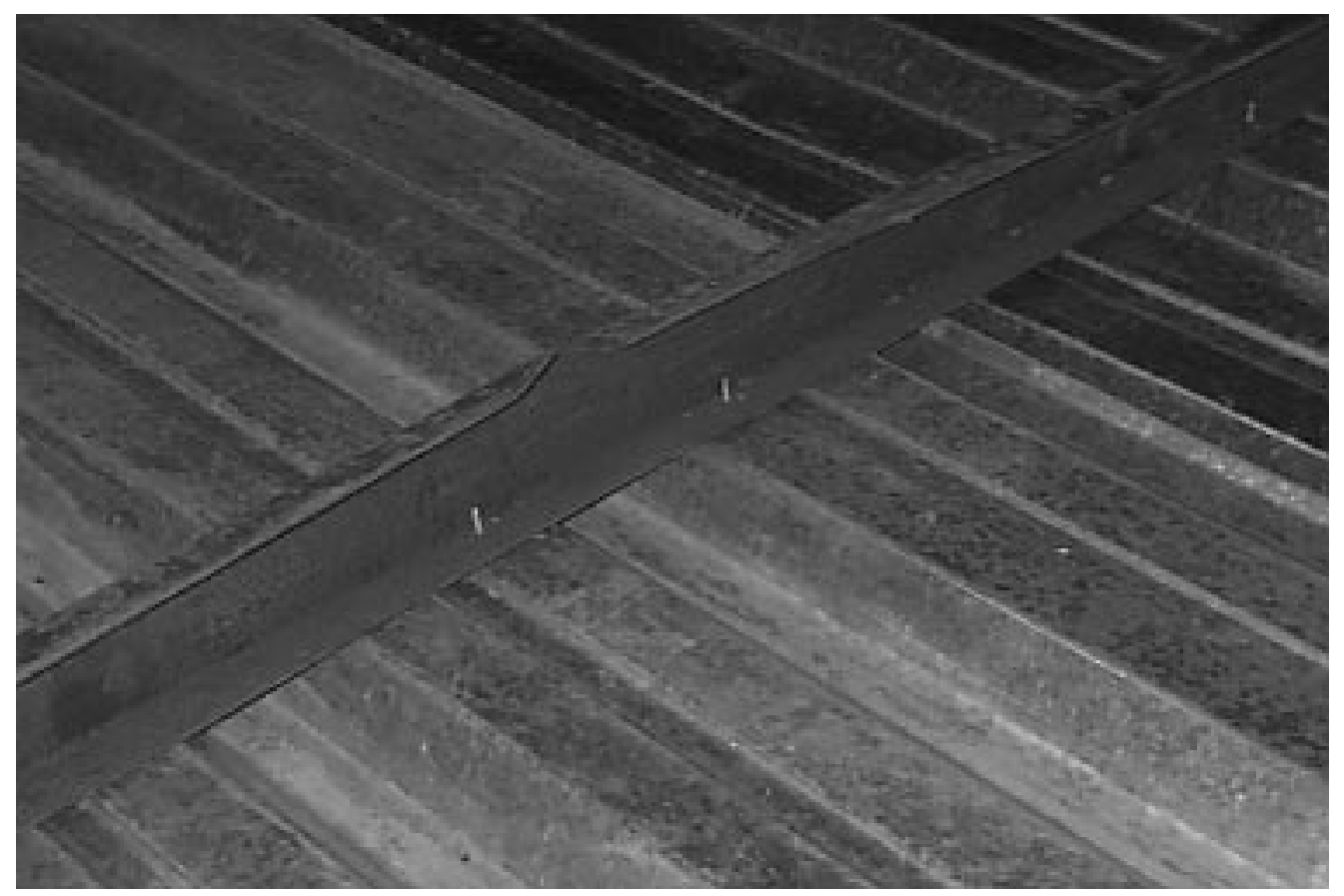

Figura 5.12: Fixação telha-terça e falha para um teste piloto.

O desenvolvimento desses ensaios iniciou-se através da execução de uma caixa de sucção em dimensões reduzidas, correspondente a uma telha de $1600 \mathrm{~mm}$ de comprimento, verificando-se a necessidade de uma vedação eficiente e a exequibilidade do projeto. Esta caixa de sucção está apresentada na figura 5.13 onde pode ser observada a ruína da telha.

Ainda na fase inicial, executou-se posteriormente um ensaio preliminar em um conjunto composto de 4 terças com $2.750 \mathrm{~mm}$ de vão e perfis tipo $U 75 \times 40 \times 2,25$.

Este ensaio teve como objetivo verificar o comportamento dos dispositivos utilizados, para em seguida dar-se o início dos testes para os conjuntos de ensaios previstos.

Esta caixa já possuía dimensões próximas das desejadas para a execução dos ensaios previstos. Novamente, a maior dificuldade 
encontrada foi a vedação, a qual, após realizada de forma adequada, permitiu a execução do ensaio sem dificuldades.

A figura 5.14 apresenta esta caixa de sucção preparada para o início do ensaio preliminar e na Figura 5.15 pode-se observar a falha ocorrida para o conjunto.

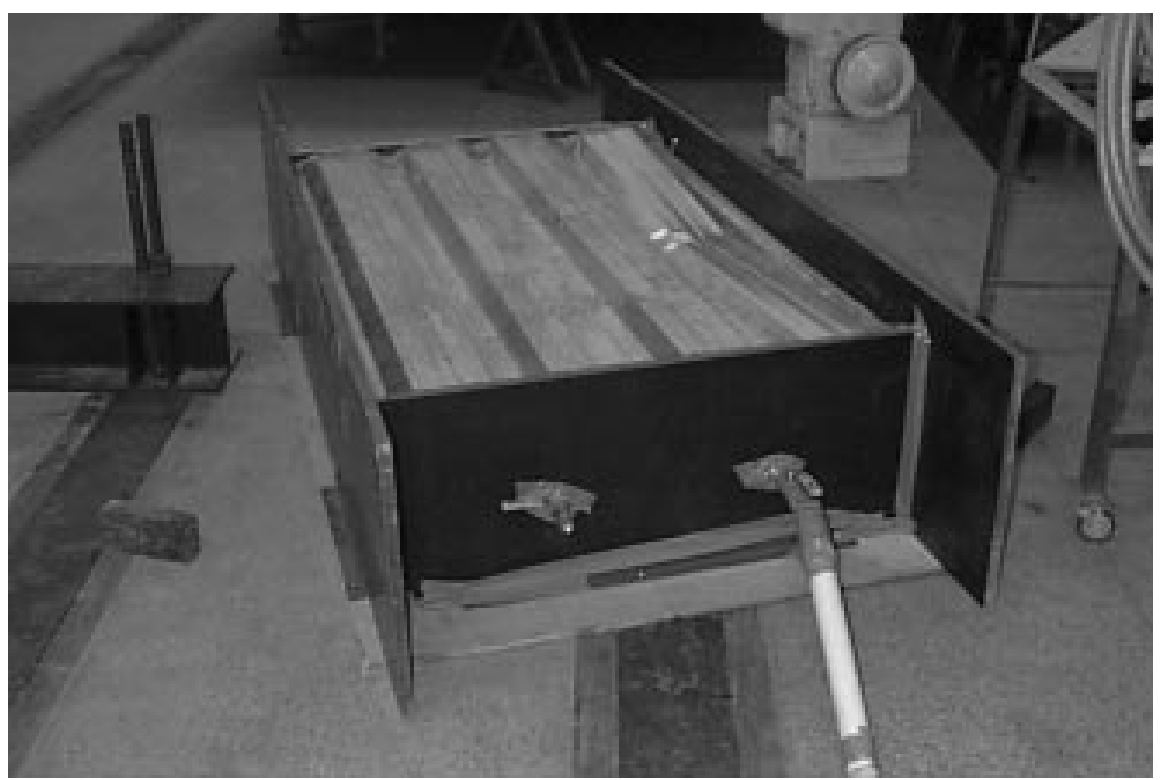

Figura 5.13: Caixa de sucção para teste em uma telha.

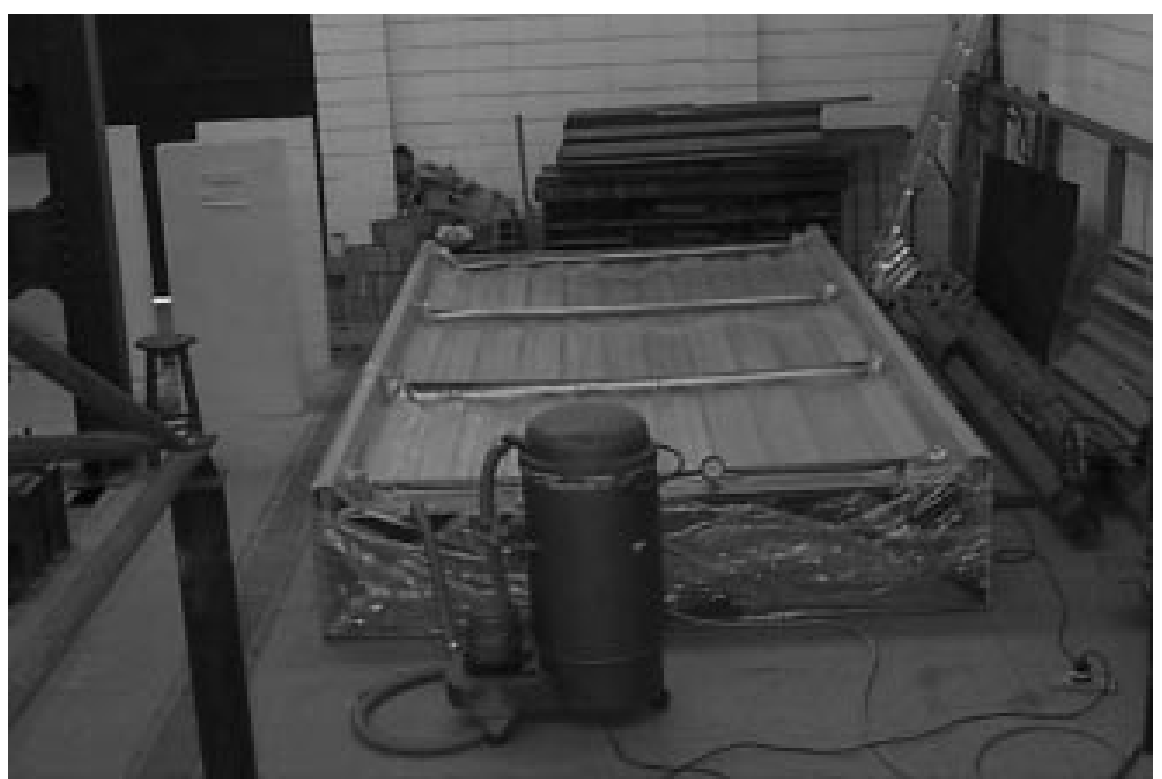

Figura 5.14: Caixa de sucção em fase de testes. 


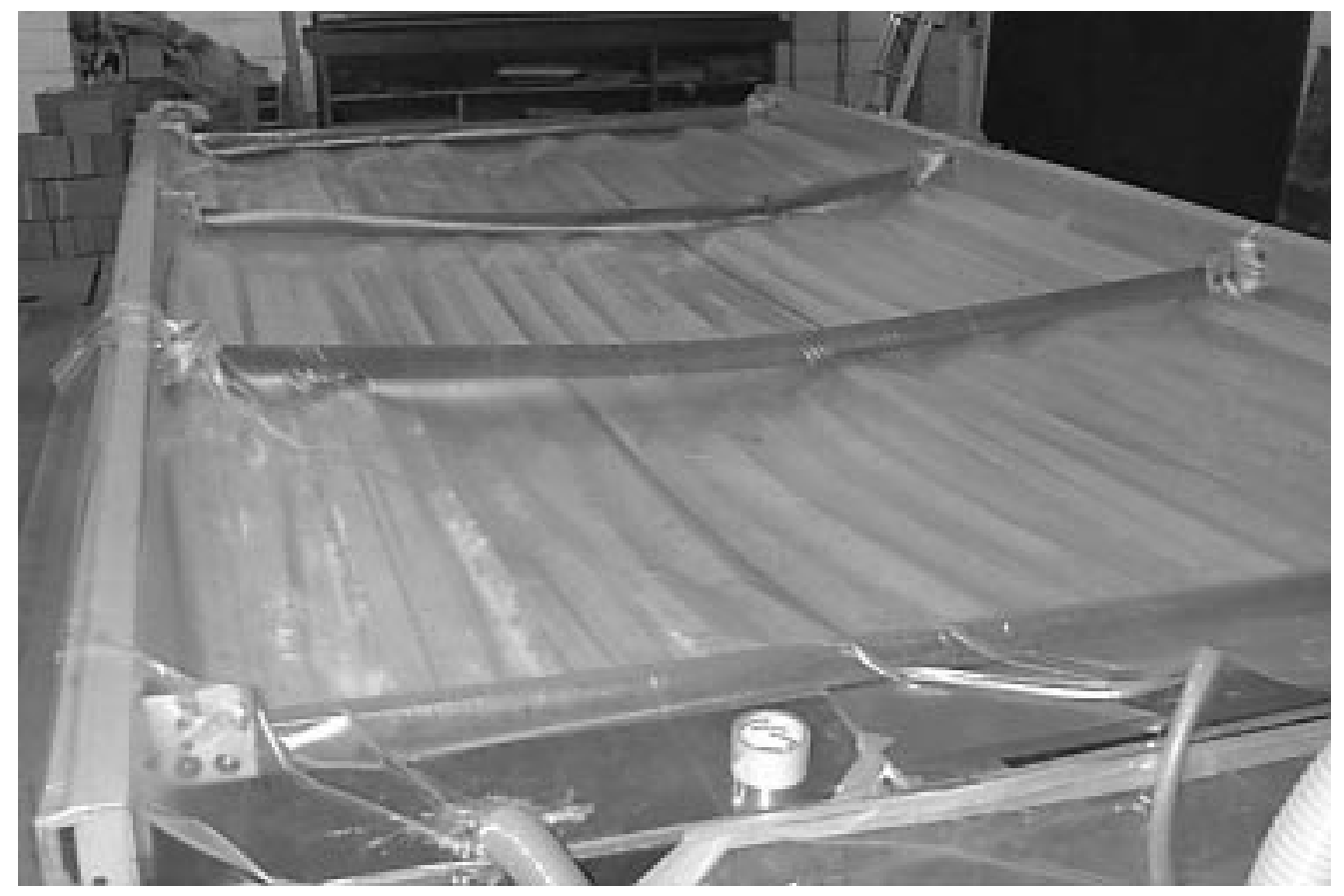

Figura 5.15: Falha do conjunto para o teste preliminar.

\subsection{Modelos ensaiados}

Foram realizados o total de 15 ensaios com três tipos de seções transversais para os perfis, sendo 7 desses ensaios executados sem linhas de correntes e 8 realizados com duas linhas de correntes, uma a cada 1/3 de vão.

Essas linhas de correntes foram executadas com cantoneiras entre os perfis e com barras de seção circular com rosca nas extremidades. Essas barras foram dispostas na diagonal para a fixação aos apoios, como se faz normalmente em coberturas. A figura 5.16 ilustra a disposição das linhas de correntes junto às terças.

$\mathrm{Na}$ tabela 5.1 apresentam-se os diferentes perfis ensaiados, suas dimensões nominais e o posicionamento das linhas de corrente. 


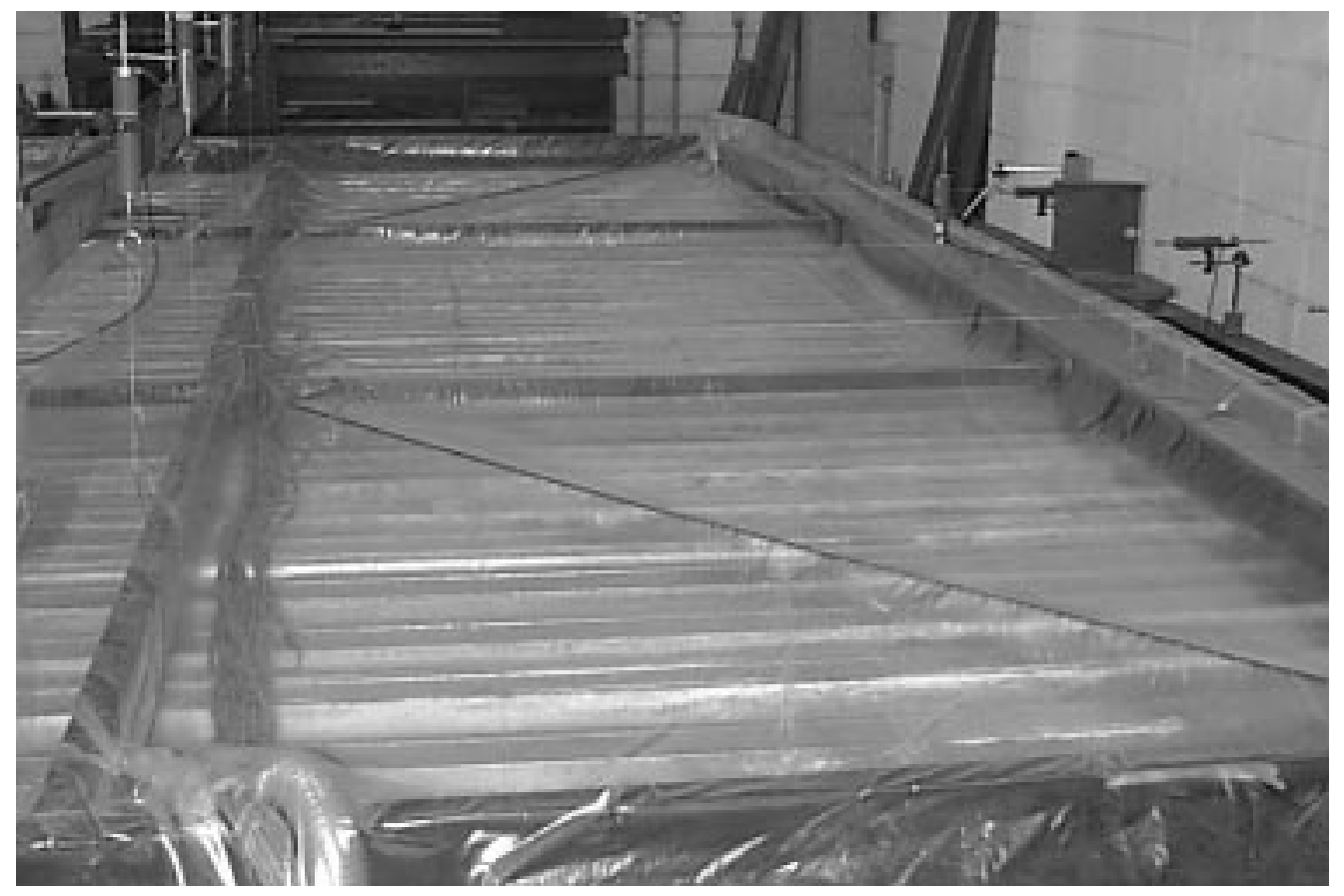

Figura 5.16: Linhas de correntes para as terças (cantoneiras e barras redondas).

Tabela 5.1 - Perfis ensaiados.

\begin{tabular}{c|c|c|c|c}
\hline Ensaio & Perfil & Fixação c/ telha & Correntes & Observação \\
\hline 1 & $\mathrm{U} 127 \times 50 \times 3,00$ & Toda onda & Não & \\
\hline 2 & $\mathrm{U} 127 \times 50 \times 17 \times 3,00$ & Toda onda & Não & \\
\hline 3 & $\mathrm{Z} 127 \times 50 \times 17 \times 3,00$ & Toda onda & Não & \\
\hline 4 & $\mathrm{U} 127 \times 50 \times 3,00$ & Convencional & Não & \\
\hline 5 & $\mathrm{U} 127 \times 50 \times 3,00$ & Convencional & Não & \\
\hline 6 & $\mathrm{U} 127 \times 50 \times 17 \times 3,00$ & Convencional & Não & \\
\hline 7 & $\mathrm{U} 127 \times 50 \times 17 \times 3,00$ & Convencional & Não & Extensômetros na alma \\
\hline 8 & $\mathrm{U} 127 \times 50 \times 2,25$ & Convencional & $1 / 3$ do vão & \\
\hline 9 & $\mathrm{U} 127 \times 50 \times 2,25$ & Convencional & $1 / 3$ do vão & \\
\hline 10 & $\mathrm{U} 127 \times 50 \times 2,25$ & Convencional & $1 / 3$ do vão & Extensômetros na alma \\
\hline 11 & $\mathrm{U} 127 \times 50 \times 3,00$ & Convencional & $1 / 3$ do vão & Extensômetros na alma \\
\hline 12 & $\mathrm{Z127 \times 50 \times 17 \times 2,25}$ & Convencional & $1 / 3$ do vão & \\
\hline 13 & $\mathrm{Z127 \times 50 \times 17 \times 2,25}$ & Convencional & $1 / 3$ do vão & Extensômetros na alma \\
\hline 14 & $\mathrm{Z127 \times 50 \times 3,00}$ & Convencional & $1 / 3$ do vão & \\
\hline 15 & $\mathrm{Z127 \times 50 \times 3,00}$ & Convencional & $1 / 3$ do vão & Extensômetros na alma \\
\hline
\end{tabular}


O aço utilizado foi o USI-SAC 41, cujos os valores da tensão limite de escoamento $\left(f_{y}\right)$ e da tensão limite de ruptura à tração $\left(f_{u}\right)$ são aqueles apresentados anteriormente na tabela 4.1.

Após preparado o conjunto a ser ensaiado, eram efetuadas as medidas das dimensões do perfil em suas extremidades e na sua seção transversal central.

A fase de carregamento iniciava-se com o escorvamento do conjunto, registrando-se os deslocamentos transversais e horizontais dos pontos instrumentados. Após verificada a conformidade dos valores obtidos pela simetria de posição e carregamento, bem como a eficiência da vedação, era iniciado o ensaio propriamente dito.

Os perfis das extremidades da caixa de sucção foram mantidos

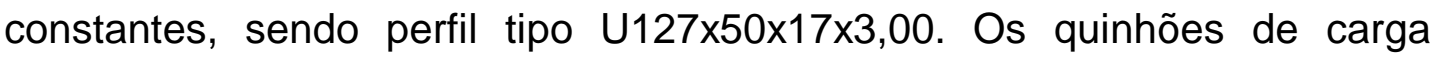
correspondente à cada perfil foi determinado proporcionalmente à sua rigidez à flexão.

\subsection{Apresentação dos resultados}

Na figura 5.17 apresenta-se o gráfico referente ao primeiro ensaio desenvolvido. Nele pode-se observar os deslocamentos horizontais e verticais ocorridos na seção transversal central, em vários pontos ao longo de sua altura. O perfil ensaiado trata-se de um perfil tipo U127×50×3,00.

Nota-se que o deslocamento da mesa inferior em relação à telha é nulo durante todo o ensaio e o deslocamento da mesa superior é maior quando medido com relação à uma base externa à caixa, resultados estes já esperado. 


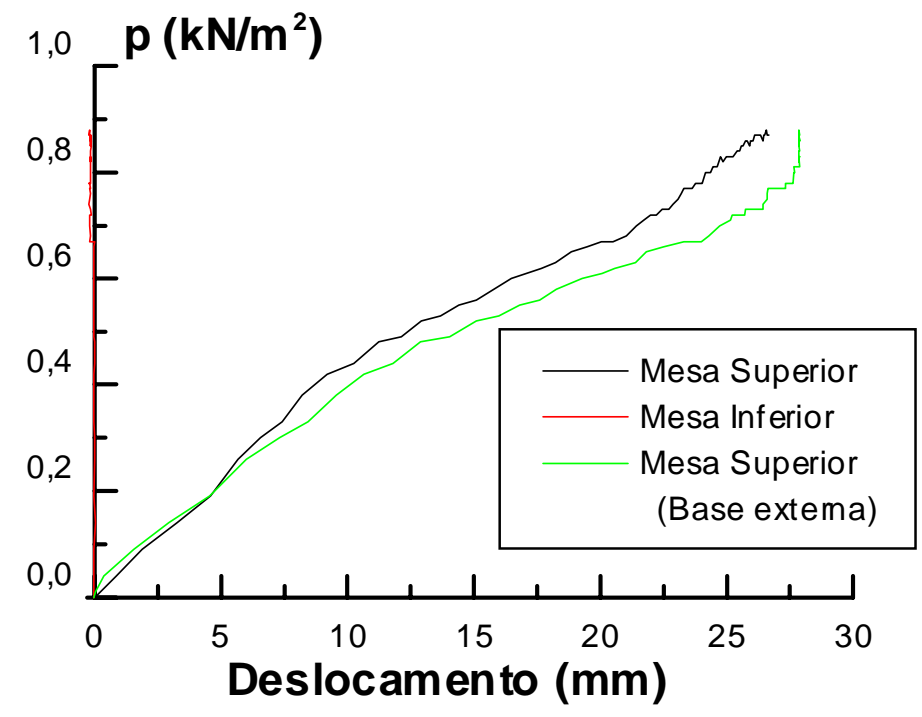

Figura 5.17: Deslocamentos horizontais para as mesas do perfil (Ensaio 1).

No gráfico da Figura 5.18 pode-se observar os deslocamentos verticais no meio do vão, medidos para a telha e para o perfil, correspondentes ao ensaio 1. Nota-se que os valores medidos apresentamse praticamente iguais.

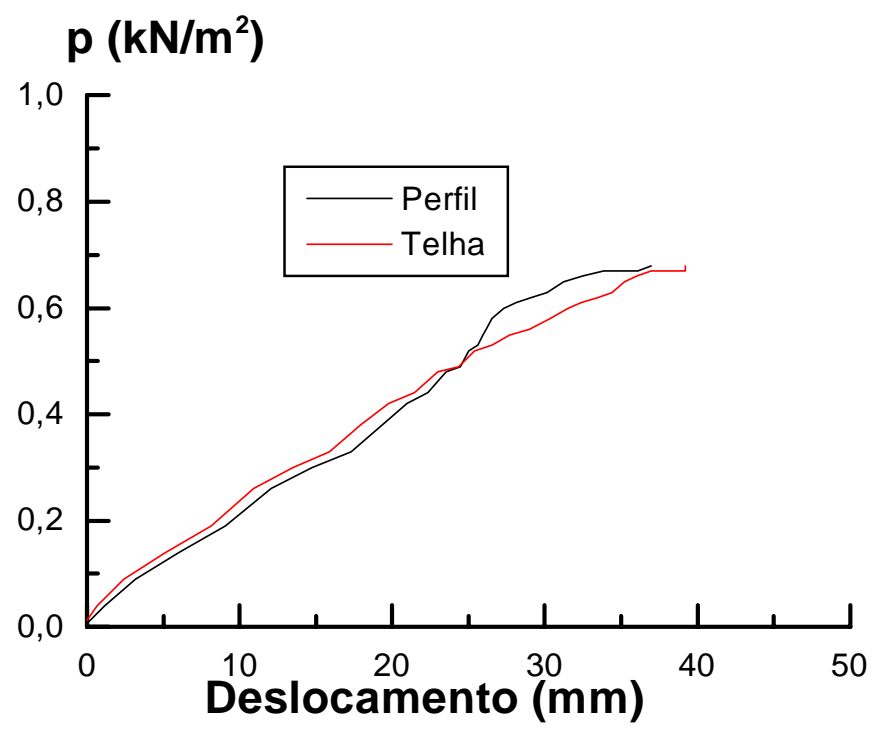

Figura 5.18: Deslocamentos verticais no centro do vão (Ensaio 1).

Esses resultados foram semelhantes para os três primeiros ensaios desenvolvidos, um para cada tipo de perfil ensaiado: perfil tipo $U$; perfil tipo 
$U$ enrijecido e perfil tipo $Z$ enrijecido. Esses resultados nortearam a instrumentação final, a qual foi seguida para os demais ensaios desenvolvidos.

Na tabela 5.2 apresentam-se os resultados da pressão aplicada nos ensaios realizados. Para efeito de comparação dos valores obtidos, essa pressão está referida a dois valores relativos da flecha: o primeiro para uma flecha igual a 1/180 do vão $(31,22 \mathrm{~mm})$ e o segundo, para uma flecha igual a 1/100 do vão $(56,2 \mathrm{~mm})$.

A utilização desses dois valores justifica-se tendo-se em vista que o primeiro é utilizado como limite de deslocamento máximo para terças enquanto o segundo admite-se como sendo aquele para o qual tem-se o prejuízo do uso da estrutura, caracterizando-se a sua falha.

$O$ valor do momento fletor na seção do meio do vão, $\mathrm{M}_{\text {ret, }}$ corresponde ao valor da pressão para $1 / 100$ do vão. Este momento é o de um carregamento uniformemente distribuído ao longo do comprimento do perfil, cujo valor é obtido pelo produto entre o valor da pressão de referência e a largura de influência para o perfil. Esta largura de influência foi determinada a partir dos deslocamentos verticais medidos no meio do vão para os perfis laterais e para o perfil instrumentado.

Os tipos das falhas ocorridas para os perfis conectados às telhas foram o de deslocamento excessivo e o de flambagem local da mesa possivelmente associado à distorção.

Os deslocamentos horizontais excessivos, já evidentes para baixos valores de pressão, induziram às falhas precoces não relatadas em bibliografia e não consideradas como um possível estado limite último nas normalizações pertinentes. Tal fato passa a ser importante e deverá ser analisado como sendo um modo de falha possível para as terças nas quais não se tem o uso de linhas de correntes. 
Tabela 5.2 - Pressão de referência para as terças.

\begin{tabular}{|c|c|c|c|c|c|}
\hline \multirow[t]{2}{*}{ Ensaio } & \multirow[t]{2}{*}{ Perfil } & \multirow[t]{2}{*}{ Corrente } & \multicolumn{2}{|c|}{$p\left(k N / m^{2}\right)$} & \multirow[t]{2}{*}{$\mathrm{M}_{\mathrm{ref}}(\mathrm{kN} . \mathrm{m})$} \\
\hline & & & $\mathrm{L} / 180$ & $\mathrm{~L} / 100$ & \\
\hline 1 & U127x50×3,00 & Não & 0,65 & 0,85 & 4,30 \\
\hline 2 & U127×50x17×3,00 & Não & 0,60 & 0,93 & 5,65 \\
\hline 3 & Z127x50x17×3,00 & Não & 0,50 & 0,80 & 3,60 \\
\hline 4 & U127x50×3,00 & Não & 0,40 & 0,61 & 3,09 \\
\hline 5 & U127x50x3,00 & Não & 0,30 & 0,50 & 2,53 \\
\hline 6 & U127x50x17×3,00 & Não & 0,33 & 0,55 & 2,78 \\
\hline 7 & U127x50x17×3,00 & Não & 0,31 & 0,52 & 2,15 \\
\hline 8 & U127x50x2,25 & Sim & 0,50 & 0,75 & 4,74 \\
\hline 9 & U127x50x2,25 & Sim & 0,20 & 0,65 & 4,41 \\
\hline 10 & U127x50x2,25 & Sim & 0,50 & 0,75 & 4,62 \\
\hline 11 & U127x50×3,00 & Sim & 0,55 & 1,00 & 6,87 \\
\hline 12 & Z127x50x17x2,25 & Sim & 0,45 & 0,80 & 5,81 \\
\hline 13 & Z127x50x17x2,25 & Sim & 0,45 & 0,80 & 5,81 \\
\hline 14 & Z127x50x17×3,00 & Sim & 0,54 & 0,96 & 8,03 \\
\hline 15 & Z127x50x17×3,00 & Sim & 0,54 & 0,98 & 8,20 \\
\hline
\end{tabular}

$\mathrm{M}_{\text {ref }}$ corresponde ao valor de $\mathrm{p}$ para $\mathrm{L} / 100$.

Da Tabela 5.2 pode-se observar dispersões nos valores de " $p$ " para os mesmos tipos de perfis correspondentes ao limite de deslocamento L/180. Tal fato pode ser justificado pelo grande número de variáveis envolvidas no problema.

O giro na seção transversal do perfil ocorre nas proximidades da junção alma-mesa tracionada e está representado no gráfico da figura 5.19, medido para o perfil tipo Z127×50×17×3,00, correspondente ao ensaio 3 .

$\mathrm{Na}$ figura 5.20 pode-se notar a grandeza dos deslocamentos ocorridos e o giro da seção ao longo do vão. 

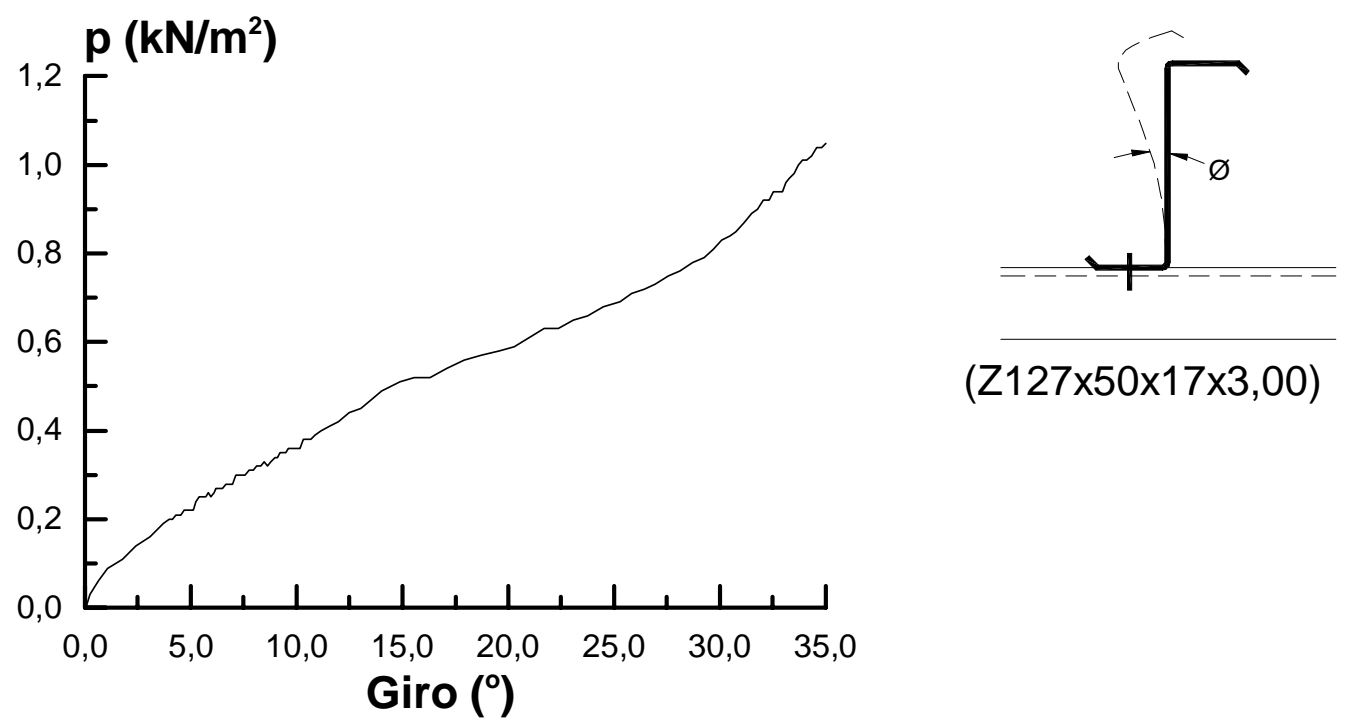

$(Z 127 \times 50 \times 17 \times 3,00)$

Figura 5.19: Giro para a seção central (Ensaio 3).

A flambagem local da mesa passou a ocorrer somente após a colocação das linhas de corrente e está ilustrada na figura 5.21, cuja fotografia foi registrada para o ensaio 8 .

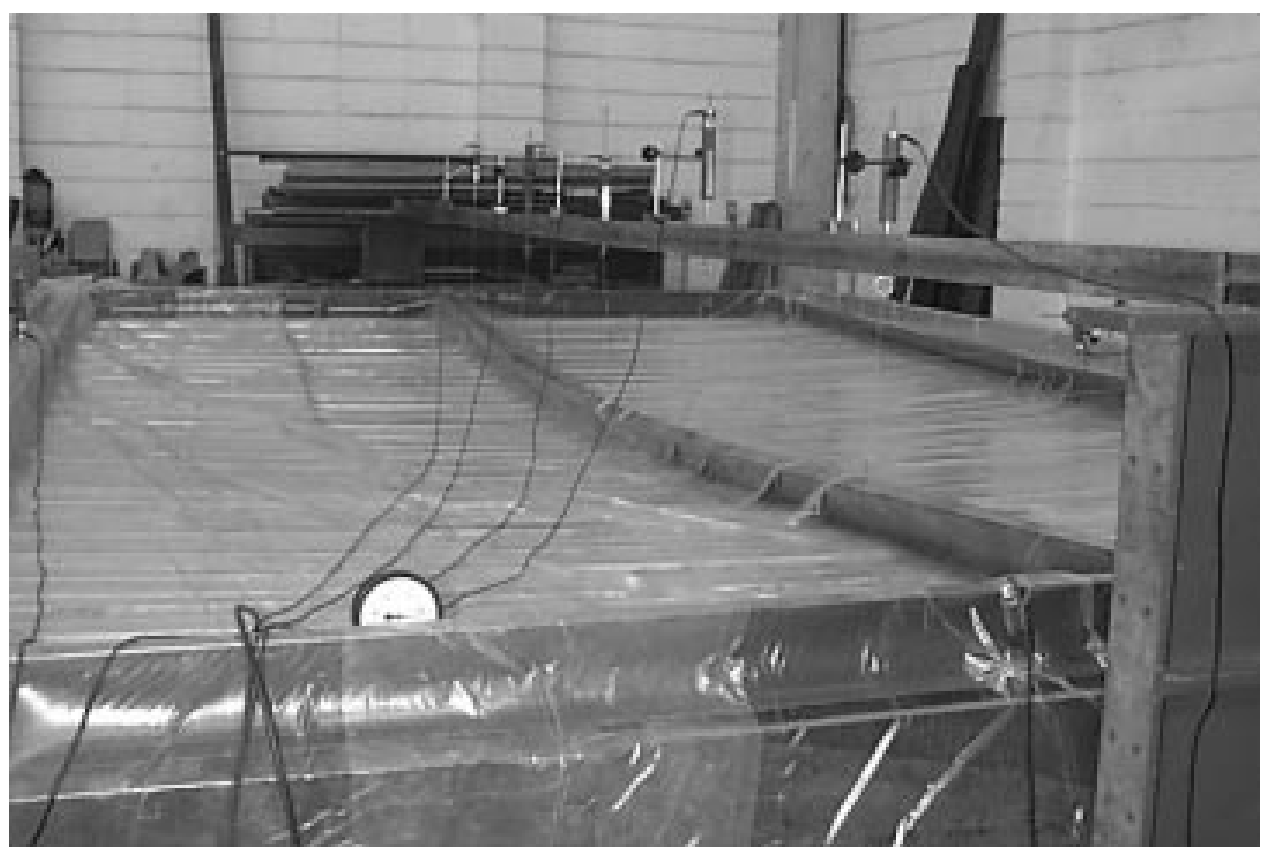

Figura 5.20: Deslocamentos horizontais e verticais observados (Ensaio 3). 


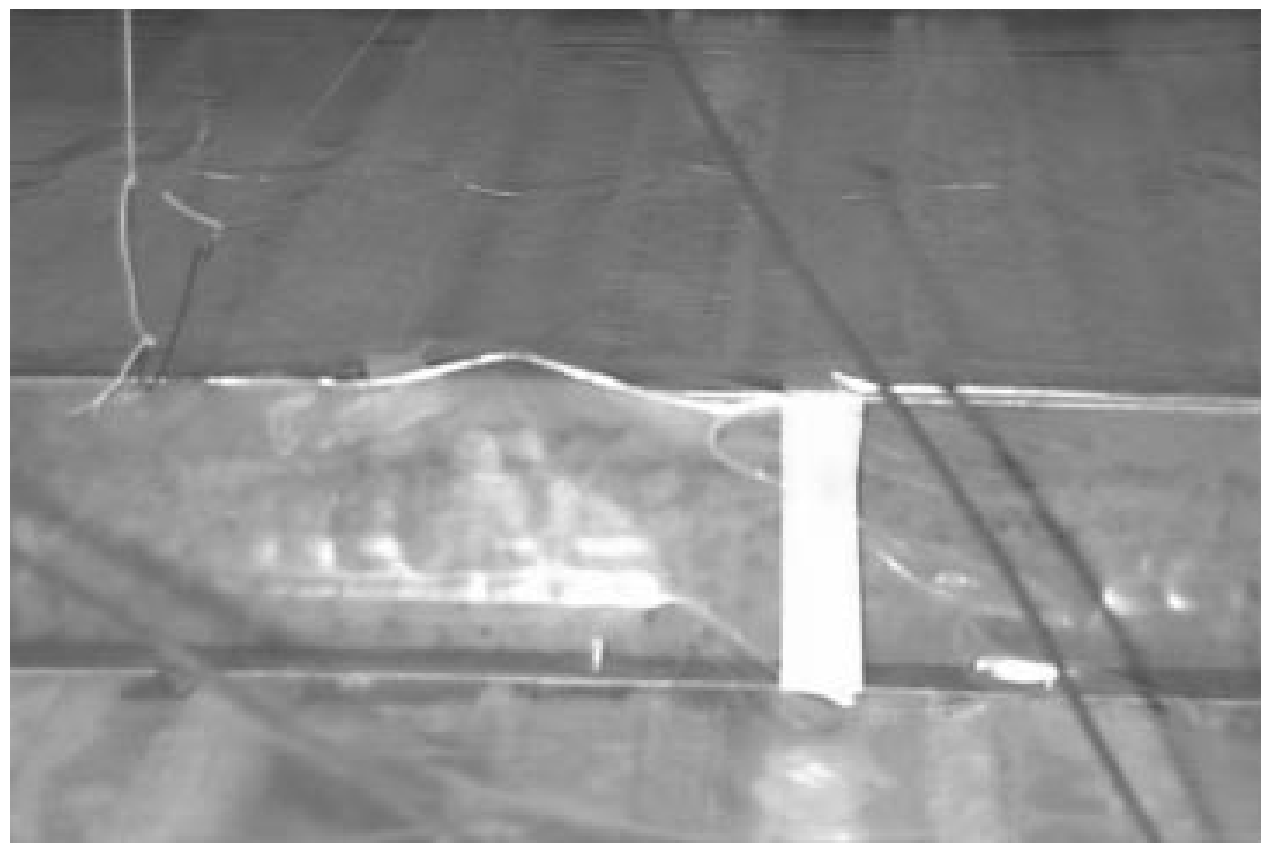

Figura 5.21: Flambagem local da mesa para uma terça em perfil tipo U127x50x2,25 (Ensaio 8).

A tabela 5.3 traz o modo de falha ocorrido para cada um dos ensaios realizados observando-se também os deslocamentos relativos medidos.

$\mathrm{Na}$ tabela 5.3 pode-se observar os valores das relações entre os deslocamentos verticais para o vão (v/L) e entre os deslocamentos horizontais para o vão (u/L). Nota-se que os valores dos deslocamentos horizontais da mesa destravada são da ordem de metade da flecha para os perfis sem correntes.

Os valores da relação entre os deslocamentos horizontais para o vão $(\mathrm{u} / \mathrm{L})$, para os perfis tipo $U$ com linhas de corrente, foram considerados como os correspondentes ao fim do carregamento, o qual deu-se após a ocorrência da FLM. Como se verá adiante, esses deslocamentos permanecem praticamente nulos até a ocorrência deste estado limite. 
Tabela 5.3 - Modos de falhas para os perfis conectados às telhas.

\begin{tabular}{c|c|c|c|c}
\hline Ensaio & Perfil & Modo de Falha & $\mathrm{v} / \mathrm{L}$ & $\mathrm{u} / \mathrm{L}$ \\
\hline \multicolumn{5}{|c}{ Ensaios sem linhas de corrente } \\
\hline 1 & $\mathrm{U} 127 \times 50 \times 3,00$ & Deslocamento excessivo & $1 / 104$ & $1 / 201$ \\
\hline 2 & $\mathrm{U} 127 \times 50 \times 17 \times 3,00$ & Deslocamento excessivo & $1 / 75$ & $1 / 173$ \\
\hline 3 & $Z 127 \times 50 \times 17 \times 3,00$ & Deslocamento excessivo & $1 / 64$ & $1 / 222$ \\
\hline 4 & $\mathrm{U} 127 \times 50 \times 3,00$ & Deslocamento excessivo & $1 / 88$ & $1 / 165$ \\
\hline 5 & $\mathrm{U} 127 \times 50 \times 3,00$ & Deslocamento excessivo & $1 / 58$ & $1 / 120$ \\
\hline 6 & $\mathrm{U} 127 \times 50 \times 17 \times 3,00$ & Deslocamento excessivo & $1 / 60$ & $1 / 112$ \\
\hline 7 & $\mathrm{U} 127 \times 50 \times 17 \times 3,00$ & Deslocamento excessivo & $1 / 60$ & $1 / 110$ \\
\hline
\end{tabular}

Ensaios com linhas de correntes

\begin{tabular}{|c|c|c|c|c|}
\hline 8 & U127x50x2,25 & Flambagem local da mesa & $1 / 67$ & $1 / 745$ \\
\hline 9 & U127x50x2,25 & Flambagem local da mesa & $1 / 67$ & $1 / 256^{*}$ \\
\hline 10 & U127×50×2,25 & Flambagem local da mesa & $1 / 77$ & $1 / 258^{*}$ \\
\hline 11 & U127×50×3,00 & Flambagem local da mesa & $1 / 91$ & $1 / 430^{*}$ \\
\hline 12 & $Z 127 \times 50 \times 17 \times 2,25$ & Deslocamento excessivo & $1 / 67$ & $1 / 5980$ \\
\hline 13 & $Z 127 \times 50 \times 17 \times 2,25$ & Deslocamento excessivo & $1 / 66$ & $1 / 2400$ \\
\hline 14 & $2127 \times 50 \times 17 \times 3,00$ & Deslocamento excessivo & $1 / 64$ & $1 / 2475$ \\
\hline 15 & $Z 127 \times 50 \times 17 \times 3,00$ & Deslocamento excessivo & $1 / 65$ & $1 / 2275$ \\
\hline
\end{tabular}

Notas: * Valores medidos após a ocorrência da FLM, sendo que, os deslocamentos horizontais na mesa comprimida permaneceram nulos até a ocorrência da FLM..

No gráfico apresentado na figura 5.22 ilustram-se os deslocamentos verticais do meio do vão, a flecha, para os perfis $U 127 \times 50 \times 3,00$, correspondentes aos ensaios com e sem correntes, respectivamente.

O valor teórico da flecha foi determinado como sendo o valor correspondente à flecha provocada por uma força uniformemente distribuída sobre a terça. $\mathrm{O}$ valor dessa força distribuída foi obtido pelo produto entre a largura de influência da terça central e a pressão correspondente.

Pode-se observar que os valores dos deslocamentos verticais para os ensaios 1 e 11 são próximos. No primeiro, as telhas foram conectadas às terças em todas as ondas, conferindo ao sistema uma rigidez possivelmente 
maior. Para o ensaio 11, a utilização das linhas de correntes confere um melhor comportamento ao perfil solicitado, onde a rotação de seção transversal é praticamente nula até a proximidade da falha do perfil. Esses deslocamentos são menores que os valores teóricos correspondentes.

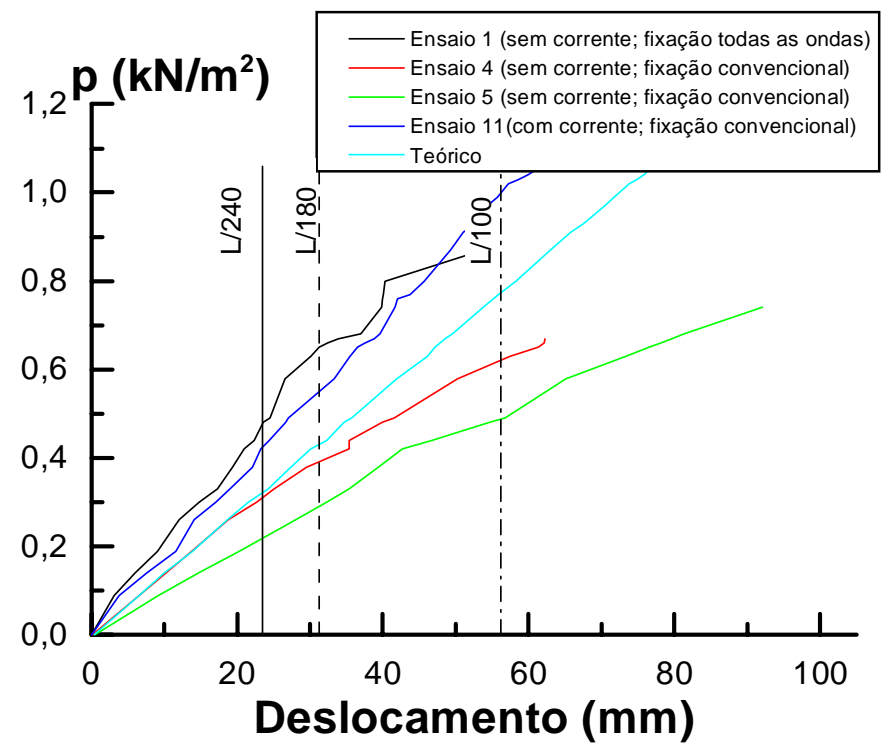

Figura 5.22: Flechas obtidas para os perfis tipo U127×50×3,00.

Para os ensaios 4 e 5 , sem a presença das linhas de correntes, os valores dos deslocamentos medidos são maiores que os calculados teoricamente, deixando de apresentar um comportamento linear para valores acima de, aproximadamente, $0,4 \mathrm{kN} / \mathrm{m}^{2}$.

Como fez-se anteriormente, o gráfico da figura 5.23 apresenta o deslocamento horizontal ocorrido para as mesas comprimidas dos perfis tipo U127×50×3,00 nos ensaios desenvolvidos. 


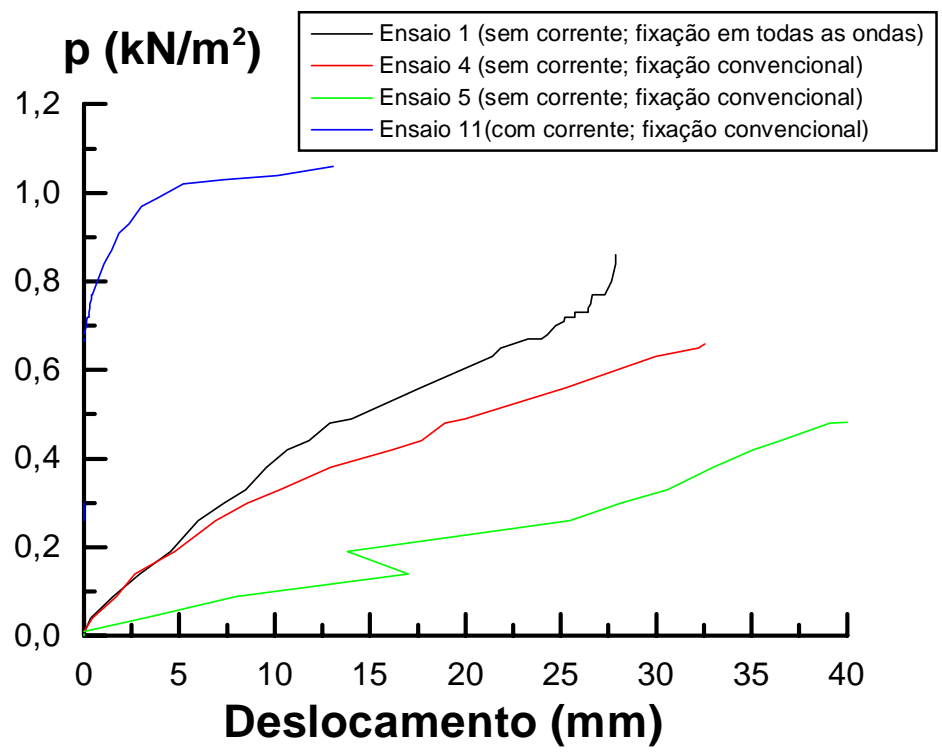

Figura 5.23: Deslocamentos horizontais das mesas comprimidas dos perfis tipo U127×50×3,00 no meio do vão.

Observa-se que esses deslocamentos horizontais acontecem de forma diferenciada em vista da presença ou não das linhas de corrente.

No caso do ensaio 11, realizado com linhas de correntes, o deslocamento horizontal da mesa comprimida é praticamente nulo até a proximidade da ocorrência da flambagem local da mesa e consideravelmente menor que os deslocamentos observados para os outros ensaios. A falha para este perfil pode ser observada na figura 5.24.

A ausência das linhas de correntes nos demais ensaios provocou um deslocamento horizontal na mesa comprimida tão logo do início do processo de carregamento sendo que esses deslocamentos atingiram valores superiores a $30 \mathrm{~mm}$. 


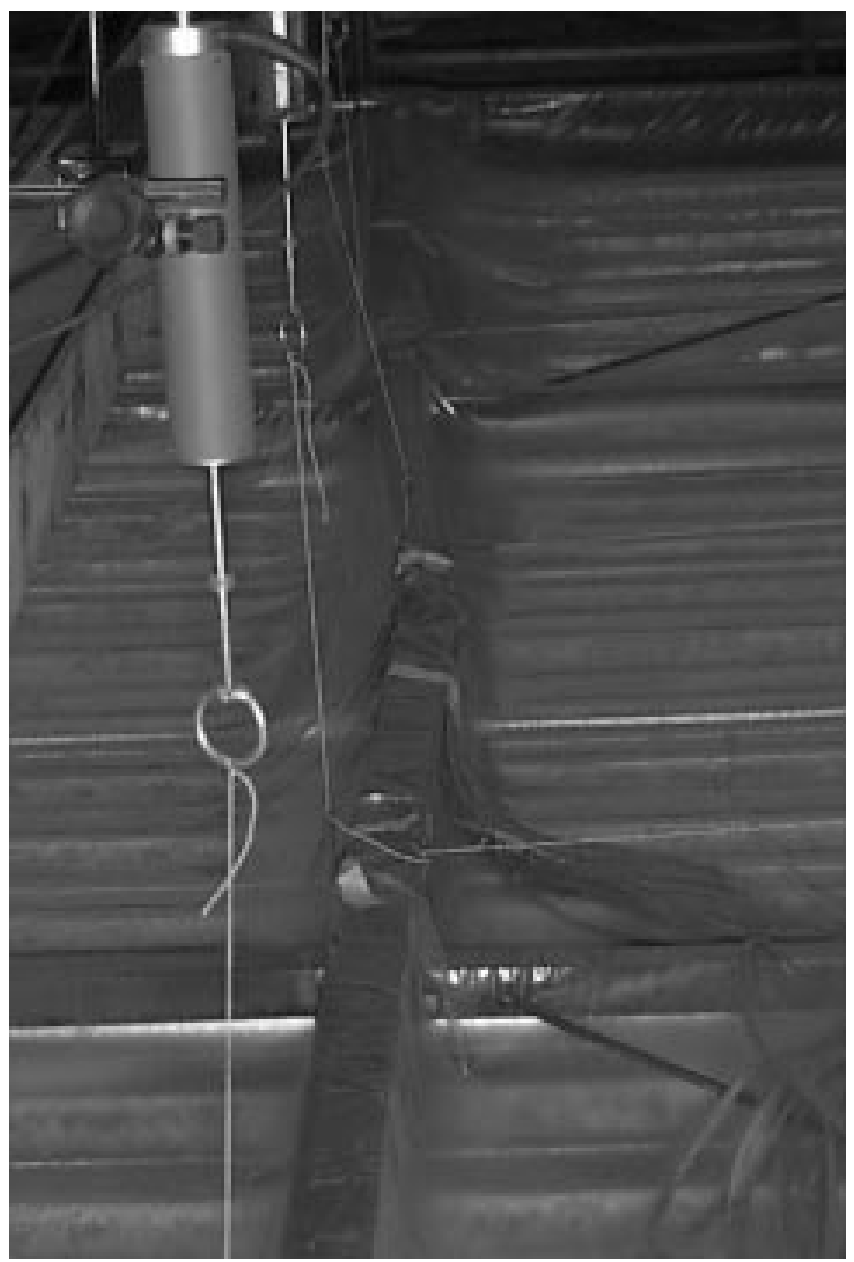

Figura 5.24: Posição deslocada após a FLM - Ensaio 11.

Ainda comparando-se os deslocamentos horizontais para a mesa superior, a figura 5.25 apresenta a curva pressão $\mathrm{x}$ deslocamento correspondente aos diversos tipos de seção transversal dos perfis ensaiados sem linhas de correntes.

A análise do gráfico permite observar que os ensaios 1, 2 e 3, onde as telhas foram fixadas aos perfis em todas as ondas, apresentaram uma maior rigidez ao deslocamento horizontal. Isto deve-se à contribuição do painel ao perfil, indicando que os deslocamentos horizontais que ocorrem na seção transversal devem ser dependentes da posição dos pontos conectados às telhas através dos parafusos. 


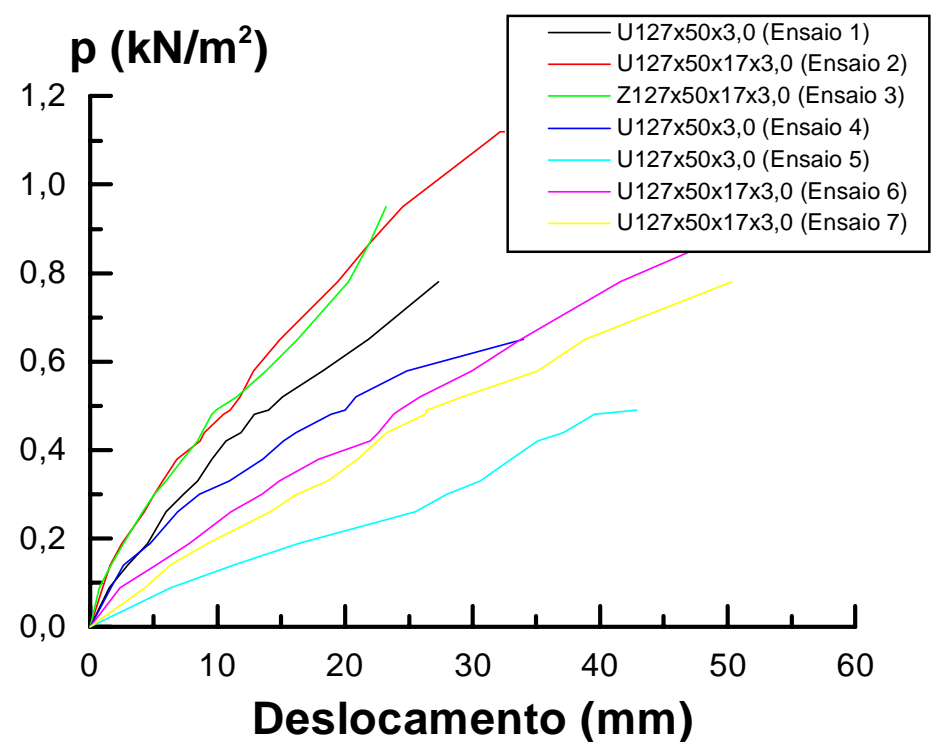

Figura 5.25: Resultado dos deslocamentos horizontais das mesas superiores no meio do vão para os perfis sem linha de corrente.

Da observação das deformações ocorridas na seção transversal do meio do vão permite fazer-se algumas considerações importantes. Na figura 5.26 apresenta-se o gráfico das deformações ocorridas nos pontos instrumentados para o ensaio 6 , perfil tipo $U 127 \times 50 \times 17 \times 3,00$.

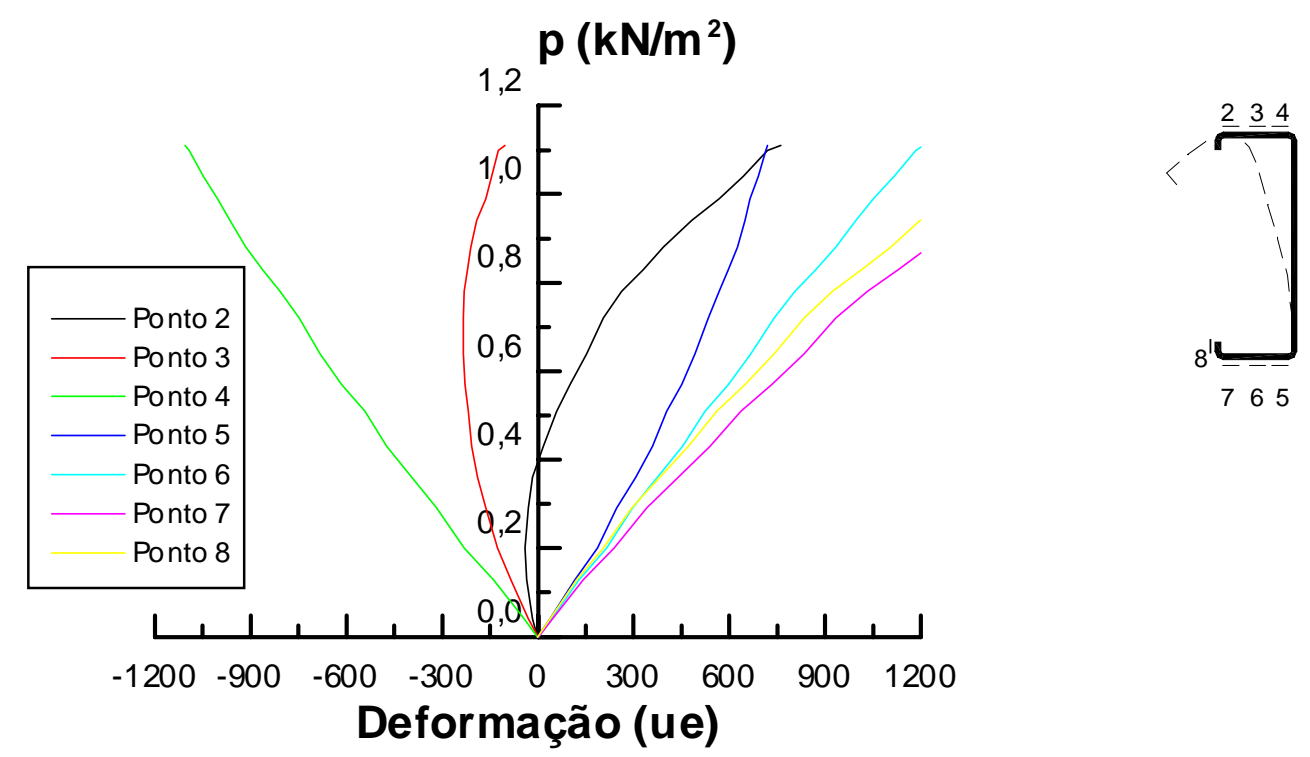

Figura 5.26: Gráfico pressão x deformação - Ensaio 6 
Nesse gráfico pode-se verificar a diminuição das deformações, em valores absolutos, para o ponto 2 , para o ponto 3 e de forma menos pronunciada, para o ponto 5 .

Tal diminuição ocorre devido a rotação elevada da seção transversal nas proximidades da junção da alma com a mesa tracionada, induzindo o aparecimento de tensões de tração nas proximidades dos enrijecedores e de tensões de compressão na região da alma, provocando, desta forma a variação na distribuição de tensões na seção transversal do perfil.

Esta constatação está em consonância com as hipóteses adotadas no modelo de Peköz, Soroushian apresentado no capítulo 2. Neste modelo, as tensões na seção transversal são calculadas admitindo-se a superposição de dois estágios distintos: o primeiro devido ao deslocamento vertical e o segundo devido ao deslocamento horizontal e giro da seção transversal.

Na figura 5.27 apresentam-se as deformações correspondentes ao

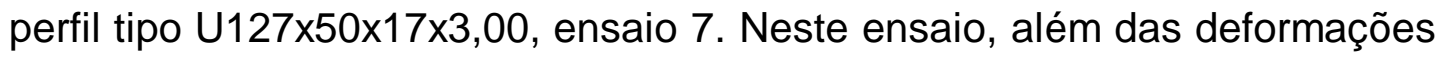
das mesas, foram medidas as deformações ao longo da alma do perfil e cujos resultados encontram-se na figura 5.28.

A figura 5.27 apresenta resultados semelhantes aos observados no ensaio 6, figura 5.26. As deformações ao longo da alma, figura 5.28, confirmam as constatações acima mencionadas.

Essa evidência foi maior para os perfis tipo $U$ enrijecido, embora também pronuncia-se de forma menos intensa para todos as outras seções transversais ensaiadas sem linha de corrente. 


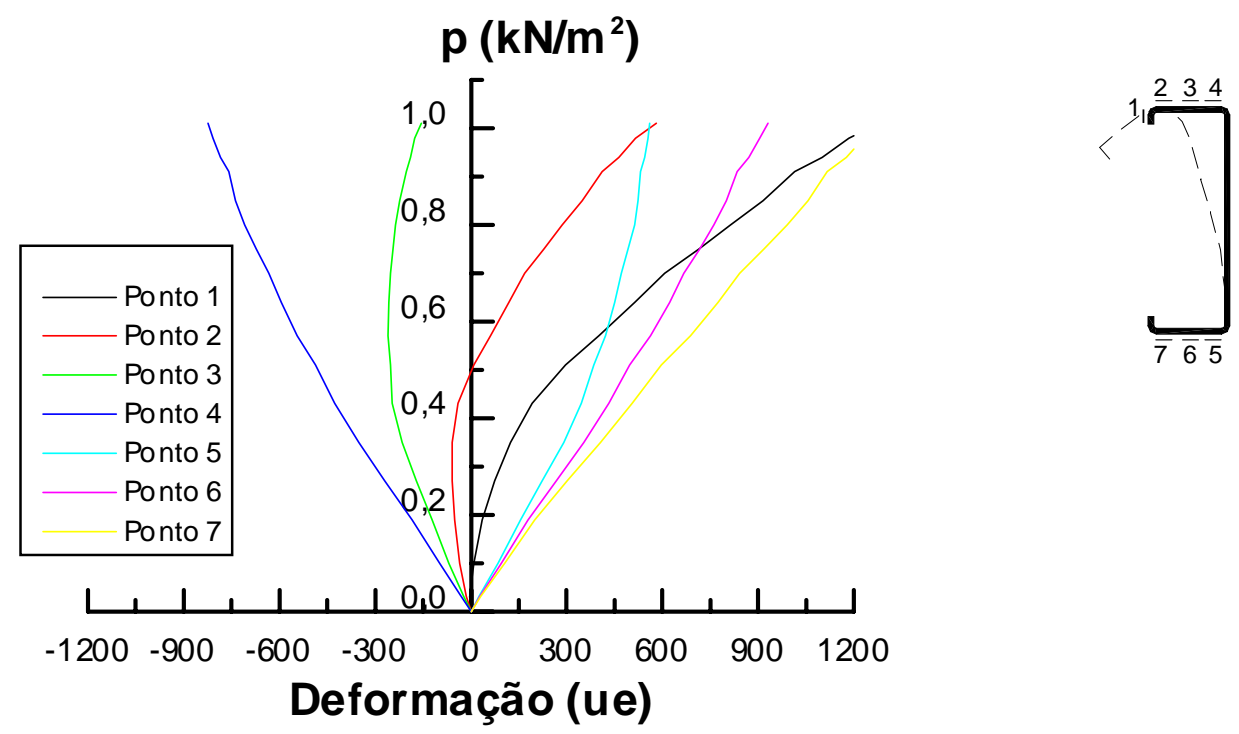

Figura 5.27: Gráfico pressão x deformações nas mesas - Ensaio 7.
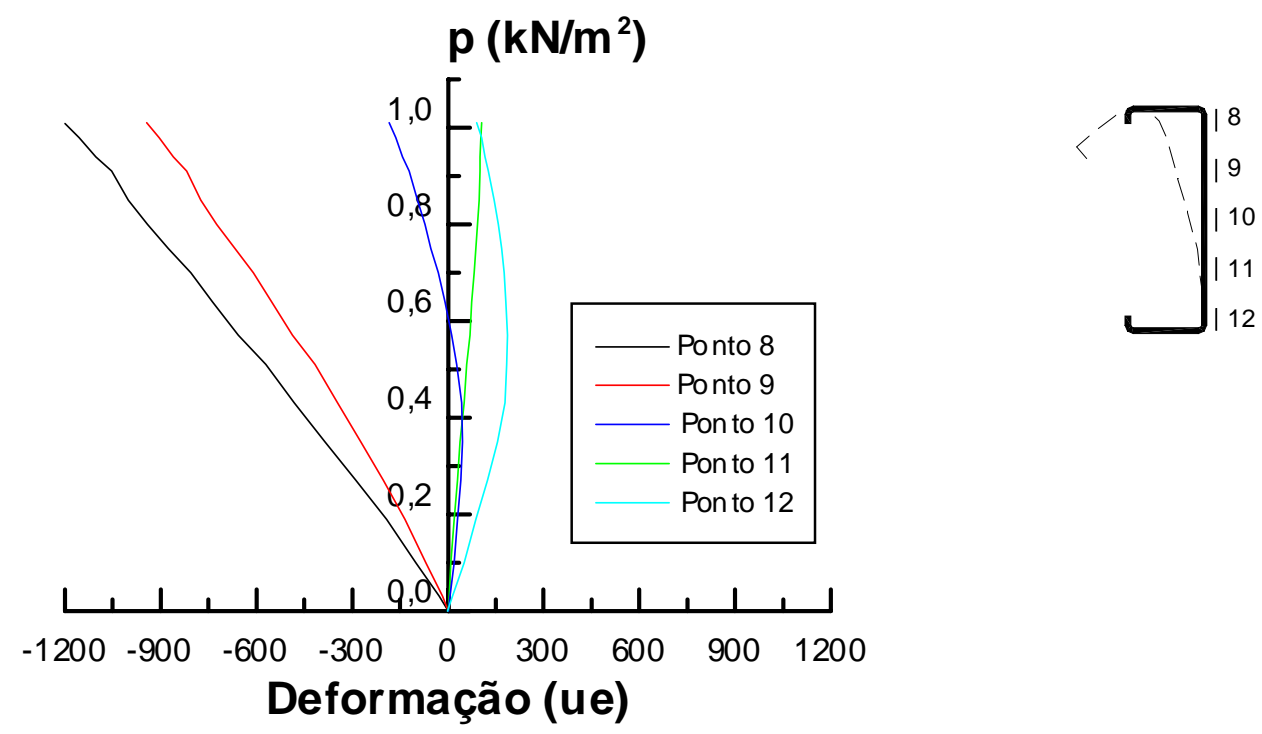

Figura 5.28: Gráfico pressão x deformações na alma - Ensaio 7.

Para os ensaios 2 e 3 , perfis tipo $U 127 \times 50 \times 17 \times 3,00$ e tipo Z127x50x17×3,00, a superposição dos efeitos do deslocamento vertical e da rotação tornam-se mais pronunciado, conforme ilustra-se na figura 5.29.

Diferentemente dos perfis tipo $U$ e tipo $U$ enrijecido, o perfil tipo $Z$ enrijecido tem um aumento de deformação para o ponto 1, no enrijecedor, e 
para o ponto 2, na mesa. Isto ocorre pelo fato dos eixos principais de inércia não serem os eixos $x$ e $y$, horizontal e vertical passando pelo centro de gravidade, respectivamente.

Ressalta-se que os ensaios 1 a 3 foram executados com a fixação das telhas feita em cada onda através dos parafusos auto-brocantes, o que pode alterar o seu comportamento quanto aos deslocamentos laterais e rotação em comparação aqueles executados com a fixação convencional.
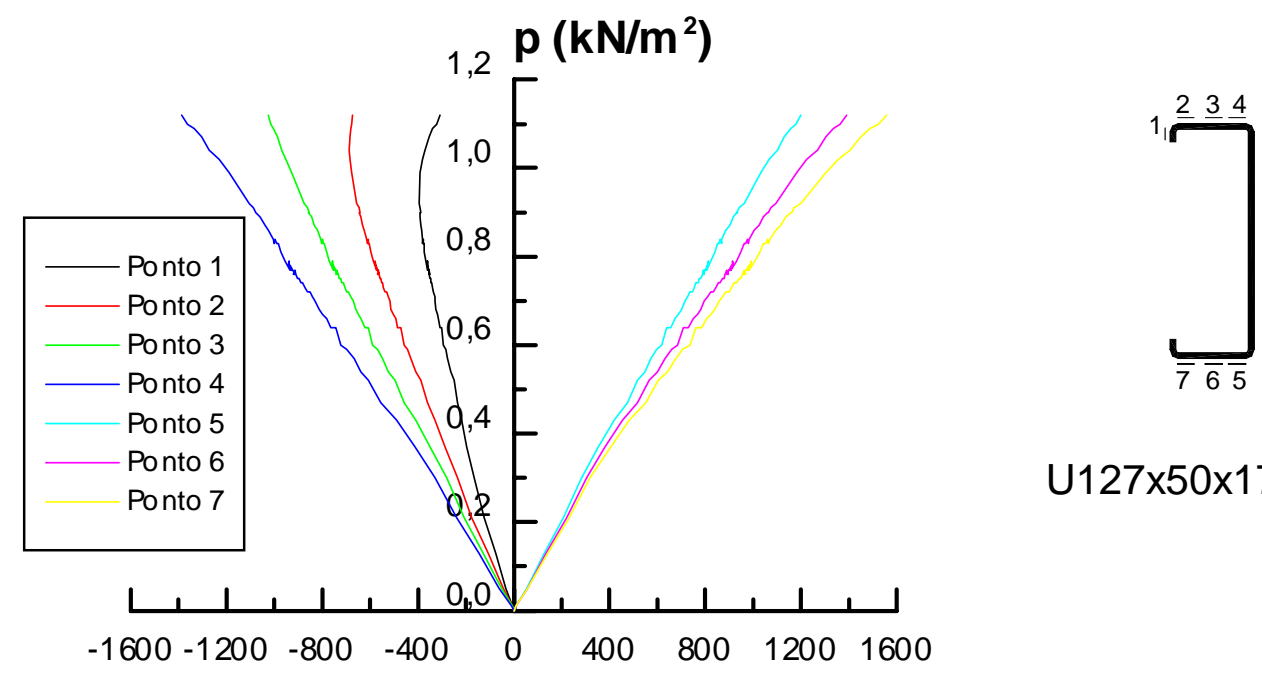

$\mathrm{U} 127 \times 50 \times 17 \times 3,00$

Deformação (ue)

a)
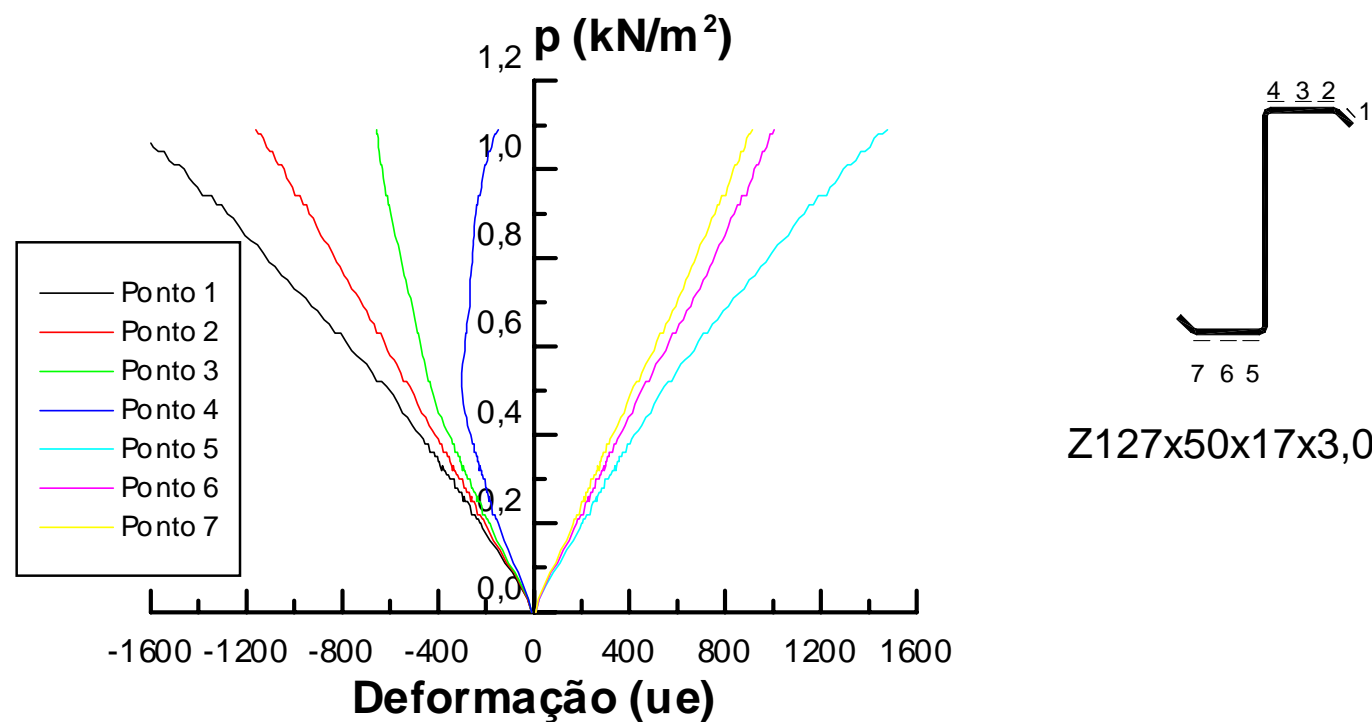

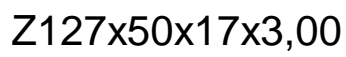

b)

Figura 5.29: Gráficos pressão x deformação. a) Ensaio 2. b)Ensaio 3. 
O comportamento dos perfis contraventados por linhas de corrente é bastante diferenciado daquele em que não se faz o uso desses elementos.

Como já observado, para os perfis sem linhas de corrente, os deslocamentos horizontais iniciam-se tão logo inicia-se o carregamento, enquanto que, na presença das linhas de correntes, esses deslocamentos permanecem nulos até a proximidade da carga última.

$\mathrm{Na}$ figura 5.30 estão apresentados em um mesmo gráfico, os deslocamentos horizontais para as mesas comprimidas dos perfis ensaiados com linhas de correntes, correspondentes aos ensaios de 8 a 15.

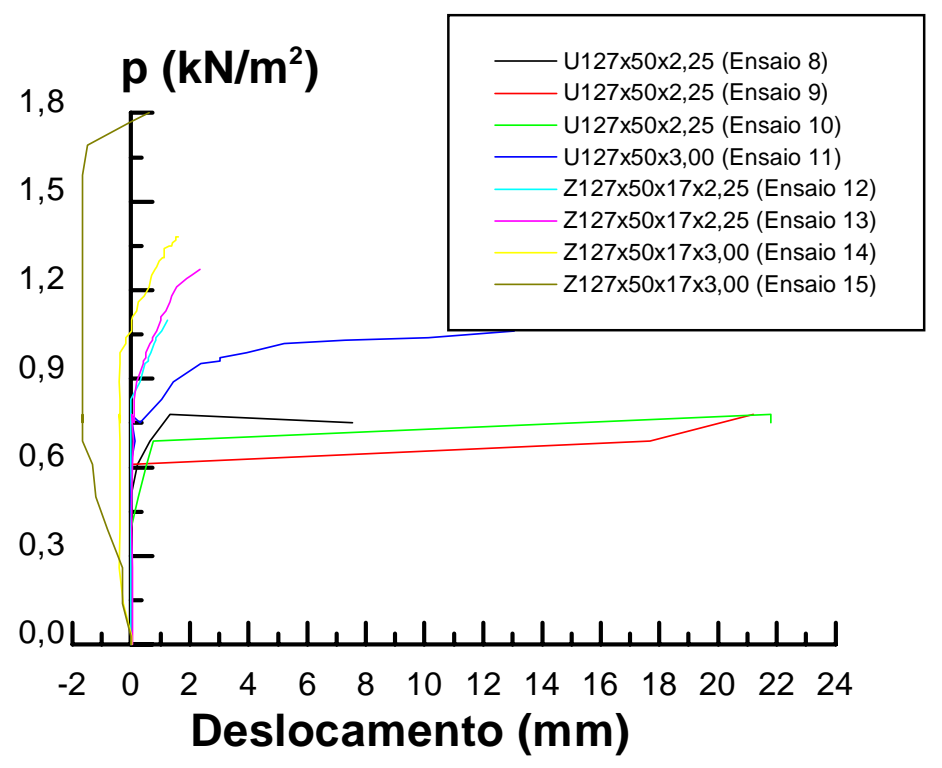

Figura 5.30: Deslocamentos horizontais no meio do vão para as mesas comprimidas dos perfis ensaiados com linhas de correntes.

Para os ensaios de 8 a 11, perfis tipo $U$, verifica-se que os deslocamentos horizontais das mesas comprimidas permanecem praticamente nulos até próximo à falha.

Da figura 5.30 pode-se também observar os deslocamentos horizontais sofridos pelos perfis tipo Z enrijecido, os quais permanecem praticamente na posição inicial até proximidades da pressão última alcançada. 
Deve-se ressaltar que os perfis tipo $Z$ enrijecido tiveram o seu ensaio limitado por excesso de deslocamento vertical. Esses deslocamentos foram da ordem de $85 \mathrm{~mm}$ para os perfis, perfazendo uma relação de, aproximadamente, 1/65 de vão, como apresentado na tabela 5.3.

Como modo de falha para os ensaios de 8 a 11, a flambagem local da mesa ocorreu em todos, onde os deslocamentos horizontais aumentaram consideravelmente, sem acréscimo da pressão.

Observa-se que, após a flambagem local da mesa, ocorre um acréscimo de pressão, indicando uma certa reserva de resistência, diferentemente do observado para os perfis isolados. Esta reserva de resistência pode ser atribuída às telhas, as quais, comportando-se como uma membrana, fornecem estabilidade ao perfil.

As deformações ocorridas para o perfil tipo $U$, ensaio 10 , estão apresentadas no gráfico da figura 5.31, onde pode-se observar a ocorrência da flambagem local da mesa, o que acarreta o alívio de deformações na seção e a continuação do carregamento após sua ocorrência.

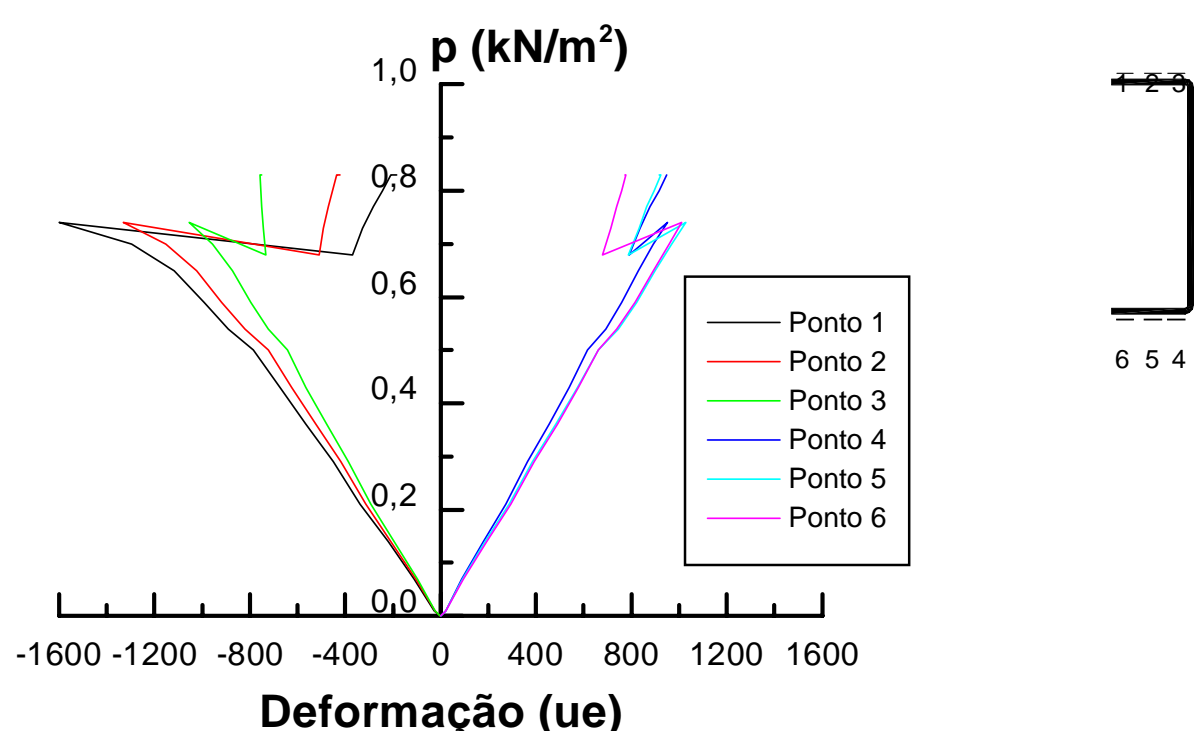

Figura 5.31: Gráfico pressão x deformação - Ensaio 10. 


\subsection{Análise dos resultados}

Da execução dos ensaios pode-se observar que houveram dois modos de falha bastante diferenciados para as terças. O primeiro, característico para as terças sem linhas de corrente, apresentou deslocamentos verticais excessivos, bem como, deslocamentos horizontais e rotação da seção transversal excessivos.

Para as terças com linhas de corrente, pode-se observar a ocorrência da flambagem local da mesa para os perfis tipo $U$ e a ocorrência de deslocamentos verticais excessivos para os perfis tipo Z. Para estes perfis, e dada a presença das linhas de corrente, praticamente não houve deslocamento horizontal da mesa comprimida.

A seguir são verificados alguns modelos de cálculo utilizados na determinação da resistência ao momento fletor para esses perfis, comparando-se os resultados com aqueles obtidos nos ensaios. Para tanto, são utilizados como referência os modelos propostos por alguns pesquisadores (LaBoube; Peköz, Soroushian) com o objetivo de verificar-se a adequação desses aos resultados obtidos.

Ressalta-se que, para fins de comparação dos resultados, os valores de pressão aplicada correspondem ao deslocamento vertical máximo de $1 / 100$ do vão do perfil.

\subsubsection{O fator de redução $F_{R}$}

Na Tabela 5.4 apresentam-se os momentos fletores correspondentes à pressão aplicada, cuja flecha obtida é de 1/100 do vão e o momento fletor de início de escoamento da seção transversal.

O valor do momento fletor referente à pressão aplicada $\left(M_{\text {ref }}\right)$ foi obtido distribuindo-se aquela pressão sobre o perfil central por meio da 
largura de influência, tendo-se, portanto, uma viga biapoiada sob carregamento uniformemente distribuído.

O momento fletor correspondente ao início de escoamento da seção transversal $\left(M_{y}\right)$ foi calculado de acordo com as propriedades efetivas da seção transversal para uma tensão de escoamento $\left(f_{y}\right)$ igual a $343 \mathrm{MPa}$, com base nas dimensões nominais da seção transversal do perfil.

Como um método de cálculo empírico para a determinação da resistência nominal do perfil, o valor de $F_{R}$, tabela 5.4 , expressa a razão entre o momento último de ensaio e o momento fletor de início de escoamento, baseado no módulo de resistência elástico da seção efetiva.

Tabela 5.4 - Momentos fletores último e de escoamento.

\begin{tabular}{|c|c|c|c|c|c|}
\hline Ensaio & Perfil & $\mathrm{p}\left(\mathrm{kN} / \mathrm{m}^{2}\right)$ & $\mathrm{M}_{\text {ref }}(\mathrm{kN} . \mathrm{m})$ & $\mathrm{M}_{\mathrm{y}}(\mathrm{kN} \cdot \mathrm{m})$ & $\mathrm{F}_{\mathrm{R}}=\mathrm{M}_{\mathrm{u}} / \mathrm{M}_{\mathrm{y}}$ \\
\hline \multicolumn{6}{|c|}{ Ensaios sem linhas de corrente } \\
\hline 1 & U127x50x3,00 & 0,85 & 4,30 & 7,52 & 0,57 \\
\hline 2 & U127x50x17x3,00 & 0,93 & 6,54 & 9,28 & 0,70 \\
\hline 3 & Z127x50x17×3,00 & 0,80 & 3,60 & 10,16 & 0,35 \\
\hline 4 & U127x50x3,00 & 0,61 & 3,09 & 7,42 & 0,42 \\
\hline 5 & U127x50x3,00 & 0,50 & 2,53 & 7,42 & 0,34 \\
\hline 6 & U127x50x17×3,00 & 0,55 & 3,86 & 9,28 & 0,42 \\
\hline 7 & U127x50x17×3,00 & 0,52 & 3,65 & 9,28 & 0,39 \\
\hline \multicolumn{6}{|c|}{ Ensaios com linhas de corrente } \\
\hline 8 & U127x50x2,25 & 0,75 & 4,74 & 5,21 & 0,91 \\
\hline 9 & U127x50x2,25 & 0,65 & 4,41 & 5,21 & 0,85 \\
\hline 10 & U127x50x2,25 & 0,75 & 4,62 & 5,21 & 0,89 \\
\hline 11 & U127x50×3,00 & 1,00 & 6,87 & 7,42 & 0,92 \\
\hline 12 & Z127×50x17×2,25 & 0,80 & 5,81 & 7,46 & 0,78 \\
\hline 13 & Z127x50x17×2,25 & 0,80 & 5,81 & 7,46 & 0,78 \\
\hline 14 & Z127x50x17×3,00 & 0,96 & 8,03 & 9,77 & 0,82 \\
\hline 15 & Z127x50x17×3,00 & 0,98 & 8,20 & 9,77 & 0,84 \\
\hline
\end{tabular}

Nota: $\mathrm{p}\left(\mathrm{kN} / \mathrm{cm}^{2}\right)$ indica o valor da pressão aplicada correspondente ao deslocamento igual a $1 / 100$ do vão $(56,2 \mathrm{~mm})$. Para este valor de pressão foi determinado o valor do momento fletor $\mathrm{M}_{\text {ref. }}$ 
Como valores médios dos resultado obtidos tem-se:

Perfil tipo U sem linha de corrente:

$F_{R}=0,50$

Perfil tipo U enrijecido sem linha de corrente:

$F_{R}=0,50$

Perfil tipo U com 2 linhas de corrente:

$F_{R}=0,89$

Perfil tipo Z enrijecido com 2 linhas de corrente:

$F_{R}=0,80$

Ressalta-se que esses valores devem ser restritos às condições utilizadas nos ensaios aqui desenvolvidos e a sua extrapolação a outras situações está sujeira a possíveis erros na avaliação da resistência ao momento fletor.

Para o perfil tipo $Z$ sem linha de corrente foi realizado apenas um ensaio, portanto, o valor obtido $\left(F_{R}=0,35\right)$ não pode ser considerado como representativo para o tipo de perfil.

Para efeitos de comparação os valores aqui obtidos podem ser confrontados com os resultados obtidos por LaBoube (1992) e incorporados ao AISI a partir de 1991. Em seu trabalho e aproveitando-se de resultados de outros estudos, LaBoube determina um coeficiente $R$ como sendo uma quantidade empírica que corresponde a razão entre o momento fletor obtido em ensaio e o momento fletor de início de escoamento.

Esse coeficiente $R$ foi obtido para perfis tipo $U$ e $Z$ enrijecidos, considerando-se vigas biapoiadas e vigas contínuas, obtendo-se como resultados os seguintes valores médios:

Perfil tipo U enrijecido (biapoiado, sem linha de corrente): $R=0,40$ Perfil tipo Z enrijecido (biapoiado, sem linha de corrente): $R=0,50$

Perfil tipo U enrijecido (contínuo, sem linha de corrente): $R=0,60$ Perfil tipo $Z$ enrijecido (contínuo, sem linha de corrente): $R=0,70$

Nas tabelas 5.5 e 5.6 estão apresentados os resultados de outros 25 ensaios realizados por LaBoube e Peköz, Soroushian em conjunto com os 
desenvolvidos por este autor para os perfis biapoiados e sem linhas de corrente, totalizando 31 ensaios realizados.

Tabela 5.5: Valores do coeficiente de redução para o perfil tipo Z.

\begin{tabular}{|c|c|}
\hline Perfil & Coeficiente de redução \\
\hline Z203x1,50 & $0,49^{a}$ \\
\hline Z203x1,52 & $0,49^{a}$ \\
\hline Z203x1,60 & $0,54^{\mathrm{a}}$ \\
\hline Z203x1,78 & $0,50^{a}$ \\
\hline Z203x1,91 & $0,55^{\mathrm{a}}$ \\
\hline Z203x2,24 & $0,55^{\mathrm{a}}$ \\
\hline Z203x2,26 & $0,51^{\mathrm{a}}$ \\
\hline Z203×2,90 & $0,56^{\mathrm{a}}$ \\
\hline Z203×2,92 & $0,42^{\mathrm{a}}$ \\
\hline$Z 240 \times 1,57$ & $0,49^{a}$ \\
\hline$Z 240 \times 1,60$ & $0,54^{\mathrm{a}}$ \\
\hline$Z 240 \times 2,69$ & $0,66^{\mathrm{a}}$ \\
\hline$Z 240 \times 2,77$ & $0,45^{\mathrm{a}}$ \\
\hline $\mathrm{Z} 240 \times 1,80$ & $0,44^{b}$ \\
\hline$Z 240 \times 1,80$ & $0,49^{b}$ \\
\hline $\mathrm{Z} 240 \times 1,80$ & $0,43^{b}$ \\
\hline$Z 240 \times 2,69$ & $0,51^{b}$ \\
\hline$Z 240 \times 2,69$ & $0,51^{b}$ \\
\hline Z127x3,00 & $0,35^{\mathrm{c}}$ \\
\hline Valor médio para perfil tipo Z: & 0,50 \\
\hline Desvio padrão para perfil tipo Z: & 0,07 \\
\hline $\begin{array}{l}\text { Devido a Peköz, Soroushian (1982). } \\
\text { Devido a LaBoube (1992). } \\
\text { Devido ao autor (1999). }\end{array}$ & \\
\hline
\end{tabular}


Tabela 5.6: Valores do coeficiente de redução para o perfil tipo U

\begin{tabular}{|c|c|}
\hline Perfil & Coeficiente de redução \\
\hline U180x1,91 & $0,73^{\mathrm{a}}$ \\
\hline U230x1,91 & $0,47^{\mathrm{a}}$ \\
\hline U230x1,96 & $0,41^{\mathrm{a}}$ \\
\hline U240x1,80 & $0,38^{b}$ \\
\hline U240x1,80 & $0,36^{b}$ \\
\hline U240x2,69 & $0,42^{b}$ \\
\hline U241 x2,69 & $0,45^{b}$ \\
\hline U127×3,00 (Ensaio 1) & $0,57^{\mathrm{c}}$ \\
\hline U127×3,00 (Ensaio 2) & $0,70^{c}$ \\
\hline U127×3,00 (Ensaio 4) & $0,42^{\mathrm{C}}$ \\
\hline U127×3,00 (Ensaio 5) & $0,34^{\mathrm{C}}$ \\
\hline U127×3,00 (Ensaio 6) & $0,42^{c}$ \\
\hline U127×3,00 (Ensaio 7) & $0,39^{c}$ \\
\hline Valor médio para perfil tipo U: & $0,47\left(0,42^{d}\right)$ \\
\hline Desvio padrão para perfil tipo U: & $0,12\left(0,06^{d}\right)$ \\
\hline \multicolumn{2}{|c|}{$\begin{array}{l}\text { a Devido a Peköz, Soroushian (1982). } \\
\text { b Devido a LaBoube (1992). } \\
\text { c Devido ao autor (1999). } \\
{ }^{\mathrm{d}} \text { Valores obtidos excluindo-se os coeficientes } 0,73 \text { e } 0,70 \text {. }\end{array}$} \\
\hline
\end{tabular}

Deve-se observar que todos os perfis ensaiados pelos outros pesquisadores eram constituídos por mesas enrijecidas por virada simples de borda com altura nominal para o enrijecedor de $20 \mathrm{~mm}$.

Pode-se concluir que os valores apresentados praticamente reproduzem os valores médios e os desvios padrão obtidos por Laboube.

Adicionalmente, para os perfis tipo $U$ o valor de $F_{R}=0,40$ demonstra ser um valor apropriado tanto para perfis com mesas enrijecidas como para os perfis com mesas não enrijecidas.

Esse mesmo procedimento para a determinação da resistência nominal ao momento fletor está incorporado ao texto-base para a norma 
brasileira para o dimensionamento de estrutura de aço constituída por perfis formado a frio, onde utiliza-se os coeficientes obtidos por LaBoube.

\subsubsection{O método de Peköz, Soroushian}

Quanto ao método de Peköz, Soroushian, como apresentado no capítulo 2, permite-se o cálculo das tensões normais máximas para os perfis ensaiados desde que sejam conhecidos os valores de $K$, o coeficiente do apoio elástico, proporcionado pelo conjunto terça-telha.

Como observado no capítulo 2, a determinação do valor de $K$ deve ser feita através de ensaios. Neste caso, de acordo com os ensaios realizados pode-se determinar a relação força horizontal $x$ deslocamento horizontal para a mesa comprimida. Essa força horizontal é uma força fictícia, determinada através da equação (2.86) e o deslocamento horizontal da mesa superior no meio do vão foi obtido durante a execução do ensaio.

Assumindo-se o valor de $q_{y}(z)$ como sendo o valor do carregamento uniformemente distribuído ao longo do vão, função da pressão aplicada, pode-se determinar o valor correspondente da força horizontal fictícia $q_{x}(z)$, equação (2.86).

$\mathrm{Na}$ figura 5.32 apresenta-se o gráfico força horizontal fictícia $\left(q_{x}(z)\right)$, contra os deslocamentos horizontais no meio do vão correspondentes ao

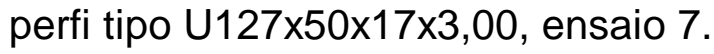

Como pode-se observar o valor de $K$ corresponde ao coeficiente angular da reta obtida por regressão linear a partir dos dados obtidos nos ensaios.

A relação linear mostrou-se adequada para todos os ensaios realizados. 


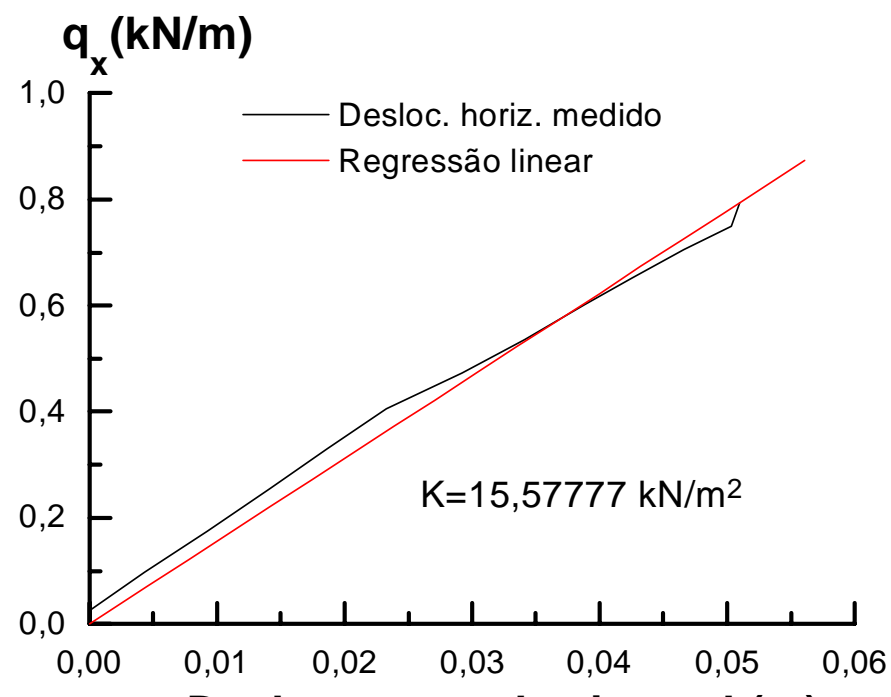

Deslocamento horizontal $(\mathrm{m})$

Figura 5.32: Determinação do coeficiente de apoio elástico - Ensaio 7.

Este coeficiente foi determinado para os 7 primeiros ensaios, sendo nos demais, ensaio 8 a ensaio 15, considerado $K \rightarrow \infty$.

A hipótese de que $K \rightarrow \infty$ para os perfis com linhas de corrente foi admitida em função dos gráficos de deslocamentos horizontais para as mesas comprimidas indicados na figura 5.30. Assumindo-se esta hipótese, os valores das tensões normais são oriundas somente da flexão simples.

A partir da determinação do coeficiente do apoio elástico pode-se calcular as tensões atuantes na seção transversal do perfil. Isto está representado na tabela 5.7 onde encontram-se os valores do coeficiente do apoio elástico $K$, as tensões normais devidas à flexão vertical $\left(\sigma_{\mathrm{x}}\right)$, as tensões normais devidas à flexão horizontal e rotação $\left(\sigma_{y}\right)$ e a tensões máximas $\left(\sigma_{\text {total }}\right)$ obtidas da soma dessas duas parcelas anteriores.

A obtenção dos valores dessas tensões está em acordo com o apresentado no capítulo 2, equações (2.88), (2.89) e (2.90).

$\mathrm{Na}$ figura 5.33 ilustra-se a superposição dessas tensões normais para um perfil tipo $U$ enrijecido. As mesmas hipóteses podem ser feitas para o perfil tipo $Z$ enrijecido considerando-se, entretanto, os seus eixos principais de inércia. 
Tabela 5.7: Tensões normais nos perfis segundo Peköz, Soroushian.

\begin{tabular}{c|c|c|c|c|c|c}
\hline Ensaio & Perfil & $\begin{array}{c}\mathrm{p} \\
\left(\mathrm{kN} / \mathrm{m}^{2}\right)\end{array}$ & $\begin{array}{c}\mathrm{K} \\
\left(\mathrm{kN} / \mathrm{m}^{2}\right)\end{array}$ & $\begin{array}{c}\sigma_{\mathrm{x}} \\
\left(\mathrm{kN} / \mathrm{cm}^{2}\right)\end{array}$ & $\begin{array}{c}\sigma_{\mathrm{y}} \\
\left(\mathrm{kN} / \mathrm{cm}^{2}\right)\end{array}$ & $\begin{array}{c}\sigma_{\text {total }} \\
\left(\mathrm{kN} / \mathrm{cm}^{2}\right)\end{array}$ \\
\hline 1 & $\mathrm{U} 127 \times 50 \times 3,00$ & 0,85 & 16,228 & 17,79 & 9,91 & 27,70 \\
\hline 2 & $\mathrm{U} 127 \times 50 \times 17 \times 3,00$ & 0,93 & 36,968 & 23,80 & 5,60 & 29,40 \\
\hline 3 & $\mathrm{Z} 127 \times 50 \times 17 \times 3,00$ & 0,80 & 6,644 & 13,21 & 6,76 & 19,96 \\
\hline 4 & $\mathrm{U} 127 \times 50 \times 3,00$ & 0,61 & 15,665 & 12,63 & 6,74 & 19,37 \\
\hline 5 & $\mathrm{U} 127 \times 50 \times 3,00$ & 0,50 & 8,761 & 10,43 & 11,06 & 21,49 \\
\hline 6 & $\mathrm{U} 127 \times 50 \times 17 \times 3,00$ & 0,55 & 17,603 & 14,07 & 7,27 & 21,35 \\
\hline 7 & $\mathrm{U} 127 \times 50 \times 17 \times 3,00$ & 0,50 & 15,578 & 12,80 & 7,51 & 20,31 \\
\hline
\end{tabular}

Da figura 5.33 pode-se notar a ocorrência das máximas tensões normais na união da mesa comprimida com a alma e na união da mesa tracionada com o enrijecedor, correspondentes ao ponto 4 e ao ponto 7 na seção transversal instrumentada, respectivamente, conforme esquema apresentado na figura 5.8.

De maneira similar, as tensões máximas para o perfil tipo $Z$ enrijecido ocorrem, de acordo com o esquema de instrumentação utilizado na figura 5.8, para os pontos 4 e 7 .
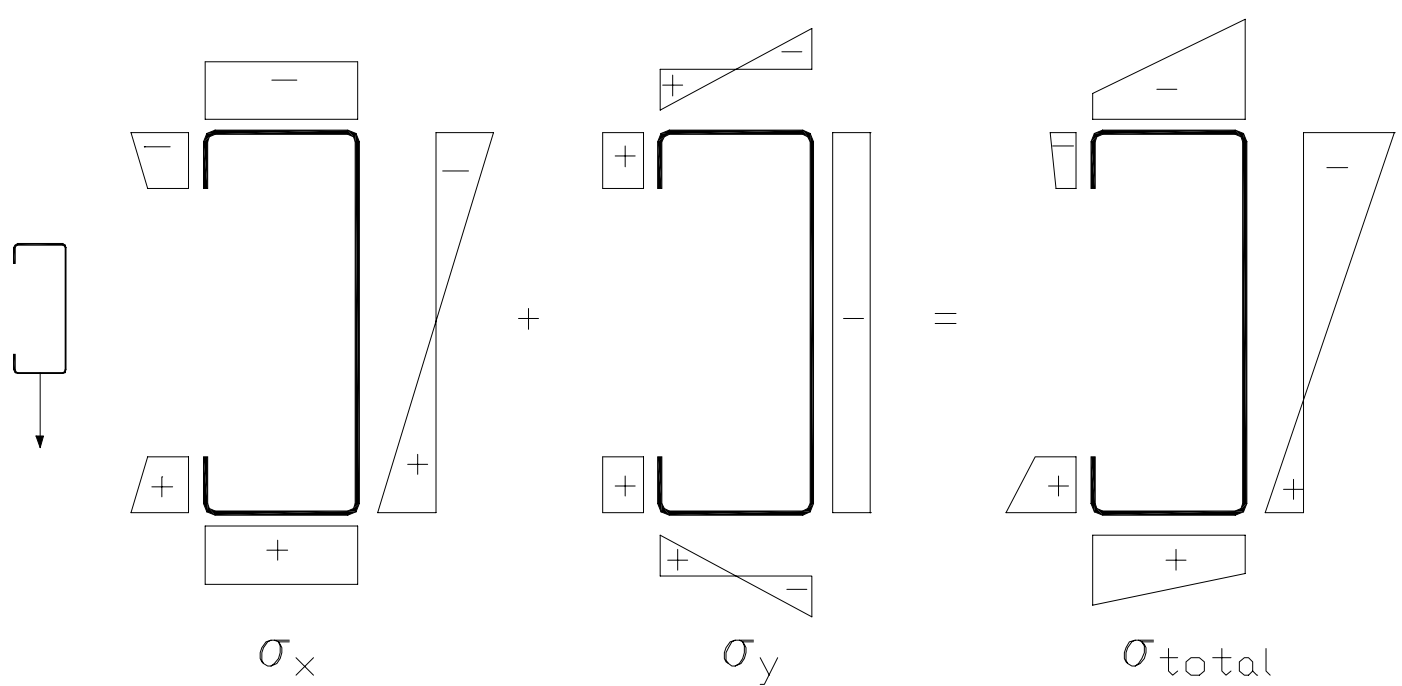

Figura 5.33: Superposição das tensões normais. 
Os valores medidos das deformações nos pontos instrumentados estão em acordo com as composições de tensões acima, figura 5.33, e pode-se verificar que as máximas deformações ocorridas são as de alongamento, portanto, correspondentes às tensões de tração.

\subsubsection{O procedimento do Eurocode (1993)}

O procedimento adotado pelo Eurocode (1993) é similar ao apresentado por Peköz, Soroushian, sendo possível o cálculo algébrico do valor do coeficiente do apoio elástico $K$.

Os resultados obtidos estão apresentados na tabela 5.8 , sendo calculados de acordo com o procedimento apresentado no capítulo 3 .

Deve-se observar que os valores do coeficiente do apoio elástico são constantes e, em geral, maiores do que os valores obtidos através dos resultados dos ensaios. Com isso, a tensão normal devida à flexão lateral e giro é menor.

O procedimento permite o cálculo de um comprimento equivalente de flambagem $\left(\mathrm{L}_{\mathrm{tz}}\right)$ para uma seção equivalente composta da mesa comprimida mais $1 / 6$ da altura da alma.

Tabela 5.8: Tensões normais nos perfis segundo o Eurocode.

\begin{tabular}{c|c|c|c|c|c|c|c}
\hline Ensaio & Perfil & $\begin{array}{c}\mathrm{p} \\
\left(\mathrm{kN} / \mathrm{m}^{2}\right)\end{array}$ & $\begin{array}{c}\mathrm{K} \\
\left(\mathrm{kN} / \mathrm{m}^{2}\right)\end{array}$ & $\begin{array}{c}\mathrm{L}_{\mathrm{fz}} \\
(\mathrm{cm})\end{array}$ & $\begin{array}{c}\sigma_{\mathrm{x}} \\
\left(\mathrm{kN} / \mathrm{cm}^{2}\right)\end{array}$ & $\begin{array}{c}\sigma_{\mathrm{y}} \\
\left(\mathrm{kN} / \mathrm{cm}^{2}\right)\end{array}$ & $\begin{array}{c}\sigma_{\text {total }} \\
\left(\mathrm{kN} / \mathrm{cm}^{2}\right)\end{array}$ \\
\hline 1 & $\mathrm{U} 127 \times 50 \times 3,00$ & 0,85 & 24,657 & 104,98 & 21,84 & 0,70 & 22,54 \\
\hline 2 & $\mathrm{U} 127 \times 50 \times 17 \times 3,0$ & 0,93 & 24,657 & 120,34 & 29,39 & 1,99 & 31,38 \\
\hline 3 & $\mathrm{Z127 \times 50 \times 17 \times 3,0}$ & 0,80 & 24,657 & 139,93 & 15,11 & 0,86 & 15,97 \\
\hline 4 & $\mathrm{U} 127 \times 50 \times 3,00$ & 0,61 & 24,657 & 104,98 & 15,51 & 0,50 & 16,01 \\
\hline 5 & $\mathrm{U} 127 \times 50 \times 3,00$ & 0,50 & 24,657 & 104,98 & 12,80 & 0,41 & 13,21 \\
\hline 6 & $\mathrm{U} 127 \times 50 \times 17 \times 3,0$ & 0,55 & 24,657 & 120,34 & 17,38 & 1,18 & 18,56 \\
\hline 7 & $\mathrm{U} 127 \times 50 \times 17 \times 3,0$ & 0,50 & 24,657 & 120,34 & 15,80 & 1,07 & 16,87 \\
\hline
\end{tabular}


Em comparação com os resultados obtidos através do modelo de Peköz, Soroushian pode-se observar que os valores do Eurocode são mais próximos aos obtidos nos ensaios, porém, ainda com valores superiores.

Os valores do coeficiente do apoio elástico são calculados pelo Eurocode e são maiores em relação aos obtidos nos ensaios segundo o método de Peköz, Soroushian, portanto, as tensões assim calculadas são menores.

\subsubsection{Flambagem por distorção}

O modo de falha observado para os perfis conectados às telhas pela mesa tracionada sugere a ocorrência da flambagem por distorção da seção transversal, conforme preconizado pelos modelos utilizados para o cálculo da carga crítica correspondente.

Serão verificados os modelos de cálculo da carga crítica propostos por Hancock, tanto para o caso de barra comprimida quanto para o caso de barras fletidas.

Seja o caso do modelo de Hancock para barras comprimidas. Assumindo-se a situação apresentada na figura 5.34, a mesa comprimida, alma e enrijecedor constituindo um elemento enrijecido sob compressão uniforme, conforme as equações (2.75), pode-se determinar os valores da força de compressão crítica. Para esta força de compressão pode-se obter a tensão critíca correspondente, a qual deve ainda ser corrigida pela parábola de Johnston para valores da tensão crítica superiores a $f_{y} / 2$. Esses valores encontram-se indicados na tabela 5.9. 


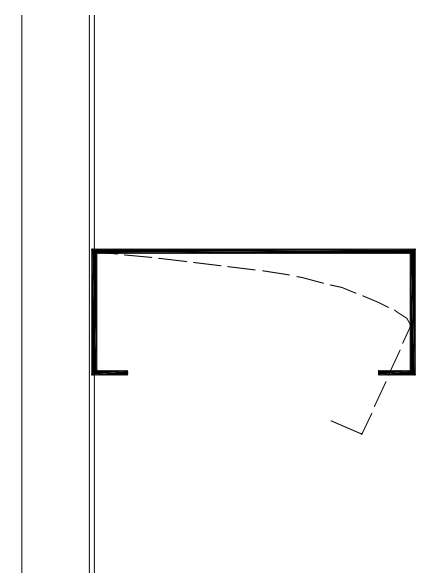

Figura 5.34: Modelo admitido para cálculo da tensão crítica de flambagem por distorção.

Tabela 5.9: Tensão crítica de flambagem por distorção para barras comprimidas.

\begin{tabular}{c|c|c}
\hline Perfil & $K_{\phi}\left(\mathrm{kN} / \mathrm{cm}^{2}\right)$ & $\sigma_{\text {Hancock }}\left(\mathrm{kN} / \mathrm{cm}^{2}\right)$ \\
\hline$U 127 \times 50 \times 3,00$ & 11,994 & 21,76 \\
\hline$U 127 \times 50 \times 17 \times 3,00$ & 11,186 & 28,53 \\
\hline$Z 127 \times 50 \times 17 \times 3,00$ & 11,084 & 28,46 \\
\hline
\end{tabular}

Agora tratando-se o problema como sendo o caso de flambagem por distorção para uma barra fletida, admitindo-se que a distorção ocorre na junção da mesa comprimida com a alma, pode-se obter os respectivos valores para a tensão crítica, cujo resultados estão apresentados na tabela 5.10, ressaltando-se que, para valor de tensão crítica superior a $t_{y} / 2$, este deve ser corrigido através da parábola de Johnston.

Tabela 5.10: Tensão crítica de flambagem por distorção para barras fletidas.

\begin{tabular}{c|c|c}
\hline Perfil & $K_{\phi}\left(\mathrm{kN} / \mathrm{cm}^{2}\right)$ & $\sigma_{\text {Hancock }}\left(\mathrm{kN} / \mathrm{cm}^{2}\right)$ \\
\hline$U 127 \times 50 \times 3,00$ & 23,99 & 27,15 \\
\hline$U 127 \times 50 \times 17 \times 3,00$ & 22,37 & 30,48 \\
\hline$Z 127 \times 50 \times 17 \times 3,00$ & 22,16 & 30,46 \\
\hline
\end{tabular}


Como pode-se notar, o modelo de Hancock simplesmente admite o coeficiente de mola rotacional na flexão igual ao dobro do obtido para o caso de compressão, obtendo-se valores de tensão crítica acima dos valores calculados para o modelo de compressão uniforme.

\subsubsection{Determinação das tensões através dos ensaios}

As tensões normais devidas ao carregamento aplicado podem ser avaliadas a partir das deformações medidas no meio da seção transversal do perfil. Essa avaliação tem por objetivo verificar os valores de tensões encontrados nos procedimentos anteriores em relação aos valores estimados a partir dos ensaios realizados.

Não se pode deixar de mencionar o fato de que trata-se de uma avaliação onde assume-se o comportamento linear na relação tensão e deformação. No caso específico dos perfis formados a frio, esta relação é admitida como válida até o valor de tensão igual a metade da tensão limite de proporcionalidade.

$\mathrm{Na}$ figura 5.35 indicam-se as tensões normais para as mesas superior e inferior correspondentes aos pontos instrumentados na seção transversal no meio do vão onde pode ser observado uma distribuição de tensões linear ao longo da largura das mesas. 


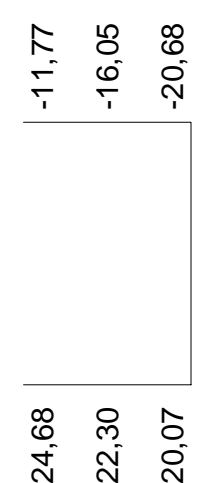

Ensaio 1

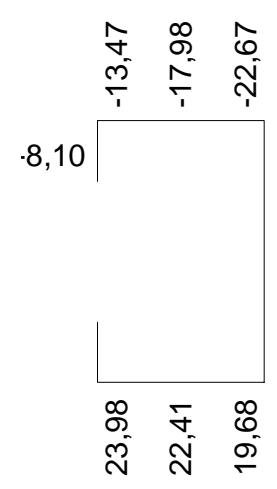

Ensaio 2

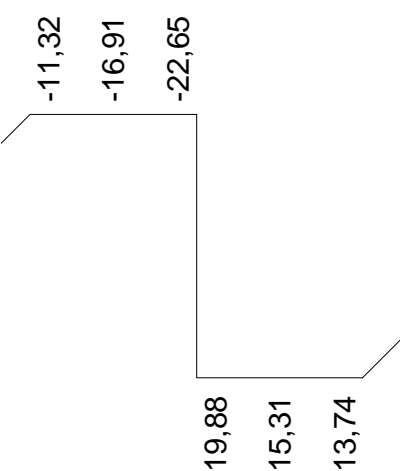

Ensaio 3

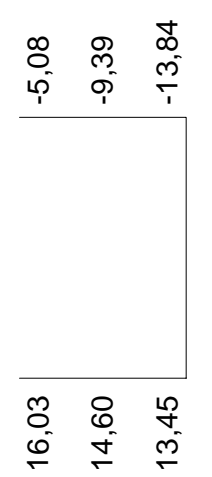

Ensaio 4

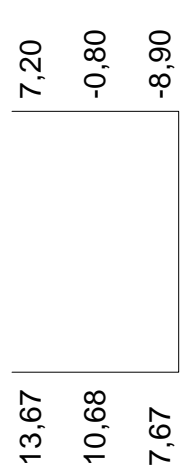

Ensaio 5

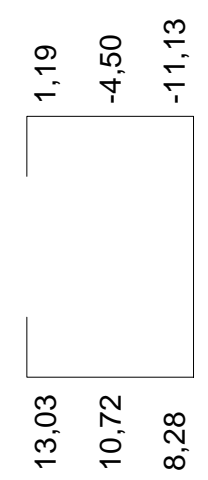

Ensaio 6

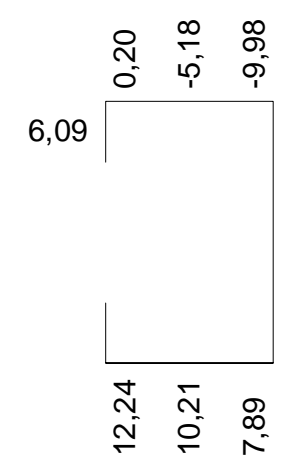

Ensaio 7

Figura 5.35: Tensões normais nas mesas obtidas nos ensaios $\left(\mathrm{kN} / \mathrm{cm}^{2}\right)$.

Os valores obtidos estão resumidos na tabela 5.11 para facilidade de comparação dos resultados.

Da análise da tabela 5.11 verifica-se que as tensões calculadas pelos vários procedimentos analisados estão acima das tensões para as quais convencionou-se como tensão última. Como exceção, para o perfil tipo Z enrijecido, ensaio 3 , obteve-se valores de tensão superior ao obtido através do modelo de Pekoz, Soroushian e do Eurocode.

Deve ser observado os valores correspondentes às tensões para os três primeiros ensaios, cujos valores de tensão normal são maiores que os obtidos nos ensaios restantes. 
Tabela 5.11: Resultados das tensões normais máximas $\left(\mathrm{kN} / \mathrm{cm}^{2}\right)$.

\begin{tabular}{c|c|c|c|c|c}
\hline $\mathrm{N}^{\circ}$ & Ensaio & $\begin{array}{c}\text { Peköz, } \\
\text { Soroushian }\end{array}$ & Eurocode & $\begin{array}{c}\text { Hancock } \\
\text { (Compressão) }\end{array}$ & $\begin{array}{c}\text { Hancock } \\
\text { (Flexão) }\end{array}$ \\
\hline 1 & 20,68 & 27,70 & 22,54 & 21,76 & 27,15 \\
\hline 2 & 22,67 & 29,40 & 31,38 & 28,53 & 30,48 \\
\hline 3 & 22,65 & 19,96 & 15,97 & 28,46 & 30,46 \\
\hline 4 & 13,84 & 19,37 & 16,01 & 21,76 & 27,15 \\
\hline 5 & 8,90 & 21,49 & 13,21 & 21,76 & 27,15 \\
\hline 6 & 11,13 & 21,35 & 18,56 & 28,53 & 30,48 \\
\hline 7 & 9,98 & 20,31 & 16,87 & 28,53 & 30,48 \\
\hline
\end{tabular}

Como já mencionado, os ensaios 1, 2 e 3, foram realizados com as telhas conectadas aos perfis através de todas as ondas. Isto pode proporcionar um melhor comportamento do perfil em relação ao deslocamento horizontal da sua mesa comprimida.

\subsubsection{Perfis com linhas de correntes}

Para o conjunto dos 8 ensaios realizados com linhas de correntes, pode-se dividi-lo em dois grupos.

O primeiro corresponde aos ensaios dos perfis tipo $U$, os quais tiveram como modo de falha a flambagem local da mesa.

Nos ensaios dos perfis tipo Z, como já observado, a falha ocorreu pelos deslocamentos verticais excessivos.

Em ambos os casos, pode-se admitir a hipótese de flexão simples para o seu dimensionamento, observando-se que, através das deformações medidas ao longo da alma dos perfis ensaiados, a linha neutra permanece próxima da meia altura da seção transversal. 


\section{CONCLUSÕES}

\subsection{Aspectos gerais sobre o desenvolvimento do trabalho}

Ao longo do desenvolvimento deste trabalho buscou-se atingir aos objetivos inicialmente propostos, os quais consistiram na análise dos diversos modos de falha aos quais estão sujeitos os perfis de chapa dobrada quando submetidos à flexão.

Este estudo envolveu duas situações de uso frequente dos perfis formados a frio nas construções em aço.

A primeira situação abordou o uso dos perfis de chapa dobrada em forma de $U$ e $U$ enrijecido como vigas de aço, enquanto elemento fletidos com restrições laterais descontínuas.

$\mathrm{Na}$ segunda situação, foram analisadas elementos com seções do tipo $U$, do tipo $U$ enrijecido e do tipo $Z$ enrijecido quando utilizados como terças, especificamente quando solicitadas à sucção devida ao efeito do vento em coberturas.

Os modos de falha característicos para esses perfis são o escoamento da seção transversal e a instabilidade global ou local.

O escoamento da seção transversal é de fácil determinação e, em geral, não ocorre para os perfis lateralmente destravados tendo-se em vista os problemas de instabilidade aos quais estão sujeitos. 
A determinação analítica da carga crítica a partir das equações diferenciais da instabilidade por flexo-torção, a teoria de Vlasov, é complexa, sendo restrita a algumas situações de carregamentos que simplificam a integração dessas equações, como se fez no capítulo 3 os perfis fletidos, sob as condições de contorno utilizadas nos ensaios desenvolvidos.

O cálculo também torna-se trabalhoso na determinação das propriedades efetivas da seção transversal da barra, exigindo processos iterativos para tal, onde o auxílio de softwares específicos tornam-se extremamente útil.

Os resultados experimentais obtidos nos ensaios dos perfis fletidos foram comparados aos valores teóricos calculados a partir das expressões teóricas da força crítica e aos valores calculados através das recomendações normativas do AISI (1996) e do Eurocode (1993), as quais foram utilizadas como documentos de referência para a elaboração do textobase da norma brasileira sobre o dimensionamento desses perfis.

Para os perfis conectados às telhas de aço, os resultados obtidos mostraram comportamentos diferenciados quando da utilização ou não de linhas de correntes, deixando clara a situação de um modo de falha por deslocamento horizontal excessivo da mesa comprimida. Esse deslocamento é resultado da rotação da seção transversal do perfil. Esta rotação é praticamente nula quando da utilização das linhas de corrente.

As seções transversais analisadas foram escolhidas tendo-se em vista a sua grande utilização em construções correntes que se utilizam dos perfis de aço formados a frio como elemento estrutural, destacando-se os perfis tipo $U$ de ampla utilização em nosso país e cujos resultados de programa experimental é escasso.

Embora analisada em caráter exploratório e com a finalidade de construir o equipamento, as medidas das imperfeições geométricas longitudinais indicaram valores dentro dos normalmente considerados nas hipóteses de cálculo admitidas.

Ressalta-se que o projeto previa inicialmente a utilização dos aços tipo SAE, sem qualidade estrutural, para a conformação dos perfis, porém, 
hoje tem-se maior oferta de aços de qualidade estrutural a custos praticamente iguais aos anteriores, justificando-se o uso do USI-SAC-41, cujo ganho de resistência e qualidade em muito sobrepõe-se a eventuais acréscimos de preço do material.

\subsection{Perfis de chapa dobrada fletidos}

Os resultados experimentais oriundos dos ensaios em vigas mostraram a predominância de dois modos de falha para os perfis e situações de carregamento analisadas: flambagem local da mesa comprimida e flambagem lateral com torção.

A metodologia empregada para a realização dos ensaios mostrou-se plenamente satisfatória, onde a regularidade dos resultados para os conjuntos similares comprovou a sua validade.

Em contrapartida, seria desejável um levantamento dos deslocamentos horizontais em um maior número de pontos ao longo do vão da viga com a finalidade de determinar-se a forma da deslocada horizontal e o giro ao longo do comprimento do perfil, permitindo-se a determinação da equação da forma deslocada do perfil na iminência da perda de instabilidade. Isto permitira um tratamento diferenciado para a solução das equações diferenciais da instabilidade por flex0-torção.

O modo de falha por flambagem distorcional não foi caracterizado, ficando possíveis evidências sobre a sua ocorrência para os perfis tipo $U$ enrijecido correspondentes aos ensaios U5 e U6, bem como para os perfis tipo Z enrijecido, correspondentes aos ensaios Z1 e Z2. Essa evidência ocorre devido aos resultados obtidos através do modelo proposto por Hancock.

Os valores teóricos da força crítica foram determinados a partir da solução aproximada das equações diferenciais da instabilidade por flexotorção e mostraram resultados próximos aos encontrados experimentalmente para as situações onde a falha deu-se por flambagem 
lateral com torção. Esses resultados teóricos são oriundos de simplificações que consideram a validade da relação elástico-linear entre tensão e deformação, consequentemente, a validade da superposição dos efeitos.

As expressões para cálculo do coeficiente de flexão $\left(\mathrm{C}_{b}\right)$ parecem ser conservadoras, onde os seus resultados não refletem as diversas formas de variação de momentos fletores ao longo do vão. Os resultados obtidos em função da variação dos diagramas de momentos fletores foram em número reduzido para se fazer uma análise mais detalhada sobre este coeficiente, entretanto, mostram um certo conservadorismo para as situações estudadas.

Os resultados calculados através do procedimento da AISI (1996) permite a utilização de coeficientes de flambagem para cada situação analisada e isto mostrou-se importante na avaliação do momento crítico.

Evidentemente, estes valores para o coeficiente de flambagem estão condicionados ao detalhe executado na fabricação dos travamentos laterais podendo-se assumir valores bastante variados, inclusive maiores que 1 .

Pode-se observar que as ocorrências de estados limites não previstos deu-se em alguns ensaios e podem estar associadad a maior proximidade dos pontos travados lateralmente, onde o gradiente de tensões na mesa comprimida oriundo da rotação da seção transversal pode inibir a flambagem local da mesa.

Por outro lado, este mesmo gradiente pode superpor-se às tensões de compressão e induzir à flambagem local da mesa, ainda que não prevista. Esta situação, para os perfis isolados, torna-se um agravante, tendo-se em vista que a ocorrência desse estado limite implica em brusca alteração no posicionamento da viga, com imediata perda da capacidade resistente, situação esta não desejada para as estruturas em geral.

Como mostrou-se as verificações efetuadas, os valores de $P_{c r}$ ficaram abaixo dos valores obtidos nos ensaios, justificando-se o uso de valores menos conservativos para os coeficientes de flambagem e 0 fator de modificação de momentos na flexão. 


\subsection{Perfis conectados às telhas de aço}

A análise experimental dos perfis conectados às telhas de aço foi desenvolvida em duas etapas: terças sem linhas de correntes e terças com 2 linhas de correntes.

Os ensaios nas terças mostraram comportamento distintos para os perfis quando da utilização ou não de linhas de corrente.

$\mathrm{Na}$ ausência de linhas de corrente, os perfis apresentam um modo de falha resultante do deslocamento horizontal excessivo da mesa comprimida, verificado para todas as seções transversais ensaiadas.

Este fato, caracterizando o estado limite último das terças sem linhas de corrente, passa a ser de fundamental importância e deverá ser analisado como um modo de falha que não é possível de ser comparado com as teorias até aqui disponíveis, devendo ser objeto de estudos futuros.

Quando da utilização das linhas de corrente, os perfis praticamente deixam de apresentar deslocamento horizontal da mesa comprimida e passam a apresentar apenas deslocamentos verticais, sugerindo a análise da terça como um barra sujeita à flexão simples.

As linhas de corrente também permitiram um ganho de resistência da terça, representado pelo aumento de pressão última na "caixa de sucção".

Os valores da pressão última, com exceção dos ensaios relativos aos perfis tipo $U$ com linhas de correntes, foram obtidos sob condições de deslocamentos excessivos, horizontais e verticais, mobilizando um comportamento da telha como membrana, proporcionando o apoio elástico ao perfil.

No projeto de terças, a ação de sucção é devida ao efeito do vento, ação de curta duração sobre a edificação e, como procedimento geral, não é imposta nenhuma restrição ao deslocamento vertical da terça, analisando-a somente sob o ponto de vista de tensões. Tal fato pode conduzir a danos indesejáveis à edificação, devendo-se impor limitações, mesmo que menos conservadoras, para esses deslocamentos. 
Em uma primeira avaliação, o método de Peköz, Soroushian apresenta resultados relativos às tensões normais coerentes com as deformações medidas na seções transversais dos perfis ensaiados. Entretanto, os valores do coeficiente de apoio elástico $(K)$ mostram-se bastante variáveis e a determinação de um valor teórico para fins de projeto necessita de um melhor estudo em função dos diversos parâmetros envolvidos, ressaltando-se que há procedimentos de ensaios específicos para a determinação desse coeficiente. Alternativamente, tais valores podem ser calculados e os obtidos aqui de forma experimental podem ser utilizados como referência.

Como vantagem, o procedimento do Eurocode traz expressão analítica para a determinação do coeficiente de apoio elástico.

Deve-se notar que a tensões calculadas por esses dois procedimentos são limitadas à tensão limite de escoamento do material. Pode-se observar a partir das tabelas 5.7 e 5.8 que as tensões calculadas estão abaixo da tensão de escoamento e são maiores que as obtidas nos ensaios, indicando claramente a limitação imposta por deslocamentos excessivos.

A flambagem por distorção onde foram analisados e apresentados os modelos propostos por Hancock, não demonstrou ser uma boa avaliação para este fenômeno, isto porque o modelo proposto admite a distorção da mesa e do enrijecedor, sendo que no caso em questão, essa distorção ocorre na ligação mesa tracionada-alma, associado ao fato de presença de tensões normais não uniformes.

O fato acima também ocorreu na avaliação segundo os procedimentos propostos por Douty e por Haussler, cujo estudo não foi apresentado neste trabalho. As tensões críticas obtidas são superiores às tensões encontradas nos ensaios, indicando uma flexão fora do plano, sem necessariamente ocorrer a distorção dos elementos da seção transversal.

Dada a quantidade de variáveis envolvidas na determinação da resistência ao momento fletor para esses perfis, o método proposto por LaBoube torna-se interessante pela sua simplicidade, embora sem um 
modelo matemático formal. $\mathrm{O}$ valor de um coeficiente de redução igual a 0,40 é adequado aos perfis tipo $U$ em geral.

A presença das linhas de correntes altera esse comportamento, como já mencionado. $O$ fato de ter-se utilizado de duas linhas de corrente justificase pela prática em construção metálica onde, para vãos dessa ordem de grandeza, isto é comum.

\subsection{Sugestões para trabalhos futuros}

Como continuidade da linha de pesquisa são sugeridos alguns temas correlatos para o desenvolvimento de trabalhos futuros, tendo como objetivo principal o estudo dos perfis de aço formados a frio, contribuindo para o uso racional desses nas construções metálicas.

Esses temas, em linhas gerais são:

1. Análise de seções tipo I, formadas por perfis duplo $U$, sob diferentes condições de carregamentos;

2. Flambagem distorcional para perfis tipo $U$ e $Z$ enrijecidos;

3. Análise de perfis tipo $Z$ quando utilizados como vigas e como terças;

4. Possível influência dos travamentos laterais (tipos e espaçamentos) sobre o modo de falha do perfil.

5. Análise experimental de vigas com restrição elástica e terças sob ações gravitacionais;

6. Análise comparativa entre as seções transversais tipo $U$ e tipo $Z$ enrijecidas utilizadas como terças;

7. Estudo da influência das linha de corrente no comportamento das terças, variando-se o número de linhas de correntes para um mesmo vão;

8. Estudo da influência da telha de aço (fixação e espessura) no comportamento das terças e variação do coeficiente do apoio elástico;

9. Análise de terças contínuas sob ações gravitacionais e ascensionais. 


\section{REFERÊNCIAS BIBLIOGRÁFICAS}

AMERICAN INSTITUTE OF STEEL CONSTRUCTION (1994) Load \& Resistance Factor Design (LRFD). AISC, vol. 1, Chicago.

AMERICAN IRON AND STEEL INSTITUTE (1996) Cold formed steel design manual. AISI, Washington.

AMERICAN IRON AND STEEL INSTITUTE (1991) LRFD Cold formed steel design manual. AISI, Washington.

ASSOCIAÇÃO BRASILEIRA DE NORMAS TÉCNICAS. (1967) Cálculo de estruturas de aço constituídas por perfis leves; NB-143. ABNT, Rio de Janeiro. 31p.

BAMBACH, M.R.; MERRICK, J.T.; HANCOCK G.J. (1998) Channel and Zsections with return lips. Fourteenth International Specialty Conference on Cold-Formed Steel Structures, p.21-38, St. Louis, Missouri, USA. Proceedings.

BASLER, K. (1961) Strength of plate girders in shear. Journal of the Structural Division, ASCE, v.87, n.ST7, p.151-180, Oct.

BLEICH, F. (1952) Buckling strength of metal structures. New York: McGraw-Hill. 508p.

CANADIAN STANDARTS ASSOCIATION (1984) Cold formed steel structural members - CAN3-S136-M84. CSA, Toronto. 
DALTRO, A. T. (1989) Comportamento último de vigas de chapa dobrada com seção em $Z$ enrijecida. Rio de Janeiro. Dissertação de Mestrado. Pontifícia Universidade Católica do Rio de Janeiro.

DESMOND, T.P.; PEKÖZ, T.; WINTER, G. (1981a) Edge stiffeners for thin-walled members. Journal of the Structural Division, ASCE, v.107, n.2, p.219-263, June.

DESMOND, T.P.; PEKÖZ, T.; WINTER, G. (1981b) Intermediate stiffeners for thin-walled members. Journal of the Structural Division, ASCE, v.107, n.ST4, p.627-649, April.

ELLIFRITT, D.S.; GLOVER, R.L.; HREN, J.D. (1998) A simplified model for distortional buckling of channels Zees in flexure. Fourteenth International Specialty Conference on Cold-Formed Steel Structures, p.39-52, St. Louis, Missouri, USA. Proceedings.

EUROCODE 3 (1993) Design of Steel Structures, Part 1.3: Cold-Formed Thin Gauge Members and Sheeting.

FRUCHTENGARTEN, J. (1995) Sobre a instabilidade de perfis de seção aberta. São Paulo. Tese de Doutoramento. Escola Politécnica da Universidade de São Paulo

HAUSLLER, R. W. (1964) Strength of elastically stabilized beams. Journal of the Structural Division, ASCE, v.90, n.ST3, p.219-263, June.

HANCOCK, G. J. (1997) Design for distortional buckling of flexural members. Thin-Walled Structures, v.27, n.1, p.3-12.

HANCOCK, G. J. (1985) Distortional buckling of steel storage rack columns. Journal of Structural Engineering, ASCE, v.111, n.12, p.2770-2783, May.

HANCOCK, G. J.; KWON, Y.B.; BERNARD, E.S. (1994) Strength design curves for thin-walled sectinos undergoing distortional buckling. Journal of Constructional Steel Research, v.31, p.169-186.

JONHSTON, N.; HANCOCK, G. (1994) Calibration of the AISI R-factor design approach for purlins using Australian test data. Engineering Structures, v.16, n.5, p.342-347. 
KALYANARAMAN, V.; PEKÖZ, T.; WINTER, G. (1977) Unstiffened compression elements. Journal of the Structural Division, ASCE, n.ST1, p.401-432, Feb.

KAVANAGH, K. T.; ELLIFRITT, D. S. (1994) Design strengths of coldformed channels in bending and torsion. Journal of Structural Engineering, ASCE, v.120, n.5, p.1599-1607, May.

KEMP, L. et al. (1995) Structural behavior of cold-formed profiles with emphasis on the Zeta-profile. Journal of Constructional Steel Research, v.34, p.207-224.

KWON, Y.B.; HANCOCK, G. J. (1992) Strength tests of cold-formed sections undergoing local and distortional buckling. Journal of Structural Engineering, ASCE, v.117, n.2, p.1786-1803, Feb.

LaBOUBE, R. A. (1992) Estimating uplift capacity of light steel roof system. Journal of Structural Engineering, ASCE, v.118, n.3, p.848-852, Mar.

LaBOUBE, R. A. (1991) Uplift capacity of Z-purlins. Journal of Structural Engineering, ASCE, v.117, n.4, p.1159-1166, April.

LAU, S.C.W.; HANCOCK, G.J. (1987) Distortional buckling formulas for channel columns. Journal of Structural Engineering, ASCE, v.113, n.5, p.1063-1078, May.

LEACH, P.; ROBINSON, P. (1993) Behavior of purlins subject to wind uplift (an assessment of EC3: Part 1.3). Structural Engineer, v.71, n.14, p.250-252, July.

LIN, C.Y. (1983) Effect of elastic restraints on the behavior of the flexural beams. Austin. 120 p. Dissertação (Mestrado) - University of Texas.

MURRAY, T. M.; ELHOUAR, S. (1994) North American approach to the design of continuous Z- and C-purlins for gravity loading with experimental verification. Engineering Structures, v.16, n.5, p.337-341.

NETHERCOT, D. A. (1983) Elastic lateral buckling of beams. In: NARAYANAN, R. Beams and beam-columns: stability and strength. Barking, UK: Applied Science. p.1-34. 
PANDEY, M. D. SHERBOUNE, A. N.; (1989) Unified v. integrated approaches in lateral-torsional buckling of beams. The Structural Engineer, v.67, p.245-249, July.

PEKÖZ, T. (1983) Diaphragm-braced thin-walled channel and Z-section beams. In: NARAYANAN, R. Beams and beam-columns: stability and strength. Barking, UK: Applied Science. p.161-184.

PEKÖZ, T.; SOROUSHIAN, D. (1982) Behavior of $\mathbf{C}$ and $\mathbf{Z}$ purlins under uplift. Sixth International Specialty Conference on Cold-Formed Steel Structures, p.409-429, St. Louis, Missouri, USA. Proceedings.

POLYZOIS, D. (1987) Sag roads as lateral supports for girts and purlins. Journal of Structural Engineering, ASCE, v.113, n.7, p.15211531, July.

POLYZOIS, D.; BIRKEMOE, P. C. (1985) Z-section girts under negative loading. Journal of Structural Engineering, ASCE, v.111, n.3, p.528-544, Mar.

POLYZOIS, D.; GUILLOTY Jr., L. J. (1991) Finite strip method for analysis of cold-formed purlins. Journal of Structural Mechanics, ASCE, v.117, n.1, p.184-203, Jan.

ROCKEY, k. C. (1967) Shear buckling of thin-walled sections. In: Chilver, A.H. Thin walled structural. New York: Chatto \&Windus, cap.20, p.248-270.

RODRIGUES, F. C. (1993) Estudo teórico-experimental de perfis de chapa dobrada submetidos à compressão. Rio de Janeiro. Tese de Doutorado, Universidade Federal do Rio de Janeiro, COPPE.

ROGERS, C. A.; SCHUSTER, R. M. (1997) Flange/web distortional buckling of cold-formed steel sections in bending. Thin-Walled Structures, v.27, n.1, p.13-29.

SALVADORI, M. G. (1955) Lateral buckling of I beams. Transactions, ASCE, v.120, p.1165-1177.

SALVADORI, M. G. (1956) Lateral buckling of eccentrically loaded I columns. Transactions, ASCE, v.121, p.1163-1178. 
SHERBOUNE, A. N.; PANDEY, M. D. (1989) Elastic, lateral-torsional stability of beams: moment modification factor. Journal of Constructional Steel Research, v.13, p.337-356.

TOMÀ, T.; WITTEMANN, K. (1994) Design of cold-formed purlins and rails restrained by sheeting. Journal of Constructional Steel Research, v.31, p.207-224.

TIMOSHENKO, S. P.; GERE, J. M. (1961) Theory of elastic stability. 2.ed. New York: McGraw-Hill. 541p.

VLASSOV, B. Z. (1962) Pièces longues en voiles minces. Paris: Eyrolles. $655 p$.

WILLIS, C. T.; WALLACE, B. (1990) Behavior of cold-formed steel purlins under gravity loading. Journal of the Structural Engineering, ASCE, v.116, n.8, p.848-852, Aug.

WINTER, G. (1959) Cold-formed, light-gage steel construction. Journal of the Structural Engineering, ASCE, v.85, n.ST9, p.151-173, Nov.

WINTER, G. (1944) Strength of slender beams. Transactions, ASCE, v.109, p.1321-1349.

WINTER, G. (1943) Lateral stability of unsymmetrical I-beams and trusses in bending. Transactions, ASCE, v.108, p.247-260.

YU, W. W. (1985) Cold formed steel design. New York: Wiley-Interscience. $545 p$.

YU, W. W.; LaBOUBE, R. A. (1998) Fourteenth International Specialty Conference on Cold-Formed Steel Structures - Design and Construction. St. Louis, Missouri, USA. Proceedings. 
ANEXO I

GRÁFICOS 


\section{LISTA DE FIGURAS}

Figura I.1: Posição dos extensômetros para os ensaios dos perfis fletidos. 211

Figura I.2: Posição dos extensômetros para os ensaios das terças.

a) Extensômetros nas mesas. b) Extensômetros nas almas.

Figura I.3: Gráfico Força x Deformação. a) Perfil U1A. b) Perfil U1B. 212

Figura I.4: Deslocamento vertical no meio do vão - Ensaio U1. 212

Figura I.5: Giro da seção transversal no meio do vão - Ensaio U1. 212

Figura I.6: Gráfico Força x Deformação. a) Perfil U2A. b) Perfil U2B. 213

Figura I.7: Deslocamento vertical no meio do vão - Ensaio U2. 213

Figura I.8: Giro da seção transversal no meio do vão - Ensaio U2. 213

Figura I.9: Gráfico Força x Deformação. a) Perfil U3A. b) Perfil U3B. 214

Figura I.10: Deslocamento vertical no meio do vão - Ensaio U3. 214

Figura I.11: Giro da seção transversal no meio do vão - Ensaio U3. 214

Figura I.12: Gráfico Força x Deformação. a) Perfil U4A. b) Perfil U4B. 215

Figura I.13: Deslocamento vertical no meio do vão - Ensaio U4. 215

Figura I.14: Giro da seção transversal no meio do vão - Ensaio U4. 215

Figura I.15: Gráfico Força x Deformação. a) Perfil U5A. b) Perfil U5B. 216

Figura I.16: Deslocamento vertical no meio do vão - Ensaio U5. 216

Figura I.17: Giro da seção transversal no meio do vão - Ensaio U5. 216

Figura I.18: Gráfico Força x Deformação. a) Perfil U6A. b) Perfil U6B. 217

Figura I.19: Deslocamento vertical no meio do vão - Ensaio U6. 217

Figura I.20: Giro da seção transversal no meio do vão - Ensaio U6. 217

Figura I.21: Gráfico Força x Deformação. a) Perfil U7A. b) Perfil U7B. 218

Figura I.22: Deslocamento vertical no meio do vão - Ensaio U7. 218

Figura I.23: Giro da seção transversal no meio do vão - Ensaio U7. 218

Figura I.24: Gráfico Força x Deformação. a) Perfil U8A. b) Perfil U8B. 219

Figura I.25: Deslocamento vertical no meio do vão - Ensaio U8. 219

Figura I.26: Giro da seção transversal no meio do vão - Ensaio U8. 219

Figura I.27: Gráfico Força x Deformação. a) Perfil U9A. b) Perfil U9B. 220

Figura I.28: Deslocamento vertical no meio do vão - Ensaio U9. 220

Figura I.29: Giro da seção transversal no meio do vão - Ensaio U9. 220 
Figura I.30: Gráfico Força x Deformação. a) Perfil U10A. b) Perfil U10B. 221

Figura I.31: Deslocamento vertical no meio do vão - Ensaio U10. 221

Figura I.32: Giro da seção transversal no meio do vão - Ensaio U10. 221

Figura I.33: Gráfico Força x Deformação. a) Perfil U11A. b) Perfil U11B. 222

Figura I.34: Deslocamento vertical no meio do vão - Ensaio U11. 222

Figura I.35: Giro da seção transversal no meio do vão - Ensaio U11. 222

Figura I.36: Gráfico Força x Deformação. a) Perfil U12A. b) Perfil U12B. 223

Figura I.37: Deslocamento vertical no meio do vão - Ensaio U12. 223

Figura I.38: Gráfico Força x Deformação. a) Perfil U13A. b) Perfil U13B. 224

Figura I.39: Deslocamento vertical no meio do vão - Ensaio U13. 224

Figura I.40: Gráfico Força x Deformação. a) Perfil U14A. b) Perfil U14B. 225

Figura I.41: Deslocamento vertical no meio do vão - Ensaio U14. 225

Figura I.42: Gráfico Força x Deformação. a) Perfil U15A. b) Perfil U15B. 226

Figura I.43: Deslocamento vertical no meio do vão - Ensaio U15. 226

Figura I.44: Gráfico Força x Deformação. a) Perfil U16A. b) Perfil U16B. 227

Figura I.45: Deslocamento vertical no meio do vão - Ensaio U16. 227

Figura I.46: Gráfico Força x Deformação. a) Perfil U17A. b) Perfil U17B. 228

Figura I.47: Deslocamento vertical no meio do vão - Ensaio U17. 228

Figura I.48: Gráfico Força x Deformação. a) Perfil U18A. b) Perfil U18B. 229

Figura I.49: Deslocamento vertical no meio do vão - Ensaio U18. 229

Figura I.50: Gráfico Força x Deformação. a) Perfil U19A. b) Perfil U19B. 230

Figura I.51: Deslocamento vertical no meio do vão - Ensaio U19. 230

Figura I.52: Giro da seção transversal no meio do vão - Ensaio U19. 230

Figura I.53: Gráfico Força x Deformação. a) Perfil U20A. b) Perfil U20B. 231

Figura I.54: Deslocamento vertical no meio do vão - Ensaio U20. 231

Figura I.55: Giro da seção transversal no meio do vão - Ensaio U20. 231

Figura I.56: Gráfico Força x Deformação. a) Perfil U21A. b) Perfil U21B. 232

Figura 1.57: Deslocamento vertical no meio do vão - Ensaio U21. 232

Figura I.58: Giro da seção transversal no meio do vão - Ensaio U21. 232

Figura I.59: Gráfico Força x Deformação. a) Perfil U22A. b) Perfil U22B. 233

Figura I.60: Deslocamento vertical no meio do vão - Ensaio U22. 233

Figura I.61: Gráfico Força x Deformação. a) Perfil U23A. b) Perfil U23B. 234

Figura I.62: Deslocamento vertical no meio do vão - Ensaio U23. 234

Figura I.63: Gráfico Força x Deformação. a) Perfil U24A. b) Perfil U24B. 235 
Figura I.64: Deslocamento vertical no meio do vão - Ensaio U24. 235

Figura I.65: Gráfico Força x Deformação. a) Perfil U25A. b) Perfil U25B. 236

Figura I.66: Deslocamento vertical no meio do vão - Ensaio U25. 236

Figura I.67: Giro da seção transversal no meio do vão - Ensaio U25. 236

Figura I.68: Gráfico Força x Deformação. a) Perfil U26A. b) Perfil U26B. 237

Figura I.69: Deslocamento vertical no meio do vão - Ensaio U26. 237

Figura I.70: Giro da seção transversal no meio do vão - Ensaio U26. 237

Figura I.71: Gráfico Força x Deformação. a) Perfil U27A. b) Perfil U27B. 238

Figura I.72: Deslocamento vertical no meio do vão - Ensaio U27. 238

Figura I.73: Giro da seção transversal no meio do vão - Ensaio U27. 238

Figura I.74: Gráfico Força x Deformação. a) Perfil U28A. b) Perfil U28B. 239

Figura I.75: Deslocamento vertical no meio do vão - Ensaio U28. 239

Figura I.76: Giro da seção transversal no meio do vão - Ensaio U28. 239

Figura I.77: Gráfico Força x Deformação. a) Perfil U29A. b) Perfil U29B. 240

Figura I.78: Deslocamento vertical no meio do vão - Ensaio U29. 240

Figura I.79: Giro da seção transversal no meio do vão - Ensaio U29. 240

Figura I.80: Gráfico Força x Deformação. a) Perfil U30A. b) Perfil U30B. 241

Figura I.81: Deslocamento vertical no meio do vão - Ensaio U30. 241

Figura I.82: Giro da seção transversal no meio do vão - Ensaio U30. 241

Figura I.83: Gráfico Força x Deformação. a) Perfil Z1A. b) Perfil Z1B. 242

Figura I.84: Deslocamento vertical no meio do vão - Ensaio Z1. 242

Figura I.85: Giro da seção transversal no meio do vão - Ensaio Z1. 242

Figura I.86: Gráfico Força x Deformação. a) Perfil Z2A. b) Perfil Z2B. 243

Figura I.87: Deslocamento vertical no meio do vão - Ensaio Z2. 243

Figura I.88: Giro da seção transversal no meio do vão - Ensaio Z2. 243

Figura I.89: Gráfico Força x Deformação - Caixa 1. 244

Figura 1.90: Deslocamento vertical no meio do vão - Caixa 1. 244

Figura 1.91: Caixa 1. a) Deslocamento horizontal das mesas no meio do vão. b)

Giro da seção transversal no meio do vão. 244

Figura I.92: Gráfico Força x Deformação - Caixa 2. 245

Figura 1.93: Deslocamento vertical no meio do vão - Caixa 2. 245

Figura 1.94: Deslocamento horizontal da mesa superior - Caixa 2.

Figura 1.95: Gráfico Força x Deformação - Caixa 3.

Figura I.96: Deslocamento vertical no meio do vão - Caixa 3. 246 
Figura I.97: Deslocamento horizontal da mesa superior - Caixa 3.

Figura I.98: Gráfico Força x Deformação - Caixa 4.

Figura 1.99: Deslocamento vertical no meio do vão - Caixa 4.

Figura I.100: Deslocamento horizontal da mesa superior e deslocamento vertical no meio do vão - Caixa 4.

Figura I.101: Gráfico Força x Deformação - Caixa 5.

Figura I.102: Deslocamento vertical no meio do vão - Caixa 5.

Figura I.103: Deslocamento horizontal da mesa superior - Caixa 5.248

Figura I.104: Gráfico Força x Deformação - Caixa 6.

Figura I.105: Deslocamento vertical no meio do vão - Caixa 6.

Figura I.106: Deslocamento horizontal da mesa superior - Caixa 6.

Figura I.107: Gráfico Força x Deformação - Caixa 7. a) Deformações nas mesas. b) Deformações na alma. 250

Figura I.108: Deslocamento vertical no meio do vão - Caixa 7.

Figura I.109: Deslocamento horizontal da mesa superior - Caixa 7.

Figura I.110: Gráfico Força x Deformação - Caixa 8.

Figura I.111: Deslocamento vertical no meio do vão - Caixa 8.

Figura I.112: Deslocamento horizontal da mesa superior - Caixa 8.

Figura I.113: Gráfico Força x Deformação - Caixa 9.

Figura I.114: Deslocamento vertical no meio do vão - Caixa 9.

Figura I.115: Deslocamento horizontal da mesa superior - Caixa 9.

Figura I.116: Gráfico Força x Deformação - Caixa 10. a) Deformações nas mesas. b) Deformações na alma. 253

Figura I.117: Deslocamento vertical no meio do vão - Caixa 10.

Figura I.118: Deslocamento horizontal da mesa superior - Caixa 10.253

Figura I.119: Gráfico Força x Deformação - Caixa 11. a) Deformações nas mesas. b) Deformações na alma. 254

Figura I.120: Deslocamento vertical no meio do vão - Caixa 11.

Figura I.121: Deslocamento horizontal da mesa superior - Caixa 11.254

Figura I.122: Gráfico Força x Deformação - Caixa 12.

Figura I.123: Deslocamento vertical no meio do vão - Caixa 12.

Figura I.124: Deslocamento horizontal da mesa superior - Caixa 12.

Figura I.125: Gráfico Força x Deformação - Caixa 13. a) Deformações nas mesas. b) Deformações na alma. 
Figura I.126: Deslocamento vertical no meio do vão - Caixa 13.

Figura I.127: Deslocamento horizontal da mesa superior - Caixa 13.

Figura I.128: Gráfico Força x Deformação - Caixa 14. a) Deformações nas mesas. b) Deformações na alma.

Figura I.129: Deslocamento vertical no meio do vão - Caixa 14.

Figura I.130: Deslocamento horizontal da mesa superior - Caixa 14.

Figura I.131: Gráfico Força x Deformação - Caixa 15. a) Deformações nas mesas. b) Deformações na alma.

Figura I.132: Deslocamento vertical no meio do vão - Caixa 15.

Figura I.133: Deslocamento horizontal da mesa superior - Caixa 15. 


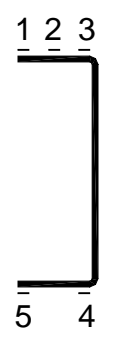

Perfil A

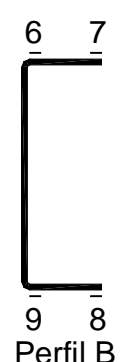

Perfil B

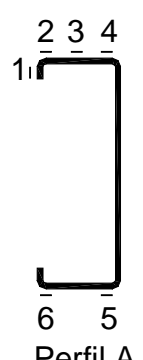

Perfil A

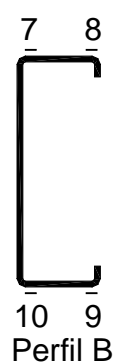

Perfil B

Figura I.1: Posição dos extensômetros para os ensaios dos perfis fletidos.

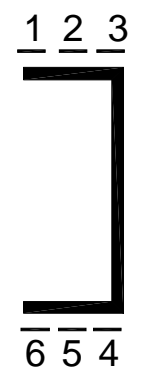

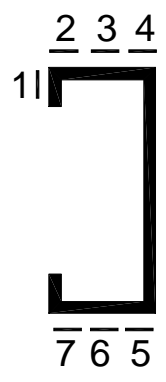

a)
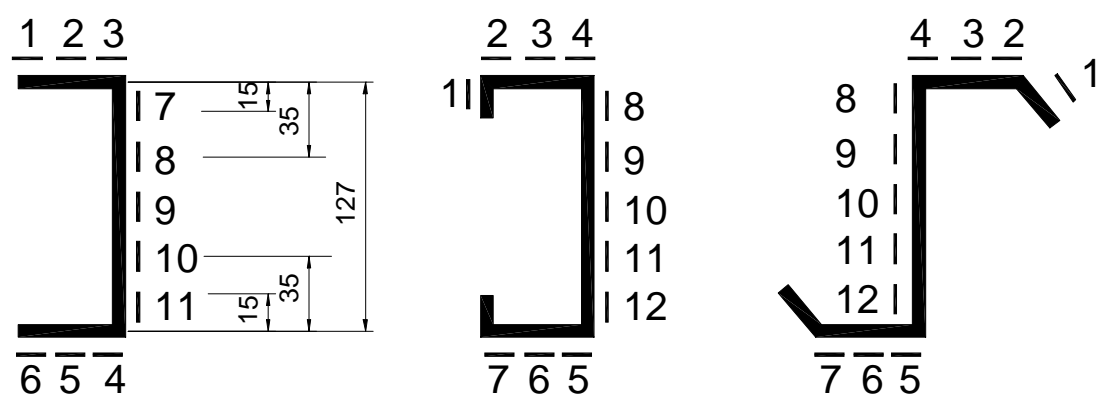

b)

Figura I.2: Posição dos extensômetros para os ensaios das terças.

a) Extensômetros nas mesas. b) Extensômetros nas almas. 


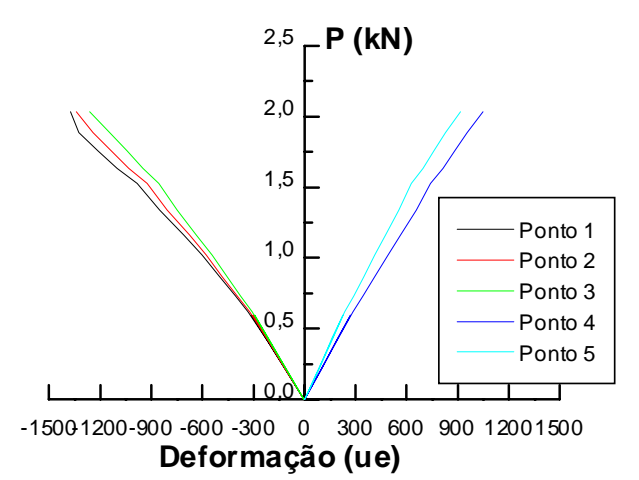

a)

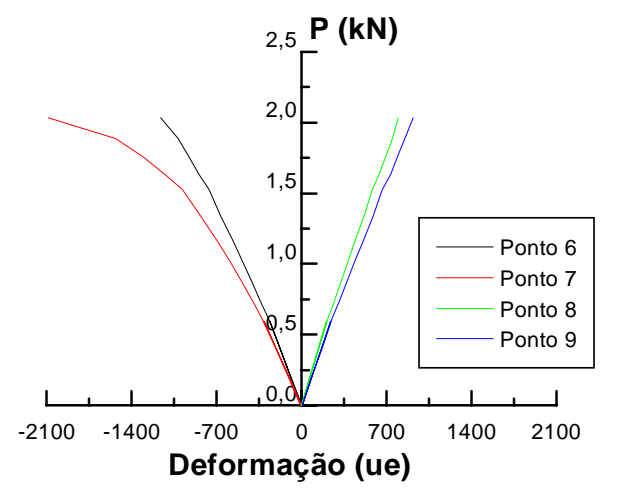

b)

Figura I.3: Gráfico Força x Deformação. a) Perfil U1A. b) Perfil U1B.

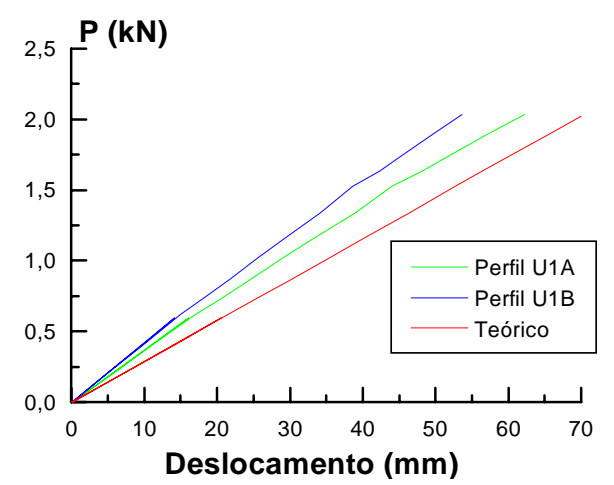

Figura I.4: Deslocamento vertical no meio do vão - Ensaio U1.

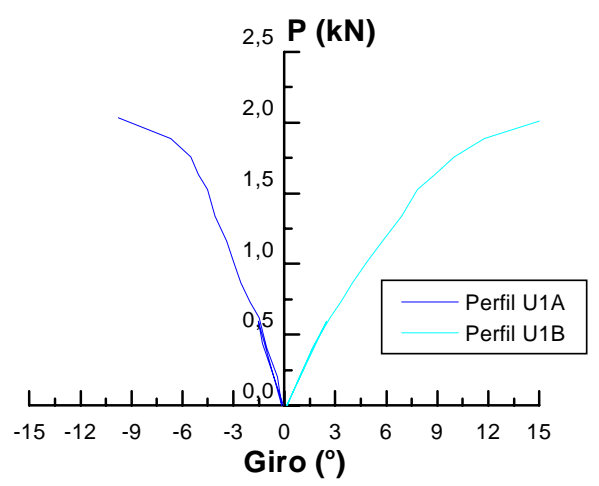

Figura I.5: Giro da seção transversal no meio do vão - Ensaio U1. 


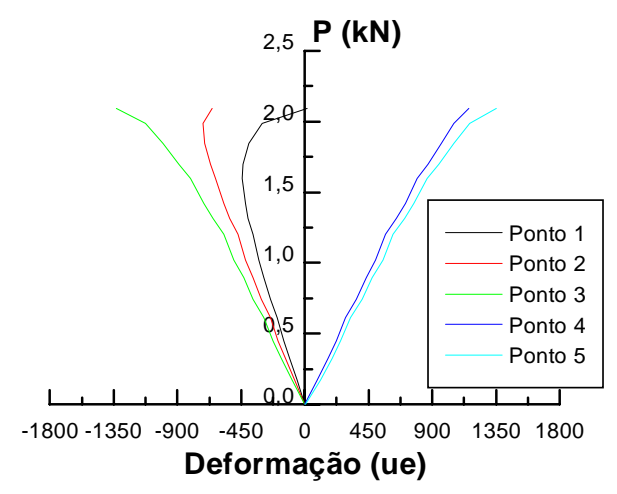

a)

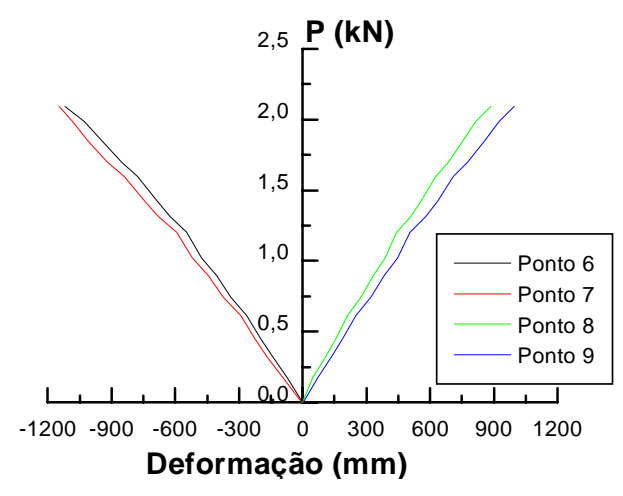

b)

Figura I.6: Gráfico Força x Deformação. a) Perfil U2A. b) Perfil U2B.

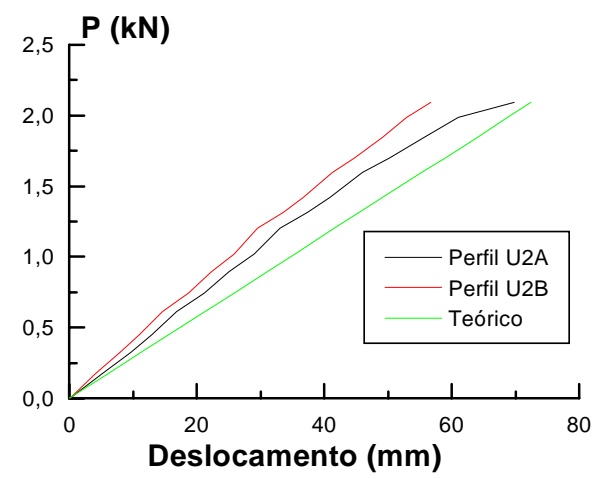

Figura I.7: Deslocamento vertical no meio do vão - Ensaio U2.

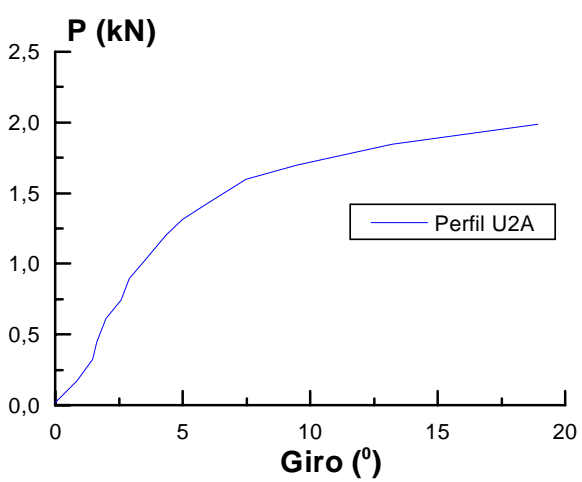

Figura I.8: Giro da seção transversal no meio do vão - Ensaio U2. 


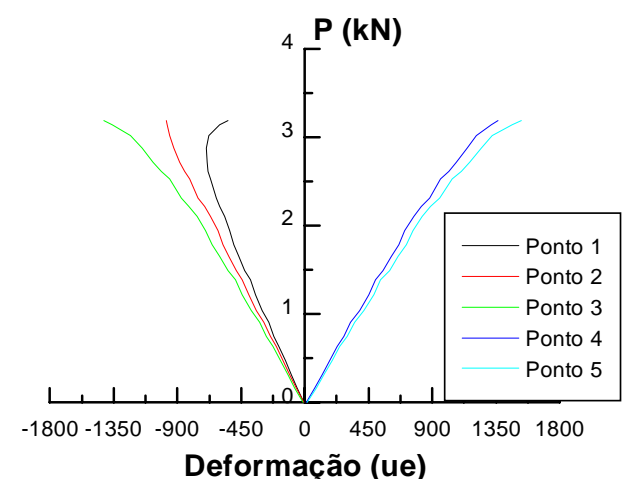

a)

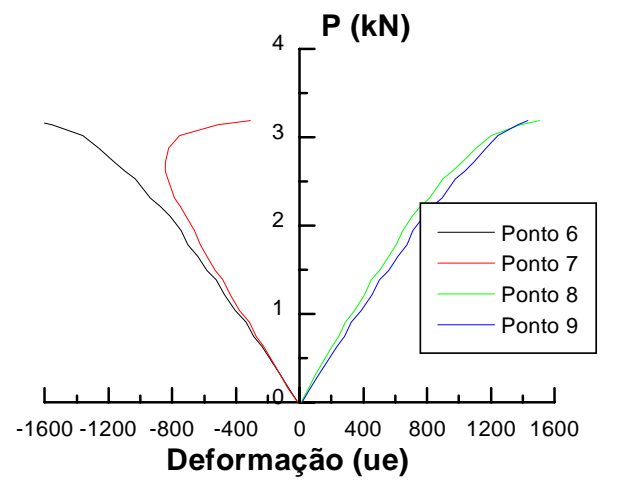

b)

Figura I.9: Gráfico Força x Deformação. a) Perfil U3A. b) Perfil U3B.

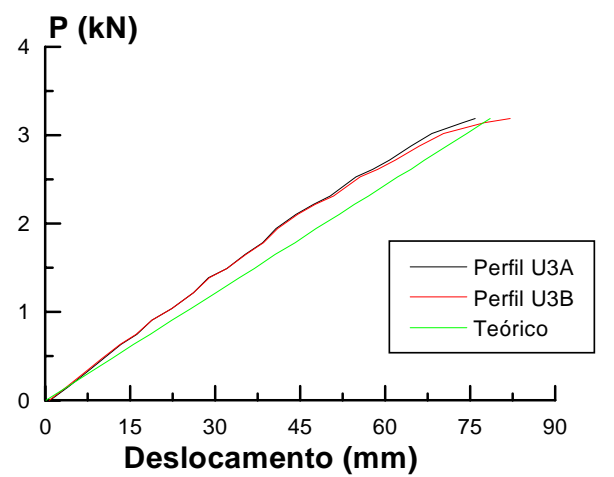

Figura I.10: Deslocamento vertical no meio do vão - Ensaio U3.

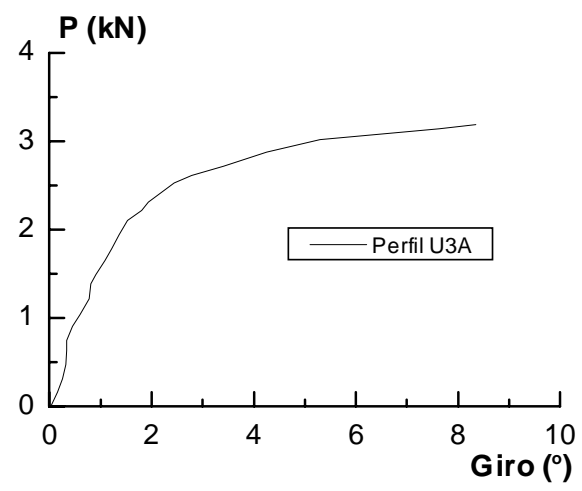

Figura I.11: Giro da seção transversal no meio do vão - Ensaio U3. 


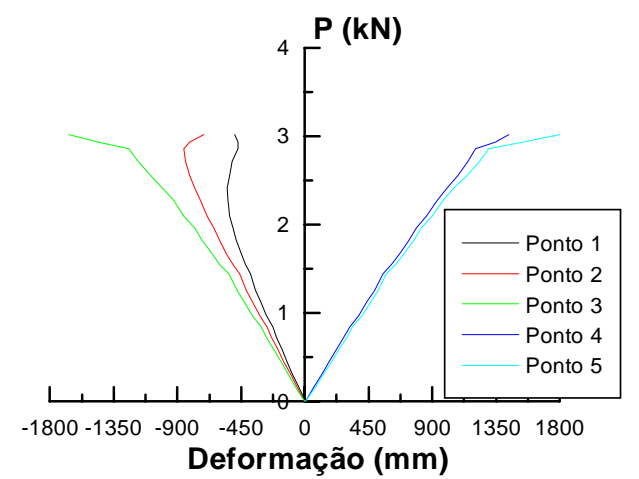

a)

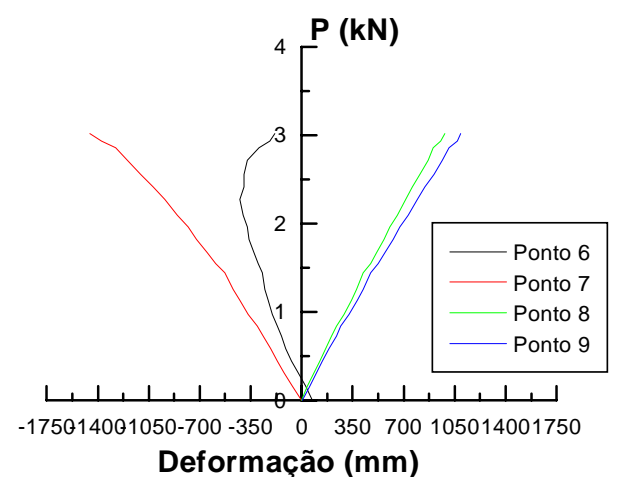

b)

Figura I.12: Gráfico Força x Deformação. a) Perfil U4A. b) Perfil U4B.

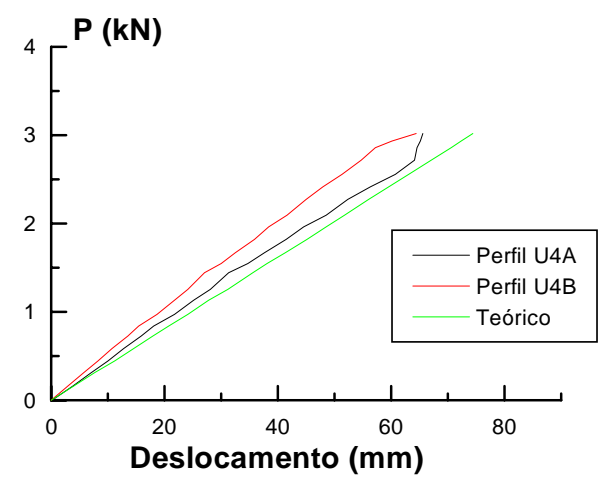

Figura I.13: Deslocamento vertical no meio do vão - Ensaio U4.

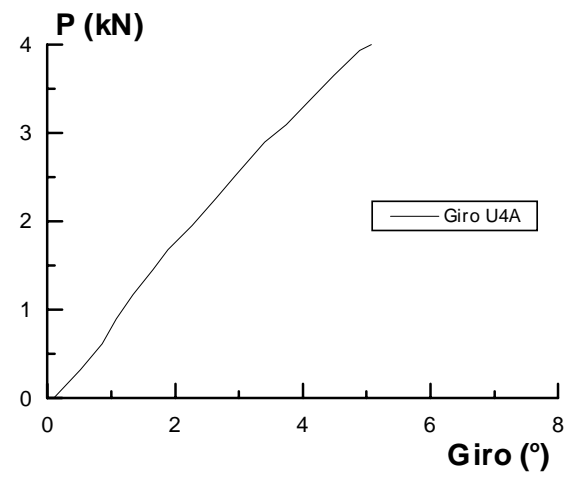

Figura I.14: Giro da seção transversal no meio do vão - Ensaio U4. 


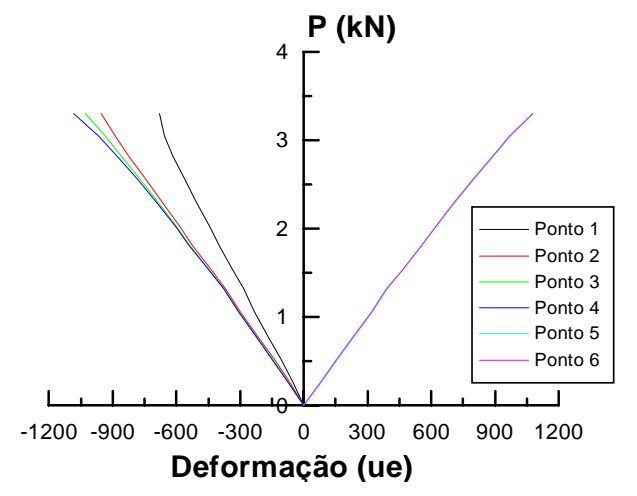

a)

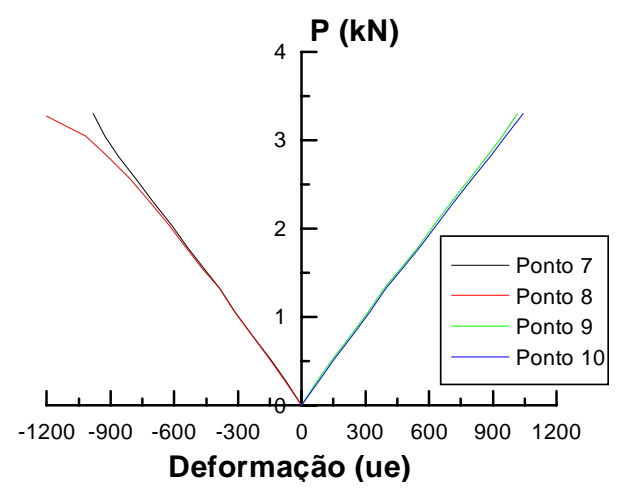

b)

Figura I.15: Gráfico Força x Deformação. a) Perfil U5A. b) Perfil U5B.

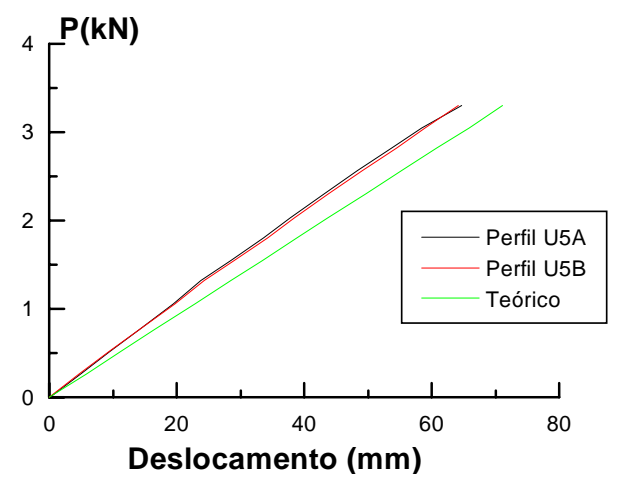

Figura I.16: Deslocamento vertical no meio do vão - Ensaio U5.

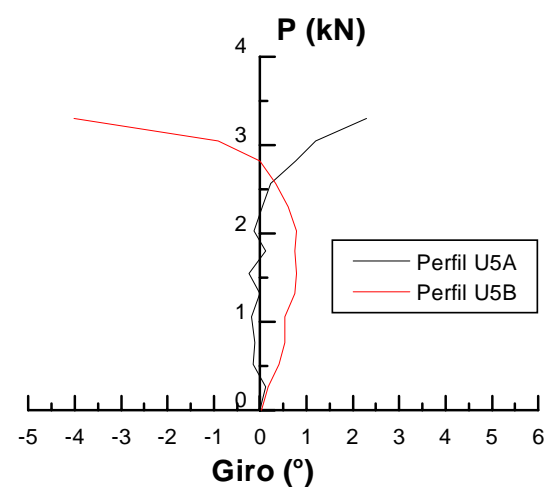

Figura I.17: Giro da seção transversal no meio do vão - Ensaio U5. 


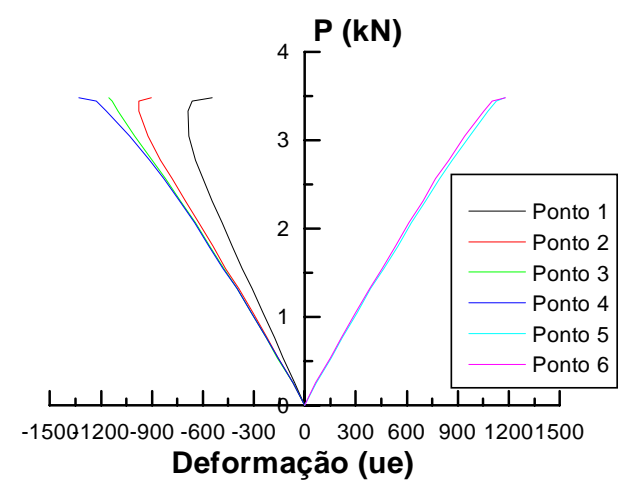

a)

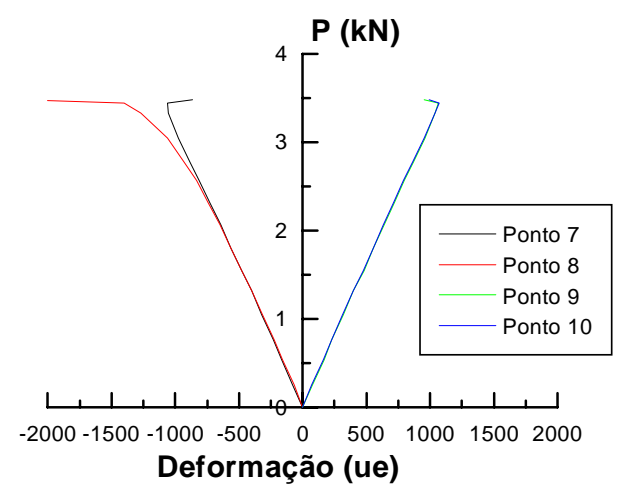

b)

Figura I.18: Gráfico Força x Deformação. a) Perfil U6A. b) Perfil U6B.

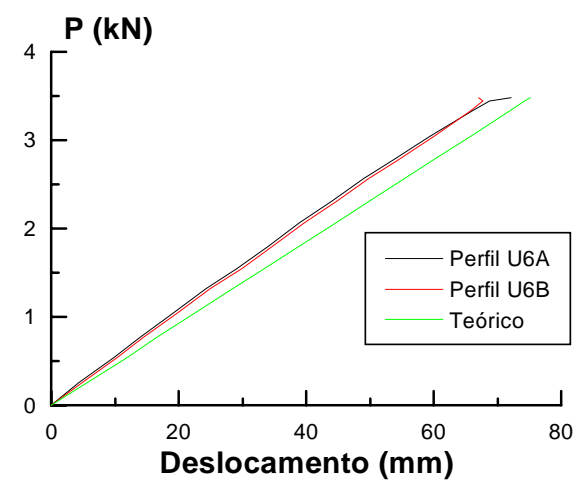

Figura I.19: Deslocamento vertical no meio do vão - Ensaio U6.

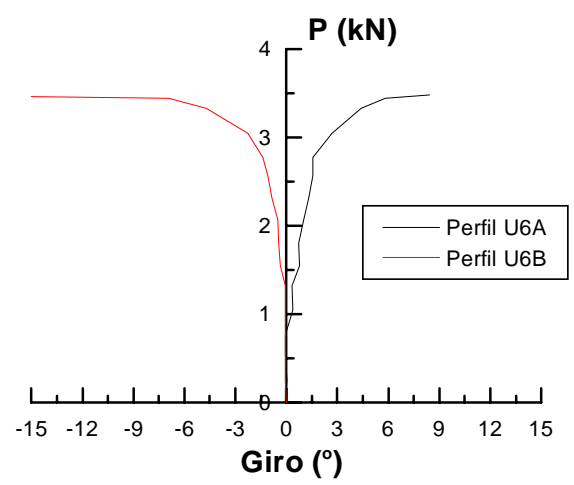

Figura I.20: Giro da seção transversal no meio do vão - Ensaio U6. 


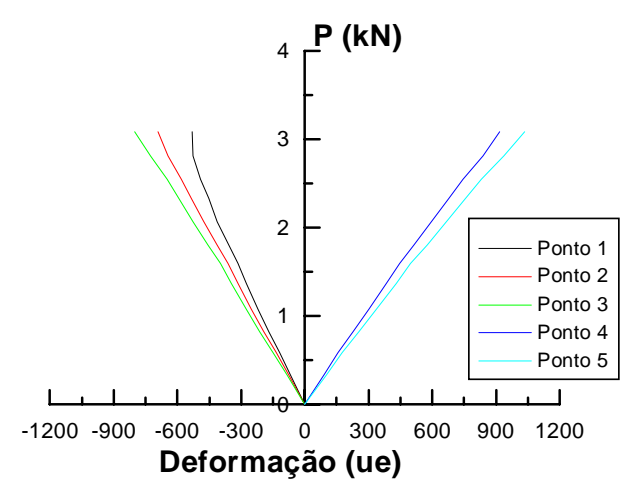

a)

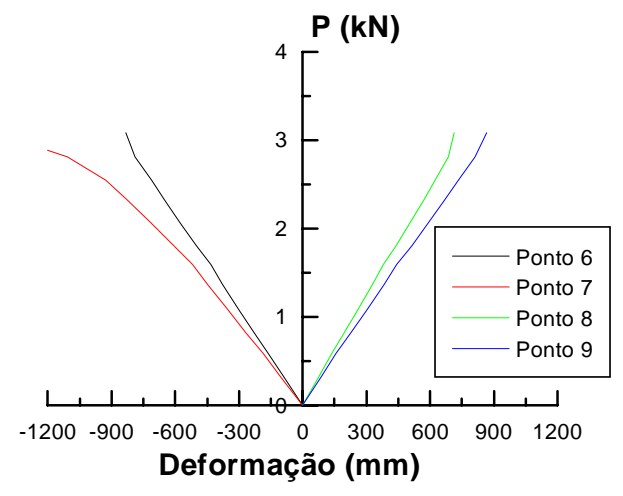

b)

Figura I.21: Gráfico Força x Deformação. a) Perfil U7A. b) Perfil U7B.

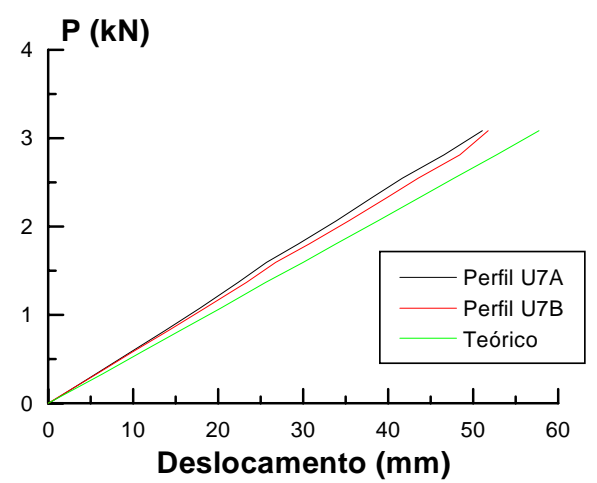

Figura I.22: Deslocamento vertical no meio do vão - Ensaio U7.

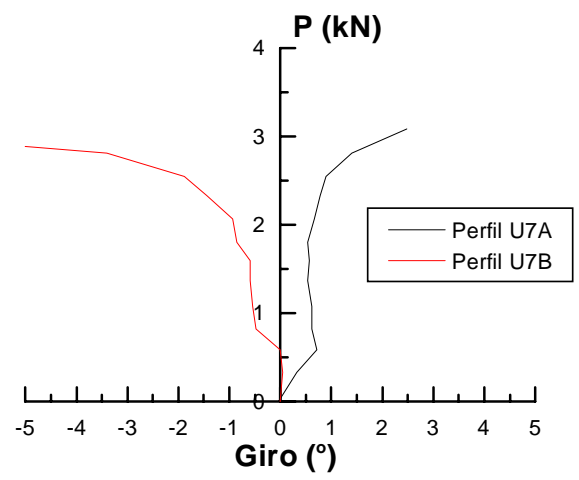

Figura I.23: Giro da seção transversal no meio do vão - Ensaio U7. 


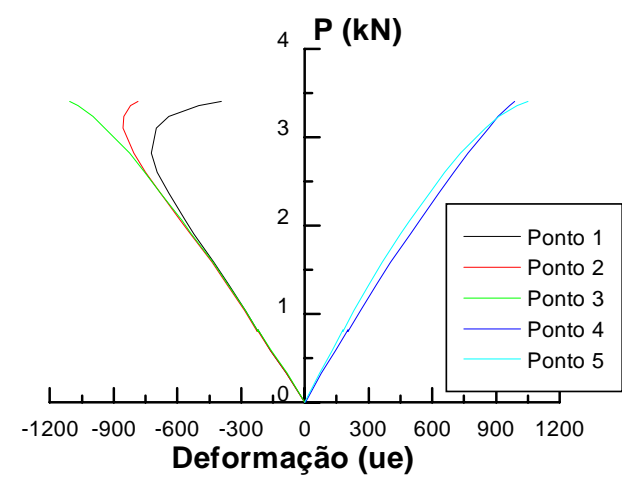

a)

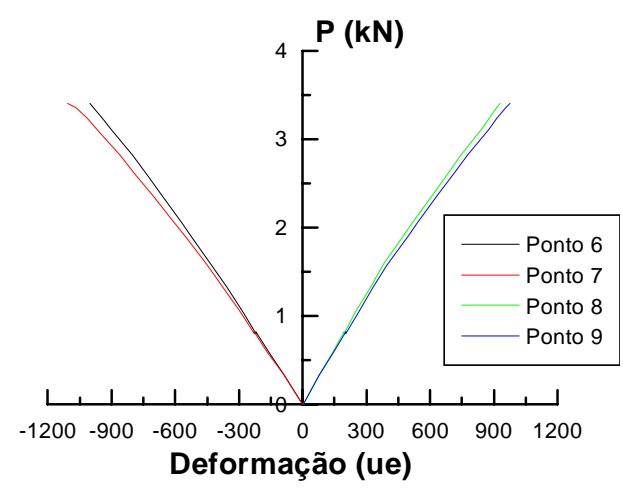

b)

Figura I.24: Gráfico Força x Deformação. a) Perfil U8A. b) Perfil U8B.

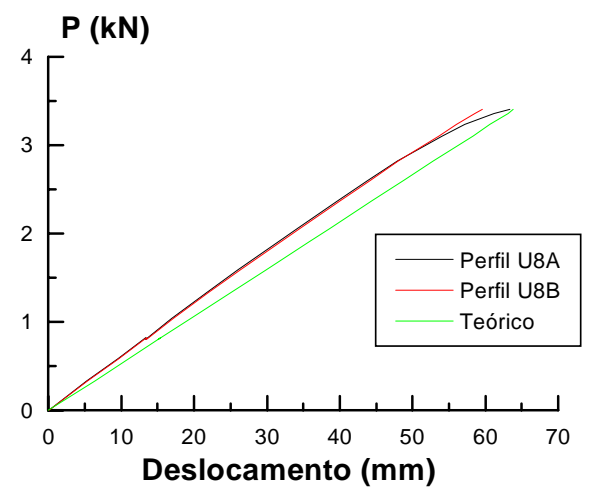

Figura I.25: Deslocamento vertical no meio do vão - Ensaio U8.

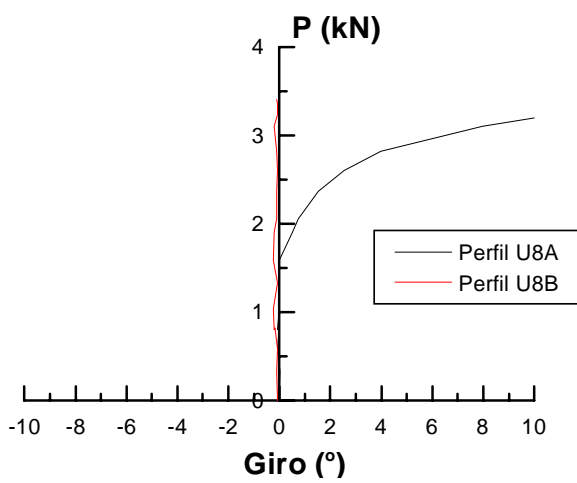

Figura I.26: Giro da seção transversal no meio do vão - Ensaio U8. 


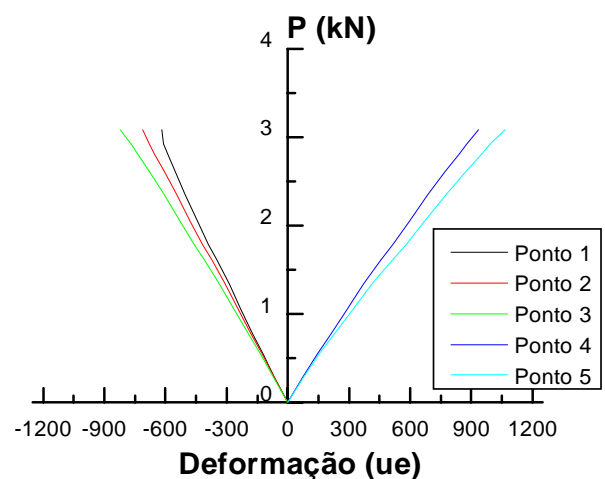

a)

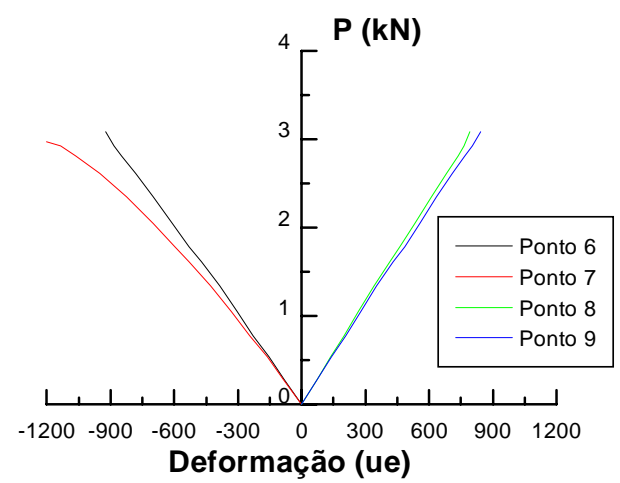

b)

Figura I.27: Gráfico Força x Deformação. a) Perfil U9A. b) Perfil U9B.

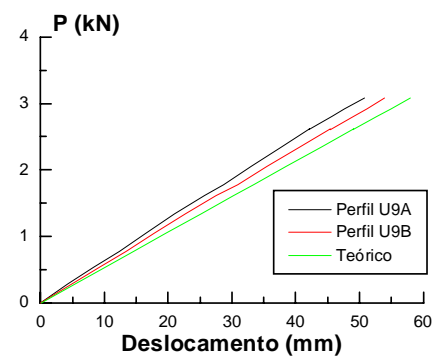

Figura I.28: Deslocamento vertical no meio do vão - Ensaio U9.

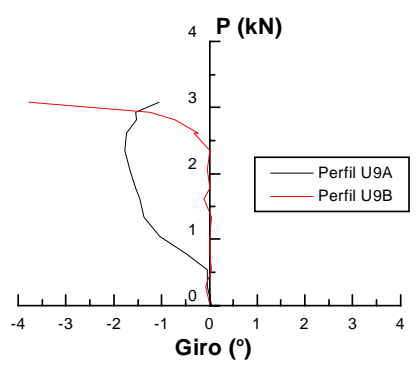

Figura I.29: Giro da seção transversal no meio do vão - Ensaio U9. 


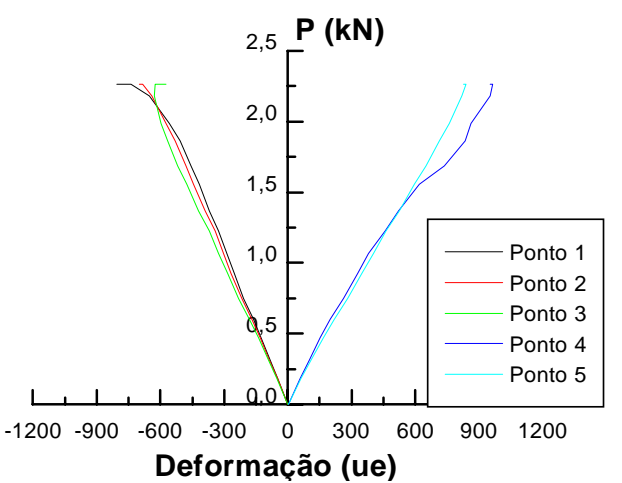

a)

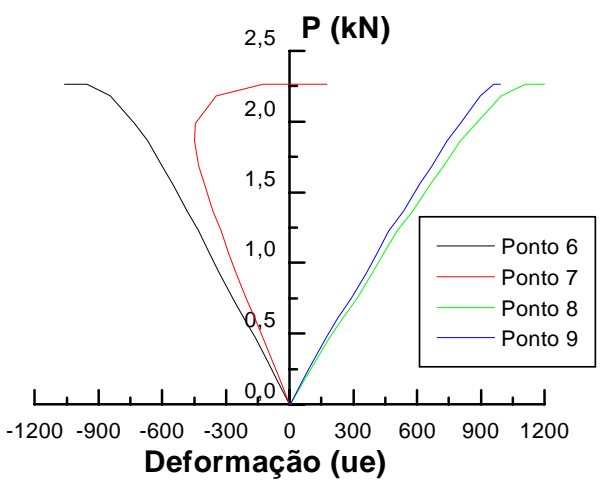

b)

Figura I.30: Gráfico Força x Deformação. a) Perfil U10A. b) Perfil U10B.

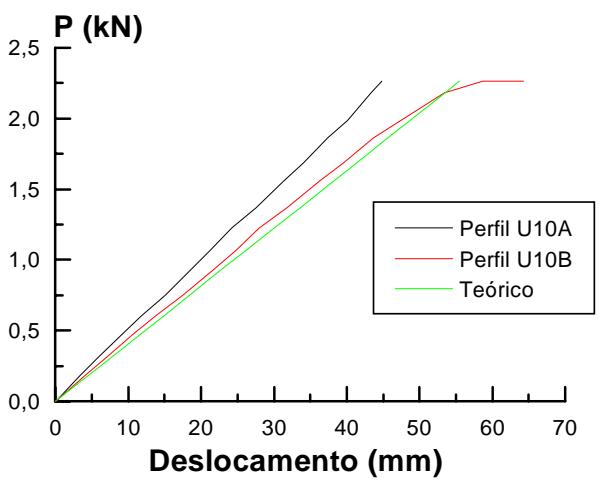

Figura I.31: Deslocamento vertical no meio do vão - Ensaio U10.

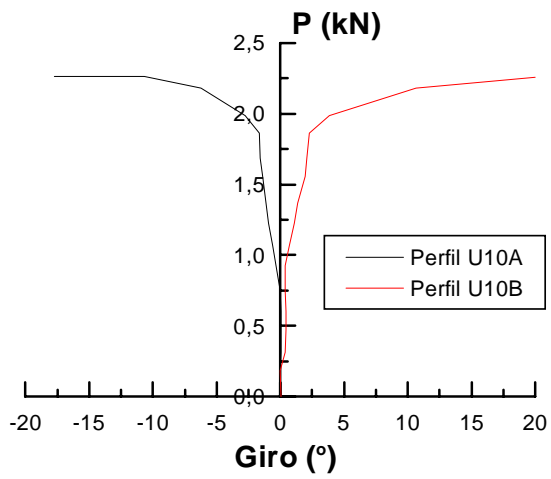

Figura I.32: Giro da seção transversal no meio do vão - Ensaio U10. 


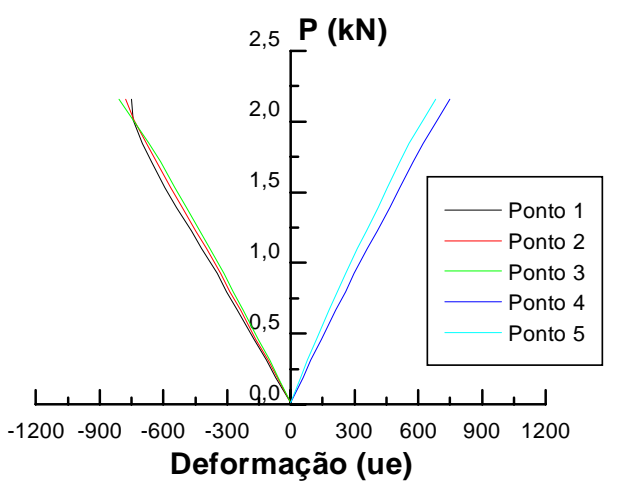

a)

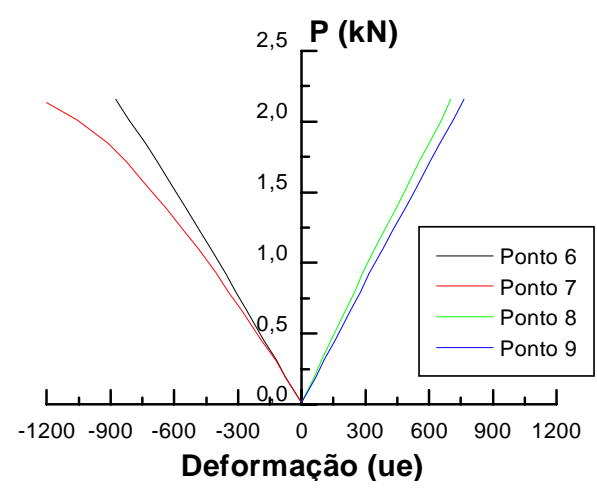

b)

Figura I.33: Gráfico Força x Deformação. a) Perfil U11A. b) Perfil U11B.

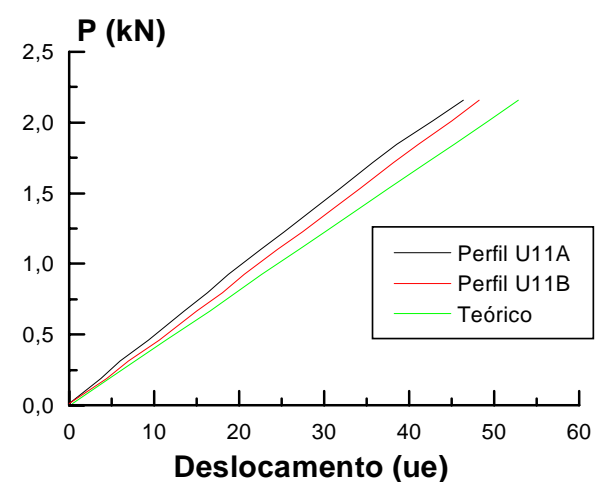

Figura I.34: Deslocamento vertical no meio do vão - Ensaio U11.

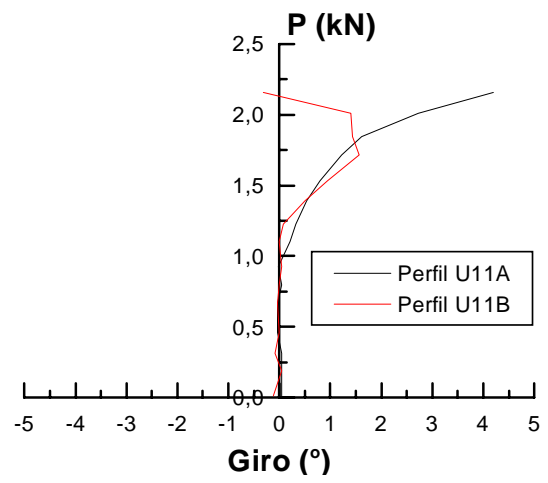

Figura I.35: Giro da seção transversal no meio do vão - Ensaio U11. 


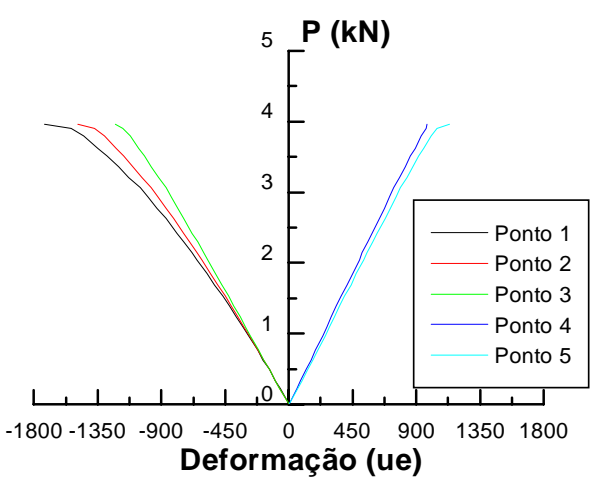

a)

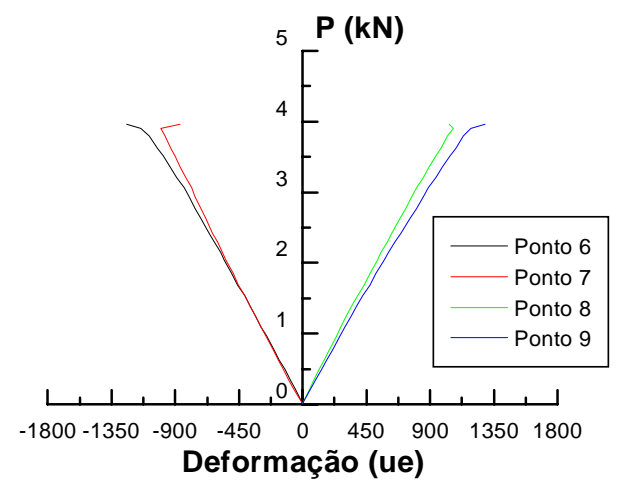

b)

Figura I.36: Gráfico Força x Deformação. a) Perfil U12A. b) Perfil U12B.

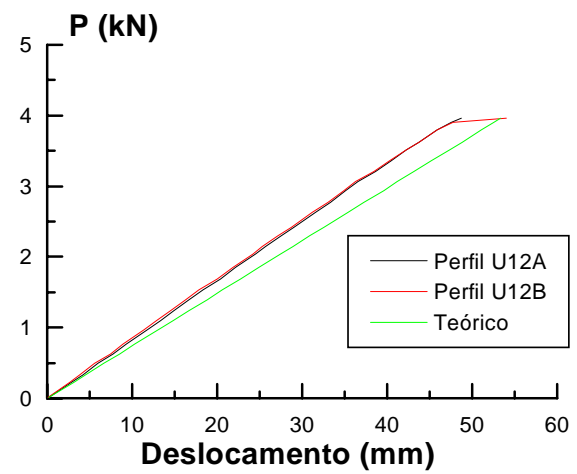

Figura I.37: Deslocamento vertical no meio do vão - Ensaio U12. 


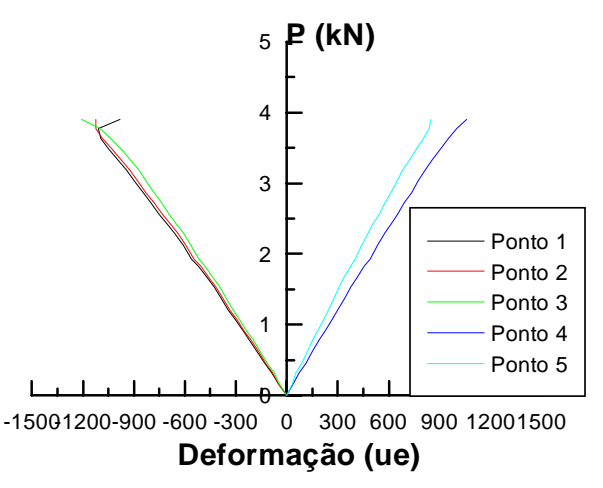

a)

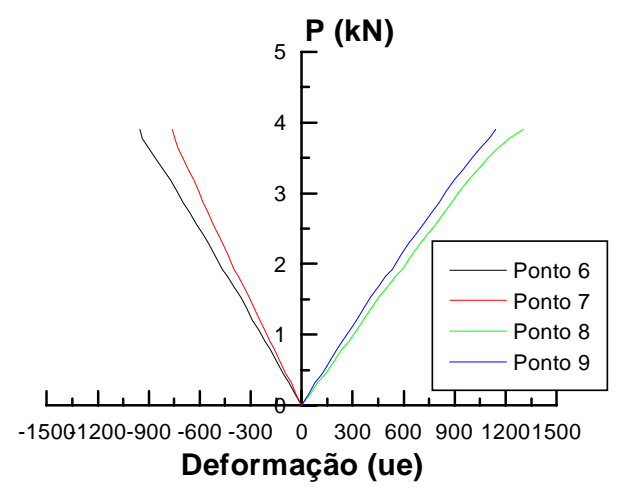

b)

Figura I.38: Gráfico Força x Deformação. a) Perfil U13A. b) Perfil U13B.

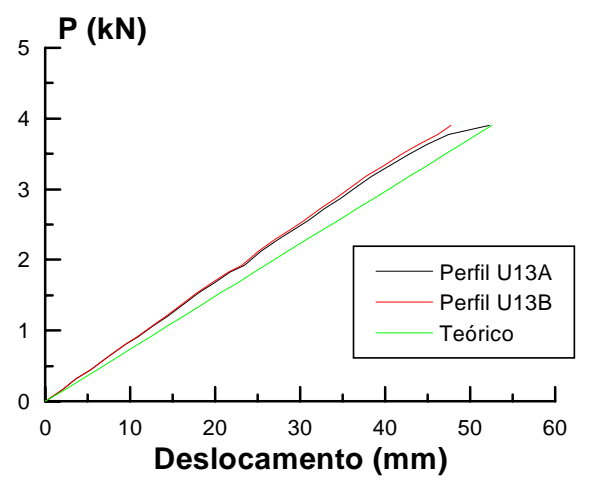

Figura I.39: Deslocamento vertical no meio do vão - Ensaio U13. 


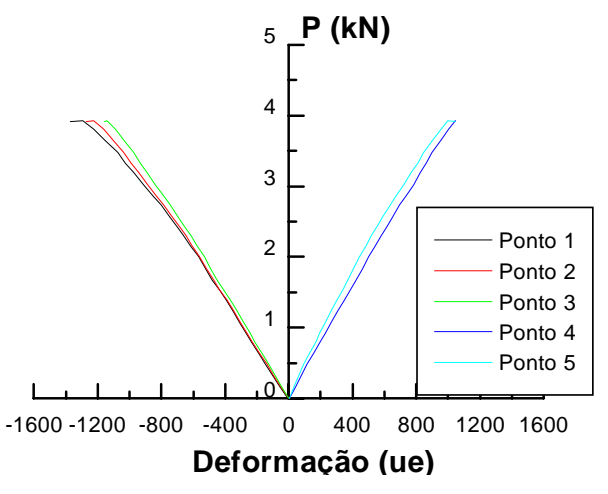

a)

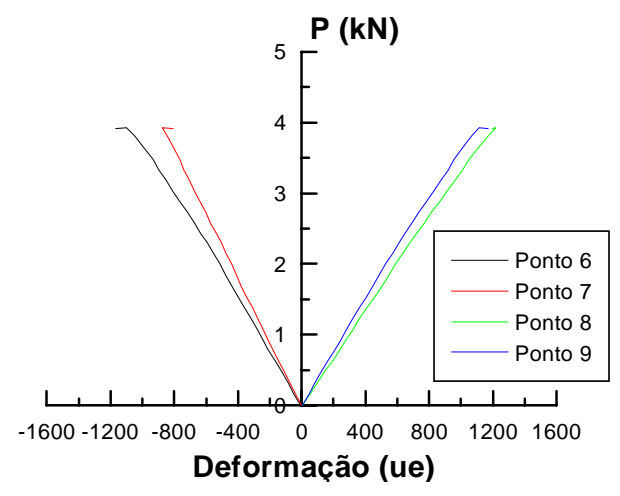

b)

Figura I.40: Gráfico Força x Deformação. a) Perfil U14A. b) Perfil U14B.

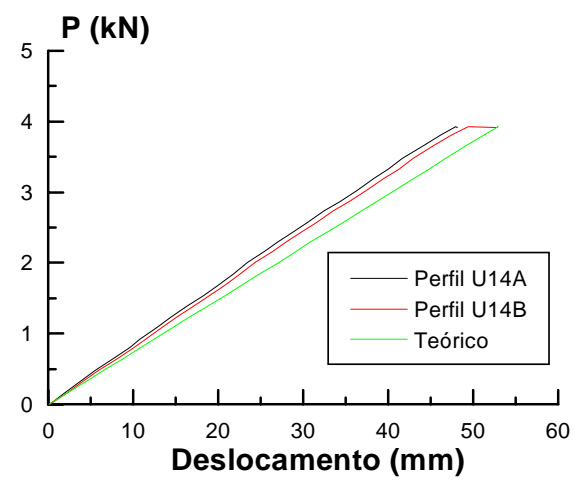

Figura I.41: Deslocamento vertical no meio do vão - Ensaio U14. 


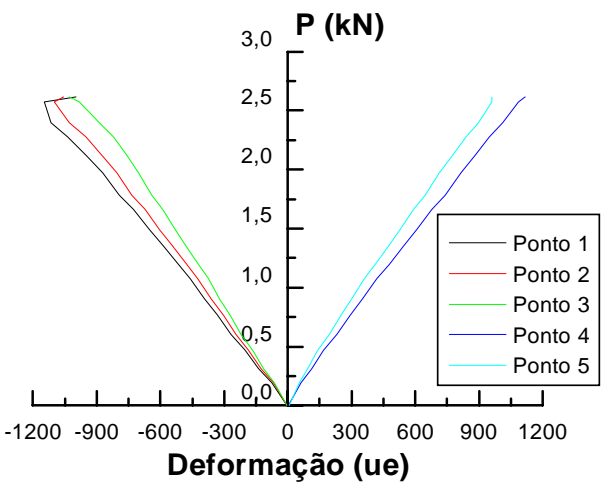

a)

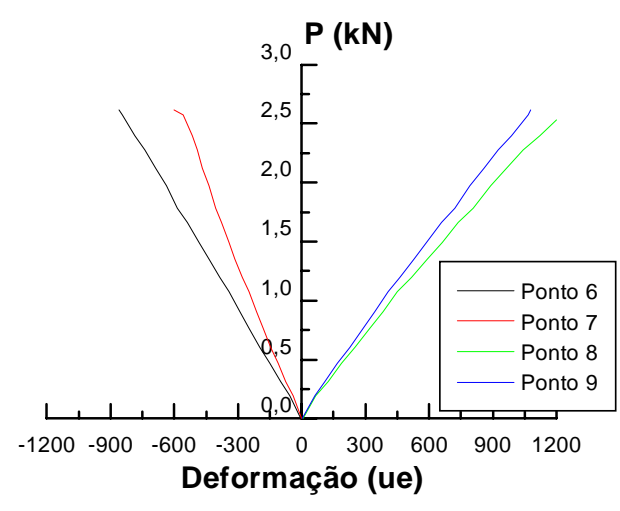

b)

Figura I.42: Gráfico Força x Deformação. a) Perfil U15A. b) Perfil U15B.

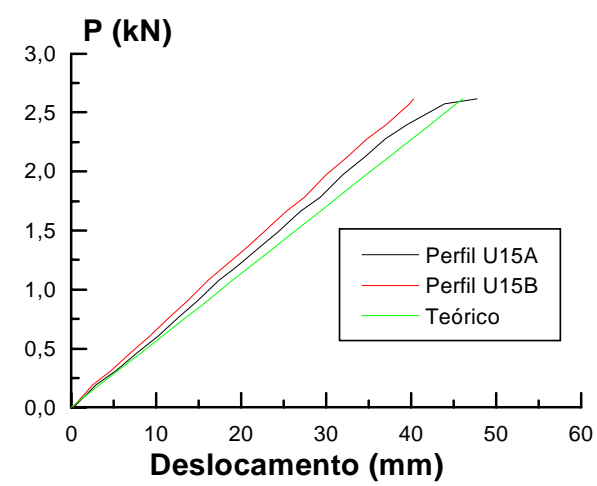

Figura I.43: Deslocamento vertical no meio do vão - Ensaio U15. 


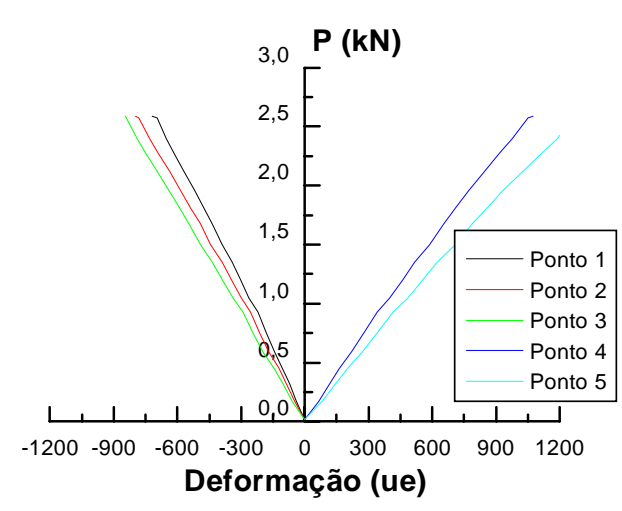

a)

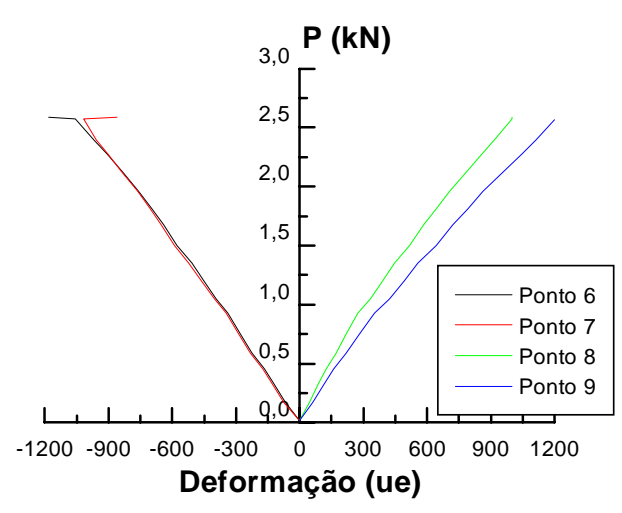

b)

Figura I.44: Gráfico Força x Deformação. a) Perfil U16A. b) Perfil U16B.

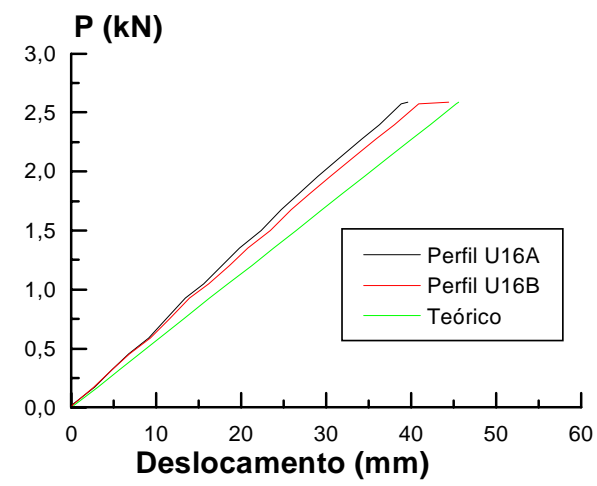

Figura I.45: Deslocamento vertical no meio do vão - Ensaio U16. 


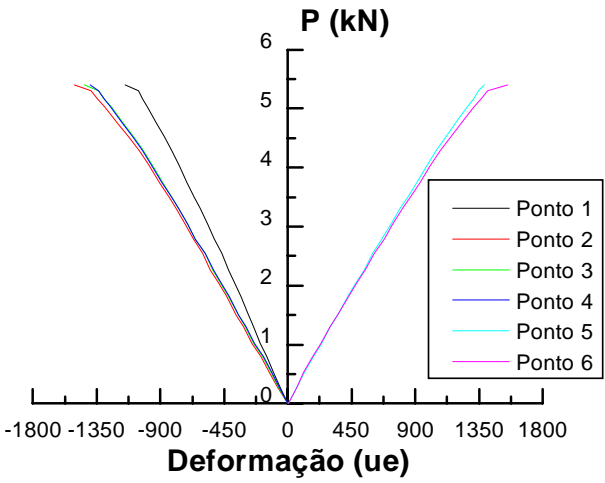

a)

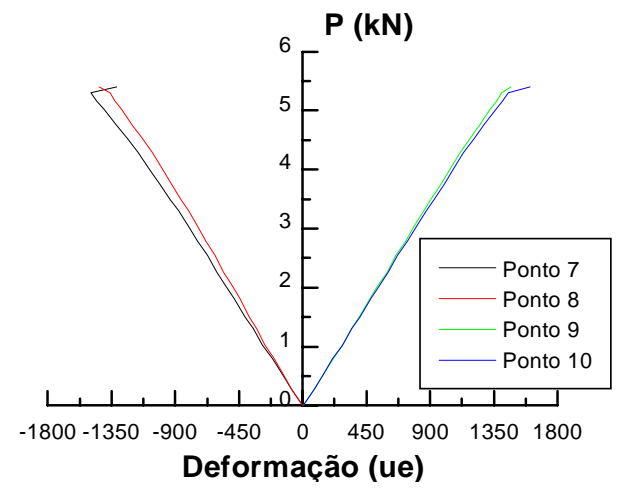

b)

Figura I.46: Gráfico Força x Deformação. a) Perfil U17A. b) Perfil U17B.

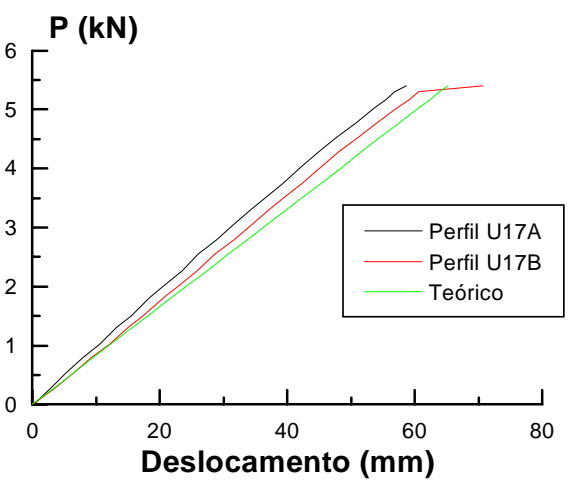

Figura I.47: Deslocamento vertical no meio do vão - Ensaio U17. 


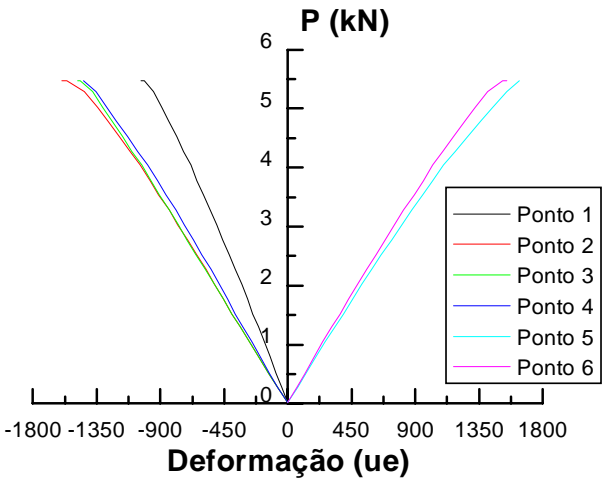

a)

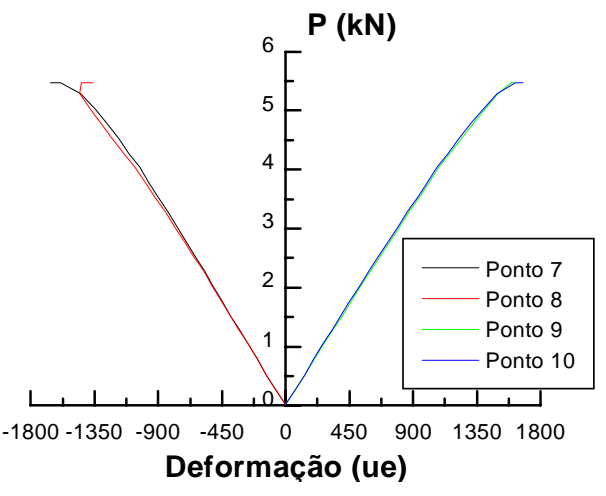

b)

Figura I.48: Gráfico Força x Deformação. a) Perfil U18A. b) Perfil U18B.

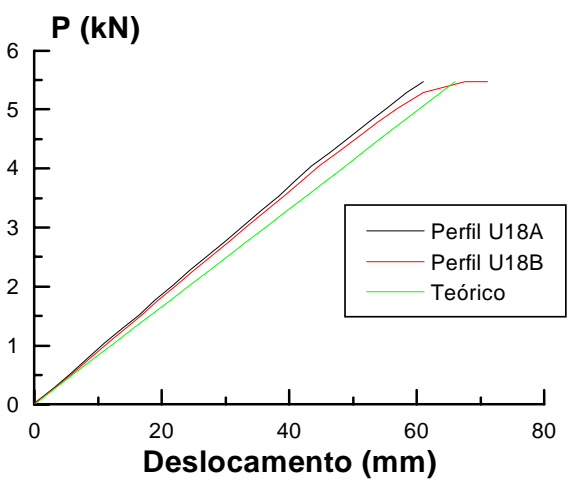

Figura I.49: Deslocamento vertical no meio do vão - Ensaio U18. 


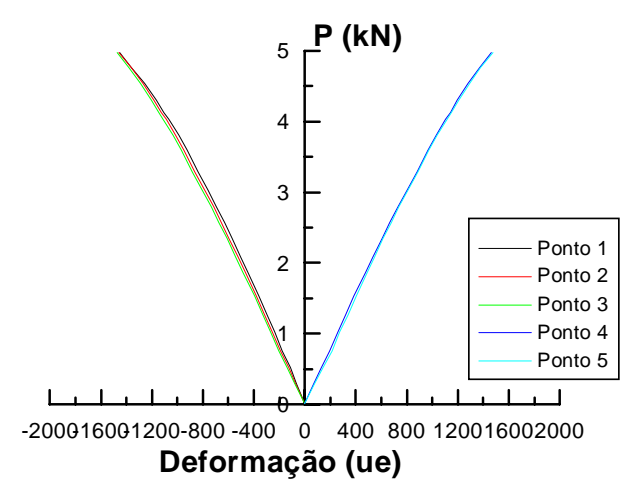

a)

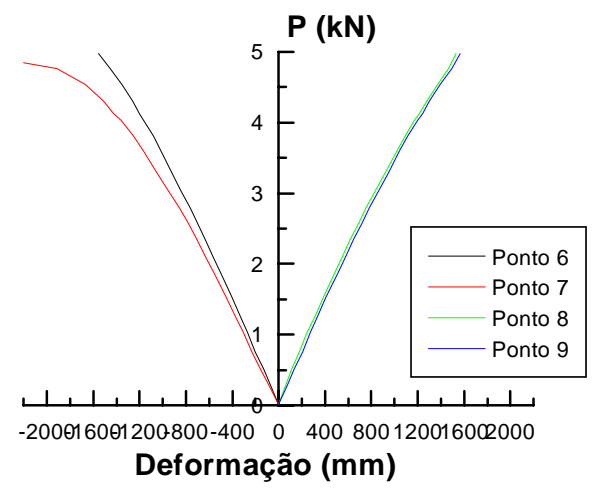

b)

Figura I.50: Gráfico Força x Deformação. a) Perfil U19A. b) Perfil U19B.

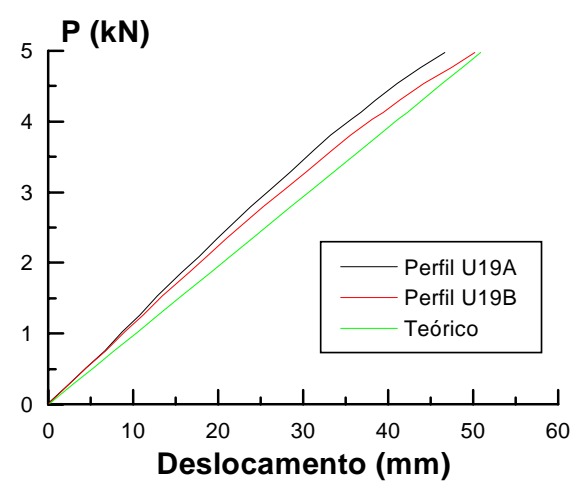

Figura I.51: Deslocamento vertical no meio do vão - Ensaio U19.

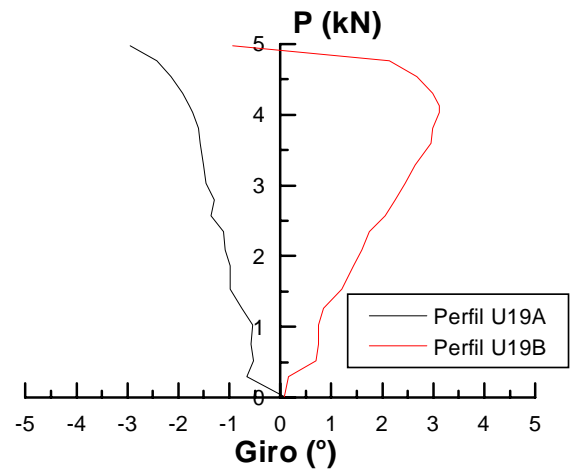

Figura I.52: Giro da seção transversal no meio do vão - Ensaio U19. 


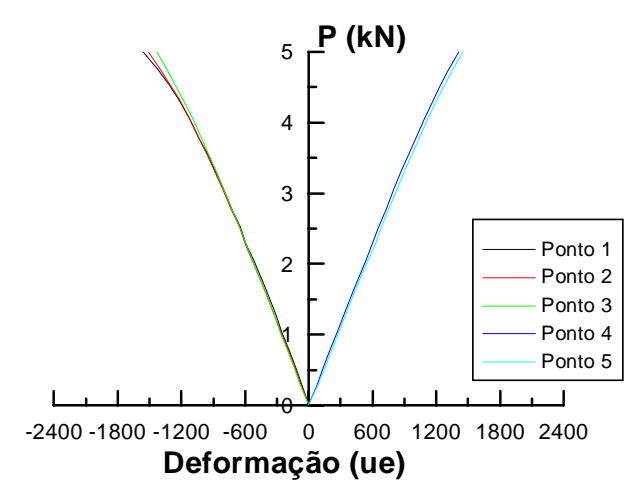

a)

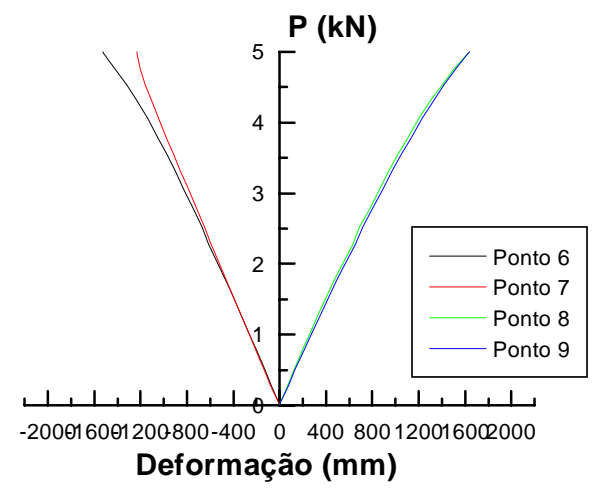

b)

Figura I.53: Gráfico Força x Deformação. a) Perfil U20A. b) Perfil U20B.

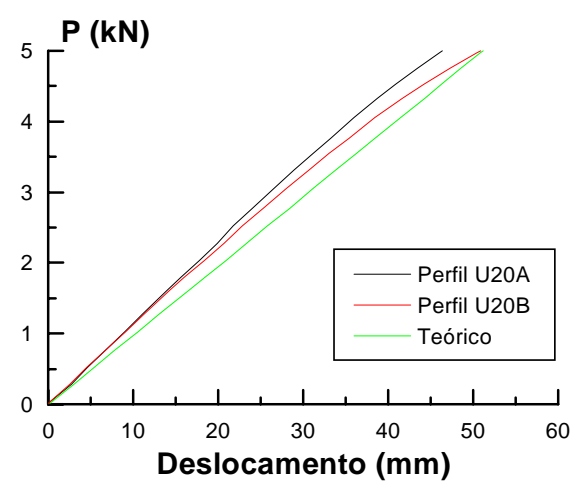

Figura I.54: Deslocamento vertical no meio do vão - Ensaio U20.

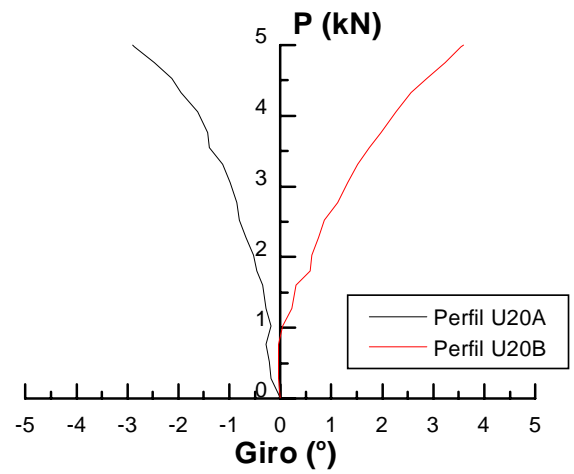

Figura I.55: Giro da seção transversal no meio do vão - Ensaio U20. 


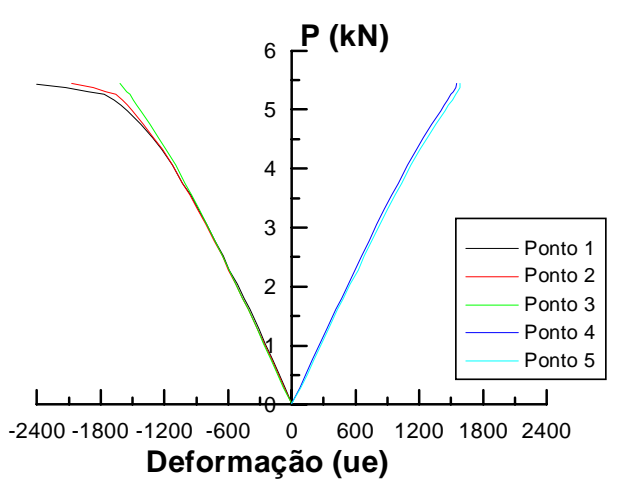

a)

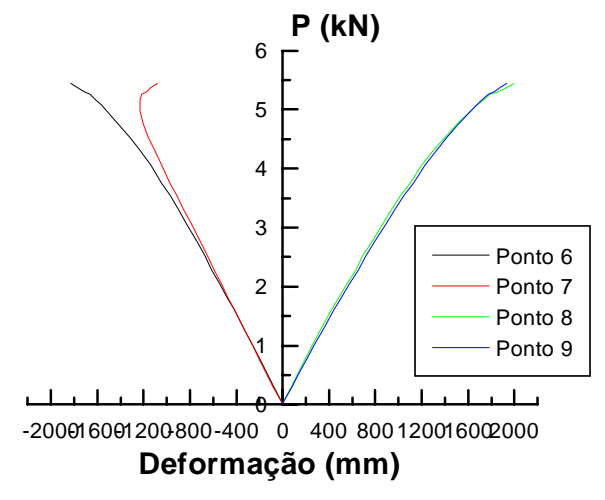

b)

Figura I.56: Gráfico Força x Deformação. a) Perfil U21A. b) Perfil U21B.

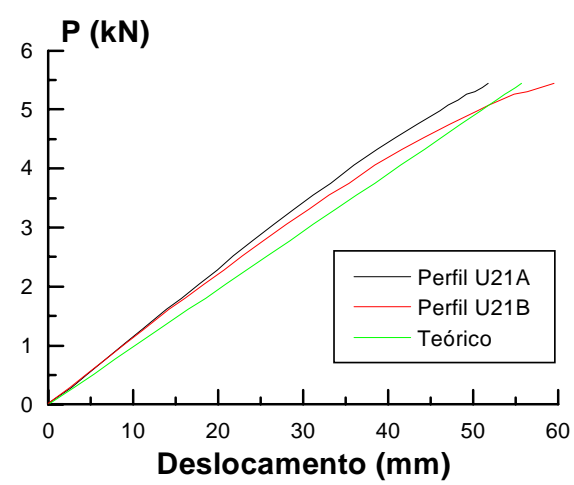

Figura I.57: Deslocamento vertical no meio do vão - Ensaio U21.

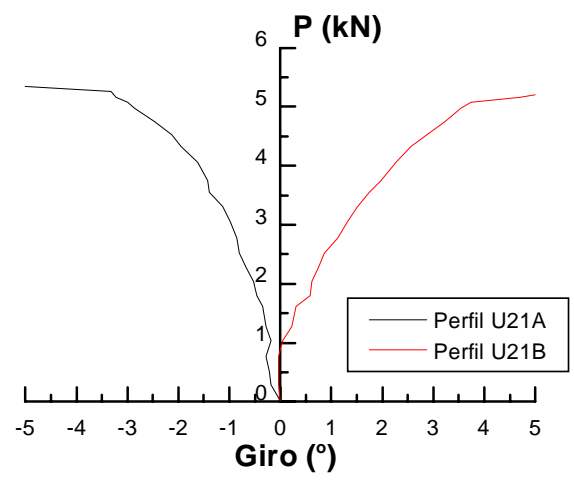

Figura I.58: Giro da seção transversal no meio do vão - Ensaio U21. 


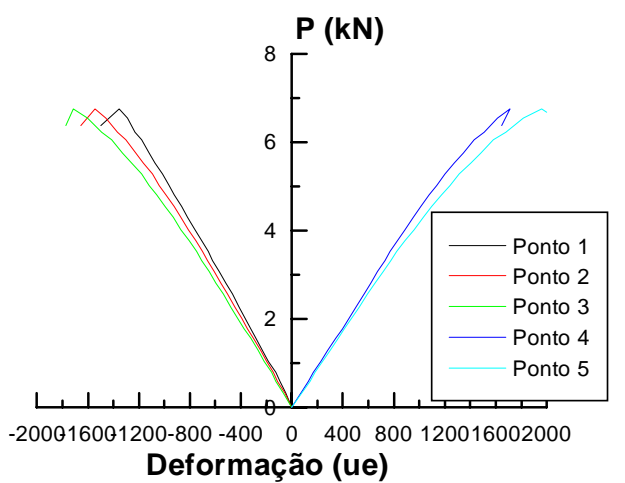

a)

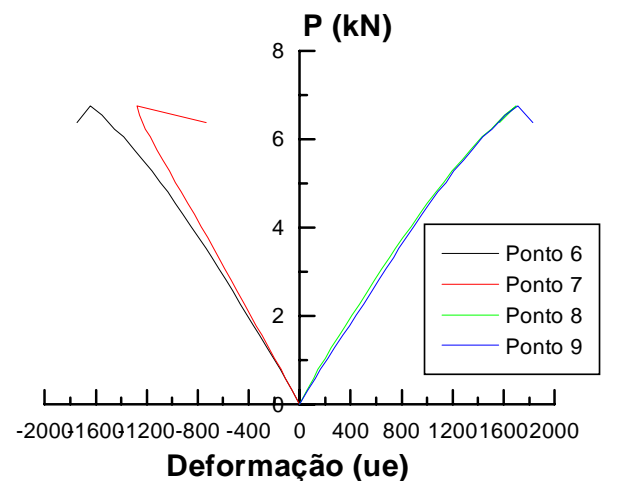

b)

Figura I.59: Gráfico Força x Deformação. a) Perfil U22A. b) Perfil U22B.

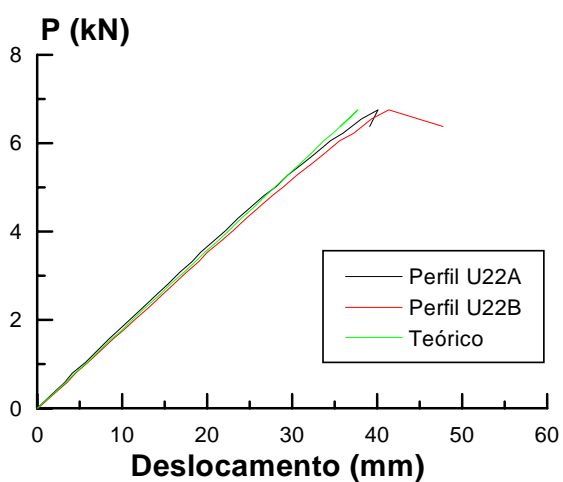

Figura I.60: Deslocamento vertical no meio do vão - Ensaio U22. 


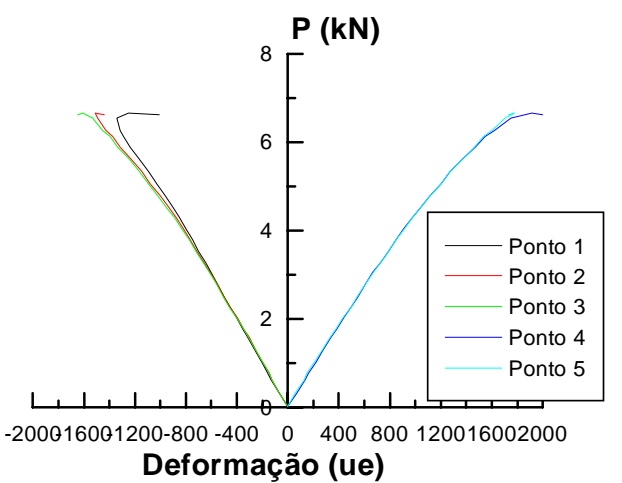

a)

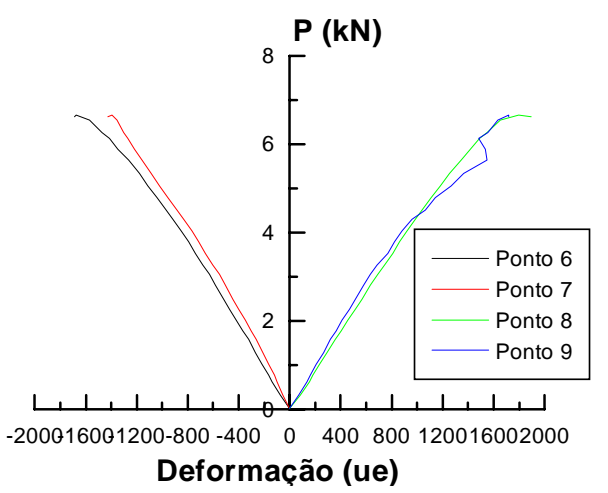

b)

Figura I.61: Gráfico Força x Deformação. a) Perfil U23A. b) Perfil U23B.

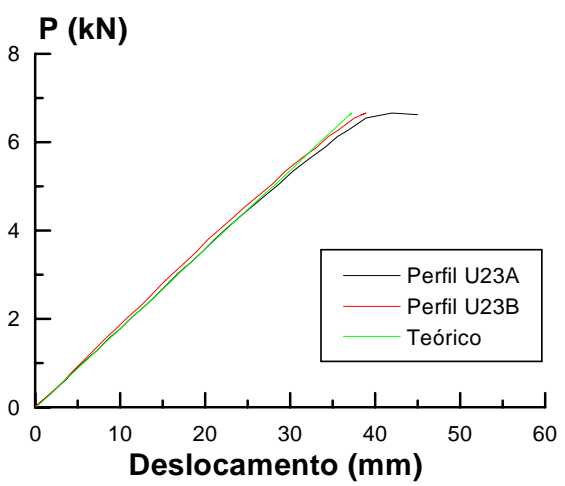

Figura I.62: Deslocamento vertical no meio do vão - Ensaio U23. 


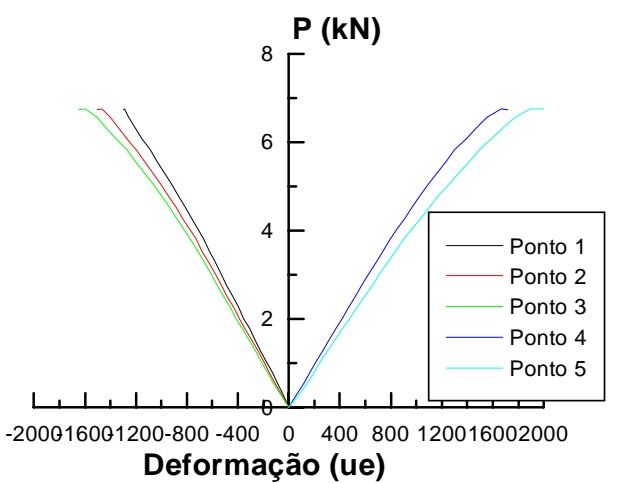

a)

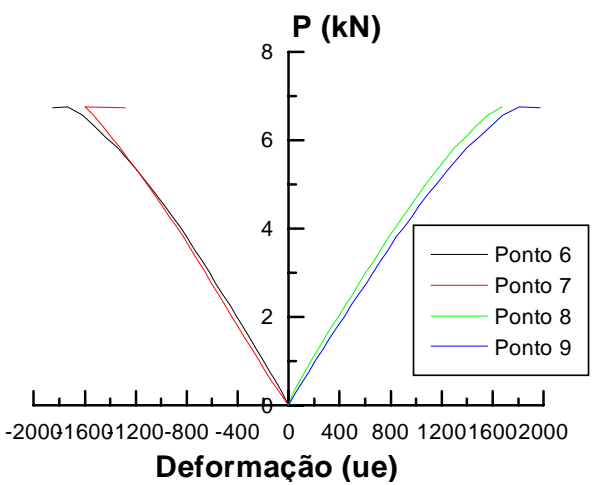

b)

Figura I.63: Gráfico Força x Deformação. a) Perfil U24A. b) Perfil U24B.

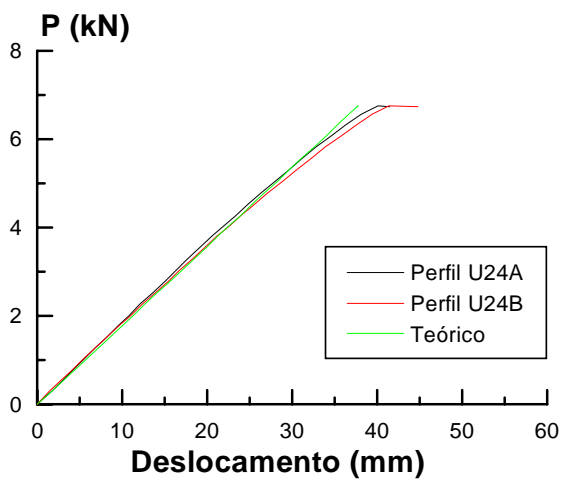

Figura I.64: Deslocamento vertical no meio do vão - Ensaio U24. 


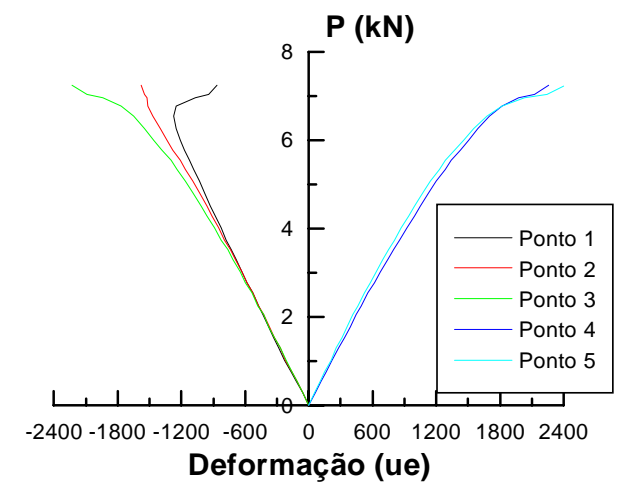

a)

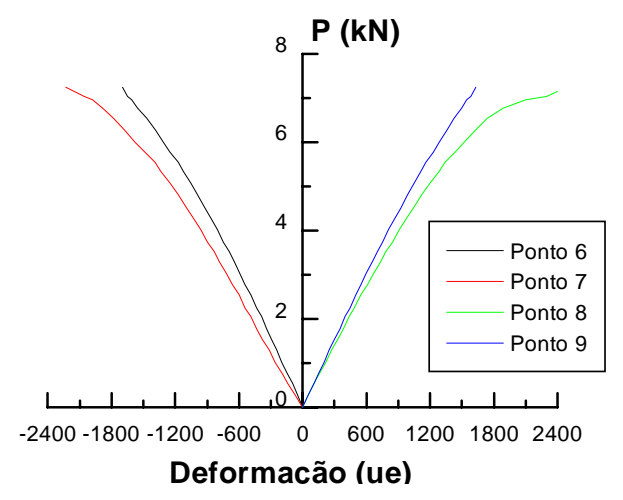

b)

Figura I.65: Gráfico Força x Deformação. a) Perfil U25A. b) Perfil U25B.

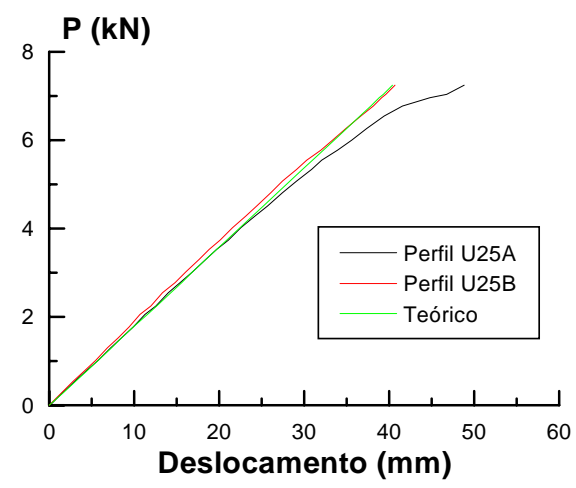

Figura I.66: Deslocamento vertical no meio do vão - Ensaio U25.

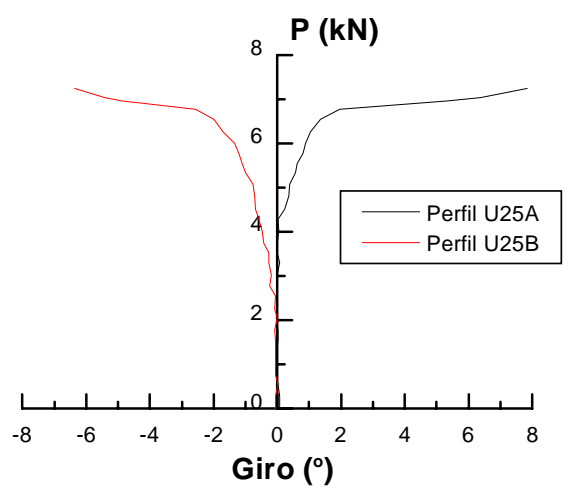

Figura I.67: Giro da seção transversal no meio do vão - Ensaio U25. 


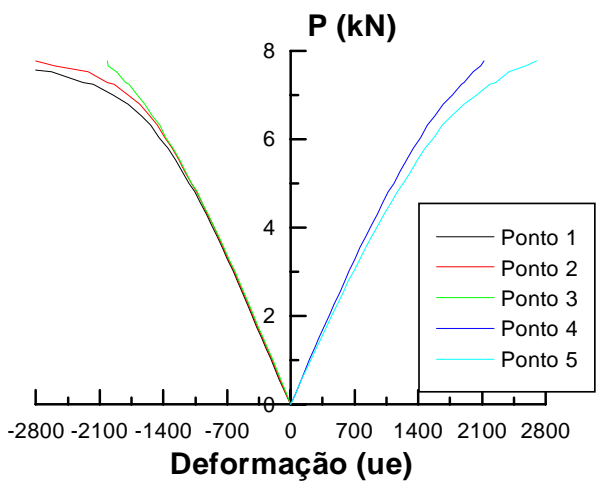

a)

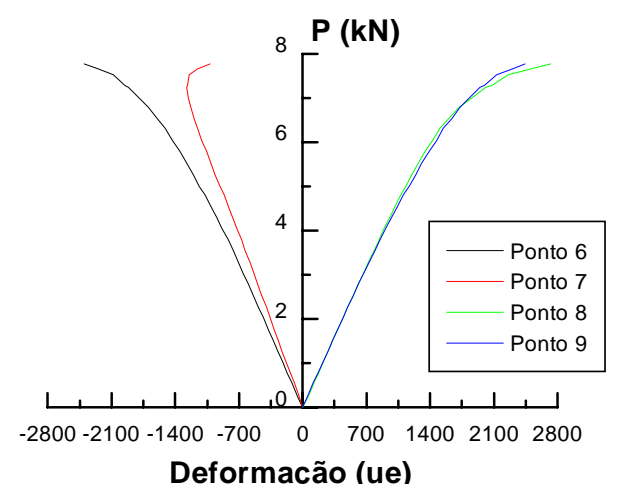

b)

Figura I.68: Gráfico Força x Deformação. a) Perfil U26A. b) Perfil U26B.

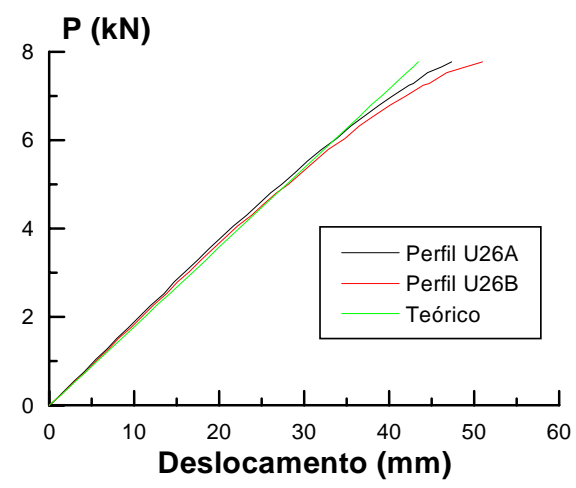

Figura I.69: Deslocamento vertical no meio do vão - Ensaio U26.

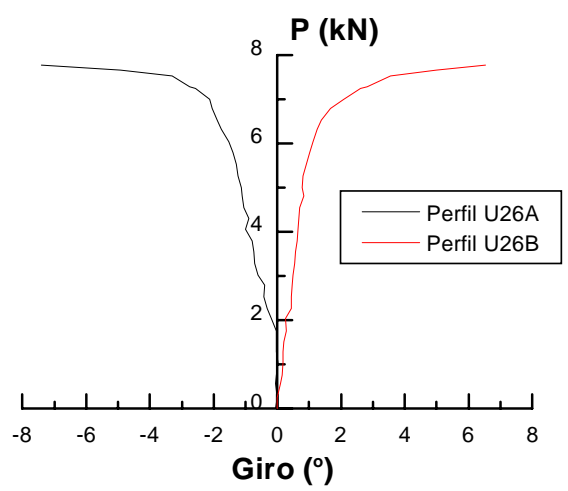

Figura I.70: Giro da seção transversal no meio do vão - Ensaio U26. 


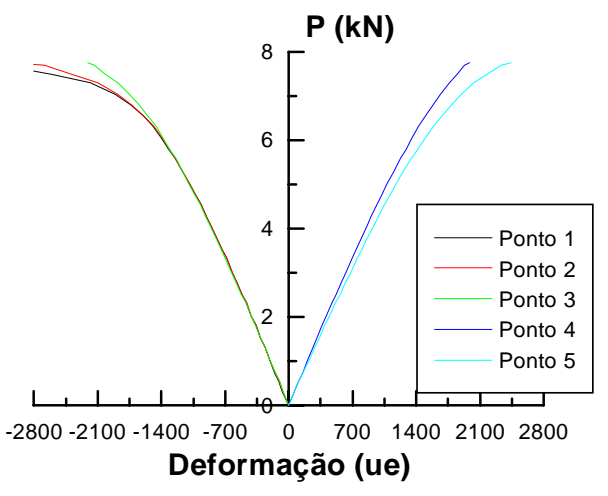

a)

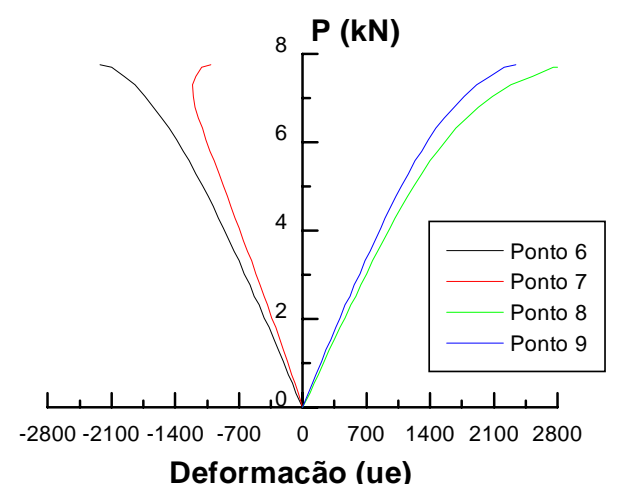

b)

Figura I.71: Gráfico Força x Deformação. a) Perfil U27A. b) Perfil U27B.

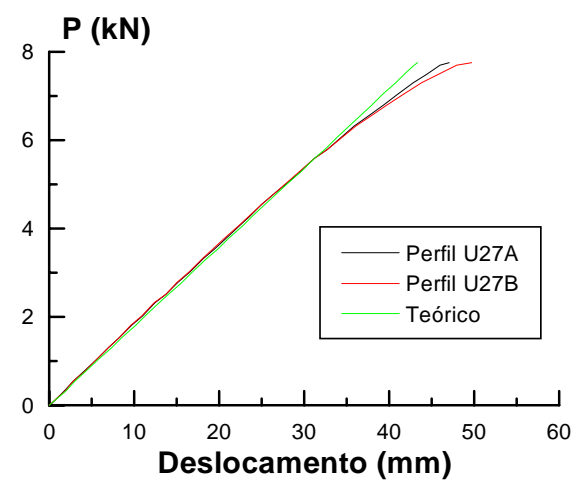

Figura I.72: Deslocamento vertical no meio do vão - Ensaio U27.

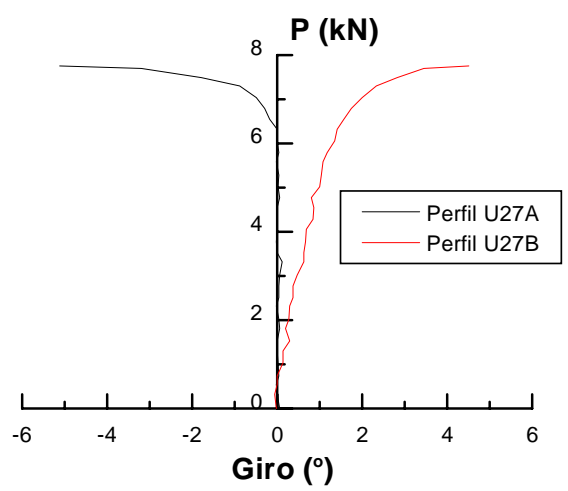

Figura I.73: Giro da seção transversal no meio do vão - Ensaio U27. 


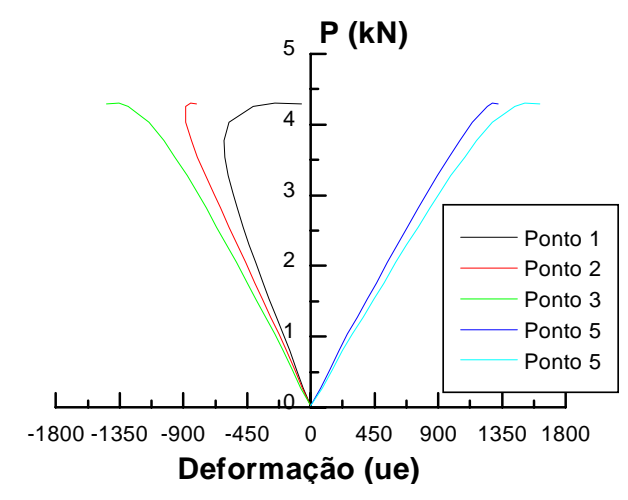

a)

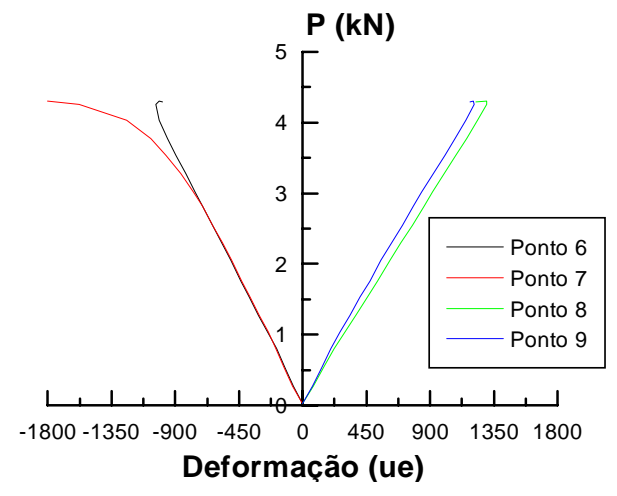

b)

Figura 1.74: Gráfico Força x Deformação. a) Perfil U28A. b) Perfil U28B.

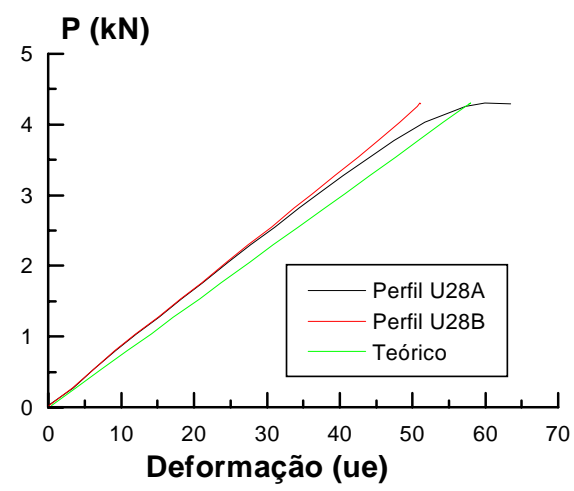

Figura I.75: Deslocamento vertical no meio do vão - Ensaio U28.

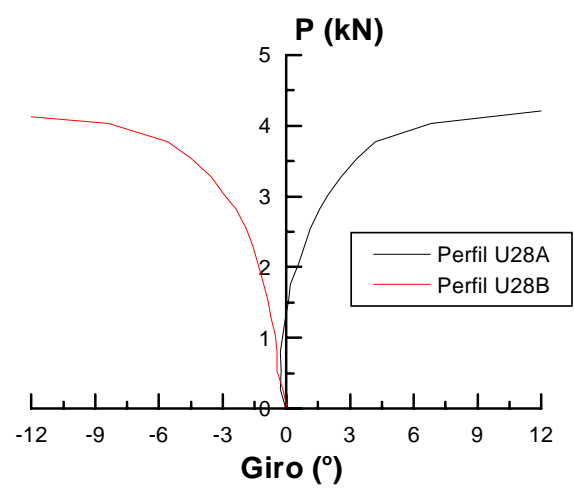

Figura I.76: Giro da seção transversal no meio do vão - Ensaio U28. 


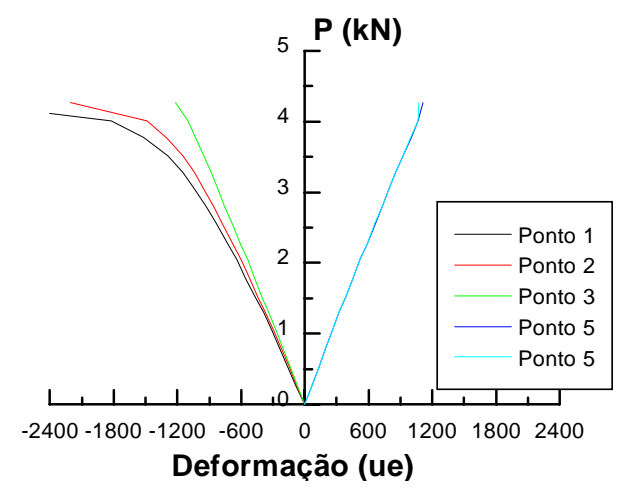

a)

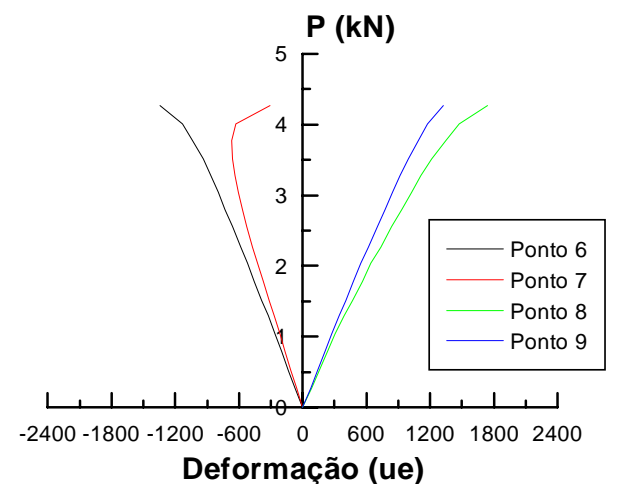

b)

Figura I.77: Gráfico Força x Deformação. a) Perfil U29A. b) Perfil U29B.

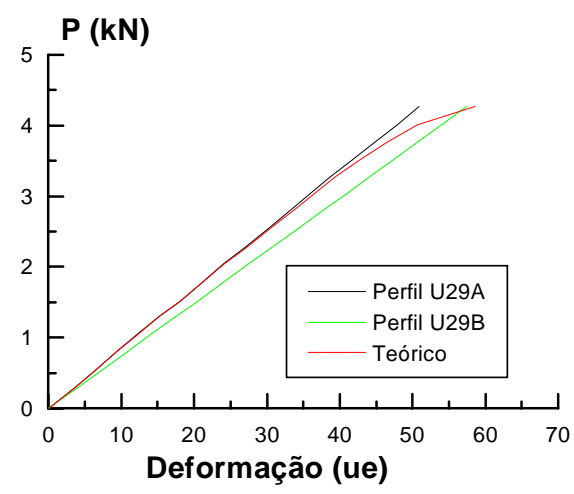

Figura I.78: Deslocamento vertical no meio do vão - Ensaio U29.

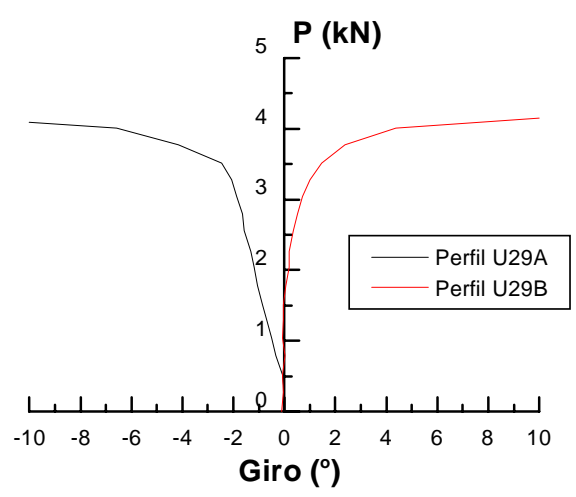

Figura I.79: Giro da seção transversal no meio do vão - Ensaio U29. 


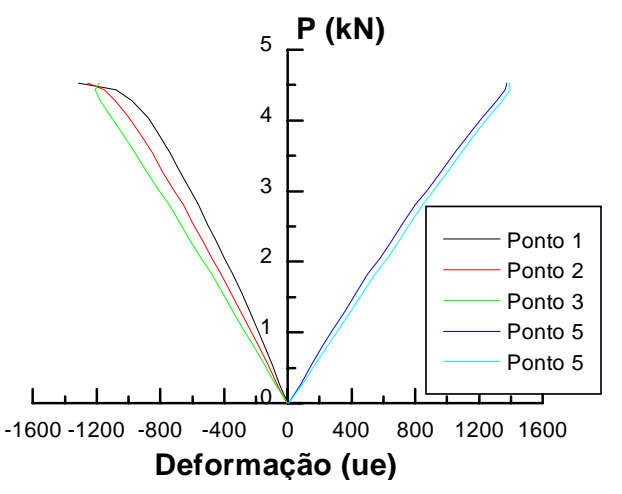

a)

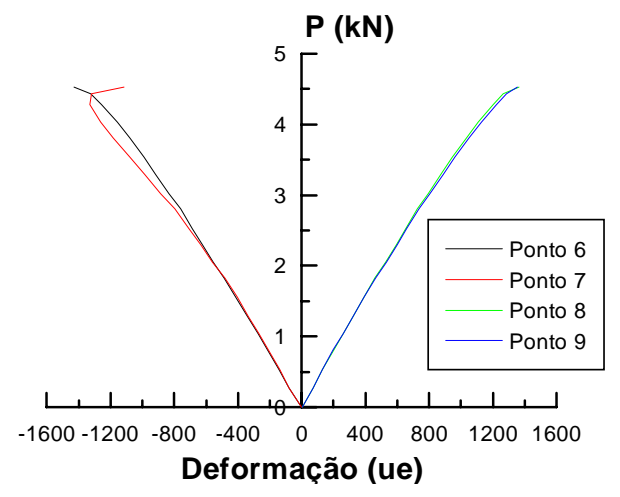

b)

Figura I.80: Gráfico Força x Deformação. a) Perfil U30A. b) Perfil U30B.

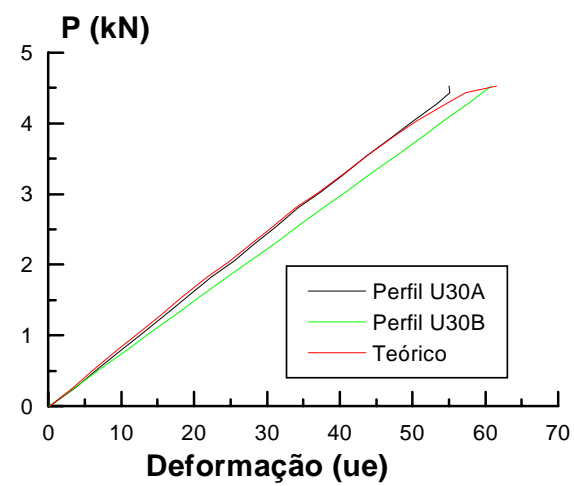

Figura I.81: Deslocamento vertical no meio do vão - Ensaio U30.

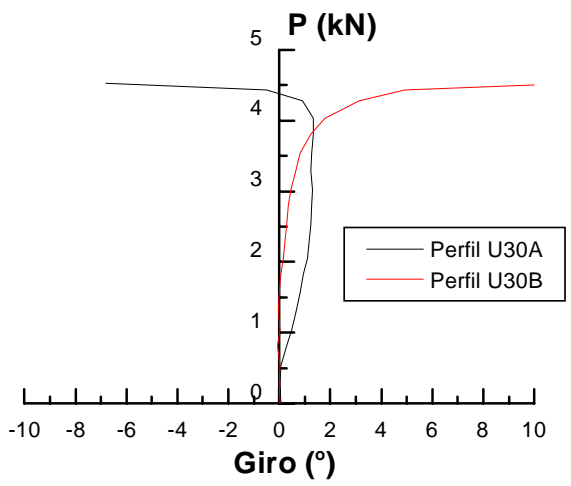

Figura I.82: Giro da seção transversal no meio do vão - Ensaio U30. 


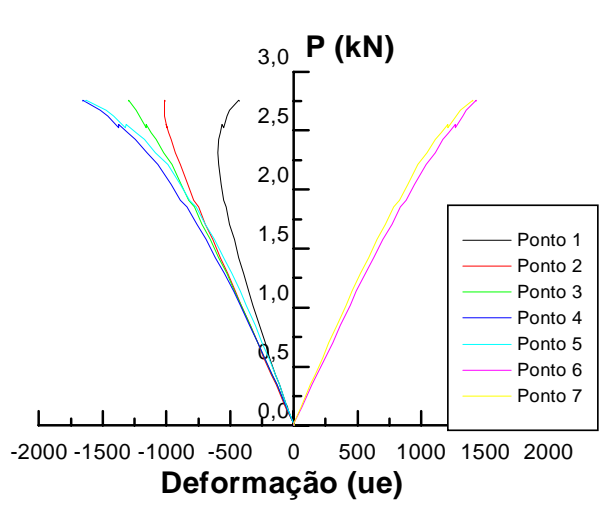

a)

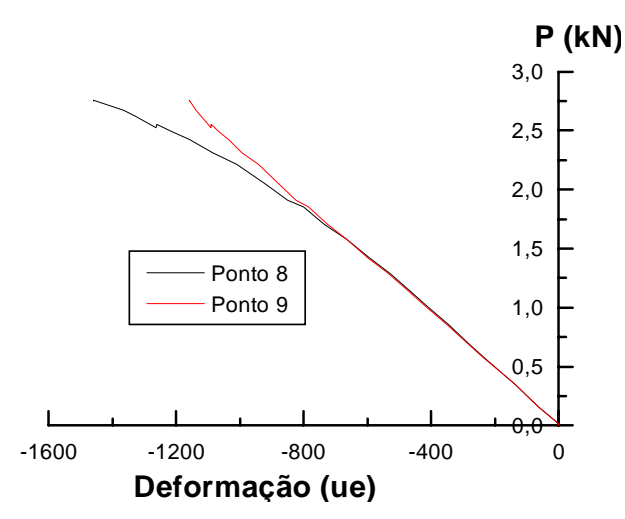

b)

Figura I.83: Gráfico Força x Deformação. a) Perfil Z1A. b) Perfil Z1B.

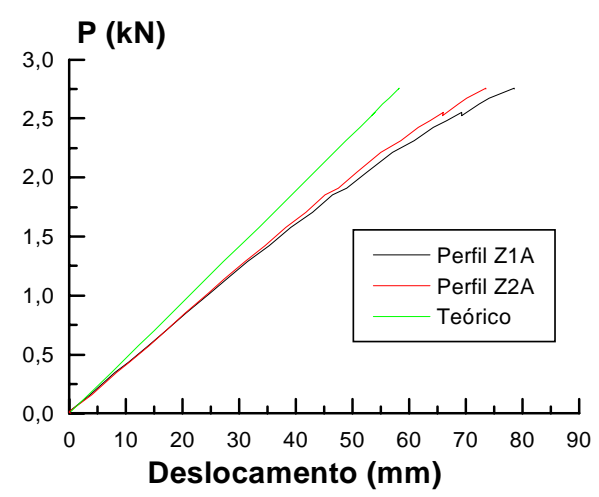

Figura I.84: Deslocamento vertical no meio do vão - Ensaio Z1.

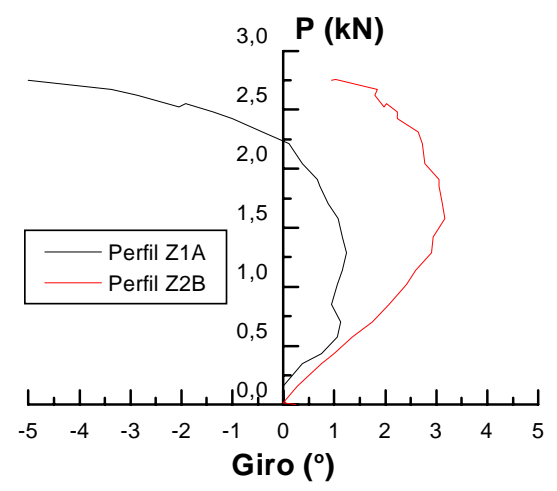

Figura I.85: Giro da seção transversal no meio do vão - Ensaio Z1. 


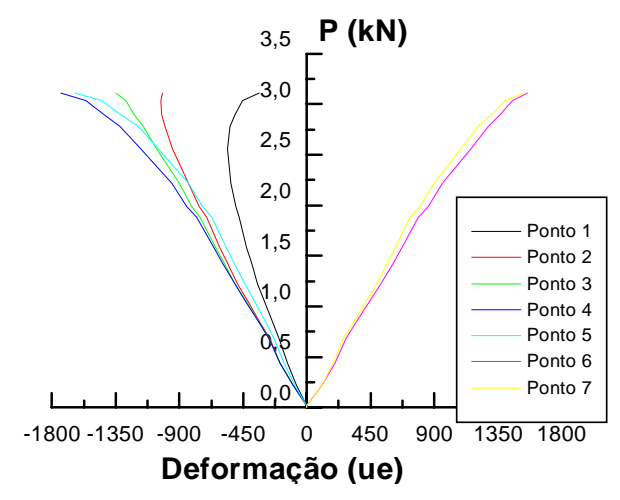

a)

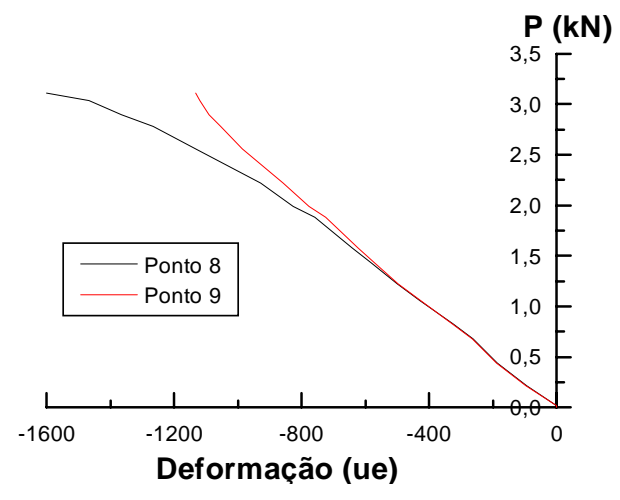

b)

Figura I.86: Gráfico Força x Deformação. a) Perfil Z2A. b) Perfil Z2B.

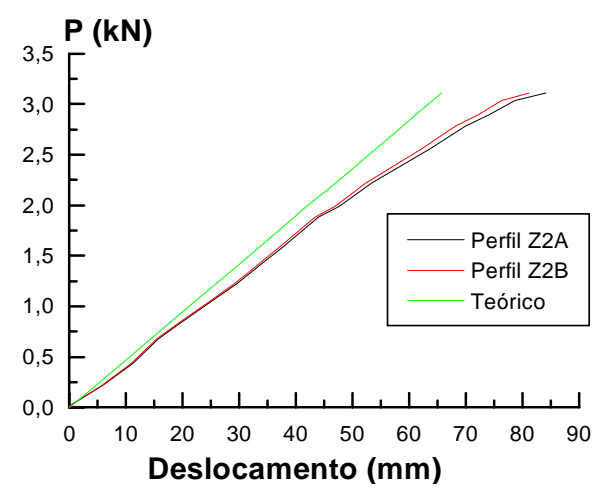

Figura I.87: Deslocamento vertical no meio do vão - Ensaio Z2.

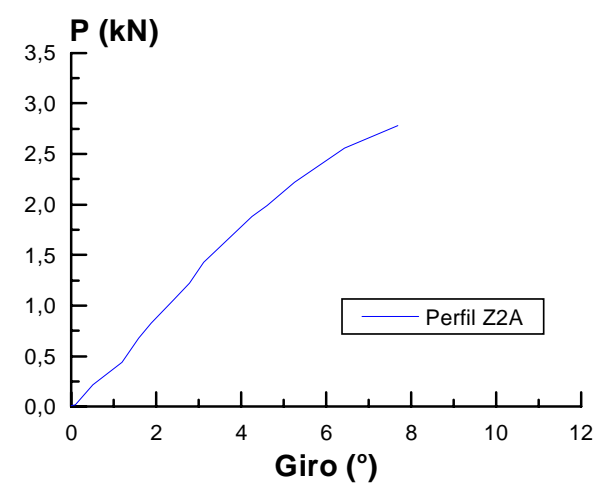

Figura I.88: Giro da seção transversal no meio do vão - Ensaio Z2. 


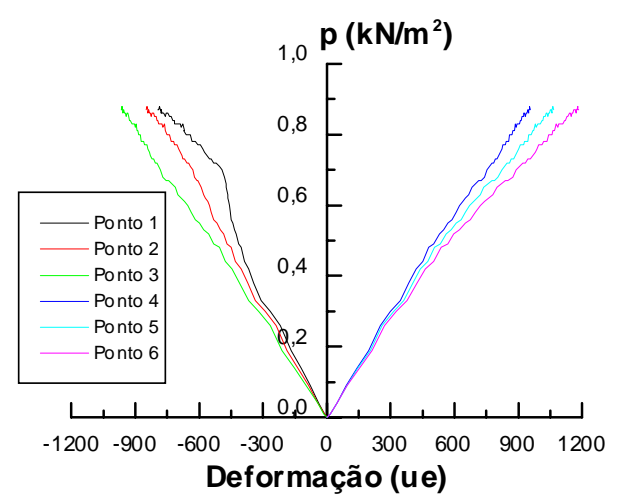

Figura I.89: Gráfico Força x Deformação - Caixa 1.

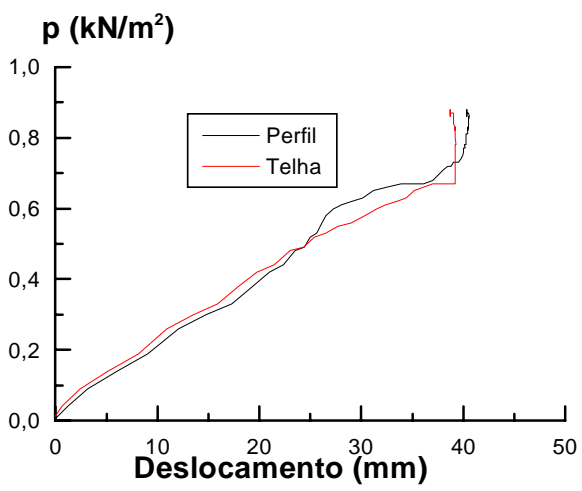

Figura 1.90: Deslocamento vertical no meio do vão - Caixa 1.

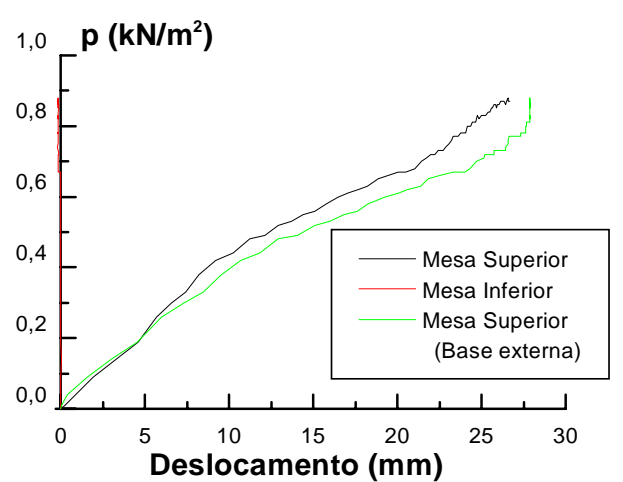

a)

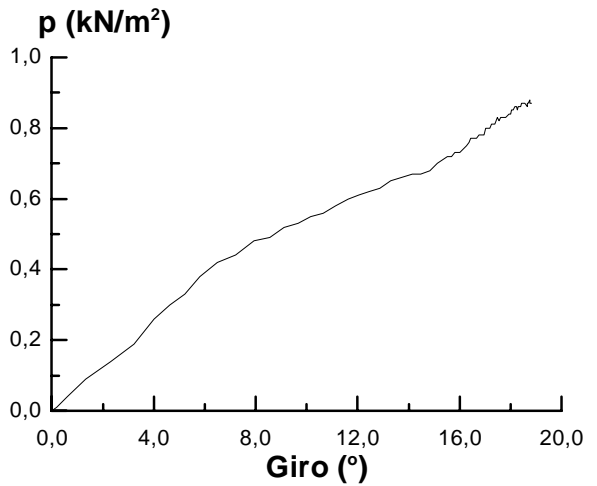

b)

Figura I.91: Caixa 1. a) Deslocamento horizontal das mesas no meio do vão.

b) Giro da seção transversal no meio do vão. 


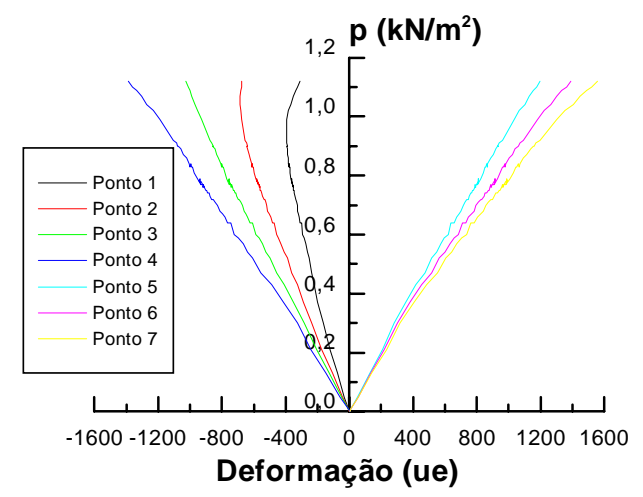

Figura I.92: Gráfico Força x Deformação - Caixa 2.

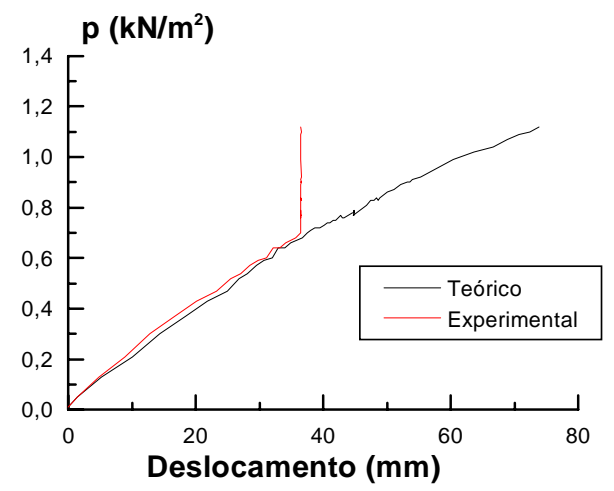

Figura I.93: Deslocamento vertical no meio do vão - Caixa 2.

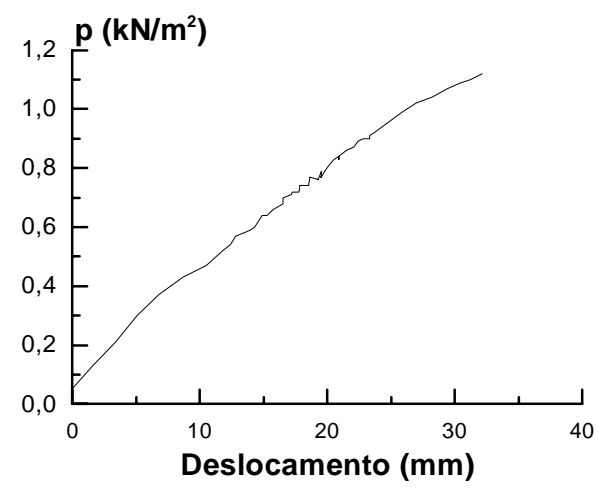

Figura 1.94: Deslocamento horizontal da mesa superior - Caixa 2. 


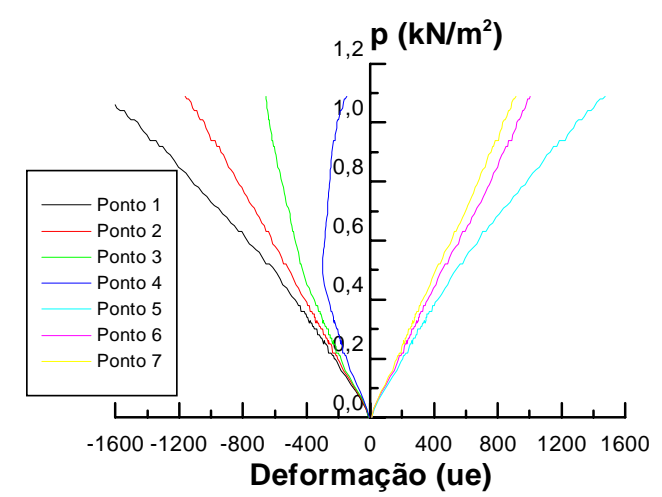

Figura I.95: Gráfico Força x Deformação - Caixa 3.

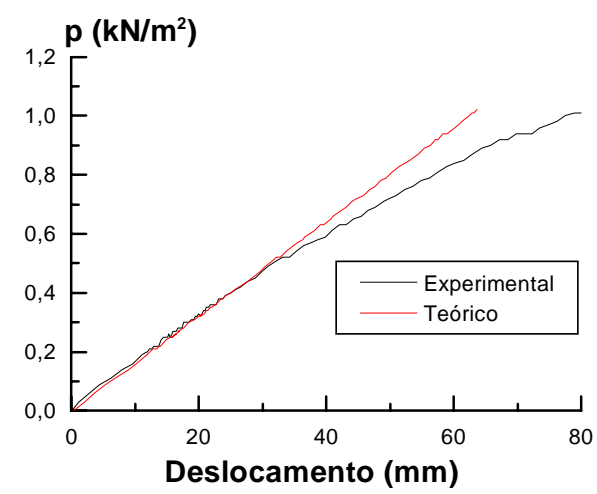

Figura I.96: Deslocamento vertical no meio do vão - Caixa 3.

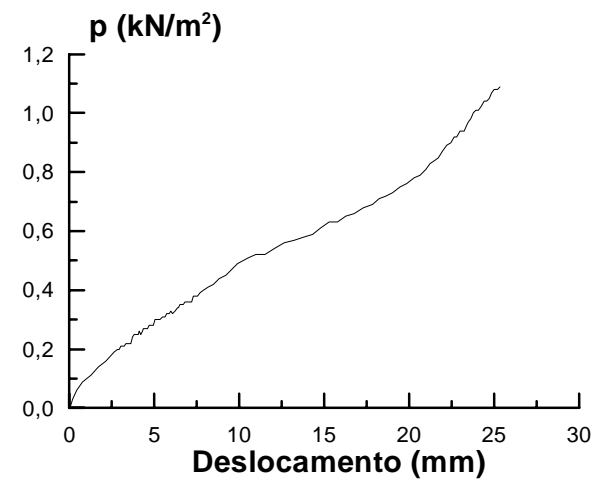

Figura I.97: Deslocamento horizontal da mesa superior - Caixa 3. 


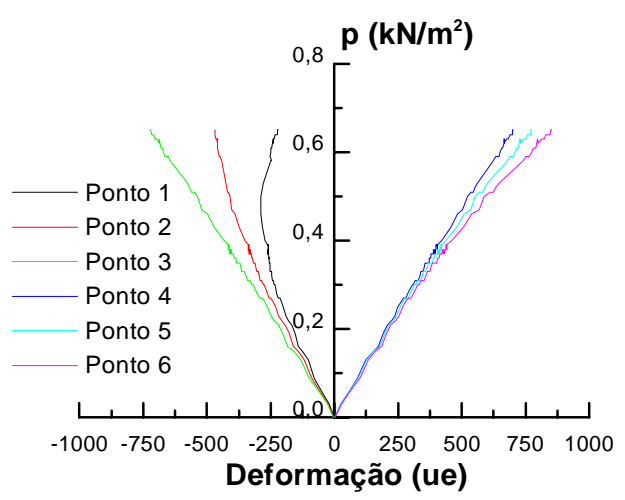

Figura I.98: Gráfico Força x Deformação - Caixa 4.

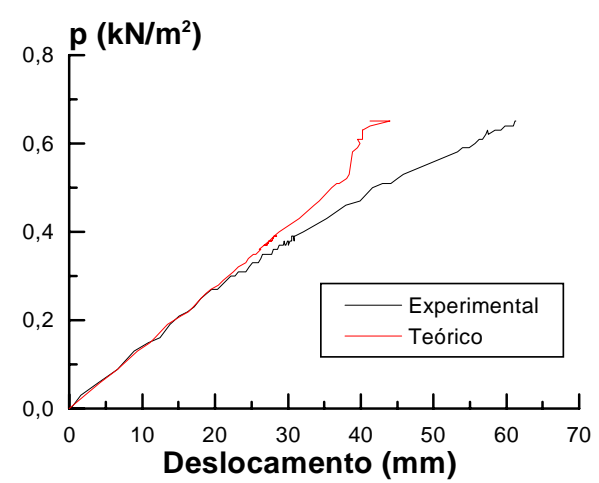

Figura I.99: Deslocamento vertical no meio do vão - Caixa 4.

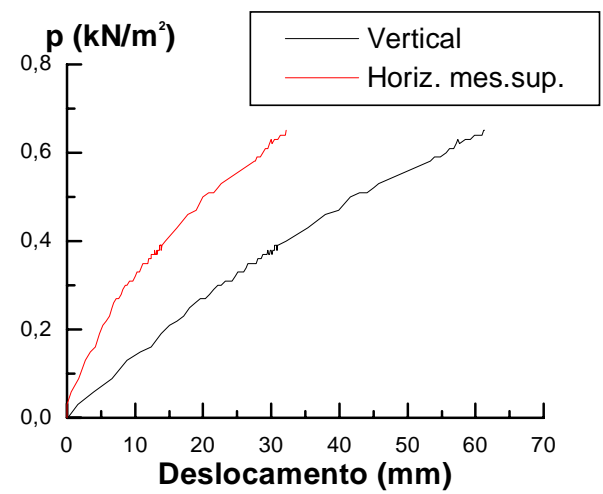

Figura I.100: Deslocamento horizontal da mesa superior e deslocamento vertical no meio do vão - Caixa 4. 


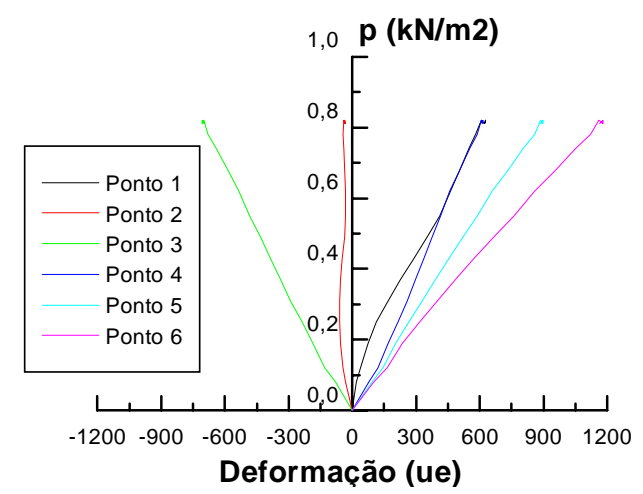

Figura I.101: Gráfico Força x Deformação - Caixa 5.

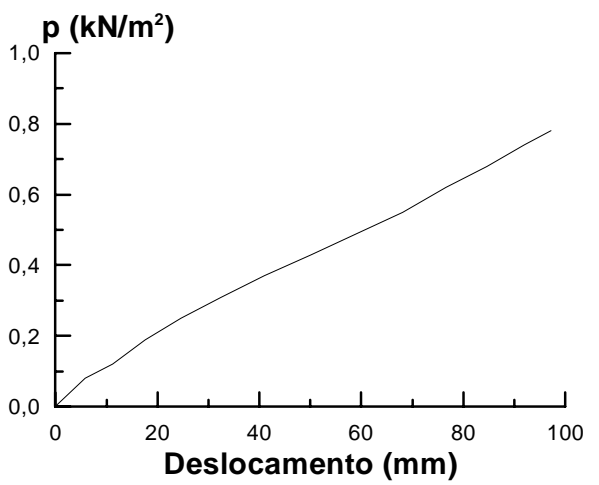

Figura I.102: Deslocamento vertical no meio do vão - Caixa 5.

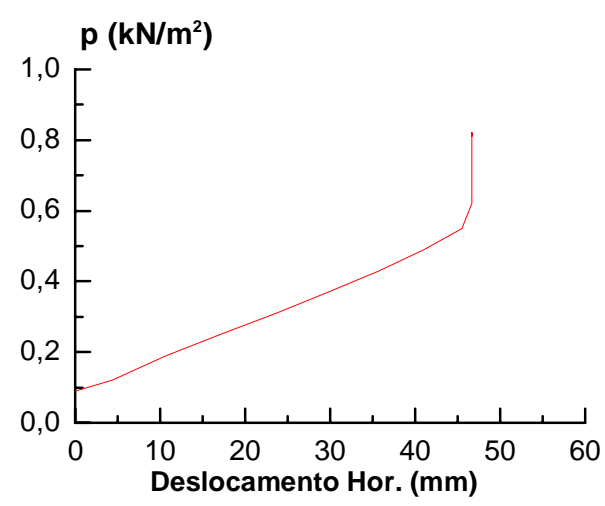

Figura I.103: Deslocamento horizontal da mesa superior - Caixa 5. 


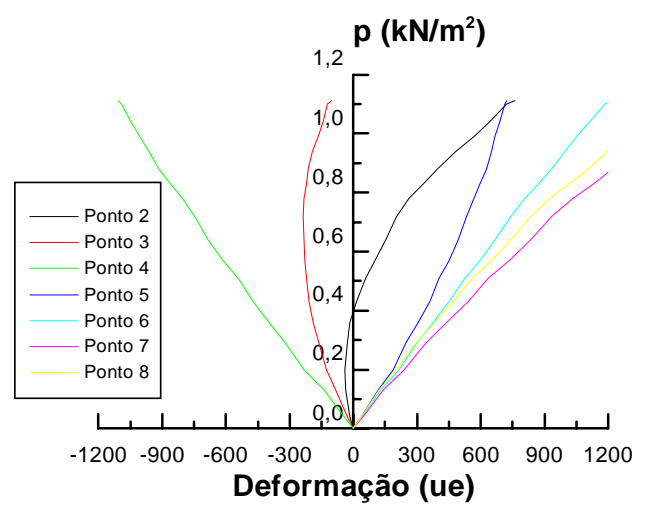

Figura I.104: Gráfico Força x Deformação - Caixa 6.

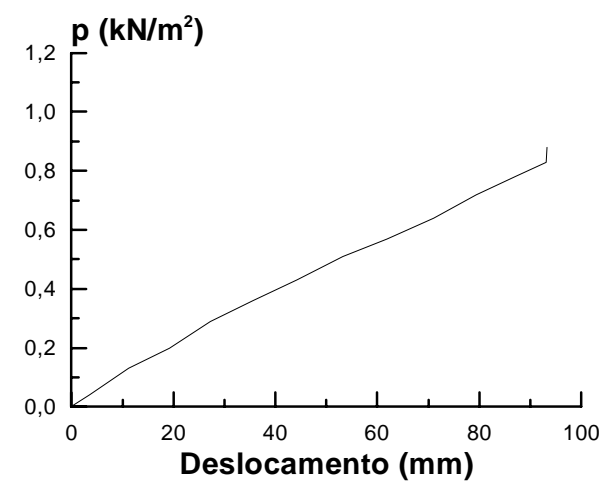

Figura I.105: Deslocamento vertical no meio do vão - Caixa 6.

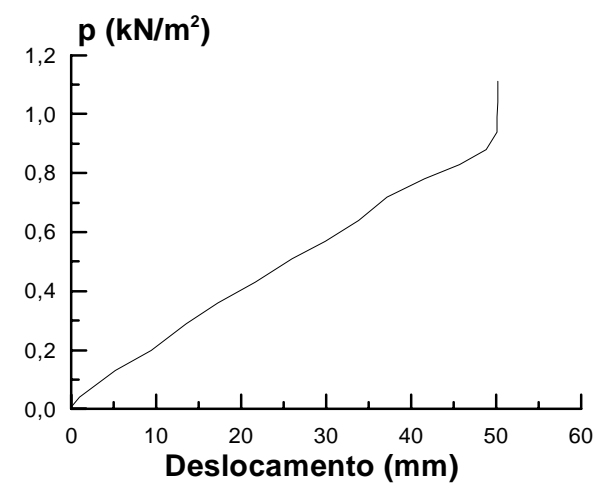

Figura I.106: Deslocamento horizontal da mesa superior - Caixa 6. 


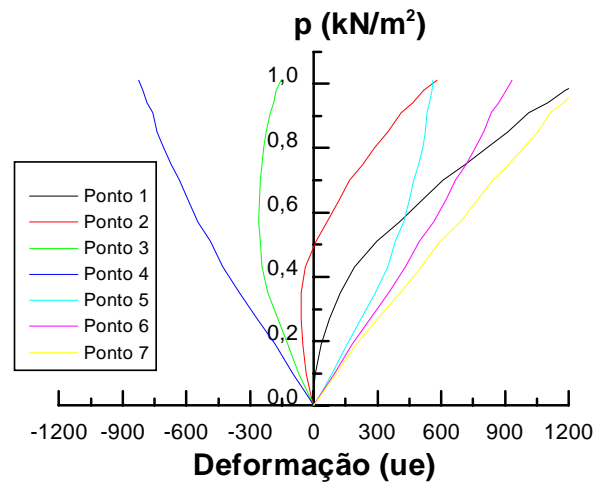

a)

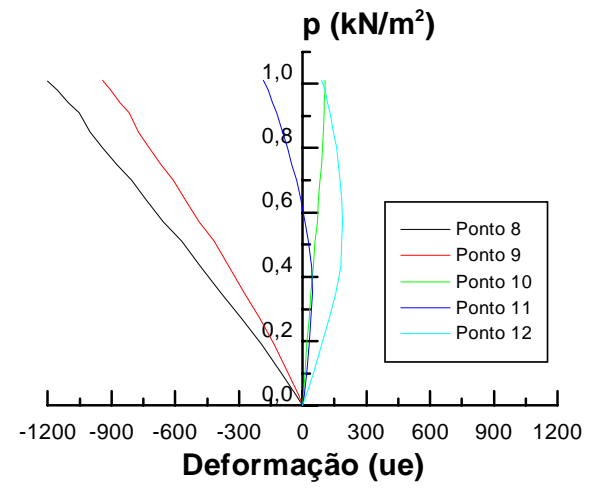

b)

Figura I.107: Gráfico Força x Deformação - Caixa 7. a) Deformações nas mesas. b) Deformações na alma.

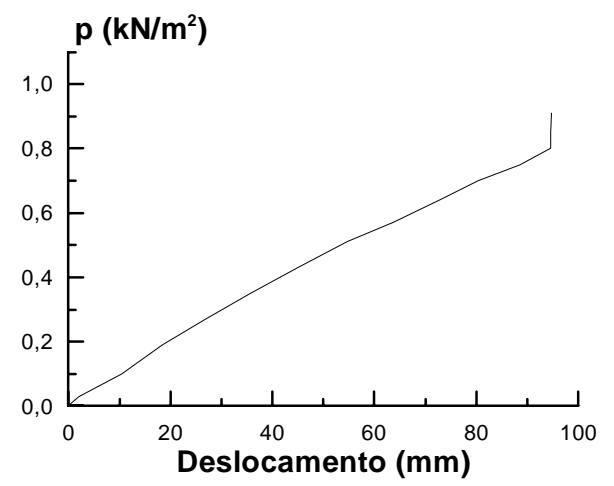

Figura I.108: Deslocamento vertical no meio do vão - Caixa 7.

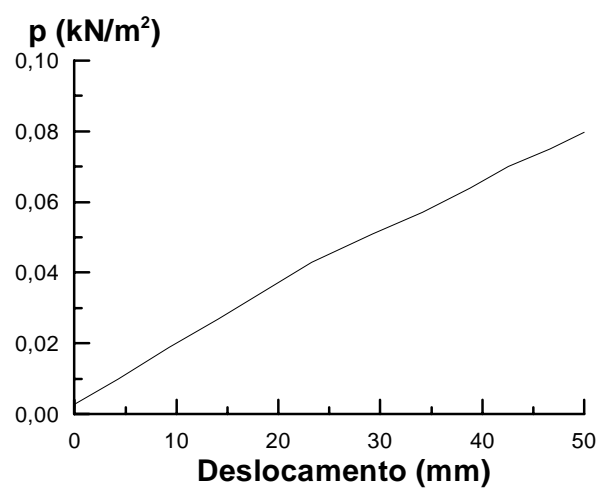

Figura I.109: Deslocamento horizontal da mesa superior - Caixa 7. 


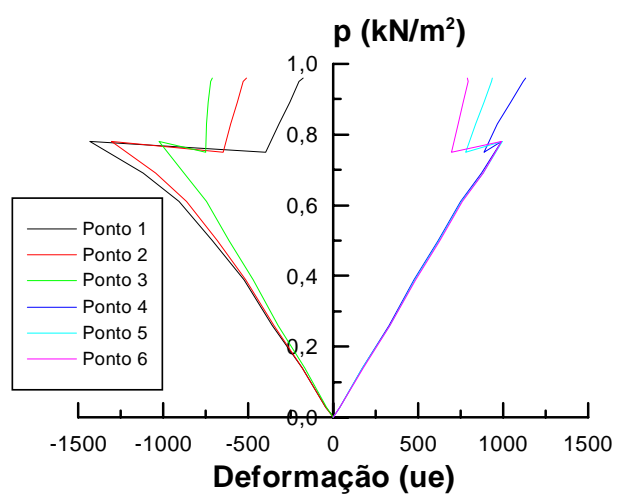

Figura I.110: Gráfico Força x Deformação - Caixa 8.

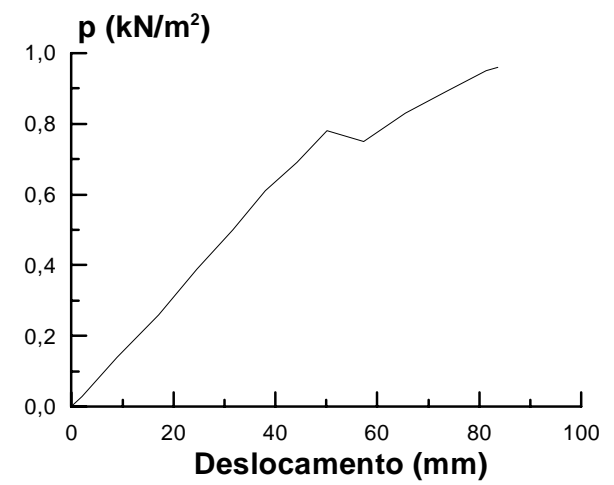

Figura I.111: Deslocamento vertical no meio do vão - Caixa 8.

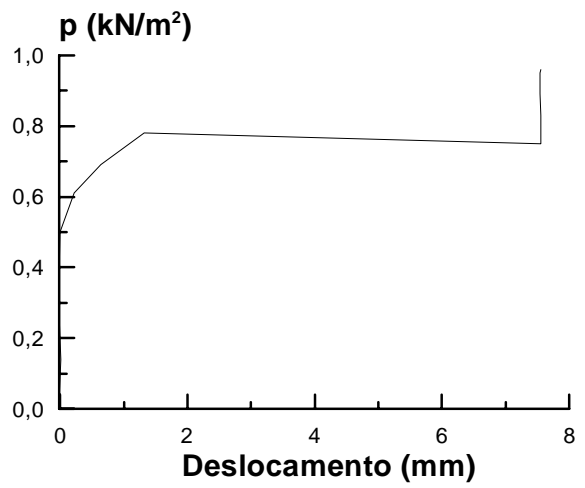

Figura I.112: Deslocamento horizontal da mesa superior - Caixa 8. 


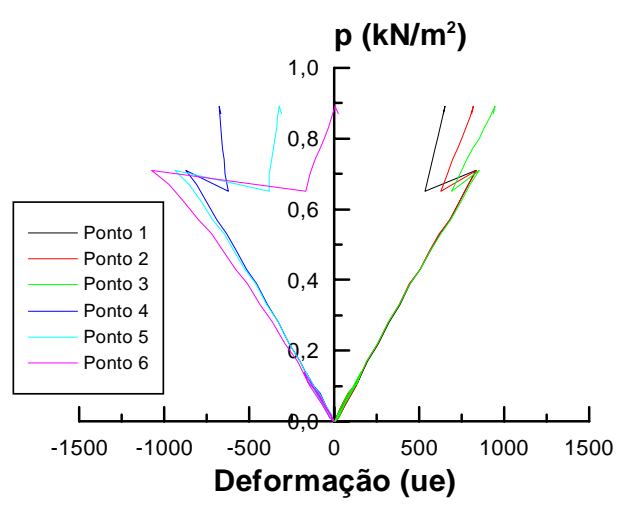

Figura I.113: Gráfico Força x Deformação - Caixa 9.

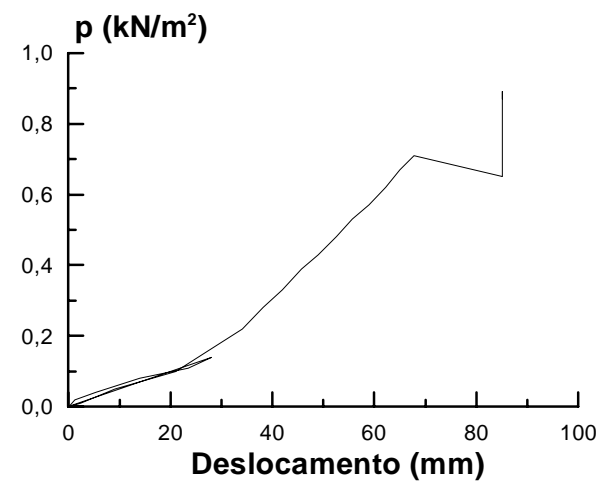

Figura I.114: Deslocamento vertical no meio do vão - Caixa 9.

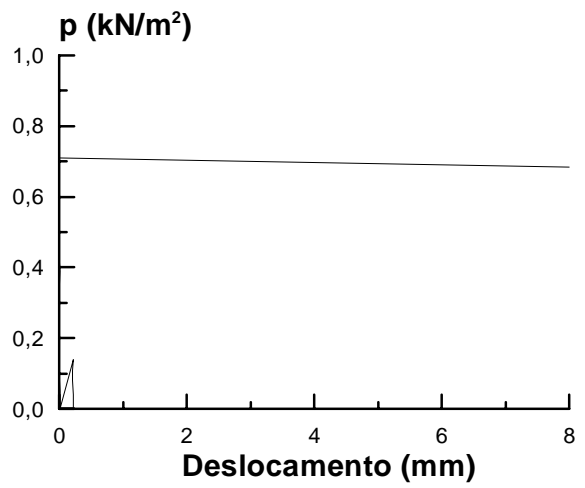

Figura I.115: Deslocamento horizontal da mesa superior - Caixa 9. 


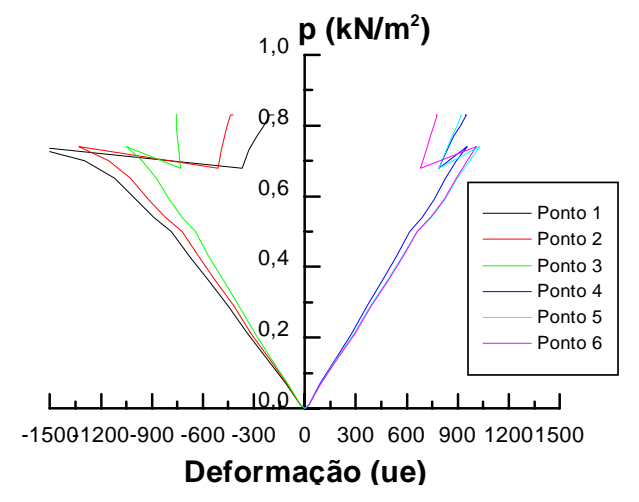

a)

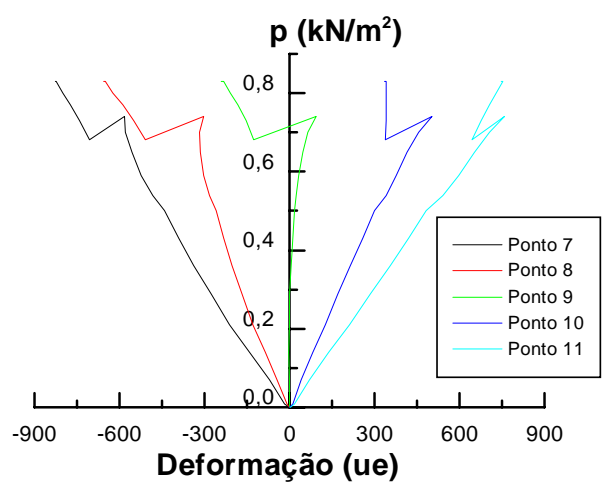

b)

Figura I.116: Gráfico Força x Deformação - Caixa 10. a) Deformações nas mesas. b) Deformações na alma.

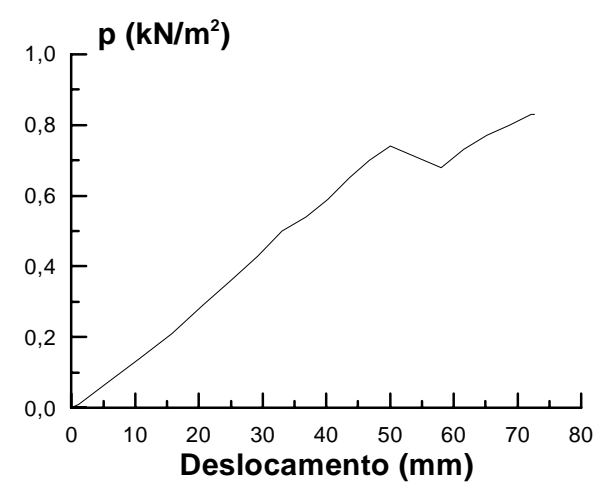

Figura I.117: Deslocamento vertical no meio do vão - Caixa 10.

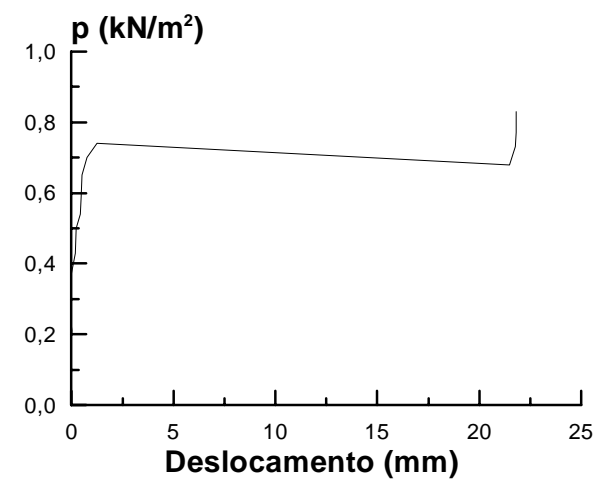

Figura I.118: Deslocamento horizontal da mesa superior - Caixa 10. 


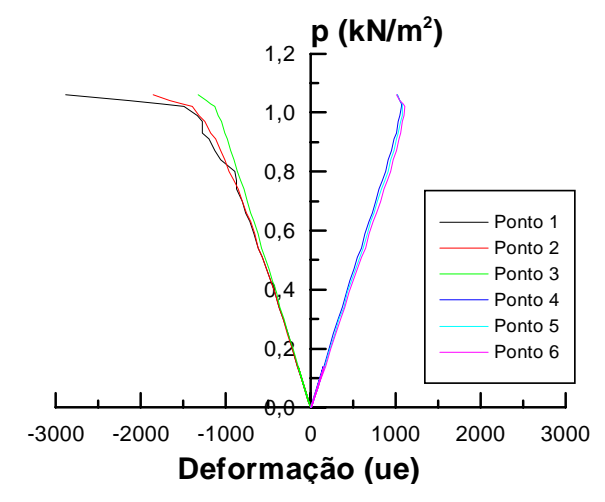

a)

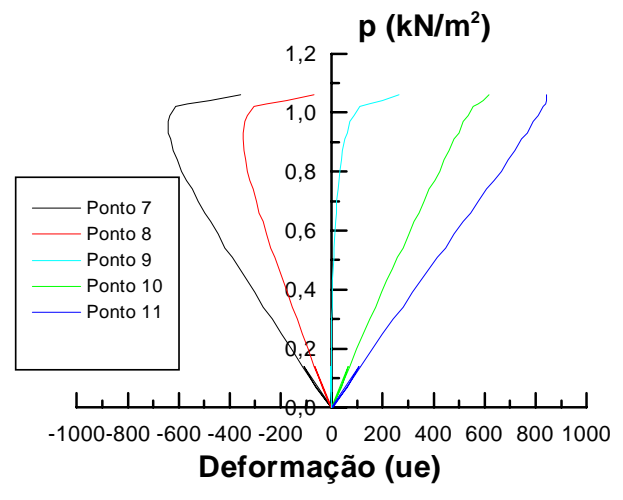

b)

Figura I.119: Gráfico Força x Deformação - Caixa 11. a) Deformações nas mesas. b) Deformações na alma.

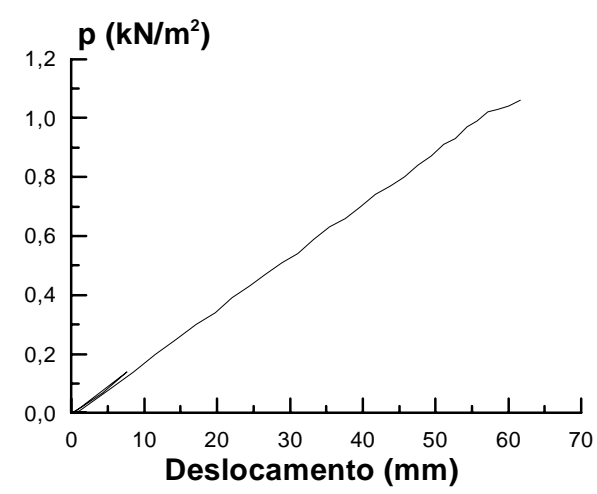

Figura I.120: Deslocamento vertical no meio do vão - Caixa 11.

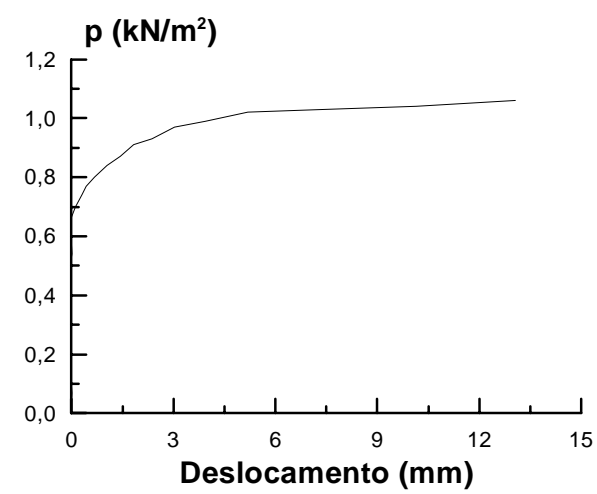

Figura I.121: Deslocamento horizontal da mesa superior - Caixa 11. 


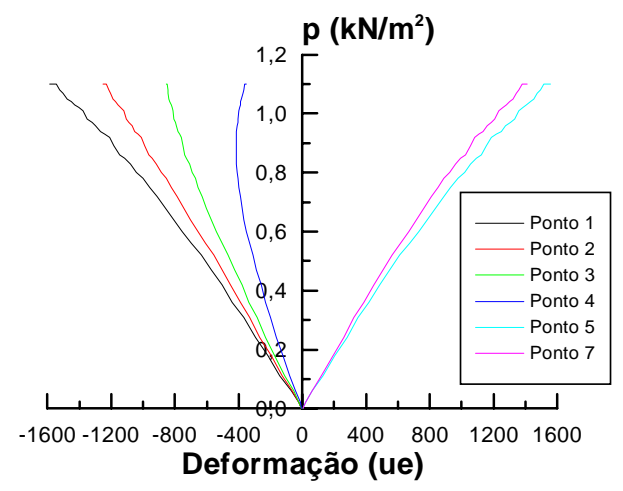

Figura I.122: Gráfico Força x Deformação - Caixa 12.

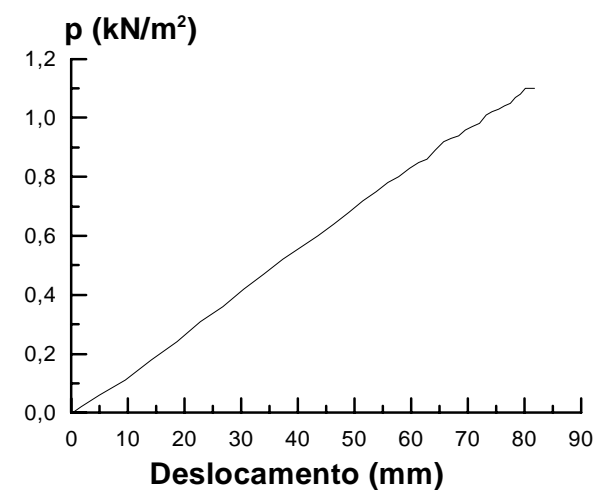

Figura I.123: Deslocamento vertical no meio do vão - Caixa 12.

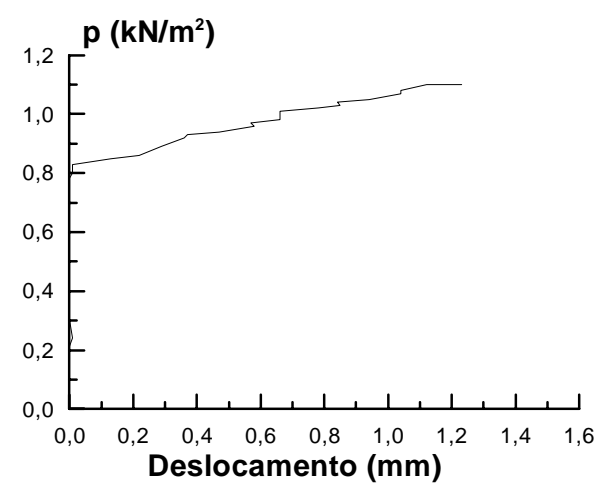

Figura I.124: Deslocamento horizontal da mesa superior - Caixa 12. 


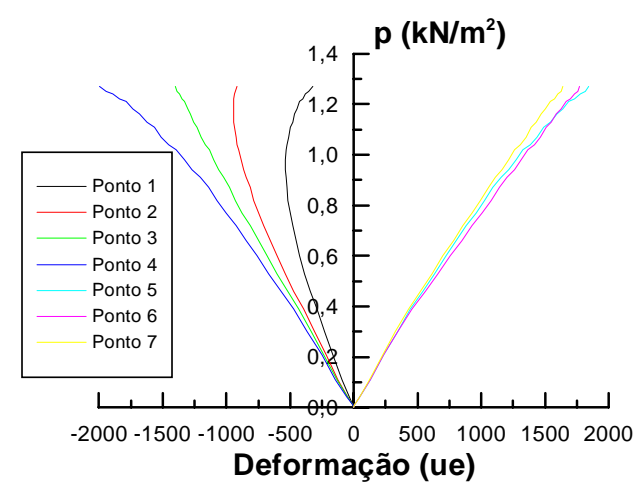

a)

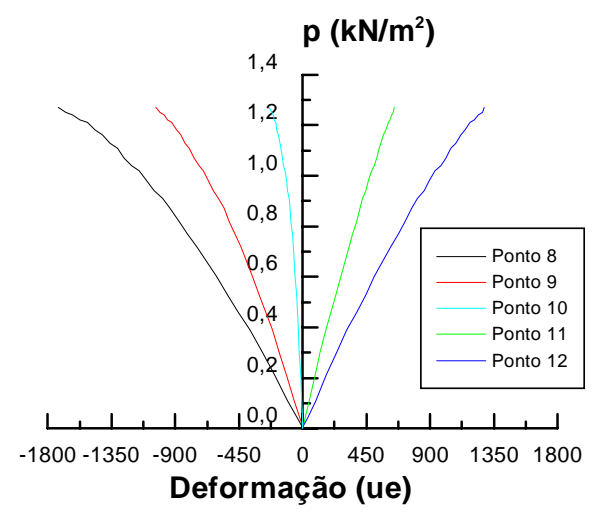

b)

Figura I.125: Gráfico Força x Deformação - Caixa 13. a) Deformações nas mesas. b) Deformações na alma.

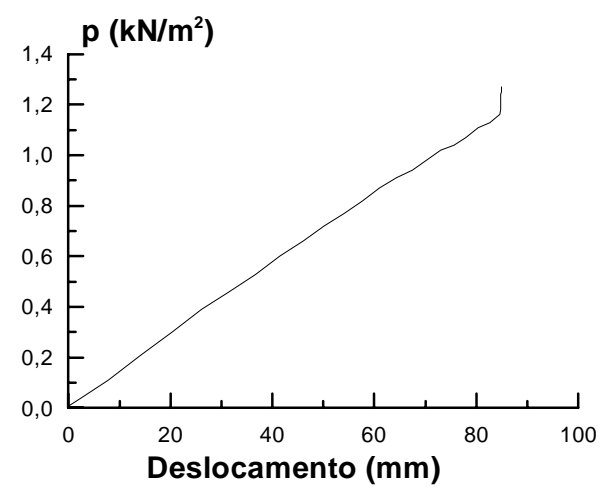

Figura I.126: Deslocamento vertical no meio do vão - Caixa 13.

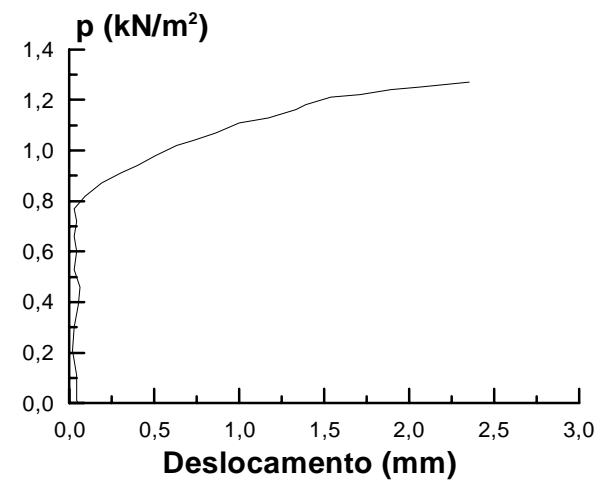

Figura I.127: Deslocamento horizontal da mesa superior - Caixa 13. 


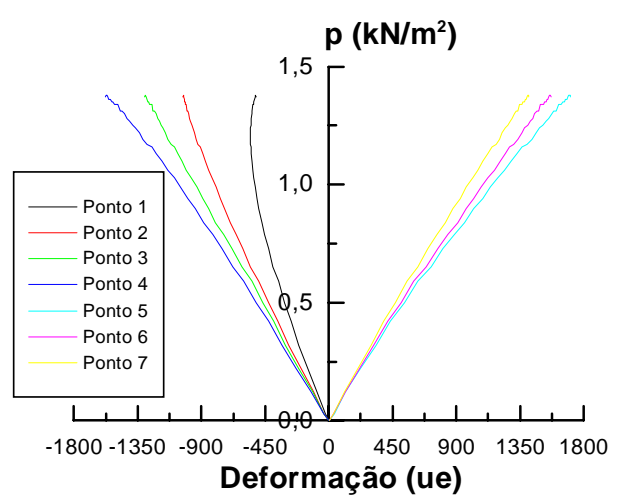

a)

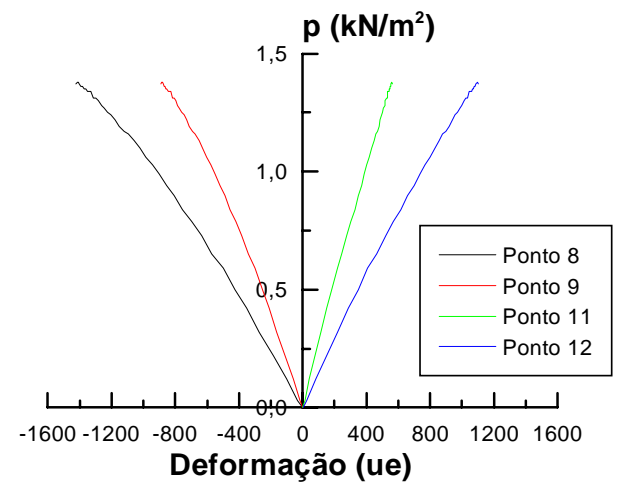

b)

Figura I.128: Gráfico Força x Deformação - Caixa 14. a) Deformações nas mesas. b) Deformações na alma.

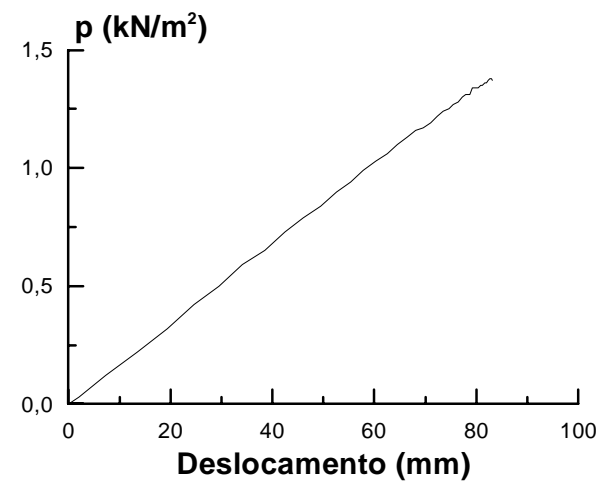

Figura I.129: Deslocamento vertical no meio do vão - Caixa 14.

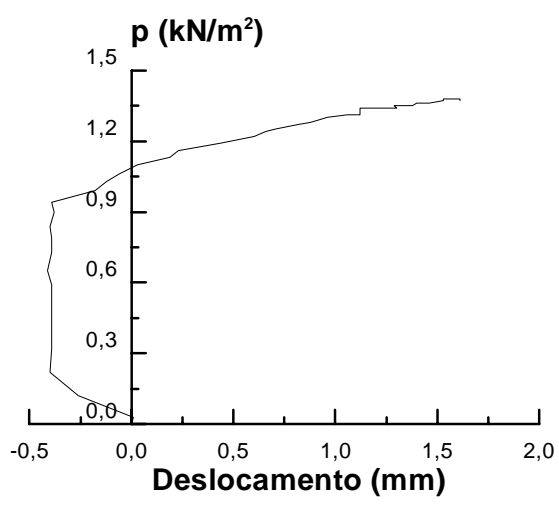

Figura I.130: Deslocamento horizontal da mesa superior - Caixa 14. 


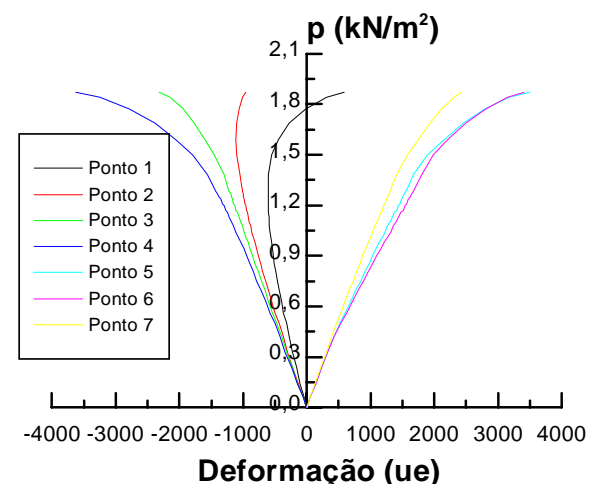

a)

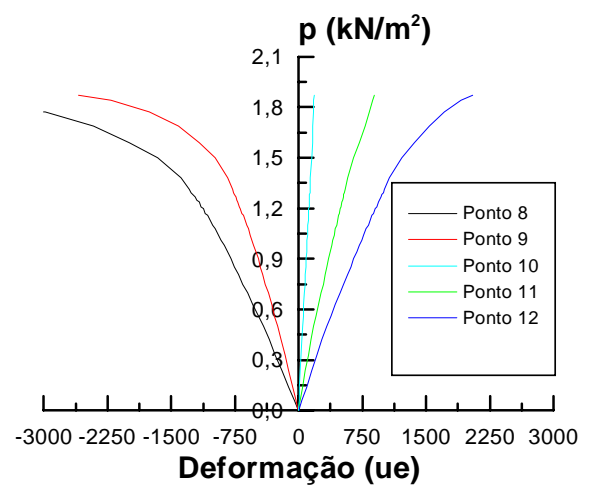

b)

Figura I.131: Gráfico Força x Deformação - Caixa 15. a) Deformações nas mesas. b) Deformações na alma.

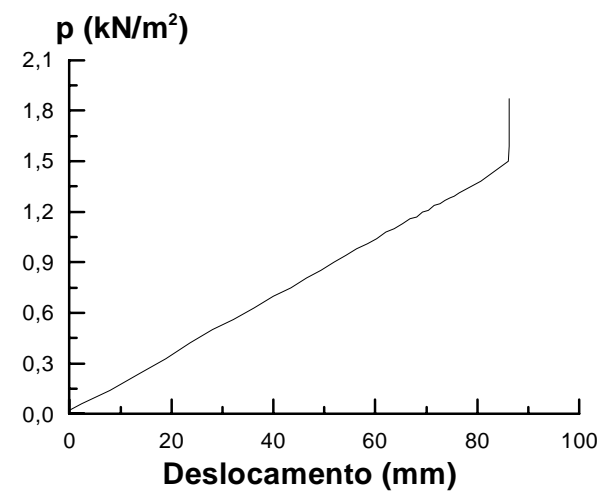

Figura I.132: Deslocamento vertical no meio do vão - Caixa 15.

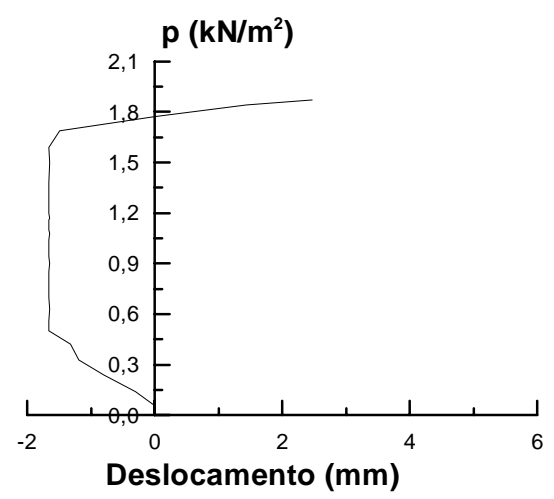

Figura I.133: Deslocamento horizontal da mesa superior - Caixa 15. 